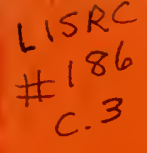

Bueley

\title{
Resumē 1968-1981
}

Monitoring the

Marine Environment

of Long Island Sound at

Millstone Nuclear

Power Station

Waterford, Connecticut

March, 1983

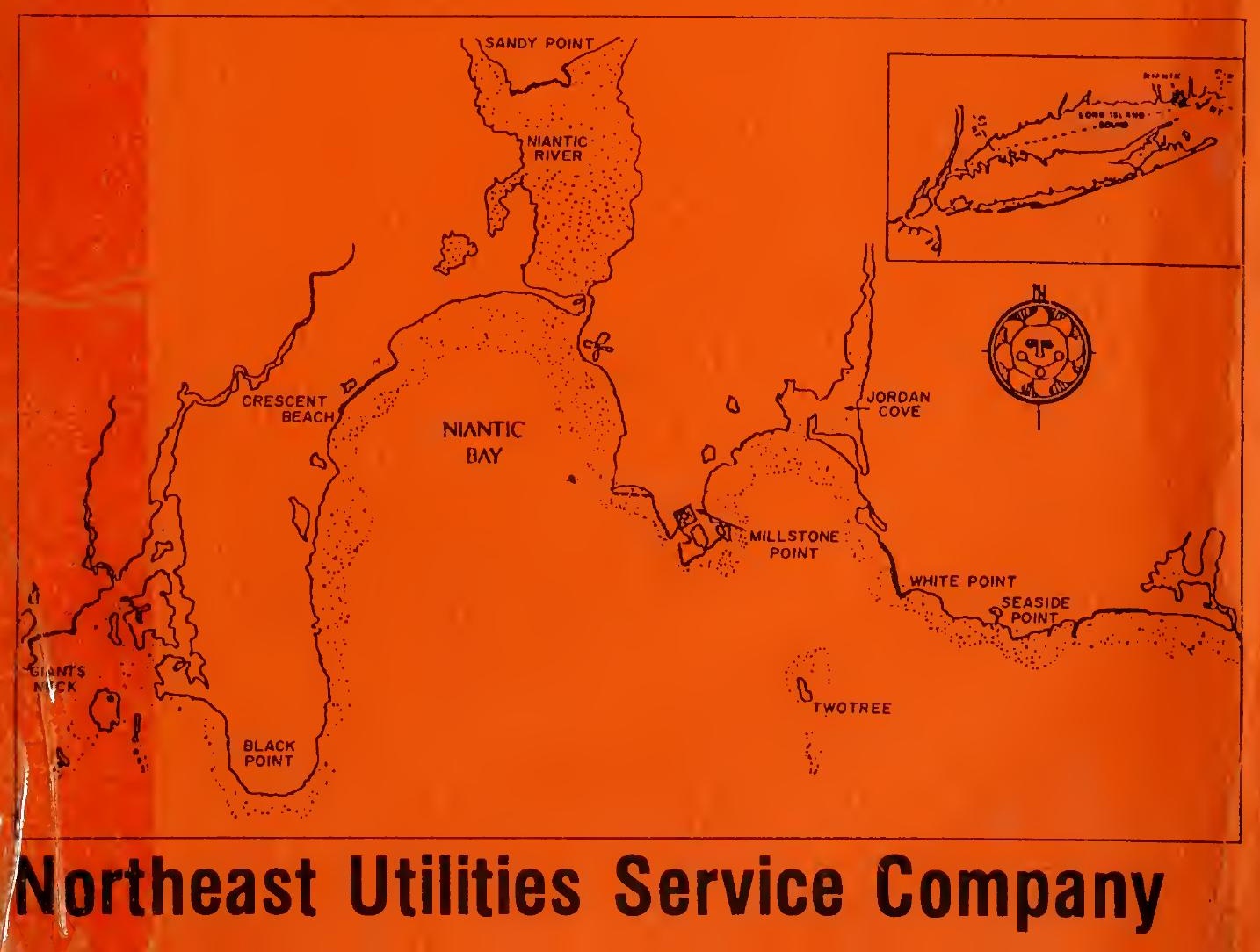





AVPT
$M S I$
$Q H$
541.15
M64
$M 62$
1983

MONITORING

THE

MARINE ENVIRONMENT

OF

LONG ISLAND SOUND

AT

MILLSTONE NUCLEAR POWER STATION

WATERFORD, CONNECTICUT

A REVIEW AND EVALUATION

$1968-1982$

Northeast Utilities Service Company 



\section{INTRODUCTION}

This report is intended to present a historical overview of the ecological studies at the Millstone Nuclear Power Station in Waterford, CT., summarizing prior evaluations upon which program changes were based, and evaluate the necessity of the present and any future studies relative to Unit 3 .

The objective of our studies, as mandated by federal and state regulatory agencies, is to assure that construction and operation of the facility results in no significant change in the ecology of local marine communities. To meet this objective, and to maintain state-of-the-art quality of our work, changes in programs may be necessary. These changes are made on the basis of scientific evidence and with the approval of our technical advisory committee.

Only by continuing review are we able to make intelligent decisions regarding the relationship of plant operation to our concern for the environment. 


Digitized by the Internet Archive in 2010 with funding from Boston Library Consortium Member Libraries 


\section{EXECUTIVE SUMMARY}

The following is a summary of the work done by the staff of the Northeast Utilities Environmental Laboratory. It includes an evaluation of each portion of the environmental program from it's beginning to present. Recommendations are offered where necessary to continue to provide state-of-the-art techniques throughout the construction and operation of Unit 3.

EXPOSURE PANELS $1968-1982$

The objective of the exposure panels program has been to characterize fouling and wood-boring communities at sites within and beyond the thermal effluent. From 1968 - 1978, one long and one short term exposure panel were collected monthly from each of six stations. Long term panels were exposed for 12 months and short term panels were exposed for one month. In 1979, the sampling approach was changed to six replicate samples being collected at five of the original six sites. Instead of making monthly collections, these panels were collected in four overlapping, six month exposure periods. This program change resulted from recommendations of Brown and Moore (1977) and Battelle (1978, 1979). In addition, several minor changes in sampling procedures occurred from 1968 - 1981 to reduce losses of panels from storms, increase the similarity in deployments between stations, improve the condition of specimens used for identification, and generally improve our understanding of community structure on exposure panels.

This evaluation concludes that the present data base is adequate for making quantitative comparisons with data to be collected after Unit 3 becomes operational. Species area curves indicate that four to six 
replicate panels can effectively collect fouling and wood-boring species. The $95 \%$ confidence limits surrounding averaged abundance data indicate that four replicate panels are sufficient to account for interpanel variability. Natural variability in community composition and abundance data from station to station, season to season and year to year has been assessed over a three year period.

Proposed studies are designed to refine our ability to assess power plant impacts. Temperature tolerance, growth, and fecundity of shipworms will be studied for native and non-native shipworm species to learn how their life histories are affected by water temperature. Data on the rates of destruction of common building materials by wood borers will provide an important link between our monitoring studies and the actual concerns of local residents. Finally, resumption of the exposure panel program prior to three unit operation will provide an updated data base and continuity between preoperational and operational phases of the investigation.

INFAUNAL SAND 1968 - 1982

Since the infaunal sand program inception in 1968, many changes have been implemented to eliminate any collection or analysis procedures, which when evaluated, appeared to reduce data quality. The past procedure of freezing samples (used until June 1976) most severely affected data quality and precludes long-term quantitative comparisons of data collected prior to June 1976 .

In 1978, an evaluation of the adequacy of 10 replicate cores (when compared to a larger surface are not additional replicates) concluded that at least 15 replicates were needed. Subsequently, direct comparisons 
of 10 vs 15 cores were made over two years using species area curves, density (mean $\pm 95 \%$ confidence interva1), and species composition. Based on these data, there was no apparent qualitative or quantitative advantage of collecting the additional 5 cores and a change back to 10 replicates was formally submitted to the Nuclear Regulatory Commission. Overal1, the present "long-term" program of 10 quarterly replicates at 4 subtidal and 2 intertidal sites will be adequate to assess Unit 3 impacts assuming the program is continued through the operational phase. This continuity is necessary given the lack of long-term data due to limitations created by previous sampling techniques (freezing samples). The only modification to this long-term study would be the inclusion of the White Point intertidal site into the routine sampling program and the sampling of a new Effluent site, since Unit 3 operation will probably preclude sampling our present site.

In the future, emphasis will be placed on performing short-term studies in areas of potentially most severe plant impacts. These data will complement the long-term base but will not require extended sampling periods. The studies include sampling inside the discharge Quarry, and along seaward transects at the Effluent and Intake. This information will be used to establish maximum plant impacts on benthic communities and will be useful in delineating any Unit 3 impacts in areas further removed from the plant. Other studies will be performed in the Jordan Cove-White Point area, the area of potentially the most severe impact once Unit 3 is operational. Studies presently being considered include eelgrass mapping and intertidal sand flat sampling. 
Since the inception of the rocky shore program in 1968, procedures have been modified to yield more quantitative data. A major change in methodology occurred in 1979, involving non-destructive sampling, recolonization studies, Fucus and Ascophyllum growth measurements, and more frequent collections. Subsequent changes have been minor.

The present rocky shore sampling program was designed to allow us to characterize local intertidal communities, in terms of species present and their abundances. Additionally, we assess spatial and temporal variability associated with these communities, and determine if differences exist that can be attributed to the operation of Millstone Nuclear Power Station. These procedures will also allow us to assess the added impact of Unit 3 construction and operation.

LOBSTERS 1975 - 1982

Population characteristics of the American lobster have been studied extensively in the vicinity of Millstone Point, Connecticut. Since 1975, 22,150 lobsters have been tagged, and pertinent biological data recorded. Catch per unit effort (CPUE) was similar among years, but was significantly higher for wire than wooden pots. Legal-size individuals ranged from $4.5-18.1 \%$ of the total catch. The percentage of culled lobsters ranged from $9.0-17.4 \%$, and was greater for wood than wire pots. The sampled pppulation was comprised of $51 \%$ males and $49 \%$ females. Berried females accounted for $3.1-6.7 \%$ of the total catch, and over half of these were $y$ sublegal size. Growth per molt averaged $13.0 \%$ and was not significant/ly different between sexes. A major period of molting occurred in the late spring and early summer. 
Three stations (Jordan Cove, Intake, and Two Tree) have each been sampled by 10 wood and 10 wire pots since 1978 . Samples were taken three times a week from May through November. In 1981, a comparison of the CPUE between wood and wire pots concluded that wire pots are a more efficient method of collecting smaller lobsters for the study. Based on the results of this comparison, the sampling scheme changed from 30 wood and 30 wire pots to 60 wire pots in 1982.

HEAVY METALS 1971 - 1982

Since 1971, Northeast Utilities Service Company (NUSCo) has supported a metals monitoring program designed to determine the contribution of Millstone Nuclear Power Station (MNPS) to heavy metal concentrations in Long Island Sound, and any subsequent bioaccumulation of metals by suspension-feeding bivalves. The overall objective of this study was to monitor levels of copper, zinc, iron, chromium, and lead present in Niantic Bay and to detect possible increases in these metal levels resulting from cooling water discharges of MNPS. Seawater samples have historically been taken five times a year (Feb., May, July, Sept., and Dec.). From 1971 to 1973, tissue samples were taken in May and December only. Starting in May of 1973, tissue samples were taken on the same schedule as seawater.

Results of this study show that oysters exposed to discharge waters indeed sequester copper to a greater extent than oysters kept in control water sites. No increased levels were observed in any of the other metals studied. Bivalves collected from study sites adjacent to the power plant's discharge outfall did not show a significant increase in the levels of any of the metals under investigation. Analysis of seawater 
showed that the cooling water discharge by the power plant contained similar levels of the metals analyzed as those found in ambient Niantic Bay waters.

This report recommends present sampling and analytic methodology remain consistent so future comparisons may be made with a reasonable degree of certainty. The need for including more statistics (eg: ANOVA) is also mentioned for future reports.

WINTER FLOUNDER 1973 - 1982

Winter flounder have been the object of a number of intensive studies at Millstone designed to provide information necessary for the assessment of power plant impact.

Surveys have been undertaken in late winter and early spring in the Niantic River to estimate the population of winter flounder in this important local spawning area. The data provided from the surveys have been used in an impact assessment model. Estimates have been made from 1973 to the present, although a sampling design using the Jolly method for open populations first began in 1976. The assumptions of the Jo11y method and methodologies used during the population surveys were evaluated. Most serious violations of assumptions included the occurrence of temporary outmigration and probable differential recapture of small winter flounder. These violations have most likely resulted in some error or bias in the population estimates. In addition, the results of the 1975 and 1980 surveys are probably less accurate than those of other years, mostly because of survey design during these years. It was recommended to obtain and implement a new computer program package to provide more flexible analyses of the population data. In addition, the population 
surveys should commence as early as possible to estimate the adult spawning population. Efforts should focus only on fish $150 \mathrm{~mm}$ or larger (fish age 2 and older). The relationship between the population estimates and the trawl catch-per-unit-effort (CPUE) was examined as the latter measure is more easily obtained and may be used in models which only require relative rather than absolute measures of abundance. No satisfactory relationship was found as of yet and further efforts should be made in this area.

Life history information gathered as part of the winter flounder population surveys were examined and parameters such as age structure, fecundity, and mortality have also been used in the impact assessment model. Efforts should be made to improve the classification of sex and reproductive condition of adults. The size at which $50 \%$ of the females are mature should be determined to improve estimates of egg production; the geometric mean regression of $\log$ length - $\log$ fecundity should also be used in these calculations. Additional measurements of winter flounder during the surveys and a stratified subsample selected for aging may improve estimates of age structure. The cohort - specific methods of calculating mortality were examined and were found to produce higher estimates of survival than previously reported. A disc tagging program has been underway since 1980 and is providing information concerning movements and estimates of fishing mortality.

The larvae of winter flounder have formed an important component of the winter-spring ichthyoplankton and their entrainment is the largest source of impact at Millstone. The entrainment sampling program has remained relatively stable over the years, and at a probability of 0.61 can detect a mean annual difference in density of $0.15\left(\log _{10}\right.$ transformed 
units). Many changes in the offshore sampling program, however, have made that data less comparable from year-to-year. One of the most important parameters estimated from ichthyoplankton data is larval mortality. Since studies in previous years weren't designed to provide this information, sampling before 1980 provided mostly inadequate results. Complex behavior of larvae and physical environmental factors in the Niantic River have confounded the determination of mortality. A workshop was held during the Fall of 1982 to develop a comprehensive study plan and sampling design to properly measure larval growth, movements, mortality, and abundance in the Niantic River. Another topic of concern is the source of winter flounder larvae that are entrained. It is suspected that sources other than the Niantic River also contribute larvae for entrainment but complex movements of both larvae and water masses would require an extremely careful study design in order to resolve this question.

The winter flounder is the most abundant species taken in the trawl monitoring program. The present sampling program can detect a $15 \%$ difference in the $\log$ transformed annual mean trawl catch (alpha $=0.05$, beta $=0.80)$. This level of detection can be considered excellent for this type of monitoring program and represents one technique available to measure potential impact of Millstone operations. Some inconsistencies were noted in the calculation of CPUE and various analyses used, which should be resolved.

The winter flounder is also the most frequently impinged fish. An analysis of the data showed that the precision of the impingement estimate could be improved greatly by reallocating sampling effort. Sampling should be increased in colder months, especially January and February, 
and decreased in summer and early fall. The impingement of winter flounder is potentially of lesser concern for impact because the sluiceway return systems to be provided at Units 1 and 3 will significantly reduce mortality.

The primary means of assessing impact of Millstone to date has been a deterministic model developed by the University of Rhode Island. It has been judged as an acceptible but conservative means of estimating impact but recent advances in modelling have made it less acceptable. A stochastic matrix model has been accepted as the basis for future evaluations which should provide more realistic estimates. The needs of this model should direct much of the future research on the winter flounder as it is the best means to integrate and reduce the large amount of available data to predict changes as a consequence of longterm plant operations.

IMPINGEMENT 1972 - 1982

The primary objective of impingement monitoring at Millstone has been to quantify total annual, species specific, mortality. In addition, means of minimizing this mortality have been evaluated experimentally and appropriate plant design changes recommended where cost-effective. Routine impingement sampling began at Unit 1 in 1972. Monitoring at Unit 2 was initiated just prior to full-power testing in September 1975.

Throughout the ten years of study, various program changes have been implemented. The principle changes to the routine impingement program were made in each of three areas, the frequency of counting, the manner in which lengths were recorded, and the method for calculating monthly totals. 
Starting in 1972, impinged organisms were collected over 24-h, identified to species and counted daily. In March 1977 the counting frequency was reduced to three $24-\mathrm{h}$ samples per week.

From January 1973 to April 1975, species length information was recorded by length categories. However, this practice did not provide accurate descriptions of the sizes of the various species impinged. Length measurements were reinstituted in May 1975 (Table 1). Lengths were also recorded prior to 1973.

Beginning in 1979-80, monthly impingement estimates were based on actual counts ( 3 days/week) extrapolated using a volumetric ratio. Previously, counts were multiplied by a real time to sample time ratio.

Research directed towards improving our understanding of the factors which influence impingement, and ultimately to reduce losses of fish due to impingement, began in 1973. These special research projects, involved cooling water flow, fish deterrent devices, impingement survival and sluiceways.

Routine impingement monitoring at Millstone together with the numerous special studies, have provided quantitative data characterizing impingement at the site. Adjustments to the field sampling aspects of the program have been made without significant loss of information.

Reductions in impingement mortalities and reductions in sampling effort will result when a sluiceway is installed at Unit 1 . Further reductions in impingement sample effort of up to $40 \%$ are feasible at Unit 2 while maintaining the current level of precision. 
Plankton $1970-1982$

Studies have been conducted since the early 1970's to evaluate the effects entrainment may have on local phytoplankton, zooplankton, and ichthyoplankton populations.

The entrainment of phytoplankton represents the potential loss of primary producers which are at the base of the marine food web. Phytoplankton studies have been conducted at Millstone since 1970; and have included species composition or abundance and assessment of entrainment impact on the phytoplankton community. Results indicate that the species composition and abundance of entrained phytoplankton are similar to adjacent areas of Long Island Sound. Chlorination was identified as the most detrimental entrainment effect on primary productivity. Phytoplankton studies at Millstone and other plant sites have demonstrated that entrainment has minimal impact on the phytoplankton community. Based on this information, phytoplankton studies were terminated as of June 1982 . Zooplankton are an important food source for young and adult fish. Entrainment loss of zooplankton could potentially affect the stability of the food web and benthic communities.

Entrainment studies (begun in 1970) have determined entrained zooplankton species composition, abundance, and the effects entrainment has on adjacent zooplankton communities. Review indicated that a recurring annual pattern in species composition exists at Millstone. Additional Unit 3 cooling water demand would not cause detectable changes in the holozooplankton (primarily copepods) community due to its reproductive capabilities and the small amount of local waters affected. Meroplankton (developmental stages of benthic invertebrates) and tychoplankton (primarily 
amphipods \& mysids) seasonality and impact potentiality is understood to a lesser degree partially due to a lack of detailed taxonomic work. More specific identification in the future would establish relative entrainment impact effect on the infaunal and epibenthic adult habitats. Additional entrainment survival studies were recommended for the amphipods due to their importance as a source of adult food, since there is a potential for high entrainment survival as has been found at other power plants.

An extensive offshore zooplankton program was developed to determine distribution of zooplankton in relation to variations which occurred in the entrainment program. This information is important in assessing the impacts of Unit 1 and 2 and serves as baseline data for Unit 3 impact assessment.

Additional evaluations indicated that larger zooplankton such as medusae and ctenophores may be more important in determining prevailing fish larvae densities than power plant entrainment. The present sampling program could explore this hypothesis with little additional effort.

Literature indicates that smaller zooplankton (especially copepod nauplii and rotifers) represent an important source of food which may explain density variations in first-feeding winter flounder and anchovy larvae. A comparability study between the presently used $0.333 \mathrm{~mm}$ net samples and the proposed $0.044 \mathrm{~mm}$ net samples would be conducted prior to recommendation of any new sampling design.

The additional ichthyoplankton mortality caused by entrainment could be a major factor in determining adult fish year class strength at Millstone. The present ichthyoplankton program (begun in 1973) is highly responsive to program objectives due to frequent evaluations and modifications. 
The program has determined natural variability, seasonality, densities and species composition of both entrained and offshore ichthyoplankton. Entrainment studies have estimated the number of fish eggs and larvae entrained and identified adult fish population which are most likely to be impacted due to entrainment losses.

An extensive offshore program was designed to obtain larval (primarily winter flounder) distribution data for use in verification of a predictive mathematical mode1. Review indicated the response of such a program was inadequate for model verification. Since 1976 the offshore program was reduced in scope. The offshore program (1973-1975) had identified the primary local spawning areas of dominant entrained taxa.

Extensive sampling programs concerning the enumeration of ichthyoplankton and larval entrainment mortality have been conducted since 1973. These ichthyoplankton programs have been evaluated and improved frequently. The present sampling program is able to detect natural annual and spatial fluctuations in density. Further recommendations to streamline the program include deletion of October - March fish egg processing and change in entrainment sampling frequency to 4 days and nights per week (one replicate each time) from the present 3 days and nights per week ( 3 replicates each time). Recommendations to investigate two potential shortcomings of the ichthyoplankton program were made. First, the evidence of survival of $\mathrm{fish}$ egg and larvae after entrainment would reduce the estimated impact of Unit 3. Second, further identification by offshore or Niantic River sampling of the sources of entrained larvae would provide better information regarding the adult population over which the three unit entrainment impact is distributed. 
Shore-zone Seines, 1969 - 1982.

The seine sampling program, established in 1969 to monitor the shore-zone fish, consists of triplicate collections taken in the two hours preceding high tide at six stations in February, May, June, July, August, September, October and December. This report is an evaluation of the seine program to determine if the shore-zone finfish assemblages are sampled adequately enough to describe their long term natural fluctuations and to distinguish these from plant induced changes. The analyses indicated that the data base has a highly skewed distribution due to a high frequency of small catches and a low frequency of large catches. In addition, significant autocorrelations exist in the data base as well. These two characteristics limit the application of appropriate normal-theory statistical tests in detecting year to year changes. Further, during three-unit operation on the ebb tide, the thermal plume is expected to encompass nearby shore zones that previously were uninfluenced by this effect. A redistribution of sampling effort is suggested so that potentially impacted areas can be more intensively studied prior to the start-up of Unit 3 .

Trawls, $1973-1982$.

The trawl sampling program, established in 1973 to monitor the demersal fish, consists of triplicate collections taken biweekly at six stations. This report is an evaluation of this program to determine if the demersal finfish assemblages are sampled adequately enough to describe their long term natural fluctuations and to distinguish these from plant induced changes. It was determined that the program provided long term and seasonal estimates of finfish that were typical of the benthic and 
near-bottom pelagic habitats of Long Island Sound. The analyses indicated that the data base had a highly skewed distribution (due to a high frequency of small catches and a low frequency of large catches) that conformed to a negative binomial distribution. After appropriate transformation, the data could be used in normal theory statistical tests that, $80 \%$ of the time (beta leve1), could detect a $15 \%$ change with the probability of 0.05 (alpha level) that a change that large occurred by chance. In addition, significant autocorrelations existed in the data bases, and these serial dependencies were found useful in time series applications. 


IMPINGEMENT:

A REVIEW AND EVALUATION 



\section{INTRODUCTION}

Impingement on the screens of circulating water intake structures is a visible and direct source of mortality to aquatic biota. Accordingly, impingement rates have been monitored intensively at many estuarine and coastal power plant sites to assess the potential for damage to localized marine populations (Stupka and Sharma 1977; Uziel and Hannon 1979). At Millstone, routine impingement sampling began at Unit 1 in 1972 , although some qualitative observations were made as early as 1971 . Monitoring at Unit 2 was initiated just prior to full-power testing in September 1975, and at that time, the program was incorporated into the Environmental Technical Specifications (ETS) for the site.

The primary objective of impingement monitoring at Millstone has been to quantify total annual, species specific, mortality. In addition, means of minimizing this mortality have been evaluated experimentally and appropriate plant design changes recommended where cost-effective. Throughout the ten years of study, various program changes have been implemented. The purpose of this report is to review and assess these changes, evaluate the adequacy of the present program and discuss future studies relative to Unit 3 operation.

\section{EVALUATION OF PROGRAM CHANGES}

The principle changes to the routine impingement program were made in each of three areas, the frequency of counting, the manner in which lengths were recorded, and the method for calculating monthly totals (Table 1). Each of these changes is discussed below. 
Table 1. Chronology of impingement monitoring at Millstone Nuclear Power Station.

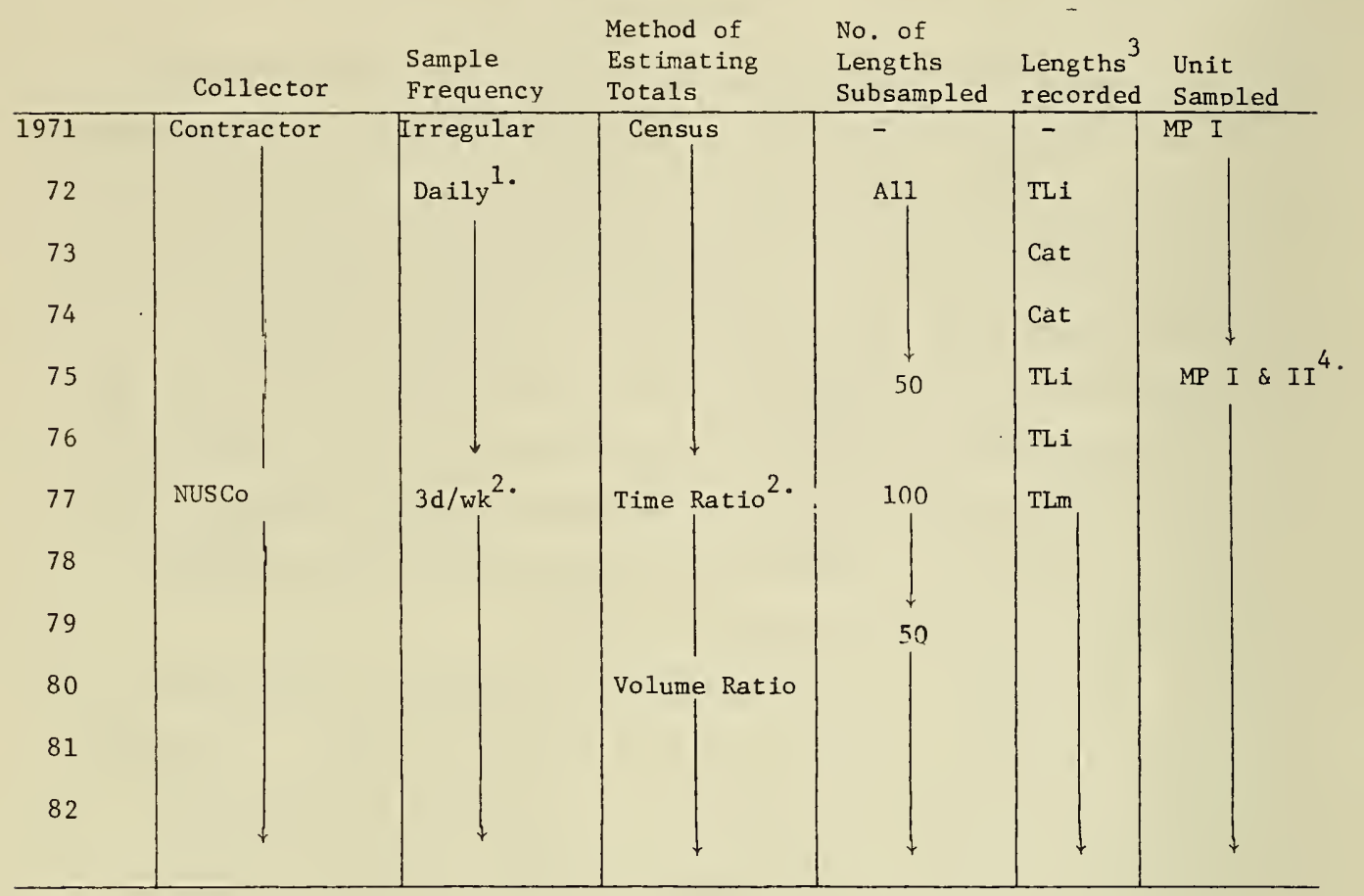

1) Began $5 / 1 / 72$

2) Began $3 / 10 / 77$

3) $\mathrm{TL}=$ Total length in inches (i) or millimeters (m) Cat = Total length categories of < 3", 3" to 6", >6" (from 1/1/73-4/30/73)

4) MP II collections began $9 / 75$ 
Starting in 1972, impinged organisms were collected over $24-\mathrm{h}$, identified to species and counted daily. In March 1977 the counting frequency was reduced to three $24-h$ samples per week. The basis for this change was documented in a letter to the NRC justifying a change to the ETS. Using data collected in 1973-75 at Unit 1, mean daily impingement estimates for each month based on 7 counts/week were compared to mean daily estimates extrapolated from three counts/week assuming these counts had been made on Monday, Wednesday, and Friday only. For winter flounder the percent difference ranged from 0.0 to 83.4 . The average percent difference was $27.3,18.3$ and 15.0 respectively for the years $1973-75$.

Since these calculations included winter flounder only, additional analyses were subsequently conducted covering the dominant species as well (NUSCo 1979). Results based on 1973 and 1974 data showed that mean differences between actual monthly totals ( 7 days/week) and estimates based on three counts/week would range from $20-50 \%$ depending on the species (Table 2). At this level of effort greater than $85 \%$ of all species impinged would be represented. For levels of effort less than 3 days/week, the error associated with the estimated monthly totals would increase rapidly.

After the March 1977 program change, the design of impingement monitoring programs received considerable attention in the scientific literature. A thorough review of the subject was provided by Murarka et al. (1978) and Kuman and Griffith (1978). For the purposes of this review, a technique outlined by El-Shamy (1979) was used to further evaluate the present sampling effort at Millstone. 
Iable 2. Mear percentage Aifference and coefficiert of variation (C.V.) for es:1mied wonth: 1 aringement abundarices c! selected apecies froo 1973 to $197 \mathrm{~L}$. Collection frequencies range from seven (daily) tc one collec:ion per week.

\begin{tabular}{|c|c|c|c|c|c|c|c|c|}
\hline \multirow[b]{2}{*}{ Sppizes } & \multirow[b]{2}{*}{ Paramet } & \multicolumn{7}{|c|}{ Collection Days } \\
\hline & & 7 & 6 & $s$ & 4 & 3 & 2 & 1 \\
\hline Archon: & $\begin{array}{l}\text { Mean } \\
\text { C.V. }\end{array}$ & $\begin{array}{l}0.0 \\
0.0\end{array}$ & $\begin{array}{r}21.45 \\
123.73\end{array}$ & $\begin{array}{r}34.67 \\
100.13\end{array}$ & $\begin{array}{l}42.18 \\
79.19\end{array}$ & $\begin{array}{l}50.64 \\
83.06\end{array}$ & $\begin{array}{l}64.42 \\
62.50\end{array}$ & $\begin{array}{l}93.22 \\
74.29\end{array}$ \\
\hline Elue crab & $\begin{array}{l}\text { Mean } \\
\text { C.l. }\end{array}$ & $\begin{array}{l}9.0 \\
0.0\end{array}$ & $\begin{array}{r}8.28 \\
77.46\end{array}$ & $\begin{array}{l}11.23 \\
84.26\end{array}$ & $\begin{array}{l}18.08 \\
77.34\end{array}$ & $\begin{array}{l}22.50 \\
78.71\end{array}$ & $\begin{array}{r}27.95 \\
101.60\end{array}$ & $\begin{array}{l}33.32 \\
73.44\end{array}$ \\
\hline Reck $c: a b$ & $\begin{array}{l}\text { Mean } \\
\text { C.V. }\end{array}$ & $\begin{array}{l}0.0 \\
0.0\end{array}$ & $\begin{array}{r}8.41 \\
93.29\end{array}$ & $\begin{array}{l}22.94 \\
93.69\end{array}$ & $\begin{array}{l}17.43 \\
94.04\end{array}$ & $\begin{array}{r}24.46 \\
103.27\end{array}$ & $\begin{array}{r}23.50 \\
136.25\end{array}$ & $\begin{array}{r}41.20 \\
159.49\end{array}$ \\
\hline Green crab & $\begin{array}{l}\text { Mean } \\
\text { C.v. }\end{array}$ & $\begin{array}{l}0.0 \\
0.0\end{array}$ & $\begin{array}{r}6.82 \\
76.17\end{array}$ & $\begin{array}{l}12.87 \\
96.42\end{array}$ & $\begin{array}{l}25.60 \\
76.76\end{array}$ & $\begin{array}{l}20.49 \\
82.06\end{array}$ & $\begin{array}{r}27.35 \\
112.30\end{array}$ & $\begin{array}{l}39.46 \\
75.27\end{array}$ \\
\hline $\begin{array}{l}\text { Three sfire } \\
\text { Sticiletack }\end{array}$ & $\begin{array}{l}\text { Mean } \\
\text { c.v. }\end{array}$ & $\begin{array}{l}0.0 \\
0.0\end{array}$ & $\begin{array}{r}23.47 \\
142.56\end{array}$ & $\begin{array}{r}30.23 \\
111.07\end{array}$ & $\begin{array}{l}36.79 \\
94.87\end{array}$ & $\begin{array}{l}49.60 \\
86.37\end{array}$ & $\begin{array}{r}57.95 \\
121.29\end{array}$ & $\begin{array}{r}90.32 \\
\text { i6t. } 89\end{array}$ \\
\hline $\begin{array}{l}\text { American } \\
\text { lobster }\end{array}$ & $\begin{array}{l}\text { Mean } \\
\text { C.V. }\end{array}$ & $\begin{array}{l}0.0 \\
0.0\end{array}$ & $\begin{array}{r}8.06 \\
88.11\end{array}$ & $\begin{array}{l}24.81 \\
85.51\end{array}$ & $\begin{array}{l}24.77 \\
88.89\end{array}$ & $\begin{array}{l}31.14 \\
98.52\end{array}$ & $\begin{array}{r}44.01 \\
109.26\end{array}$ & $\begin{array}{l}48.27 \\
99.20\end{array}$ \\
\hline spider ctab & $\begin{array}{l}\text { Mean } \\
\text { C.V. }\end{array}$ & $\begin{array}{l}0.0 \\
0.0\end{array}$ & $\begin{array}{r}13.40 \\
141.28\end{array}$ & $\begin{array}{r}20.64 \\
102.48\end{array}$ & $\begin{array}{l}36.85 \\
80.93\end{array}$ & $\begin{array}{l}46.06 \\
79.22\end{array}$ & $\begin{array}{l}67.45 \\
85.81\end{array}$ & $\begin{array}{r}77.53 \\
113.03\end{array}$ \\
\hline Squid & $\begin{array}{l}\text { Kean } \\
\text { C.V. }\end{array}$ & $\begin{array}{l}0.0 \\
0.0\end{array}$ & $\begin{array}{r}8.66 \\
101.50\end{array}$ & $\begin{array}{l}25.92 \\
83.87\end{array}$ & $\begin{array}{l}24.67 \\
98.20\end{array}$ & $\begin{array}{l}31.55 \\
96.57\end{array}$ & $\begin{array}{l}46.60 \\
69.60\end{array}$ & $\begin{array}{l}48.31 \\
65.46\end{array}$ \\
\hline Silverside & $\begin{array}{l}\text { Mean: } \\
\text { C.V. }\end{array}$ & $\begin{array}{l}0.0 \\
0.0\end{array}$ & $\begin{array}{r}15.12 \\
131.26\end{array}$ & $\begin{array}{l}21.35 \\
99.45\end{array}$ & $\begin{array}{l}30.63 \\
88.20\end{array}$ & $\begin{array}{l}37.76 \\
77.79\end{array}$ & $\begin{array}{l}46.62 \\
98.69\end{array}$ & $\begin{array}{l}62.39 \\
73.05\end{array}$ \\
\hline vitut:y & $\begin{array}{l}\text { Mean } \\
\text { c.v. }\end{array}$ & $\begin{array}{l}0.0 \\
0.0\end{array}$ & $\begin{array}{l}13.32 \\
96.49\end{array}$ & $\begin{array}{r}24.20 \\
104.01\end{array}$ & $\begin{array}{l}35.95 \\
97.25\end{array}$ & $\begin{array}{l}41.97 \\
94.07\end{array}$ & $\begin{array}{l}47.66 \\
92.43\end{array}$ & $\begin{array}{l}72.26 \\
82.40\end{array}$ \\
\hline Lady crab & $\begin{array}{l}\text { Mean } \\
\text { C.V. }\end{array}$ & $\begin{array}{l}0.0 \\
0.0\end{array}$ & $\begin{array}{r}8.67 \\
121.65\end{array}$ & $\begin{array}{r}25.74 \\
106.23\end{array}$ & $\begin{array}{l}20.50 \\
90.10\end{array}$ & $\begin{array}{l}26.25 \\
80.87\end{array}$ & $\begin{array}{l}34.92 \\
84.54\end{array}$ & $\begin{array}{l}43.33 \\
66.12\end{array}$ \\
\hline $\begin{array}{l}\text { Winter } \\
\text { f Jounder }\end{array}$ & $\begin{array}{l}\text { Mean } \\
\text { C.v. }\end{array}$ & $\begin{array}{l}0.0 \\
0.0\end{array}$ & $\begin{array}{r}7.02 \\
102.35\end{array}$ & $\begin{array}{l}11.51 \\
75.39\end{array}$ & $\begin{array}{l}15.82 \\
82.81\end{array}$ & $\begin{array}{l}20.13 \\
79.64\end{array}$ & $\begin{array}{l}25.78 \\
80.62\end{array}$ & $\begin{array}{l}39.64 \\
69.54\end{array}$ \\
\hline $\begin{array}{l}\text { Windowrane } \\
\text { flounder }\end{array}$ & $\begin{array}{l}\text { iesn } \\
\text { c.t. }\end{array}$ & $\begin{array}{l}0.0 \\
0.0\end{array}$ & $\begin{array}{r}9.34 \\
64.29\end{array}$ & $\begin{array}{l}25.80 \\
76.55\end{array}$ & $\begin{array}{l}18.35 \\
84.24\end{array}$ & $\begin{array}{l}26.07 \\
79.61\end{array}$ & $\begin{array}{l}42.71 \\
80.20\end{array}$ & $\begin{array}{l}51.37 \\
88.01\end{array}$ \\
\hline Cunner & $\begin{array}{l}\text { Mean } \\
\text { C.V. }\end{array}$ & $\begin{array}{l}0.0 \\
0.0\end{array}$ & $\begin{array}{l}11.80 \\
88.21\end{array}$ & $\begin{array}{l}16.30 \\
85.57\end{array}$ & $\begin{array}{l}24.17 \\
82.87\end{array}$ & $\begin{array}{l}30.35 \\
82.75\end{array}$ & $\begin{array}{l}43.78 \\
77.66\end{array}$ & $\begin{array}{l}59.57 \\
73.06\end{array}$ \\
\hline Tautog & $\begin{array}{l}\text { Mean } \\
\text { C.v. }\end{array}$ & $\begin{array}{l}0.0 \\
0.0\end{array}$ & $\begin{array}{l}14.65 \\
86.04\end{array}$ & $\begin{array}{l}24.68 \\
83.62\end{array}$ & $\begin{array}{l}27.67 \\
89.52\end{array}$ & $\begin{array}{r}36.01 \\
100.02\end{array}$ & $\begin{array}{r}44.69 \\
136.39\end{array}$ & $\begin{array}{l}63.25 \\
79.2:\end{array}$ \\
\hline
\end{tabular}

\footnotetext{
'For each species actual (daily) monthly fopingement counts vere compared to an estiatied tctal using different ccllection schedules. Mear difference equals the average of these wean differences.
} 
To evaluate the adequacy of impingement data, El-Shamy calculated a confidence limit $(+2 \mathrm{SE})$ for the mean number of a species impinged per day in each month and over a year. Precision was the $\bar{X}$ divided by $2 S E$. To determine if improvements in the precision could be obtained given a fixed annual level of effort, he used a stratification and optimum allocation approach. This approach was applied to Millstone data as follows.

First, to verify those error estimates reported previously (NUSCo 1978), precision of the annual mean daily estimates were calculated for selected species grouped together. These included winter flounder, cunner, blackfish, grubby, silversides, threespine stickleback, blue crab, lady crab and American lobster. Calculations were limited to Unit 1, 1976 data since counts were made daily during that year. A comparison of the precision associated with sampling schedules of 1 to 7 days/week is given in Table 3. At a collection frequency of three days per week, a precision of $80 \%$ was achieved. Precision here is defined as $1-\frac{2 S E}{\bar{X}}$. In theory, a complete census would yield a precision value of 1.00 (Snedecor and Cochran 1978). Although the data bases and statistical techniques differ, a comparison of this analysis with NUSCo (1978) shows similar results; a $20-50 \%$ margin of error in the earlier study and an $80 \%$ precision value in this study. As effort drops below 3 days/week the precision falls off rapidly.

To determine if precision could be improved by redistributing and optimizing present effort, data collected at Units 1 and 2 from 1978-81 were stratified by month and effort reallocated according to E1-Shamy (1979). Annual and monthly precision factors were determined for the current program and for a reduced (10-50\%) schedule of optimized sampling 
Table 3. Annual mean, standard error, and precision associated with the reduction of sample effort using 1976 impingement data from Millstone Point Unit 1.

\begin{tabular}{|c|c|c|c|}
\hline $\begin{array}{c}\text { No. } \\
\text { Samples } \\
\text { Per Week }\end{array}$ & ${ }^{1}$ Mean $\frac{(\mathrm{fish})}{\text { Day }}$ & $\begin{array}{c} \pm 2 \text { Standard } \\
\text { error }\end{array}$ & ${ }^{2}$ Precision \\
\hline 7 & 36.36 & 1.52 & .96 \\
\hline 6 & & 3.0 & .92 \\
\hline 5 & & 4.2 & .89 \\
\hline 4 & & 5.4 & .85 \\
\hline 3 & & 7.2 & .80 \\
\hline 2 & & 9.6 & .73 \\
\hline 1 & & 15.0 & .59 \\
\hline
\end{tabular}

1) at the $95 \%$ confidence level

2) Precision $=\left(1-\frac{2 S E}{\text { Mean }}\right)$ 
effort. Results showed that the present program of uniform effort between strata (approximately 13 days/month) has a precision value of 0.79. As expected this is similar to the factor $(0.80)$ for 3 days per week mentioned previously. Results were the same when data from individual years (1978 and 1980) were used. The present sample schedule when optimized, (redistributing effort to months with larger variances), results in a precision factor increase to 0.88 . A program of optimum sample distribution with $40 \%$ less effort ( $92 / 156$ days) would yield approximately the same precision value as the current program (Tables 4 and 5). A specialized application of this analysis using only winter flounder data, is found in the Winter Flounder Program Review. Results between these two analyses compare favorably with only a slight difference in sample distribution among months (strata).

\section{Length Measurement}

From January 1973 to April 1975, species length information was recorded by length categories to facilitate reporting and monitoring of ETS 1 imitations (Table 1). However, this practice did not provide accurate descriptions of the sizes of the various species impinged. Length measurements were reinstituted in May 1975 (Table 1). Lengths were also recorded prior to 1973. To determine the adequacy of the present practice of measuring up to 50 individuals per sample, a chisquare test for homogeneity between distributions (PROC FREQ, Helwig and Council 1979) was performed on selected, abundant species impinged at Unit 2 during 1977-78. Species selected were those impinged at a rate greater than 50 per day. During 1977-78, 100+ individual lengths per species were recorded. Twelve dates where the number of lengths 


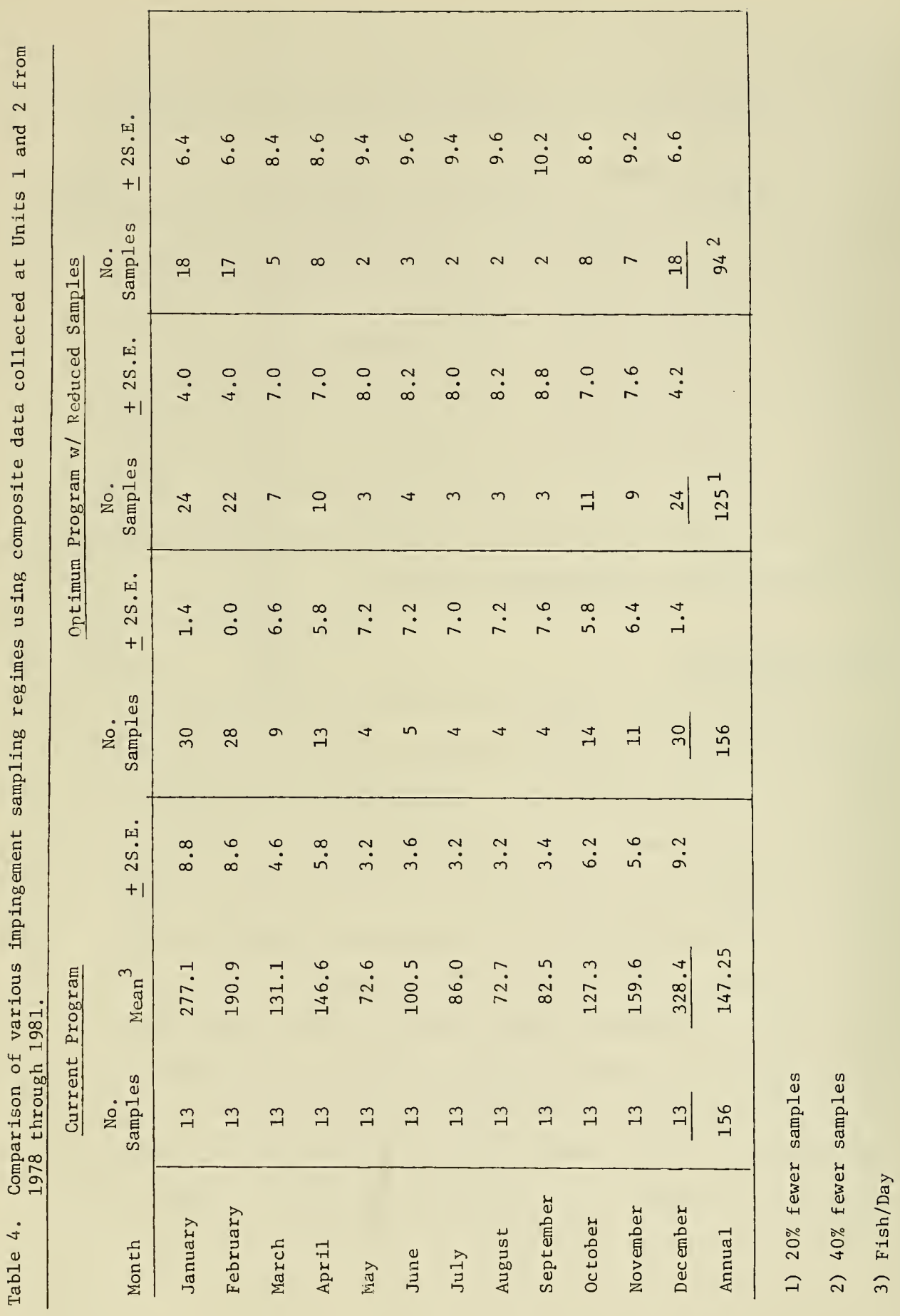


Table 5. Annual mean, standard error, and precision based on optimized sampling effort (1978-1981 impingement data from Millstone Units 1 and 2).

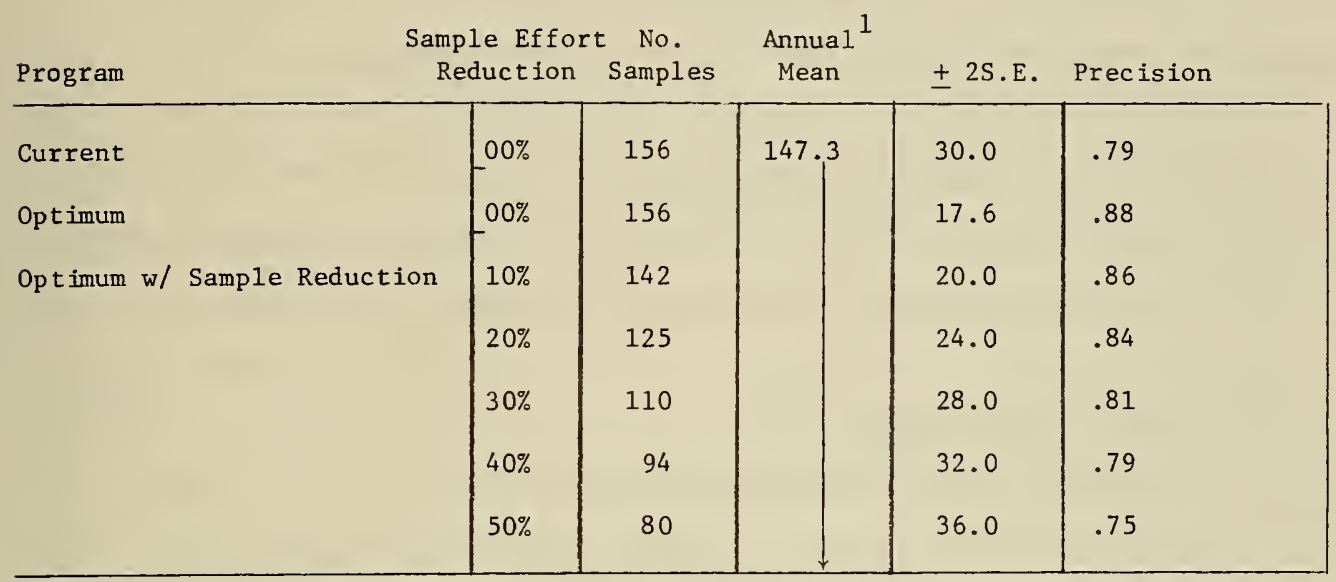

1) in Fish/Day 
recorded for a species exceeded 100 were randomly chosen to form the data base. Fifty individuals per sample date (600 tota1) for each species were then randomly removed from this base (with replacement) and the length distributions derived from each were compared. Of the five species considered (winter flounder, Atlantic silverside, threespine stickleback and grubby, Atlantic long-finned squid), all demonstrated extreme closeness of fit $(P>.98$, Table 6$)$. Therefore, subsamples of 50 individuals per species are adaquate to represent length information.

\section{Estimating Monthly Impingement}

The third change concerns the technique used to estimate species impingement totals. Beginning with the 1979-80 annual report (NUSCo 1981a) monthly impingement estimates were based on actual counts ( 3 days/week) extrapolated using a volumetric ratio. Previously counts were multiplied by a real time to sample time ratio. The volumetric method estimates impingement by multiplying the actual monthly count for each species by a ratio of the cooling water flow during the days sampled in the month to the total cooling water flow for that month. The volumetric method is considered more accurate in that impingement levels have been found to be influenced by cooling water flow (Con Ed. 1977; PSE\&G 1980; NUSCo 1982; WPLC 1976). A comparison of estimates based on each method showed that differences are only a matter of a few percentage points.

Despite efforts to control precision and accuracy of impingement data there were factors known to introduce sample bias resulting in underestimates of impingement totals and overestimates of mean lengths. For example, at Units 1 and 2, specimens have been lost for a variety of 
Table 6. Results of chi-square test to determine the effectiveness of subsampling 50 Individuals per spectes for length information.

TAXA

Number of Organisms

Statistics

Total

subsample sample

DF

chi-square

Winter flounder

600

1360

16

.9877

At1. silverside

600

1060

19

.9997

Threespine stickleback $\quad 600$

1279

8

.9994

Grubby

600

1423

29

.9911

At 1. long-finned squid

600

1072

13

.9898 
reasons. Many small fishes pass through the collection basket drain holes ( $>3 / 4^{\prime \prime}$ diameter). To demonstrate the effect of this bias, the mean length of each major fish and invertebrate taxa sampled during routine impingement was compared to the mean length based on samples taken concurrently (December 1981 - April 1982) for a special impingement study (NUSCo 1981b). In the special study, a $3 / 8$ inch (9 mm) mesh net was used to collect impinged organisms. Results showed large differences in mean length between the two data sources for most species reflecting a general skew in mean length towards the larger sizes (Table 7).

Further, during periods of high debris loading, commonly in the spring and fall, the baskets clog quickly resulting in loss due to overflow. Occasionally samples are terminated prematurely due to unscheduled dumping of the debris by operations and/or maintenance personnel. Inadvertant disposal of trash to the land-fill site has also occurred. And finally, plant personnel searching for food, bait, or just the desire to return live specimens to the water before they die, has likewise resulted in short counts.

Through improved communications, plant management and personnel are now more cognizant of our need for accurate samples. Unscheduled dumping or disposal of trash has been reduced. Intrusions by plant personnel have been eliminated.

To correct for loss of organisms through the drain holes or through overflow would require smaller apertures (minimum $3 / 8$ " mesh) in the collection baskets at both units and shorter sample periods during times of heavy debris loading. The additional effort required many not be warranted at this time for Unit 1 since a sluiceway is being installed at that unit. The extent to which data at Unit 2 are effected by this bias, however, may be of future concern. 
Table 7. Mean length of dominant species sampled during routine impingement and impingement mortality studies at Unit 2 from December 1980 through April 1981.

\section{Species}

Mortality

Lady crab

Green crab

Lumpfish

Sticklebacks

Sea snail

Atlantic silverside

Tomcod

Grubby

Silver hake

Winter flounder

Pipefish

$49.1 \mathrm{~mm}$

28.6

62.2

52.9

72.3

96.9

163.9

86.0

95.3

169.6

162.9

\section{Data Source}

95.7

53.0

70.4

98.2

181.1

99.2

118.0

238.7
238.0 
Research directed towards improving our understanding of the factors which influence impingement, and ultimately to reduce losses of $\mathrm{fish}$ due to impingement, began in 1973. These special research projects are listed below with a brief summary of results.

Diel Patterns in impingement - This study divided the regular 24-h sampling scheme into two $12-\mathrm{h}$ periods. Collections revealed that most impingement occurred at night (NUSCo 1977). Similar studies at other power plants resulted in similar findings (PSE\&G 1980; Boston Ed 1982; F1०Po 1977; PG\&E 1980; JCP\&L 1981).

Storms - Impingement records between 1976 to 1981 were examined to see if storms (expressed as high wind conditions) caused an increase in impingement. A statistically significant difference in impingement before and after storms was noted (NUSCo 1981a).

Cooling Water Flow - Examination of historical impingement data together with EDAN data revealed that impingement totals at Units $I$ and 2 were found to be significantly correlated with condenser cooling water flow (NUSCo 1982).

Fish Deterrance - Since 1975 many techniques and devices have been tested or employed in an effort to reduce impingement levels at Units 1 and 2. Among them were:

1) Electric Fish Screens (NUSCo 1976),

2) Fish Barrier Nets (NUSCo 1976),

3) Acoustic repulsion (NUSCo 1976),

4) Underwater light (NUSCo 1976), 
5) Benthic fish barrier (NUSCo 1980, 1981a),

6) Surface fish barrier (NUSCo 1981a).

Most of these techniques were only marginally effective in reducing impingement. Some were deficient because they created possible personnel hazards or because of the high cost of operating and maintaining them.

Other electric utilities, including Mystic Station (SWEC 1979), Port Washington (WPLC) 1976), Indian Point (Con Ed 1975, 1980), and J.P. Pulliam (WPLC 1978), have attempted similar techniques also with limited success. At this time, many nearby plants have or are in the process of installing or backfitting fish return sluiceways as a cost-effective method of reducing fish losses (JCP\&L 1981; CHG\&E 1977; Boston Ed 1982; NUSCo 1981b). Artificial propagation is also being employed in an attempt to mitigate impingement losses of striped bass (Morone saxatilis) on the Hudson River estuary (Con Ed 1977).

Survival - Records of impingement survival at Millstone Point date back to April 1974. These data represent immediate survival associated with impingement and specimen handling. Results reported show that, in general, survival is species specific, and varies temporally throughout the year. Delicate fish, like the herrings, have the lowest survival (0-40\%) while crabs and lobsters because of their hard exoskeleton experience much higher survival ( > 75\%), (NUSCo 1982).

In 1977 , a program of extended (96-h) survival was undertaken to estimate the immediate and delayed effects of impingement stress, and subsequent handling. Results of this study were very similar to the data collected during routine impingement sampling.

Sluiceways - The most recent and intensive survival study was conducted between December 1980 and April 1981. This study was made in 
conjunction with a larger program to evaluate the feasibility of backfitting fish-return sluiceways into the fish/trash collection systems at Units 1 and 2 . Unit 3 presently has plans for a similar fish-return system. Initial and extended (60-h) survival estimates for the 1980-81 study were found to be higher than those of 1977. The dissimilarities between the reports may be attributable to differences in sample size, seasonality of the data, or improvements to the sampling procedures which eliminated all stresses on the organisms except those attributable to impingement (NUSCo 1981b, 1982). Similar studies done at Bowline Point Generating Station, N.Y. (O\&RU 1977) and at Oyster Creek Generating Station, N.J. (JCP\&L 1981) showed that survival estimates there were generally similar to ours (NUSCo 1981b). The conclusion of the sluiceway study was that $\mathrm{fish}$ and shellfish losses at Unit 1 could be reduced in a cost-effective manner with the addition of a sluiceway there. However, construction of a sluiceway at Unit 2 was not cost-beneficial. Conclusion

Routine impingement monitoring at Millstone together with the numerous special studies, have provided quantitative data characterizing impingement at the site. Adjustments to the field sampling aspects of the program have been made without significiant loss of information.

Reductions in impingement mortalities and reductions in sampling effort will result when a sluic eway is installed at Unit 1 . Further reductions in impingement sample effort of up to $40 \%$ are feasible at Unit 2 while maintaining the current level of precision.

For the future, the following programs are proposed:

1) evaluation of Units 1 and 3 sluiceway effectiveness, 
2) investigation of possible reimpingement associated with slucieway operation and

3) continued monitoring of impingement at Unit 2. 

Boston Ed (Boston Edison Company). 1982. Marine Ecology Studies Related to Operation of Pilgrim Station. Semi-Annual Report \#19. Boston, Mass.

CHG\&E (Central Hudson Gas \& Electric Co.). 1977. Impingement Survival Studies at Roseton and Danskammer Point Generating Stations. Prepared by Ecological Analysts for Central Hudson Gas \& Elect. Corp., Poughkeepsie, N.Y.

Con Ed (Consolidated Edison). 1975. Indian Point Impingement Study Report for the Period 1 January 1974 through 31 December 1974. Prepared by Texas Inst. Inc. for Consolidated Edison Company of New York, N.Y.

- 1977. Influence of Indian Point Unit 2 and the Steam Electric Generating Plants on the Hudson River Estuary, with emphasis on Striped Bass and the Fish Populations. J.T. McFadden, Ed., Submitted to Consolidated Edison Company of New York, N.Y.

- 1980. Hudson River Ecological Study in the Area of Indian Point. 1979 Annual Report. Prepared by Texas Instruments, Inc. for Consolidated Edison Co. of New York, N.Y.

E1-Shamy, F.M. 1979. Impingement Sampling Frequency. A Multiple Population Approach. Environmental Science and Technology. Vo1. 13, p.315-329.

FloPo (Florida Power Corp.). 1977. Final Report Andote Unit No. 1 Post-Operation Ecological Monitoring Program 1976. Vol. V. Submitted by Texas Instruments.

JCP\&L (Jersey Central Power \& Light Co.). 1981. Ecological Studies at Oyster Creek Nuclear Generating Station. Progress Report September 1979 - August 1981. Morristown, N.J. Prepared by Ecological Analysts, Inc., Sparks, Md.

Kuman, K.D. and J.S. Griffith. 1978. Temporally Stratified Sampling Programs for Estimating Fish Impingement, in Fourth National Workshop on Impingement, Ecological Analysts, Melville; N.Y. 'p 281-290.

Murarka, I.P., S.A. Spigare11i, and D.J. Bodeau. 1978. Statistical Comparison and Choice of Sampling Designs for Estimating Fish Impingement at Cooling Water Intakes. L.D. Jensen, Ed. Ecological Analysts, Melville, N.Y. p 267-280.

, and D.J. Bodeau. 1977. Sampling Designs and Methods for Estimating Fish Impingement Losses at Cooling-Water Intakes. By Argonne Nationa1 Labs, Argonne, I11. $277 \mathrm{pp}$.

NUSCo (Northeast Utilities Service Company). 1976. Environmental assessment of the condenser cooling water intake structures (316b) Demonstration), Volumes 1 and 2, submitted by Northeast Utilities Service Company to Connecticut Dept. Environmental Protection.

- 1977. Annual Report, 1976. Ecological and Hydrographic Studies Millstone Nuclear Power Station, Waterford, Connecticut.

- 1978. Annual report, 1977. Ecological and Hydrographic Studies, Millstone Nuclear Power Station, Waterford, Connecticut. 
1979. Annual report, 1978. Ecological and Hydrographic Studies, Millstone Nuclear Power Station, Waterford, Connecticut.

- 1980. Annual report, 1979. Monitoring the Marine Environment of Long Island Sound at Millstone Nuclear Power Station, Waterford, Connecticut.

- 1981a. Annual report, 1980. Monitoring the Marine Environment of Long Island Sound at Millstone Nuclear Power Station, Waterford, Connecticut.

- 1981b. Feasibility of modifying the Millstone Units 1 and 2 cooling water intake screen wash system to improve the return of $\mathrm{fish}$ to Long Island Sound. Submitted to the State of Connecticut, Dept. of Environmental Protection.

- 1982. Annual report, 1981. Monitoring the Marine Environment of Long Island Sound at Millstone Nuclear Power Station, Waterford, Connecticut.

O\&RU (Orange and Rockland Utilities, Inc.). 1979. Bowline Point Impingement Survival Studies 1975-1978 Overview Report. Prepared by Ecological Analysts, Inc. for Orange \& Rockland Utilities, Pearl River, N.Y.

PG\&E (Pacific Gas \& Electric Co.). 1980. Potrero Power Plant Cooling Water Intake Structures 316b Demonstrations. Prepared by Ecological Analysts. for Pacific Gas and Electric Co., San Francisco, Calif.

PSE\&G (Public Service Electric \& Gas Co.). 1980. An Interpretive Analysis of Impingement and Entrainment. April 1977 - December 1978. Salem Nuclear Generating Station. Newark, N.J. Prepared by Ichthyological Associates, Middletown, Del.

Snedecor, G.W. and W.G. Cochran, 1978. Statistical Methods. Iowa State Univ. Press., Ames, Iowa. 593pp.

Stupka, R.C., and R.K. Sharma. 1977. Survey of Fish Impingement at Power Plants in the United States. Vol. III. Estuaries and Coastal Waters. Argonne National. Lab., Argonne, I11. 310pp.

SWEC (Stone \& Webster Engineering Corp.) 1979. Alternative Intake Designs for Reducing Fish Passes, Mystic Station - Unit 7. By Stone \& Webster Engineering Corp. Boston, Mass.

Uziel, M.S. and E.H. Hannan. 1979. Impingement. An Annotated Bibliography for Electric Power Research Institute. Palo Alto, Calif.

WPLC (Wisconson Power and Light Co.). 1976. Port Washington Power Plant. Final Report W.P.D.E.S. Intake Monitoring Studies.

- 1978. J.P: Pulliam Power Plant Fish Impingement April 1977 December 1977. Wisconsin Public Service Corp. 


PLANKTON ECOLOGY:

A REVIEW AND EVALUATION 



\section{INTRODUCTION}

Power plant entrainment of planktonic organisms is of ecological concern due to the large volume of water used for condenser cooling. Organisms entrained are subjected to a rapid increase in temperature, mechanical stress, and at times the presence of biocides. Plankton studies have been conducted at Millstone Nuclear Power Station since 1970. The objective of these studies is to provide information on the distribution and seasonal abundances of plankton in the waters around Millstone Point, and in the cooling water of the Millstone Nuclear Power Station. This information is necessary to understand the general ecology of the local plankton populations, and assess the potential impact of the power plant. Plankton studies have examined phytoplankton, zooplankton and ichthyoplankton.

This report summarizes plankton studies conducted at Millstone and evaluates the need of the present and future studies relative to Units 1 and 2 and the startup of Unit 3.

\section{PHYTOPLANKTON}

Phytoplankton are an essential component of the marine ecosystem since they are primary producers. The loss of phytoplankton due to entrainment was of concern because of the potential loss of energy assimilation capacity at the base of the food chain. Various special studies to assess the impact of entrainment and a monitoring program have been conducted from 1970 to 1982 .

Woods Hole Oceanographic Institution conducted several phytoplankton studies at Millstone Unit 1 from September 1970 through June 1972 
(Carpenter 1975). These studies were conducted to: 1) determine entrained phytoplankton species composition and whether entrained cells were destroyed; 2) determine the effects of entrainment on primary productivity; 3$)$ determine the effects of plant operation on the phytoplankton community in adjacent waters.

Species composition and abundance of phytoplankton entrained were determined from cell counts on whole water samples. Samples were collected biweekly at the Intake (Figure 1) from September 1970 through June 1971 and examined with the Utermohl technique. Concurrent with the Intake sampling during March through June 1971, samples were collected at the Discharge and Quarry Cut to determine if cells were destroyed during plant passage. No significant difference was found between Intake and Quarry Cut cell densities (Carpenter 1975).

The effect of entrainment on primary productivity was examined during 1971 with light-dark bottle carbon-14 samples collected at the Intake, Discharge and Quarry Cut (Carpenter et a1. 1972, Carpenter 1975). After plant passage, without chlorination, productivity increased in the cooler periods and decreased when the discharge temperature exceeded $28^{\circ} \mathrm{C}$. Chlorination decreased productivity even at concentrations below which would control biofouling. To minimize stress on the phytoplankton community, the recommended chlorination regime was intermittent chlorination for the shortest possible period.

The effect of plant operation on the phytoplankton community adjacent to Millstone was examined from August 1971 through June 1972 (Carpenter 1975). Chlorophyll a and primary productivity were measured at two control stations and two stations in the effluent mixing zone (predicted $5-10 \%$ phytoplankton reduction). No detectable difference was found 


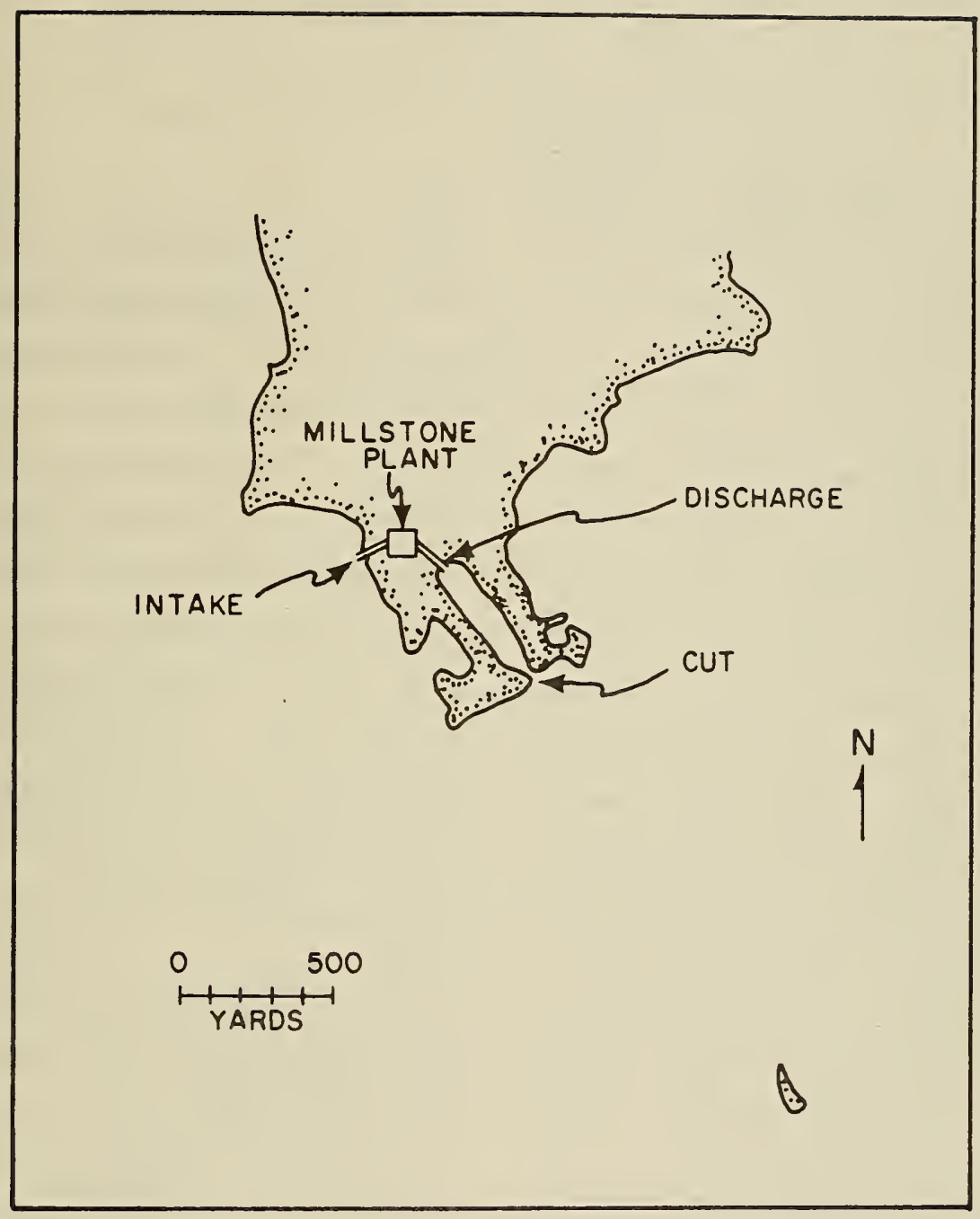

Figure 1. Entrainment sampling sites. 
between control and effected stations with five chlorophyll a and three productivity replicates at a station. Based on the variability of the chlorophy11 a samples it was determined that an average of 88 samples per station would be necessary to detect a $5 \%$ change (Carpenter et al. 1974a). Field variability made it impractical to detect the small differences expected due to entrainment.

The remaining phytoplankton studies at Millstone were conducted to determine the species composition and abundance of phytoplankton entrained over an extended period of time. Normandeau Associates, Inc. collected biweekly whole water samples for cell counts at Unit 1 Discharge from Ju1y 1975 through December 1976 (NUSCo 1976, 1978). Phytoplankton cells were identified and enumerated using Palmer-Maloney and Sedgwick-Rafter cells. NUSCo staff conducted the studies from January 1977 until its termination in June 1982. Weekly whole water samples were collected at Unit 1 and Unit 2 discharges on alternate weeks. Samples were processed for chlorophy11 a and cell counts (NUSCo 1978, 1979a, 1980, 1981). Cells were enumerated with the Utermohl technique, similar to the earlier Woods Hole Oceanographic Institution cell counts. The continuous series of cell count data has well documented the species composition and seasonality of the phytoplankton community in the Millstone area. Microflagellates and diatoms, are the dominant groups entrained (Table 1), as was found in the early 1970's (Carpenter 1975). Spring and summer blooms have been apparent (Figure 2), with diatoms (primarily Skeletonema costatum) and Phaeocystis spp. abundant in the spring bloom and microflagellates followed by diatoms abundant in the summer bloom. Seasonality of chlorophyll a concentrations is closely related to total phytoplankton abundance (Figure 2). 
Table 1. Phytoplankton percent species composition, mean of annual densities, minimum and maxium annual densities, and sample frequency(N) in entrainment samples 1977-1980.

\begin{tabular}{|c|c|c|c|c|c|}
\hline & Percent & $\begin{array}{c}\text { Mean of Annua } \\
\text { Densities } \\
\text { (\# cells } x \\
10^{5} / 1 \text { iter) } \\
\end{array}$ & $\begin{array}{c}\text { Densit } \\
\text { (Min } \\
\end{array}$ & $\begin{array}{l}\text { ty Range } \\
- \text { Max) } \\
\end{array}$ & $\underline{\mathrm{N}}$ \\
\hline Unknown microflagellate & 41.0 & 9.39 & $4.63=$ & -19.75 & 200 \\
\hline Skeletonema costatum & 21.0 & 4.80 & $0.85=$ & -9.21 & 195 \\
\hline Phaeocystis spp. & 6.7 & 1.54 & $0.15-$ & -4.55 & 40 \\
\hline Unidentified Chlorophyceae & 6.7 & 1.53 & 0.02 & -3.00 & 88 \\
\hline Cryptomonadaceae & 4.7 & 1.23 & $0.50-$ & -1.41 & 180 \\
\hline Chaetoceros spp. & 3.4 & 0.78 & $0.60-$ & -1.30 & 158 \\
\hline Thalassiosira nordenskioldii & 1.7 & 0.40 & $0.15-$ & -0.86 & 72 \\
\hline Unknown pennate diatoms & 1.7 & C. 39 & $0.21-$ & -0.67 & 195 \\
\hline Thalassiosira spp. & 1.7 & 0.39 & $0.28=$ & -0.71 & 118 \\
\hline Asterionella spp. & 1.5 & 0.34 & $0.10-$ & -0.61 & 105 \\
\hline Cerataulina bergonii & 1.3 & 0.30 & $0.01-$ & -0.66 & 29 \\
\hline Unknown centrate diatoms & 1.1 & 0.26 & $0.11-$ & -0.58 & $135^{\prime}$ \\
\hline Leptocylindrus minimus & 0.9 & 0.20 & $0.04=$ & -0.43 & 64 \\
\hline Nitzschia spp. & 0.8 & 0.18 & $0.09-$ & 0.29 & 144 \\
\hline Rhizosolenia delicatula & 0.6 & 0.14 & $0.04-$ & -0.42 & 68 \\
\hline Thalassionema nitzschoides & 0.5 & 0.11 & $0.08-$ & -0.15 & 67 \\
\hline Leptocylindrus danicus & 0.4 & 0.10 & $0.01-$ & -0.27 & 41 \\
\hline Melosira sulcata & 0.4 & 0.08 & $0.05=$ & -0.13 & 51 \\
\hline Navicula spp. & 0.4 & 0.08 & $0.01=$ & -0.33 & 18 \\
\hline Pyramimonas spp. & 0.3 & 0.08 & $0.04=$ & -0.13 & 74 \\
\hline Thalassiosira rotula & 0.3 & 0.06 & $0.04-$ & -0.13 & 26 \\
\hline
\end{tabular}




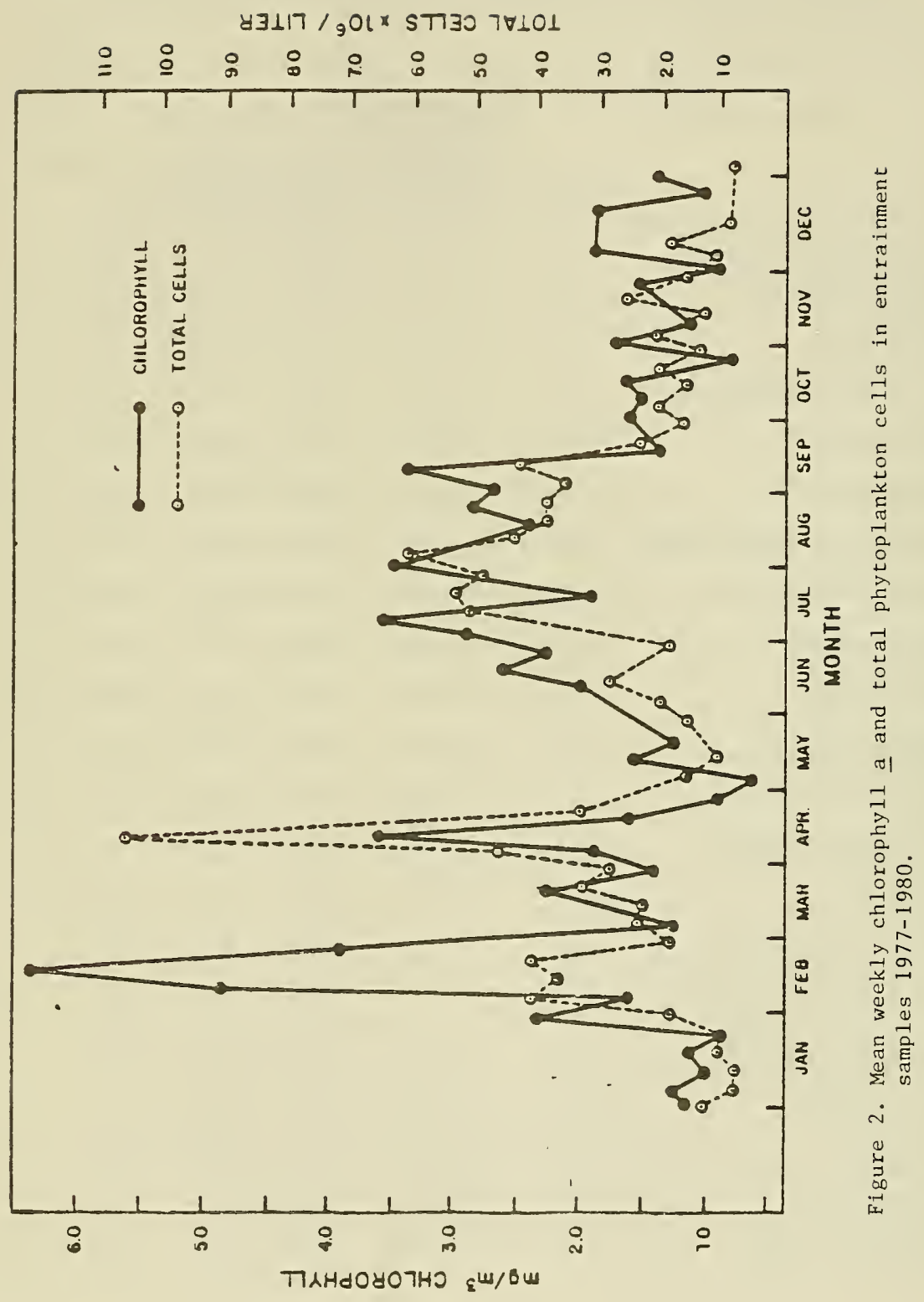




\section{Phytoplankton Program Evaluation}

It has become increasingly apparent that power plant operation has negligible impact on the phytoplankton community. Carpenter (1975) at Millstone found that the higher discharge temperature depressed productivity only during warmer periods which has been found in other studies (Morgan and Stross 1969, Brook and Baker 1972, Tilly 1974, Briand 1975, Kreh and Derwort 1976, Miller et a1. 1976, Flemer and Sherk 1977, McKellar 1977). Chlorination has the greatest impact on phytoplankton, but during chlorination the predicted 5-10\% decrease in productivity and biomass in the effluent mixing zone at Millstone could not be detected (Carpenter et a1. 1974a). Phytoplankton studies at Cape Cod Canal and Montaup Power Plants demonstrated that entrained phytoplankton populations, similar to those at Millstone, recover with virtually no change in species composition and density, once returned to the receiving waters even with chlorination (Goldman and Quinby 1979).

The phytoplankton community in the vicinity of Millstone is not unique. The species composition and seasonality at Millstone are similar to adjacent areas of Long Island Sound (Riley 1952, Nuzzi 1973, Smayda 1973, NUSCo 1976, Staker and Bruno 1978, LILCo 1981). A1though differences in annual abundance have been detected (NUSCo 1981), these are due to natural population fluctuations and not associated with power plant impact. These density differences appear to be regional and not localized (LILCo 1982).

We have adequately documented the phytoplankton community in the vicinity of Millstone over an extended period of time. Studies at Millstone and other sites have demonstrated that entrainment impact is minimal on the local phytoplankton community. At the consensus of NUSCo 
staff and members of the Environmental Advisory Committee, the phytoplankton program was terminated in June 1982.

\section{Recommendations}

We recommend that no further phytoplankton studies be conducted at Millstone, as part of preoperational studies for Unit 3. The data base will be maintained for future reference.

\section{ZOOPLANKTON}

The zooplankton community is an important component of the marine ecosystem and consists of holoplankton, meroplankton and tychoplankton. Holoplankton are primarily copepods which spend their entire life cycle in the water column. Meroplankton are developmental stages of benthic invertebrates which are planktonic only in their early life stages. Tychoplankton are benthic organisms which become planktonic by active migration into the water column or incidental uplifting by water currents. Zooplankton are an important food source for young and adult fish. Entrainment loss of zooplankton could potentially affect the stability of the benthic community and the food web. Zooplankton studies have been conducted at Millstone since 1970 and include entrainment and offshore studies.

\section{Entrainment Zooplankton}

Woods Hole Oceanographic Institution (WHOI) conducted zooplankton entrainment studies at Millstone Unit 1 from November 1970 through June 1975. These studies were conducted to determine the entrained zooplankton species composition, abundance and survival; and the entrainment effects on adjacent waters. 
The species composition and abundance of entrained zooplankton was examined by WHOI for one annual cycle from 1970 to 1971 (Carpenter et al. 1971a, 1971b). Day and night samples (0.333-mm-mesh) were collected biweekly at the Intake (Figure 1) with additional samples collected at the Discharge and Quarry $\mathrm{Cut}$ as part of an entrainment mortality study. Intake samples were collected from 1973 to June 1975 but only a portion of these samples was processed.

Entrainment survival studies emphasized copepods and included comparison of copepod densities at the Intake and Quarry Cut, live-dead counts, copepod sinking rates, and latent mortality (Carpenter et a1. 1974b, 1975). The results indicated that approximately $70 \%$ of the copepods entrained did not survive. The mortality was not immediate but occurred up to five days after entrainment. After plant passage the copepods sink and accumulate in the deeper waters of the Quarry and are not returned to Long Island Sound. Mortality was attributed primarily to mechanical damage with chlorination and increased temperature having minimal affects.

The effect of plant operation on the copepod population in waters adjacent to Millstone was examined on five dates in 1971 and 1972 (Carpenter 1975). Two control stations and two stations in the effluent mixing zone were sampled.' No detectable differences were found between control and affected stations with five replicate tows per station. Examination of the variability of copepod densities between replicates showed that an average of 300 replicate tows at a station would be necessary to detect a 5\% change (Carpenter et al. 1974a).

Zooplankton entrainment sampling procedure was changed in mid 1975 to increase the accuracy of entrainment estimates and has remained 
nearly the same to present. The major change was the use of Discharge samples $(0.333-\mathrm{mm}-m e s h)$ rather than the Intake samples to determine the species composition and estimate entralnment densities. The higher water velocity at the Discharge provided more accurate sample volume estimates and reduced the possibility of net avoidance by zooplankton. Normandeau Associates, Inc. conducted zooplankton entrainment sampling from July 1975 through December 1976. In 1975, one sample from the 18 weekly ichthyoplankton samples $(0.333-$ mm-mesh) was used for zooplankton identification and enumeration. Alternate day and night weekly samples were processed. In 1976 to the present, a day and night sample from each week was processed for zooplankton. NUSCo staff conducted the zooplankton entrainment program from 1977 to the present. Zooplankton entrainment studies, since mid 1975, have provided a long time series of quantitative data on the densities of entrained zooplankton.

The ability of the present entrainment zooplankton program to detect changes in annual abundance was examined with power curves (EROL 1982). The power of a statistical test, used in testing differences in means, is the probability of detecting a specified difference between means. Power curves were calculated for eight dominant zooplankton taxa with paired comparisons of years 1976 through 1980 (total of ten comparisons for each taxa). Calculations were based on $\log _{10}$ transformed data with a two tailed test at $\alpha=0.05$. For each of the taxa, the power curves were almost identical for the ten paired comparisons of years 1976 through 1980. The 1979-1980 comparison is presented (Figure 3). The detectable difference at a power of 0.80 was determined from the power curves (Figure 3) and compared to yearly entrainment sample means (mean of $\log _{10}$ transformed data). The detectable difference was examined 


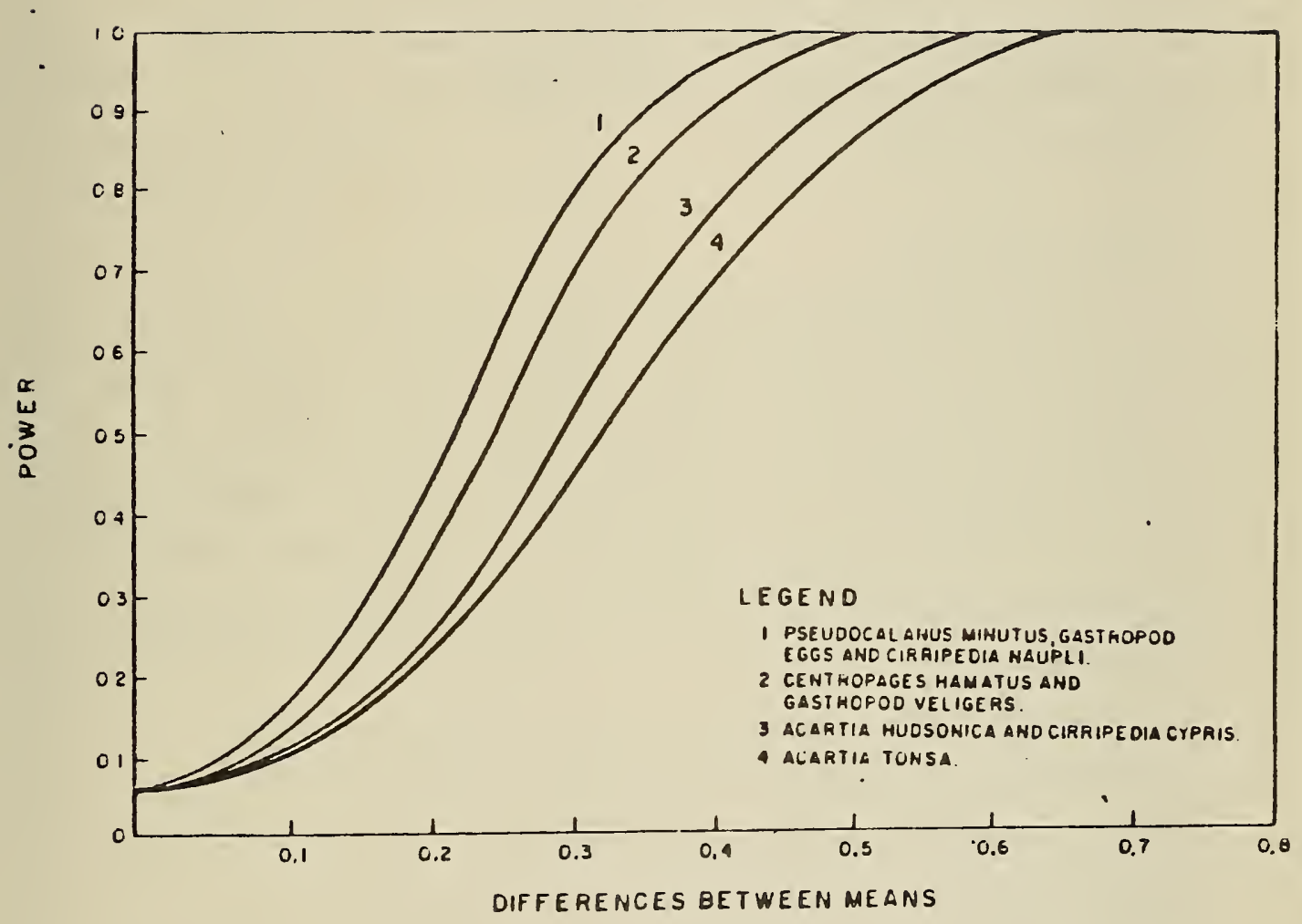

Figure 3. Power curves for dominant zooplankton taxa. Calculated from $1979-1980$ entrainment data ( $\log _{10}$ transformed) for a two-tailed
t-test with $\alpha=0.05$. 
as the percent of each yearly mean and the range of yearly percents from 1976 through 1980 is presented (Table 2). The detectable difference as the percent of the yearly mean ranged from about $20 \%$ to $30 \%$ for dominant copepods (‥ minutus, $\underline{\text { C. hamatus, }} \underline{\text { A. hudsonica, }} \underline{\text { A. tonsa) }}$ and from about $20 \%$ to $60 \%$ for dominant meroplankton (gastropod eggs and veligers, cirripedia nauplii and cyprids). The present zooplankton entrainment sampling effort is sufficient to detect a large change in dominant zooplankton abundance.

\section{Of fshore Zooplankton}

An extensive offshore zooplankton sampling program has been conducted at Millstone to determine the spatial distribution of the local zooplankton community. Ichthyoplankton samples were subsampled for zooplankton identification and enumeration. Several changes were made in sampling frequency, stations sampled, and tow type, due to ichthyoplankton data evaluations. The rationale for the changes are presented in the ichthyoplankton section.

Battelle (Clapp Laboratories) collected offshore zooplankton samples from 1973 through 1979 and processed samples collected through 1977. NUSCo staff processed samples since 1978 and collected the offshore samples since 1980. A extensive sampling program was conducted from 1973 through 1975 with day and night sampling, with surface, bottom and oblique tows (0.333-mm-mesh) at different frequencies (NUSCo 1976) and with up to 16 stations (Figure 4). The sampling program was reduced in 1976 to six stations sampled monthly with day oblique tows. This reduced sampling program maintained sufficient stations to examine inshore offshore density changes. Since 1979, offshore sampling has been conducted at one station located in mid-Niantic Bay (Station 5). A day and night 
Table 2. The detectable difference between yearly means at a power of 0.80 and the range of percents of the yearly means(1975-1980) that could be detected. Based on $\log _{10}$ transformed entrainment data and a two tailed t-test at $\propto=0.05$.

\begin{tabular}{lcc}
\hline Taxa & $\begin{array}{c}\text { Detectable } \\
\text { Difference }\end{array}$ & $\begin{array}{c}\text { Range of Percent } \\
\text { of Yearly Mean }\end{array}$ \\
${ } }$ & 0.30 & $17.4-21.4$ \\
Centropages hamatus & 0.33 & $22.4-27.3$ \\
Acartia hudsonica & 0.41 & $20.1-29.5$ \\
Acartia tonsa & 0.46 & $23.1-26.3$ \\
Gastropod eggs & 0.30 & $21.4-27.3$ \\
Gastropod veligers & 0.33 & $38.4-53.2$ \\
Cirripedia nauplii & 0.30 & $22.9-39.2$ \\
Cirripedia cypris & 0.41 & $31.3-62.1$ \\
l Based on power curves Figure & 3 &
\end{tabular}




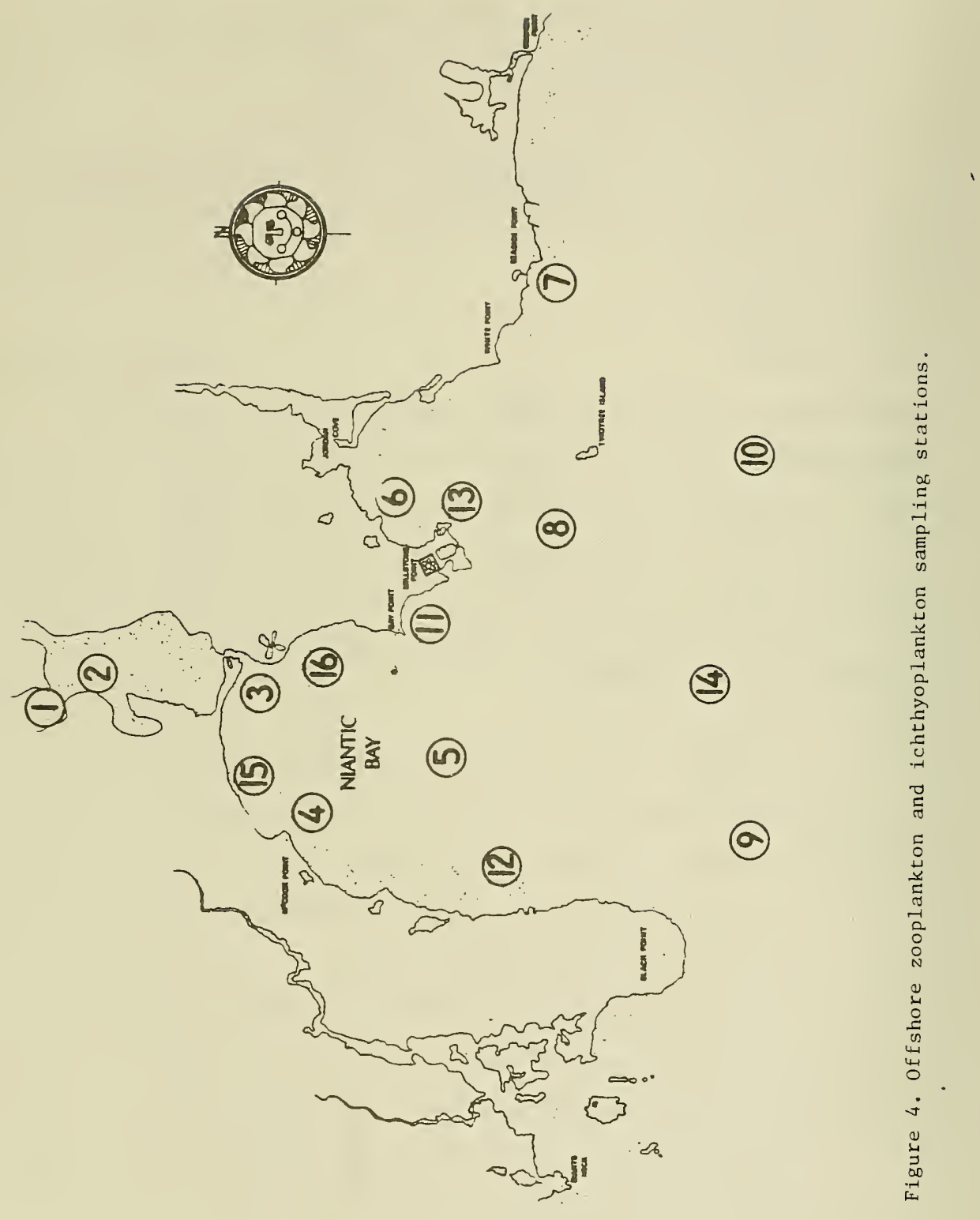


oblique tow (0.333-mm-mesh) is collected biweekly (September - March) to week1y (April - August).

\section{Zooplankton Program Evaluation}

The zooplankton studies conducted at Millstone have provided a long time series of data on local zooplankton variability, and temporal and spatial distributions. This information is important in assessing the impact of Units 1 and 2 and serves as baseline data for Unit 3 impact assessment.

Entrainment data extends back to 1970 , and has shown a recurring annual pattern in species composition. Deevey (1956) described winterspring and summer-fall communities in Long Island Sound which are similar to those found at Millstone. Winter-spring taxa include Acartia hudsonica,

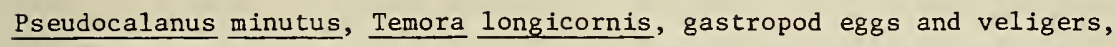
barnacle nauplii and cyprids, and polychaete nectochaete larvae. The summer-fall community includes Acartia tonsa, Pseudodiaptomus coronatus, and brachyuran and pagurid zoea and megalops. Quantitative estimates of entrainment densities are comparable from 1976 to the present. However, mid 1975 and earlier sample volume estimates are questionable due to poor meter response in the low velocities at the Intake station and quantitative comparisons are not possible (NUSCo 1976).

The extensive offshore zooplankton program in the 1970 's has explained variation in entrainment densities. Some dominant taxa are entrained in greater numbers at night than during daylight (amphipods and mysids). The day and night, surface and bottom offshore tows indicated an upward migration pattern at night, causing greater entrainment of these organisms 
at night. Offshore studies have detected spatial differences for dominant taxa (NUSCo 1978, 1979a). Acartia hudsonica was more abundant in the Niantic River and inshore areas of Niantlc Bay than in offshore Long

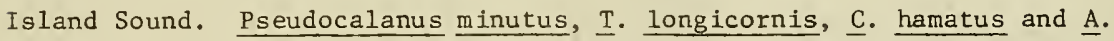
tonsa were more abundant in offshore deeper water stations.

Copepods, the dominant holoplankton group, have been emphasized in the zooplankton program at Millstone, as well as, in other power plant studies. Copepod mortality studies at Millstone (Carpenter 1975) identified mechanical stress as the major cause of mortality. This differs from studies conducted at other plants where chlorination was the major cause of mortality (Gentile et al. 1976, Heinle 1976). Capuzzo (1980) in a review of zooplankton entrainment studies concluded that power plant entrainment losses of copepods cannot be shown to cause a serious reduction in secondary productivity where adequate dilution of cooling waters is provided. This low impact is due to the small percentage of the population entrained and the high reproductive rates of the unaffected copepods.

Meroplankton and tychoplankton entrainment impact has received less attention than holoplankton. Amphipods, the dominant tychoplankton entrained at Millstone, are an important food source for demersal fish (Richards 1963). The estimated average daily entrainment of amphipods since 1976 is greater than $200 \times 10^{6}$ /day which represents a potentially large loss of benthic biomass and prey for fish. Although large numbers of amphipods are entrained, other studies have found that many survive entrainment (Ginn et a1. 1974, Cannon et al. 1977). Entrainment mortality studies on dominant tychoplankton and meroplankton taxa would mitigate apparent large losses due to entrainment. In addition more specific 
identification of tychoplankton and meroplankton would indicate which benthic habitats are most susceptible to entrainment impact.

The effects of zooplankton on the natural varfability of ichthyoplankton have not been adequately addressed by the zooplankton program. The zooplankton availibility as a food source for larval fish might influence larval survival. Recent field studies at Mt. Hope Bay, Rhode Island (Brayton Point) demonstrated that anchovy and winter flounder larval abundances were related to copepod nauplii and rotifer densities, respectively (MRI 1981). Anchovy larval growth and survival were directly related to the density of copepod nauplii (Houde 1977, 1978). Food availability has been related to winter flounder stocking density and survival rate (Laurence 1977). Rotifers and copepod nauplii are too sma11 to be sampled by the presently used $0.333-\mathrm{mm}-\mathrm{mesh}$ net. A pumped microzooplankton sampling technique (0.044-mm-mesh net) would sample rotifers and copepod nauplii, as well as, adult copepods and meroplankton presently captured with the present $0.333-$ mm-mesh net. Concurrent sampling with both techniques would determine if microzooplankton sampling yields comparable estimates of larger copepodites and adult copepods and meroplankton. If comparable, the present zooplankton sampling (0.333-mm-mesh) could be replaced with microzooplankton sampling, except that the larger less abundant tychoplankton would be processed from 0.333-mm-mesh ichthyoplankton samples.

Predatory zooplankton can influence both zooplankton and larval fish abundance. At Millstone, the lionsmane jellyfish (Cyanea), siphonophores (of the genus Sarsia), and ctenophores (Mnemiopsis leidyi) are possible zooplankton and larval $\mathrm{f}$ ish predators. Seasonally these organisms are very abundant in the Millstone area and studies have indicated that 
they could cause high larval fish mortality (Pearcy 1962, Fraser 1969).

The present zooplankton program does not include quantitative measurements of medusae and ctenophores. They are captured in plankton tows and could be measured volumetrically.

$\underline{\text { Recommendations }}$

We recommend that the present zooplanton program be continued with zooplankton processing from $0.333-\mathrm{mm}$-mesh ichthyoplankton samples at the Discharge and Station 5. This will maintain the long time series of data which is important for assessing plant impact compared to natural variability. In addition, we feel the following recommendations should be considered to better assess entrainment impact: 1) more specific identification of tychoplankton and meroplankton; 2) conducting entrainment mortality studies on dominant tychoplankton taxa (primarily amphipods). Also, we feel the following additions to the zooplankton program would provide information on factors affecting fish larval abundance: 1) sampling of smaller zooplankton utilized as a food source by larval fish, 2) quantitative measurement of ctenophore and medusae abundance in 0.333-mm-mesh samples as potential predators of fish larvae.

\section{ICHTHYOPLANKTON}

Natural ichthyoplankton mortality rates are one of the most important controlling factors in adult fish stock abundance (Cushing et al. 1973, Bannister et a1. 1974, May 1974, DeAngelis et a1. 1977). Additional mortality due to entrainment could affect local fish populations. Because of this potential entrainment impact, ichthyoplankton studies have been conducted at Millstone since 1973. Included in these studies are estimates of ichthyoplankton entrainment density and species composi- 
tion, entrainment mortality, thermal tolerance and offshore distribution. Special winter flounder studies have been conducted because of their local importance, and a more detailed evaluation on winter flounder larval studies is presented in the Winter Flounder Evaluation. The Millstone ichthyoplankton studies have been continously improved through evaluation and modification.

Woods Hole Oceanopgraphic Institution Entrainment Studies

Woods Hole Oceanographic Institution (WHOI) conducted the first ichthyoplankton entrainment studies at Millstone Unit 1 from April 1973 through June 1975. The numbers of fish eggs and larvae entrained were estimated from 30 weekly, plankton samples $(0.333-m m-m e s h, 1-m$ diameter net, single TSK flow meter). Once each week three day and three night tows were taken at Unit 1 Intake (at 1, 3, $5 \mathrm{~m}$ depths), Discharge, and Quarry Cut (Figure 1).

Entrainment Iarval mortality was estimated for Unit 1 by capturing larvae at the Intake, Discharge and Quarry Cut (Carpenter 1975). After a 24 hour holding period at Intake water temperatures, the average mortality was $20 \%$ in the Intake group (control), $70 \%$ in the Discharge group, and $41 \%$ in the Quarry Cut group. Some mortality was likely induced by net capture. Based on these data, entrainment larval nortaiity ranged from about 20 to $50 \%$.

Laboratory thermal tolerance studies were conducted on larvae of the silverside (Menidia menidia), mummichog (Fundulus sp.), and winter flounder (Pseudopleuronectes americanus) (Carpenter 1975). These studies were designed to assess thermal effects of power plant entrainment. Larvae were subjected to a $13^{\circ} \mathrm{C}$ temperature increase for time periods 
ranging up to $9 \mathrm{hrs}$, then returned to ambient temperature and held for five days. Low mortality was observed for silversides and mummichogs ( $<10 \%$ in most cases). Winter flounder larvae less than $5 \mathrm{~mm}$ (premetamorphosis) exhibited high mortality (29 to $89 \%$ ) with increased mortality at longer exposure times. Metamorphosed winter flounder larvae ( $>5 \mathrm{~mm}$ ) had virtually no mortality at exposures of as long as 9 hrs.

\section{Present Entrainment Program}

The present entrainment study was conducted by Normandeau Associates, Inc. (NAI) beginning in July 1975 and includes collection of three sequential replicate net tows $(0.333-\mathrm{mm}$ net, $1-\mathrm{m}$ mouth, NAI- electronic flow meters) at the Discharge on each of three days and three nights weekly. Thus, eighteen entrainment ichthyoplankton samples have been taken weekly to the present. Sampling began at the Discharge of Unit 2 in September 1975. Sampling is alternated weekly between both discharge stations when plant operations permit. NUSCo staff has conducted the entrainment ichthyoplankton studies since 1977.

\section{Bases for Present Entrainment Program}

This sampling frequency and technique was developed as the result of an evaluation of the WHOI program (NUSCo 1976) and was adopted to improve accuracy of sampling and sensitivity of subsequent analyses. Several changes were made as a result of the evaluation. The TSK flow meter was replaced by an NAI-Electronic Readout Box (ERB) flow meter system which was accurate at low current velocities and could account for potential reductions in flow due to net clogging (NUSCo 1976). The 
Intake sampling station was eliminated because low Intake flow velocities resulted in poor flow meter response and net avoidance by zooplankton and ichthyoplankton. The Quarry Cut station was eliminated as it was not representative for entrainment estimates since quarry residence time might allow organisms to settle out. The Discharge station was selected for entrainment sampling because flow velocities were sufficiently fast to eliminate problems of poor flow meter response and net avoidance. Using an estimated variance formula, the degree of precision of the sample mean for estimating the population mean was established, for various confidence levels. The present sampling scheme was chosen since it would provide a larval winter flounder sample mean within $40 \%$ ( $\alpha=$ 0.05) of the population mean with a practical sampling effort.

The Discharge sampling location and collection method was changed by NAI from the previous WHOI study (NUSCo 1976). Comparison of the WHOI and NAI sampling techniques were made in September 1975. During the month a total of 144 samples were taken by simultaneous collections with both techniques. A comparison of the data using analysis of variance and paired t-tests determined that WHOI and NAI sampling techniques at the Discharge did not differ significantly $(\alpha=0.05)$ in their estimates of fish larval or egg abundance. Thus, justification for directly comparing Discharge data from the earlier WHOI and ongoing program was established.

An evaluation in 1978 concluded that the present entrainment sampling effort permits detection $(\alpha=.10,1-\beta=0.80)$ of a difference in $\left(\log _{10}\right.$ transformed) mean annual densities for larval winter flounder and anchovies of about $15 \%$ and $20 \%$, respectively. This level of detectability was achievable in part because the sampling program was evenly distributed over tidal stages and day-night periods. 
Fa11 Entrainment Sampling Reduction

Early in 1978 an evaluation of the entrainment ichthyoplankton program recommended a reduction in the fall (October through December) sampling effort from 18 samples per week to 6 (3 day and 3 night samples, one day per week). The basis for the reduction was that the samples collected in October through December contain low numbers of $\mathrm{f}$ ish eggs and larvae and did not provide much quantitative information on dominant entrained ichthyoplankton taxa. A two-thirds reduction in the number of samples collected in these fall months was demonstrated not to affect our ability to meet the objectives of the entrainment studies. The fall reduction was implemented in 1981 after receiving Nuclear Regulatory Commission (NRC) approval.

\section{Flow Meter Change}

A change in the entrainment sampling flow meter system was made in February 1980. The change involved replacement of the NAI-Electronic Readout Box (ERB) system with an array of four General Oceanics (GO) model \#2030 flow meters. The bases for discontinuing use of the ERB were high design and fabrication costs, poor maintenance record, and inability to account for vertical and horizontal differences in flow. The advantages of the GO array were its low cost and maintenance requirements, ability to account for vertical and horizontal flow differences, and linear response over a range of velocities. The Go meters were identical to those used in the offshore plankton program and could be calibrated regularly by NUSCo personnel.

The validity of using four GO flowmeters versus the ERB was assessed indirectly since concurrent sampling data with both flow meter systems 
was not available. The analysis was based on towtime and tidal stage compared to volume estimates. It was determined that the volume estimates from the four GO meter array were more accurate than the ERB estimates since the Go array accounted for horizontal and vertical differences in discharge flow. Dr. F. Bolen (pers. comm.) of the University of Connecticut, a noted hydrology expert, indicated that such results would be expected due to the configuration of the discharges, the water velocities, and the net position. His judgement was that the four Go flowmeters would more accurately characterize the flow through the plankton net.

\section{Detectability of Present Entrainment Program}

Absolute differences between ichthyoplankton population means that would indicate a plant-related impact are not known. Therefore, in a 1980 evaluation (NUSCo 1980), power curves were constructed for a range of hypothetical differences in means. Power curves for differences between Station 5 (offshore) and the Discharge in 1979 and between pairs of years from 1976 through 1979 at the Discharge were calculated for total larvae and five important local larval taxa (winter flounder, sand lance, cunner, anchovies, and tautog). The curves were based on a twotail test of $\alpha=0.05$ and the data were transformed by $\log _{10}$ to satisfy the normal assumptions of parametric test used.

Power curves for spatial differences between the Discharge and Station 5 in 1979 were almost identical for winter flounder, sand lance, cunner and tautog (probability of detecting a difference in means of 0.25 was 0.85 ) which indicated the same probability of detecting a specified difference in densities of these species. The power of detecting a specific difference in means for $\log _{10}$ transformed data was highest 
for total larvae and lowest for the anchovies (the probability of detecting a difference in means of 0.25 was 0.97 for total larvae and 0.45 for the anchovies). The highest power for total larvae corresponds to the greatest number of samples. The lowest power for anchovies indicated greater variability in sample density since anchovies were the second most frequently sampled taxon.

For each of the six taxa, the power curves for detecting differences between yearly means at the Discharge were almost identical for the six paired comparisons of years 1976 through 1979. This similarity in power curves irrespective of which years were compared indicated a similar probability of detecting a specified change in mean density for any two years. The probability of detecting a difference of 0.15 in mean density from $\log _{10}$ transformed data, between 1978 and 1979 for total larvae, sand lance, winter flounder, cunner, anchovies and tautog was 0.97 , $0.76,0.61,0.52,0.47$ and 0.38 , respectively. Caution should be used when comparing taxa since the size of the population mean will determine the ecological importance of a specific difference between yearly means.

Proposed Changes to the Entrainment Program

As the result of a 1981 evaluation additional modifications to the entrainment ichthyoplankton program (E.T.S. Change Request \#81-2, 1981) have been recommended and will be implemented pending NRC approval. These recommendations include discontinuing identification of $\mathrm{fish}$ eggs from entrainment samples collected during October through March and changing the entrainment sampling frequency to one day and one night sample on each of four days weekly. 
Discontinuing the identification of entrainment eggs (October through March) was proposed because: 1) the eggs entrained during October through March represent only the very beginning or end of the spawning season for several species; 2) the eggs of several species which spawn primarily during fall and winter are not susceptable to entrainment because they are demersal; 3) the primary spawning area of some species is outside the source area for condenser cooling water; 4) the number of eggs entrained during October through March is low compared to individual fecundities.

The proposed change in the entrainment sampling frequency was based on variance component estimates of the dominant $10 \mathrm{fish}$ larval taxa utilizing a nested factorial model and five years (1976-1980) of ichthyoplankton entrainment data. Variance due to temporal components (day, week) was shown to comprise more than $67 \%$ of the overall variance for each taxa tested. Examining variance estimates on the weekly means of dominant larval taxa (based on a modification of the equation by Sokal and Rohlf 1969), showed that greater efficiency can be accomplished through increased consideration of the temporal component (increase in the days sampled from three to four). A change in entrainment sampling frequency to the proposed one day, one night sample, four days per week would have virtually no effect on sensitivity of analyses on the taxa of greatest importance (Table 3). At the same time it represents a major reduction in effort for the entrainment ichthyoplankton program.

Offshore Ichthyoplankton Program 1973 through 1975

The 1973 through 197.5 offshore ichthyoplankton program, conducted by Battelle (W.F. Clapp Laboratories), was designed to provide information, 


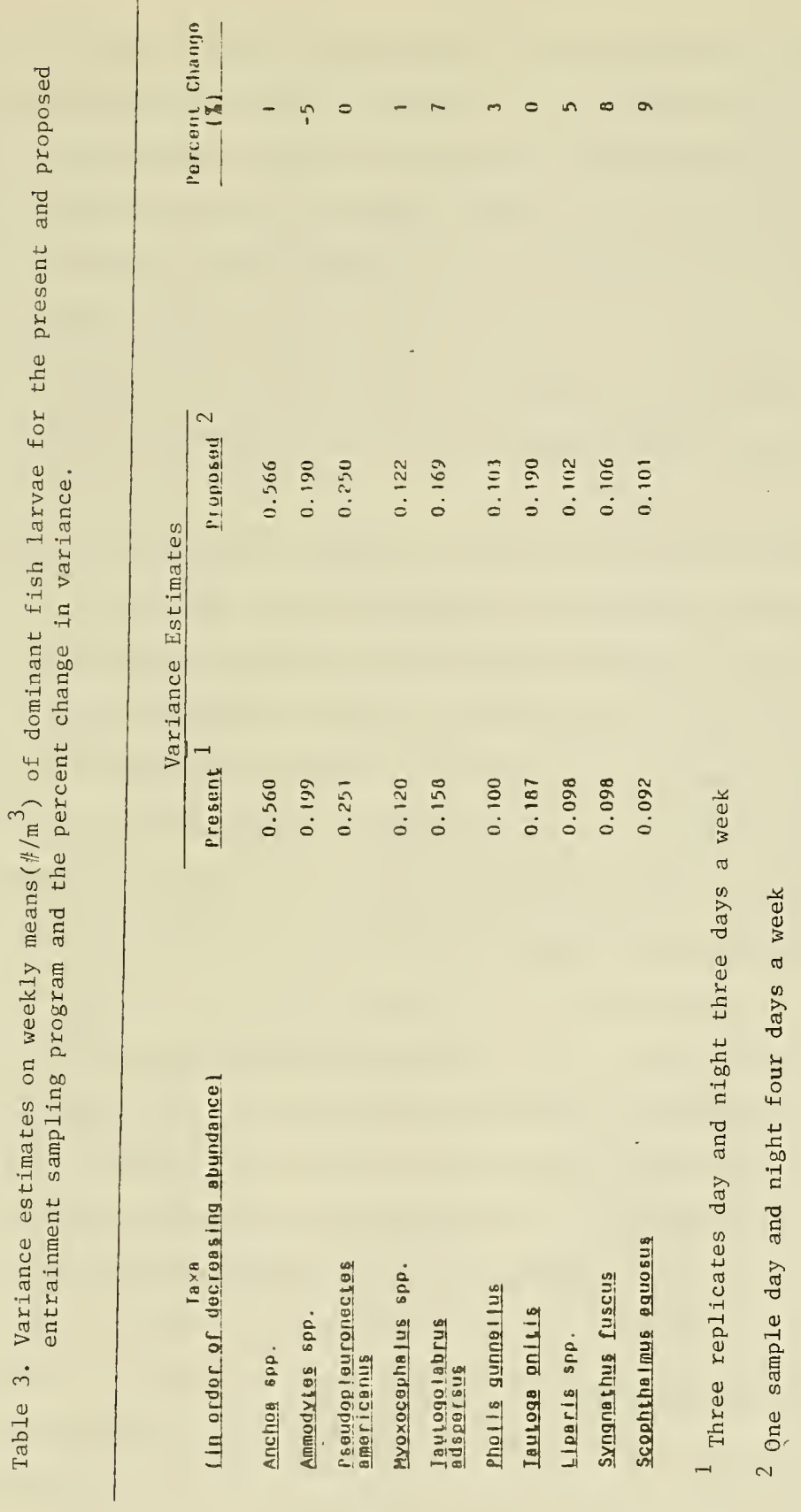


to assist in the generation and interpretation of the entrainment impact predictive models. The objectives of the offshore program (Sissenwine et al. 1973) were to determine: 1) the seasonal succession of the plankton community; 2) the spatial and temporal onset of spawning of important fish species; 3) the fish larvae and egg concentrations at the model boundaries; 4) the larval mortality rate of selected fish species; 5) larval concentration for model verification; 6) and whether estimates of the total production of $\mathrm{f}$ ish eggs and larvae were compatible with adult population estimates. Winter flounder was chosen as the primary subject species for study.

Combinations of stations 1-16 (Figure 4) were sampled from 1973 through 1975 with various sampling frequencies, tow types (surface, bottom, oblique), net types ( $0.505 \mathrm{~mm}$-mesh, $0.333-\mathrm{mm}$ mesh) and times (day, night) (NUSCo 1976). Stations 1-10 were sampled in 1973, with the addition of stations $11-13$ in 1974 and 14-16 in 1975. Stations 11-16 were added with the intent of better estimating the near-shore distribution of larvae (or those on the model boundary).

\section{Comparison of Off shore and Entrainment Sampling}

Studies were conducted in 1973 to determine the catch comparability of the offshore sampling net $(0.333-\mathrm{mm}-\mathrm{mesh}, 60-\mathrm{cm}$ mouth, General Oceanic flow meter) to the entrainment sampling net $(0.333-\mathrm{mm}-\mathrm{mesh} 100-\mathrm{cm}$ mouth TSK flow meter) and Battelle and WHOI laboratory processing techniques (Sissenwine et al. 1973). Towing velocities of 25,75 , and $125 \mathrm{~cm} / \mathrm{sec}$ were considered for both net types. Samples from both net types were processed by each group (Battelle and WHOI). Results from processing and analysis of more than 100 samples indicated there was no significant 
$(\alpha=0.10)$ difference in the ability of the nets to catch eggs or larvae or in laboratory processing technique. Both net types appear to catch larvae more efficiently at higher towing velocities but the catch of eggs is less sensitive to approach velocities.

\section{Examination of Offshore Program as Mode1 Verification}

A 1975 evaluation of the offshore program (Vaughn et al. 1976) concluded that the offshore sampling scheme was inadequate for verification of the winter flounder dispersal model, and recommended dye studies as more useful for this purpose. The offshore program was inadequate primarily because the stations were not sampled simultaneously as it was impractical to do so. In 1976, the offshore program was reduced to six stations (2, 5, 6, 8, 11, 14) sampled monthly during daylight with oblique tows and additional monthly surface and bottom tows in May through August. The objective of the program was to determine the densities and seasonal succession of the plankton community in the Millstone area, and not for model verification. This sampling program was sufficient to examine inshore-offshore density changes.

\section{Bases for Present Offshore Program}

An extensive examination of the offshore ichthyoplankton program and objectives was conducted in 1978 (NUSCo 1979b). The results of this evaluation were the basis for the present offshore ichthyoplankton sampling program, initiated in 1979, with day and night oblique tows (0.333-mm-mesh bongo nets) collected more frequently at station 5 only. The evaluation demonstrated that: 1) Station 5 was most representative of the cooling water source area in Niantic Bay; 2) oblique bongo tows 
provided a representative tow type integrating elements of the entire water column; 3) a balance of day and night samples was very important in assessing the densities of ichthyoplankton that may avoid capture in nets during the day or may alter their vertical distribution over the diel period; 4) the $0.333-m m-m e s h$ net size was more desirable than the 0.505-mm-mesh net because it captured higher densities of smaller larvae and was the same mesh used in the entrainment program; 5) at least 30 to 40 day or night samples each month should be collected over the biologically active seasons of the year, or over specific growth periods for individual ichthyoplankton species to detect a 40-50\% difference in mean annual density.

Special larval winter flounder sampling has been conducted in the Niantic River since 1979 during March through May, the larval development period of winter flounder. Station 2 (Figure 4) was sampled in 1979 and 1980; Stations 1 and 2 in 1981 and 1982. Winter flounder and the Niantic River are of special interest since winter flounder are a potentially impacted local population of commercial and recreational importance, and the Niantic River is their principal local spawning area. An evaluation of the special Niantic River plankton tows from 1979 to present are described as a portion of the Winter Flounder Program Evaluation.

\section{Ichthyoplankton Program Evaluation}

The Millstone ichthyoplankton studies are highly responsive to program objectives and labor efficient due to frequent evaluations and modifications. The ability of the program to detect change in the ichthyoplankton community has been increased through improvements in sampling and analytical methodology. The program has been useful in 
assessment of Units 1 and 2 environmental impact and is providing an extensive time series of data important for 3 Unit impact assessment.

Entrainment studies have determined the natural variability, seasonality, densities, and species composition of entrained ichthyoplankton (Table 4). This information has identified fish populations likely to have the greatest potential for entrainment impact. These populations include anchovies, sand lance and winter flounder which generally have represented over $80 \%$ of the fish larvae entrained and cunner and tautog comprising over $80 \%$ of the fish eggs entrained.

The extensive offshore ichthyoplankton program of the mid-1970's provided information on ichthyoplankton spatial distribution in the Millstone area. From this information we have been able to identify the primary spawning areas of important taxa. The Niantic River appears to be the primary local spawning area for anchovies and winter flounder based on the high density of anchovy eggs collected in the river (1974 1975) and the abundance of small winter flounder larvae. Although spatial distributions have been identified, additional offshore information on the net export of larvae out of the Niantic River and the import of larvae from adjacent areas of Long Island Sound would provide a perspective as to what portion of the ichthyoplankton population is entrained.

Estimated annual entrainment of eggs and larvae is determined from sample densities and cooling water volume. The estimates have been large for dominant taxa (Table 5) and we have assumed a "worst case" of $100 \%$ mortality in lieu of conducting entrainment mortality studies. Entrainment mortality studies at other sites have indicated that many eggs and larvae survive (Cannon et al. 1977, Ginn et al. 1977). The 
Table 5. Average annual fish egg and larval entrainment estimates (millions) for Millstone 1 and 2; and the theoretical annual maxium number of eggs and larvae entrained (million) for Millstone 1, 2 and 3. Based on entrainment data May 1979-April 1981 for eggs and 1976-1980 for larvae.

\begin{tabular}{|c|c|c|c|c|}
\hline \multirow[b]{2}{*}{ Species } & \multicolumn{2}{|c|}{ Millstone 1 and 2} & \multicolumn{2}{|c|}{ Millstone 1,2 , and 3} \\
\hline & $\begin{array}{l}\text { Average } \\
\text { Eggs } \\
\text { (Miliions) } \\
\end{array}$ & $\begin{array}{l}\text { Average } \\
\text { Larvae } \\
\text { (Millions) } \\
\end{array}$ & $\begin{array}{l}\text { Theoretical } \\
\text { Maximum Egjst } \\
\text { (Millions) } \\
\end{array}$ & $\begin{array}{l}\text { Theoretical } \\
\text { Maximum Larvaet } \\
\text { (Milions) }\end{array}$ \\
\hline Anchovies & 650.0 & 836.4 & 1303.6 & 1639.7 \\
\hline Sand lance & 0.5 & 177.9 & 0.9 & 472.3 \\
\hline Winter flounder & 9.2 & 129.1 & 23.8 & 291.0 \\
\hline Grubby & 1.7 & 270.0 & 6.2 & 68.8 \\
\hline Cunner & 3199.4 & 24.3 & 9463.5 & 50.6 \\
\hline Iautog & 1439.6 & 20.5 & 3650.7 & 41.3 \\
\hline
\end{tabular}

NOTE:

* Theoretical maximum values are based on average annual values and maximum potential annual flow volumes. 
effect of entraining eggs and larvae has been related to aduIt fish stocks with the equivalent adult calculation (Horst 1975). This is a conservative model that requires minimal data and should produce overestimates of impact (Horst 1980). Conducting entrainment mortality studies would provide information that would reduce the large numbers of ichthyoplankton that are assumed to be killed by entrainment. The use of a population model similar to the proposed stochastic model for winter flounder would provide more definitive information on the effect of entrainment on adult $\mathrm{f}$ ish populations.

\section{Recommendations}

We recommend that the present ichthyoplankton program be continued into the operational period of Unit 3 with the following modifications:

1) Discontinuation of fish egg identification from fall and winter (October through March) entrainment samples.

2) Replacement of the presently used (January through September) entrainment sampling scheme with the more efficient, recently proposed, eight samples per week scheme (one day and one night sample on 4 days weekly).

We also recommend that following studies be implemented to adequately assess the impact of 3 Unit operation.

1) Development of site specific estimates of egg and larval mortality caused by entrainment.

2) Identification of the primary source areas of dominant ichthyoplankton, the associated densities, and entrainment losses (winter flounder is of primary interest). 

Bannister, R.C. A., D. Harding, and S.J. Lockwood. 1974. Larval mortality and subsequent year-class strength in the plaice (Pleuronectes platessa L.). Pages 21-38 in J.M.S. Blaxter, ed. The early life history of fish. Springer Verlag, New York.

Briand, F.J.P. 1975. Effects of power plant cooling systems on marine phytoplankton. Marine Biology. 33:135-146.

Brook, A.J., and A.L. Baker. 1972. Chlorination at power plants: Impact on phytoplankton productivity. Science 176:1414.

Cannon, T.C., S.M. Jinks, L.R. King, and G.J. Lauer. 1977. Survival of entrained ichthyoplankton and macroinvertebrates at Hudson River Power Plants.

Pages 71-90. L.D. Jensen, ed. Fourth National workshop on entrainment and impingement. E.A. Communications, Melville, N.Y.

Capuzzo, J.M. 1980. Impact of power plant discharges on marine zooplankton: A reviews of therma1, mechanical and biocidal effects. Hergalandes Meeresunters $33: 422-433$.

Carpenter, E.J., S.J. Anderson, and B.B. Peck. 1971a. First semi-annual report to NUSCo. Woods Hole Oceanographic Institution.

- 1971b. Second semi-annual report to NUSCo. Woods Hole Oceanographic Institution.

- 1972. Third semi-annual report to NUSCo. Woods Hole Oceanographic Institution.

- 1974a. Copepod and chlorophyll a concentrations in receiving waters of a Nuclear power station and problems associated with their measurement. Estuarine and Coastal Mar. Sci. 2(1):83-89.

Carpenter, E.J., B.B. Peck and S.J. Anderson. 1974b. Survival of copepods passing through a nuclear power station on Northeastern Long Island Sound, USA. Mar. Biol. 24:49-55.

Carpenter, E.J. 1975. Integrated report to NUSCo on entrainment of marine organisms. Woods Hole Oceanographic Institution.

Cushing D.H., and J.G.K. Harris. 1973. Stock and recruitment and the problem of density dependence. in B.D. Parrish, ed. ICES Rapp. P.V. Reun. 164:142-155.

DeAngelis, D.L., S.W. Christensen, and A.G. Clark. 1977. Responses of a fish population model to young-of-the year mortality. Oak Ridge National Laboratory Pub1. No. 1065.

Deevy G.B. 1956. Oceanography of Long Island Sound. V. Zooplankton. Bu11. Bing ham. Oceanogr. Col1. 15:113-155.

EROLS. 1982. Millstone Point Power Station, Unit 3. Environmental Report, Operating License Stage. Prepared by Stone and Webster Engineering Company and Northeast Utilities Services Company. 
Flemer, D., and A. Sherk, Jr. 1977. The effects of steam electric station on entrained phytoplankton. Hydrobiologia 55(1):33-44.

Fraser, J.H. 1969. Experimental feeding of some medusae and chaetognatha. J. Fish. Res. Bd. Can. 26(7):1743-1762.

Gentile, J.H., J. Cardin, M. Johnson, and S. Sasnowski. 1976. Power plants, chlorine and estuaries. EPA- 600/3-76-055, 28 pp.

Ginn, T.C., W.T. Waller, and G.J. Lauer. 1974. The effects of power plant condenser cooling water entrainment on the amphipod Gammarus sp. Water Res. 8:937-945.

G. V. Poje, and J.M. O'Connor. 1977. Survival of planktonic organisms following passage through a simulated power plant condenser tube Pages 91-101 in L.D. Jensen, ed. Fourth National workshop on entrainment and impingement. E.A. Communications, Melville, N.Y.

Goldman, J.C. and H.L. Quinby. 1979. Phytoplankton recovery after power plant entrainment. JWPCF 51(7)1816-1823.

Heinle, D.R. 1976. Effects of passage through power plant cooling systems on estuarine copepods. Environ. Pollut. 11:39-58.

Horst, T.J. 1975. The assessment of impact due to entraininment of ichthyoplankton, Pages 107-118 in S.B. Saila ed. Fisheries and energy production. D.C. Heath and Co., Lexington MA. 300 pp.

- 1980. The equivalent adult model a general model for fisheries impact assessment. Presented at the Northeast Fish and Wildlife Conference, Ellenville, N.Y.

Houde, E.D. 1977. Food concentration and stocking density effect on survival and growth of laboratory - reared larvae of bay anchovy Anchoa mitchilli and lined sole Achirus lineatus. Mar. Biol. (Ber1) 43:333-341.

- 1978. Critical food concentrations for larvae of three species of subtropical marine fishes. Bu11. Mar. Sci. 28(3):393-411.

Kreh, T.V., and J.E. Derwort. 1976. Effects of entrainment through Oconee Nuclear Station on carbon-14 assimilation rates of phytoplankton. Pages 21-38 in G.W. Esch and R.W. McFarlane, eds. Thermal Ecology II. ERDA Conf.-750425.

Laurence, G.C. 1977. A bioenergetic model for the analysis of feeding and survival potential of winter flounder (Pseudopleuronectes americanus) during the period from hatching to metamorphosis. Fish. Bul1. $75: \overline{529-546 .}$

LILCO (Long Island Lighting Company). 1981. Preoperational aquatic ecology study Shoreham Nuclear Power Station, Unit 1, 1980. GEOMET Technologies, Inc. Melleville, New York.

- 1982. Aquatic ecology study, Shoreham Nuclear Power Staion, Unit 1. Preoperational 1981 report. GEOMET Technoplogies, Inc., Hicksville, New York. 
May, R.C. 1974. Larval mortality in marine fishes and the critical period concept Pages 3-20 in J.H.S. Blaxter; ed. The early life history of fish. Springer Verlag, N.Y.

McKellar, Jr., H.N. 1977. Metabolism and model of an estuarine bay ecosystem affected by a coastal power plant. Ecological Modeling 3:85-118.

Miller, M.C., G.R. Hater, T.W. Federle, and J.P. Reed. 1976. Effects of power plant operation on the biota of a thermal discharge canal. Thermal Ecology $2: 251-258$.

Morgan, R.P., and R.G. Stross. 1969. Destruction of phytoplankton in the cooling water supply of a steam electric station. Ches. Sci. 10:165-171.

MRI (Marine Research, Inc.) 1981. Food of larval winter flounder, menhanden, and bay anchovy, and the prediction of larval abundance from food density. Report to New England Power Co. by Marine Research, Inc. Falmouth, Mass. 46pp.

NAI (Normandeau Associates, Inc.). 1976. New Haven Harbor Station ecological monitoring studies. Prepared for the United Iluminating Company. Normandeau Associates, Inc. Bedford, New Hamshire.

NUSCo (Northeast Utilities Services Company). 1976. Annual report, 1975. Ecological and hydrographic studies, Millstone Nuclear Power Station, Waterford, Connecticut.

- 1977. Annual report, 1976. Ecological and hydrographic studies, Millstone Nuclear Power Station, Waterford, Connecticut.

- 1978. Annual report, 1977. Ecological and hydrographic studies, Millstone Nuclear Power Station, Waterford, Connecticut.

- 1979a. Annual report, 1978. Ecological and hydrographic studies, Millstone Nuclear Power Staion, Waterford, Connecticut.

- 1979b. Evaluation of past offshore ichthyoplankton program at Millstone Point and recommendations for the 1979 sampling programs. Technical Report presented to fall 1978 EAC meeting. $67 \mathrm{pp}$.

. 1980. Annual report, 1979. Monitoring the marine environment of Long Island Sound at Millstone Nuclear Power Staion, Waterford, Connecticut.

- 1981. Annual report, 1980. Monitoring the marine environment of Long Island Sound at Millstone Nuclear Power Station, Waterford, Connecticut.

- 1982. Annual report, 1981. Monitoring the marine environment of Long Island Sound at Millstone Nuclear Power Station, Waterford, Connecticut.

Nuzzi, R. 1973. Final Report to Long Island Lighting Company (LILCo) on preoperational ecological monitoring program at Shoreham, Long Island, New York. Section III: Phytoplankton. 
Pearcy, W. G. 1962. Ecology of an estuarine population of winter flounder, Pseudopleuronectes americanus (Walbaum) IV. Food habits of larvae and juveniles. Bu11. Bing. Oceanogr. Col1. 18:1-78.

Richards, S.W. 1963. The demersal fish population of Long Island Sound II. Food of the juveniles from a sand-shell locality (Station I). Bull. Bingham. Ocean. Coll. 18:32-72.

Riley, G.A. 1952. Phytoplankton of Block Island Sound. Bull. Bingham. Oceanogr. Co11. 8(3):40-64.

Sissenwine, M.P., K.W. Hess, and S.B. Saila. 1973. A mathematical model for evaluating the effect of power plant entrainment on populations near Millstone Point, Connecticut. MES-NUSCo report No. 1.

Smayda, T.J. 1973. The growth of Skeletonema costatum during a winter spring bloom in Narragansett Bay, Rhode Island. Norw. J. Bot. 20:219-247.

Staker, R.D., and S.F. Bruno. 1978. An annual phytoplankton study in coastal waters off Eastern Long Island (Block Island Sound). Botanica Marina. $21: 439-449$.

Sokal, R.R., and F.J. Rohlf. 1969. Biometry. The principles and practice of statistics in biological research. W.H. Freeman and Co., San Francisco. $776 \mathrm{pp}$.

Tilly, L.S. 1974. Respiration and net productivity of the plankton community in a reactor cooling reservoir. Pages 462-474 in J.W. Gibbons and R.R. Sharitz, eds., Thermal ecology. AEC Symposium Series (CONF-730505), Augusta, GA.

Vaughn, D.S., N. Buske, and S.B. Saila. 1976. Evaluating the effect of power plant entrainment on populations near Millstone Point, Connecticut. URI NUSCo report No. 4. 


ROCKY SHORE SURVEY, 1968-1982:

A REVIEW AND EVALUATION 

Rocky shores of northeastern North America and the communities that have developed on them are important components of the marine ecosystem. Per unit area, the intertidal zone and near-shore waters are among the most highly productive regions of the world (Mann 1973). Intertidal algae provide food directly and indirectly, to sna1ls, crabs, and other benthic invertebrates, as well as fish, shore-birds, and man (Bold and Wynne 1978; Edwards et a1. 1982; Menge 1982). Many plants release over $50 \%$ of their annual biomass as detritus and dissolved nutrients (Josselyn and Mathieson 1978). The larger perennial algae in particular contribute to the intertidal community's physical structure by providing shade and protection to plants and animals living beneath them, and attachment space for epiphytes growing upon them (Stephenson and Stephenson 1972; Menge 1975).

In addition to their intrinsic values, rocky intertidal communities have attributes that are important to a biological monitoring program. Some of the organisms that make up the community are long-lived, and capable of integrating effects of environmental conditions over many years. Other species are ephemeral, and in their presence and abundance respond very quickly to changing conditions. Some specles are sessile or slow-moving, and continuously exposed to potential impacts; others are motile, and their abundance and distribution at any locality are an indication of the suitability of the environment at that time. Many intertidal organisms show prectse seasonal patterns in their occurrence, abundance, and reproductive status; these patterns allow comparisons between sites and between years. Finally, the accessibility and stability of the rocky shore itself permit establishment of permanent sampling 
stations, and physical conditions at these stations can be experimentally altered to determine the relationships of intertidal organisms to each other, and to various environmental factors.

The initial objective of the Rocky Shore Survey was to observe the dominant species of the sessile fauna and flora of the local intertidal region. The survey was primarily qualitative in nature, but as time went by, the objectives were expanded to include more quantitative data, and the sampling procedures were modified accordingly. The present objectives of the Rocky Shore Survey are to Identify the attached plant and animal species at sites in the vicinity of Millstone Nuclear Power Station (MNPS), to establish temporal and spatial patterns of occurrence and abundance at these sites, and to recognize the physical and biological factors that induce variability at these sites. More specifically, we must determine if differences in the biota of these sites exist that could be attributed to the operation of the power station.

\section{Past History}

The rocky intertidal sampling program (Fig. 1) began in May 1968; five stations (White Point, Fox Island-South, Fox Island-North, Bay Point, and Black Point) were to be visited five times per year (May, July, Sept., Dec., Feb.). Qualitative observations were to be made along undescribed horizontal transects. By September 1968, sampling procedures had become more rigorously defined; 100 foot long transects were established between MLW and +1 meter for qualitative observations. Six randomly placed, permanently marked quadrats, $50 \mathrm{~cm}$ on a side, were used for quantitative studies: percent coverage by dominant organisms, 


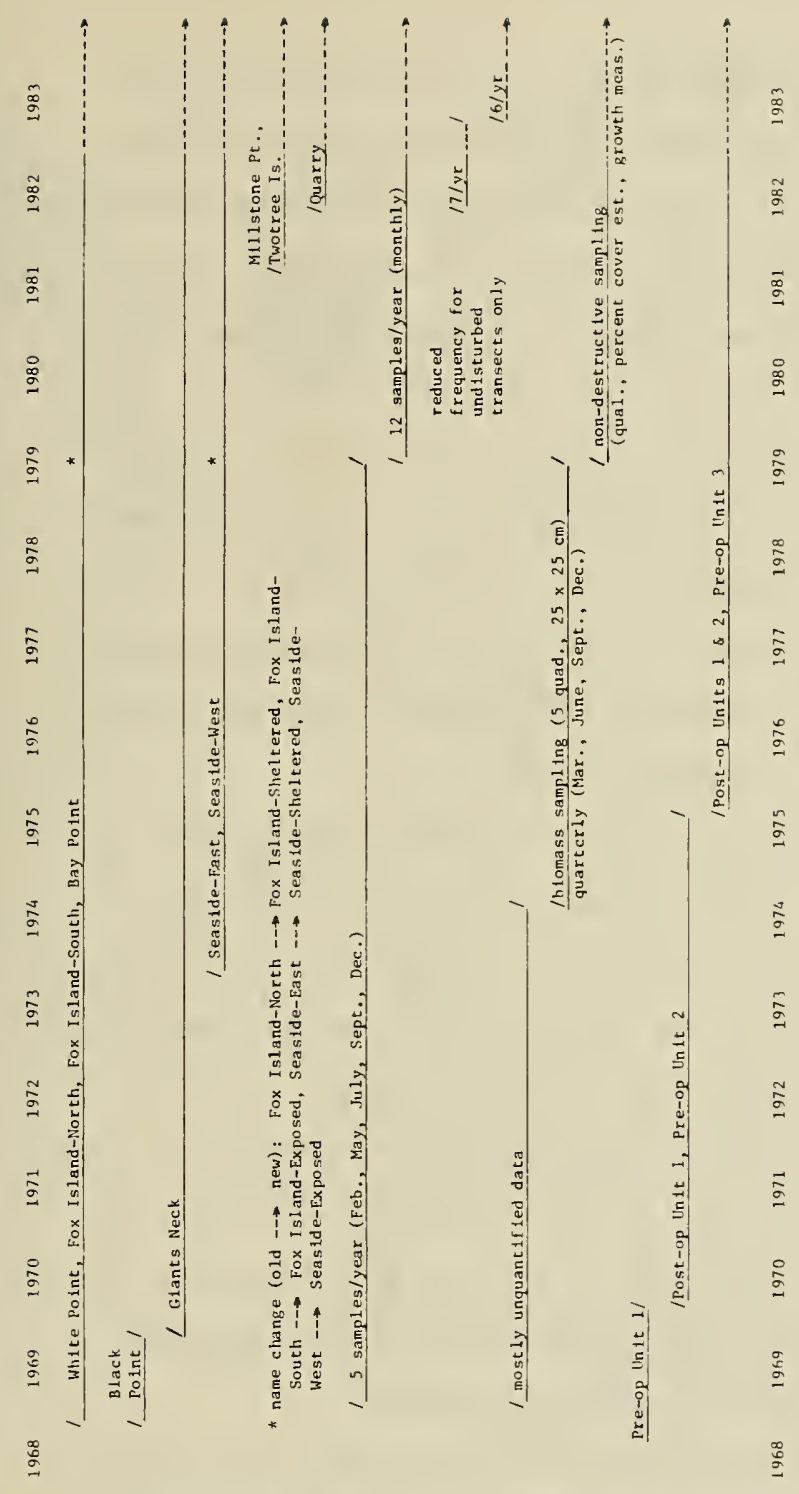

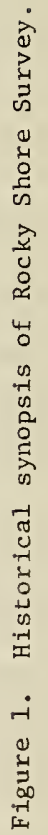


and sizes of barnacles, snafls, and Fucus and Ascophyllum plants (5 each/quad.).

In February 1969, the Black Point station was dropped and a new station, at Giants Neck, was added. By May 1969, attempts were being made to get more quantitative data: 30 barnacles per quadrat were measured, and several methods for determining algal growth were tried. By September 1969, no method had proved satisfactory, and that facet of the program was dropped.

Pre-operational studies continued until Unit 1 went on-line in December 1970; the only described changes involved relocation of some of the quadrats, and the adoption of a subjective rank scale to rate the relative abundance of selected invertebrates. No reported changes in methodology occurred until February 1973, when two additional stations were added (Seaside-East and Seaside-West).

In June 1973, quantitative intertidal studies were undertaken at White Point, Fox Island-South, and Giants Neck; at each site, five quadrats (each $25 \mathrm{~cm}$ on a side) were scraped for subsequent biomass determination. In that form, the sampling program was continued through December 1978 (Unit 2 became operational in this period, Dec. 1975).

In August 1978, the rocky intertidal sampling program was evaluated, and extensive modifications were proposed (Appendix I). The modified sampling procedures were instituted in February 1979, emphasizing nondestructive sampling, recolonization studies, Fucus and Ascophyllum growth measurements, and more frequent collections.

In the new program, seven rocky intertidal stations (Fig. 2) were sampled monthly. At each station, five permanent transects were established perpendicular to the water-line, one--half meter wide and extending from Mean High Water to Mean Low Water levels. Each month, the entire 


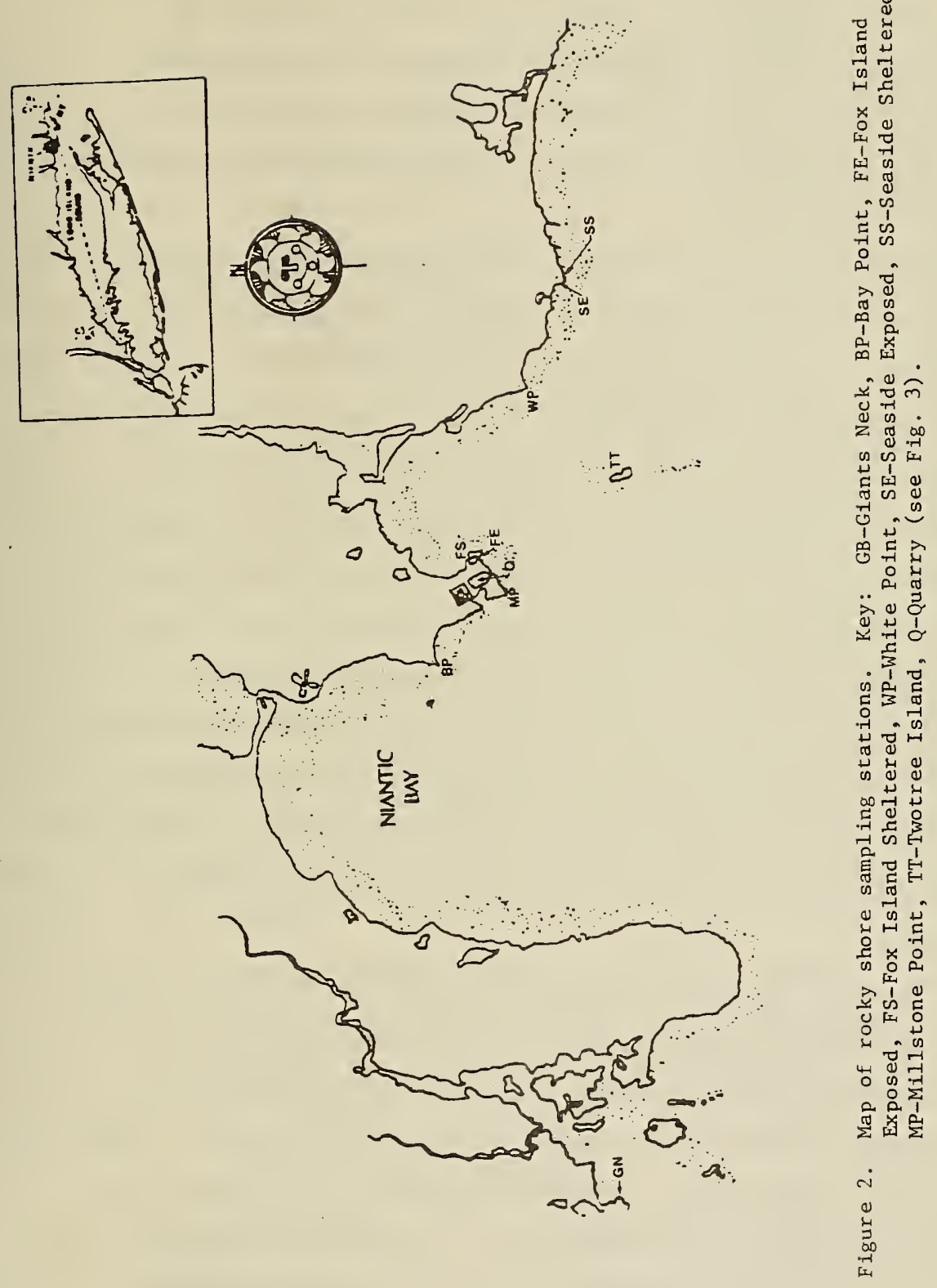


area of each strip was non-destructively sampled in $0.5 \times 0.5 \mathrm{~m}$ quadrats; the percent coverage of all organisms and remaining free space was subjectively determined and recorded. An additional percentage was given for the occurrence of 'understory' organisms, to give a more accurate representation of species that are partially or totally obscured by the canopy layer.

Beginning in April 1979, additional experiments were conducted to determine rates and patterns of recolonization following substratum denudation. At four of the rocky shore stations (Giants Neck, Fox Island-Exposed, Fox Island-Sheltered, and White Point), three strip transects additional to those previously described were established. After initial determinination of species composition and percentage of substratum covered, each strip was scraped free of all attached algae and invertebrates and burned with a Liquid Petroleum Gas torch. All recolonization transects were sampled monthly in the same manner as described for the undisturbed transects. To determine the effect that time of year in which denuding occurred might have on recolonization, a second experiment was established in September 1981, 30 months after the spring denuding, when all recolonization strips at each station were reburned.

At each of the four recolonization stations, exclusion cage studies were undertaken to determine the effects of grazing and predation on recolonization rates and patterns. In April 1979, nine areas were selected at each station, three areas in each of three tide zones (high, mid, and low tidal levels). In each area, two $20 \times 20 \mathrm{~cm}$ patches were burned and cleared; one was covered with a stainless steel mesh cage, the other was left as a control. Each month, the percent cover of colonizing organisms was determined and recorded; additionally, counts 
of snails, barnacles, and mussels were made (snails in the entire $20 \mathrm{x}$ $20 \mathrm{~cm}$ area, mussels and barnacles in 10 random $2.5 \times 2.5 \mathrm{~cm}$ subplots). If present, the 20 longest thalli of Fucus vesiculosus were measured in each caged and control area. As with the recolonization transects, an attempt was made to determine the effect that season of denuding has on rates and patterns of recolonization. The caged and control areas were reburned in June 1980 (15 months after the spring denuding), and again in September 1981 (15 months after the summer denuding). A proposed winter denuding in December 1982 w111 complete a seasonal cycle.

Algal growth studies are also conducted on Ascophyllum nodosum at four sites: at Giants Neck, White Point, and at two sites on Fox IslandExposed (one low intertidal, one high intertidal). Starting in spring of 1979,50 plants at each site were chosen randomly and tagged; five vegetative tips per plant were marked with colored tapes. Each month, the length of each labeled tip was measured from bladder to apex. Each group of plants was monitored until the following spring, when a new group of plants was chosen and tagged at each site. Because two years of analyses showed no significant differences in growth due to tidal height at the experimental stations, the higher Fox Island site was dropped in spring of 1981.

In addition to the quantitative studies outlined above, monthly qualitative algal collections have been made at each of the seven rocky intertidal stations since February 1979, and a reference herbarium is maintained.

\section{$\underline{\text { Present Procedures }}$}

Based on conclusions drawn from over 2 years of monthly sampling, slight modifications were made to the above program in October 1981. 
One modification was based on the determination of optimum sampling frequency for quantitative collections. We found that five collections per year, in the months specified by our Environmental Technical Specifications, were not adequate to assess seasonal variability in the undisturbed transects, but that six collections per year (bi-monthly) were sufficient. The substitution of sampling months required a change in our Tech Specs; the justification for the change request is included in Appendix II. Pending approval of the request, the undisturbed transects are being sampled seven times in 1982; it is anticipated that bi-monthly sampling will begin in January 1983. This sampling schedule applies only to the undisturbed transects, where the changes over time are slower and more predictable; all qualitative algal collections, Ascophyllum growth measurement, and sampling of recolonization transects, exclusion cages, and control areas will continue to be made monthly.

Another change to the rocky shore sampling program that went into effect October 1981 was the addition of two intertidal sampling stations. One station is on Millstone Point, between the Intakes and the Effluent cut (Fig. 2). Qualitative algal collections, and monitoring undisturbed transects at this site, should allow us to determine the extent to which heated effluent water, that may be recirculating back into the intakes, is affecting the intertidal community. This information will be particularly important as Unit 3 pre-operational data.

The other new station is on Twotree Island (Fig. 2). According to the hydrographic models this site is presently non-impacted, but the thermal plume resulting from 3 unit operation may affect it. Sufficient substratum for permanent transects is lacking, so Twotree Island will be sampled qualitatively only; floristic characterization will be useful as Unit 3 pre-operational data. 
A final modification to the sampling program to date occurred in May 1982. Prior to this time, qualitative algal collections were made at various locations in the effluent quarry, but only at irregular intervals. As of May, collections are made monthly, at three sites within the quarry, and along the west bank of the discharge cut (Fig. 3).

\section{RESULTS AND EVALUATION}

\section{Qualitative Collections}

At the rocky shore stations that have been sampled monthly since February 1979, 129 species of algae have been identified, exclusive of diatoms and blue-green algae (Appendix III). Not all species were found at any one station, nor were they all found in any one collection period, but the annual flora has been characterized, and has remained consistent with time.

One measure of consistency in the flora is the ratio of numbers of species in each major algal division. Of the 129 species found, 59 were reds (Rhodophyta), 33 browns (Phaeophyta), and 37 greens (Chlorophyta). These values are compared to those reported from previous years (NUSCo $1980,1981,1982$ ) in Table 1a. Regardless of the number of species, the relative proportions are virtually identical. When the 1981 data are analysed by station (Table $1 \mathrm{~b}$ ), the same proportions are apparent, again independent of species number.

To illustrate the applicability of qualitative species proportions in assessing rocky shore flora over a wide range of conditions, Table lc presents the same pattern in results from other studies in New England. With elevated temperatures, however, the relative proportions alter. Schneider (1981) sampled algae from the Millstone effluent quarry over an 18 month period, and found 42 species in the 3 major algal 


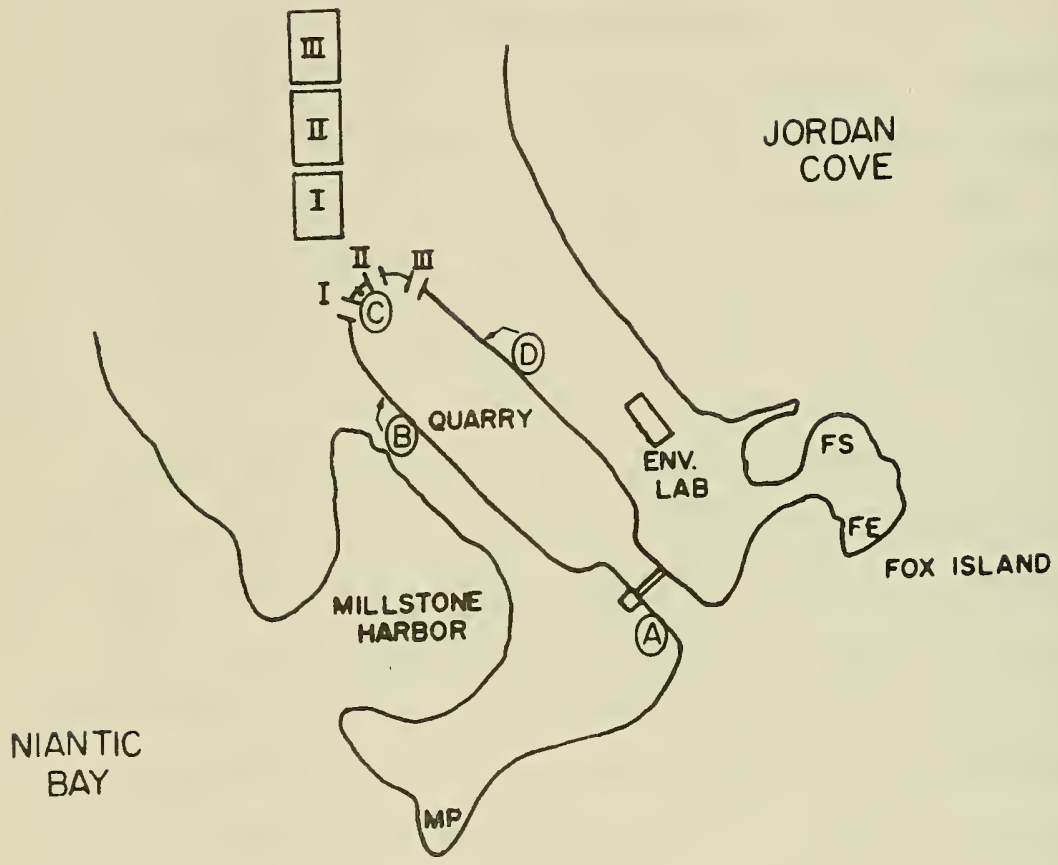

Figure 3. Map of effluent quarry sampling sites. 
Table 1. Number of species and relative proportion of each major algal division: a) Rocky shore survey, annual totals, 1979-1981, b) Rocky shore survey, 1981 data, by station, c) Results from other studies (1-Millstone exposure panel program (1968-1981), 1i - Mathieson et al. (1981), 1iiSchneider (1981). Values presented as: \# species (relative \%) (See text for additional explanation).

$\begin{array}{lcccc}\text { a) } & 1979 & 1980 & 1981 & \text { total } \\ \text { Rhodophyta } & 45(44) & 46(45) & 56(45) & 59(46) \\ \text { Phaeophyta } & 26(25) & 25(25) & 33(27) & 33(25) \\ \text { Chlorophyta } & 32(31) & 30(30) & 35(28) & 37(29) \\ \text { Total } & 103 & 101 & 124 & 129\end{array}$

b)

$\begin{array}{lllllll}\text { GN } & \text { BP } & \text { FE } & \text { FS } & \text { WP } & \text { SE } & \text { SS }\end{array}$

$\begin{array}{lllllllll}\text { Rhodophyta } & 36(44) & 42(49) & 32(45) & 29 & (40) & 40(44) & 28(43) & 34\end{array}(44)$

$\begin{array}{lllllllll}\text { Phaeophyta } & 22(26) & 22(26) & 16(22) & 19(26) & 27 & (29) & 19(29) & 22\end{array}$

Chlorophyta 25 (30) $21(25) \quad 24$ (33) 25 (34) 25 (27) 18 (28) 22 (28)

$\begin{array}{llllllll}\text { Total } & 83 & 85 & 72 & 73 & 92 & 65 & 78\end{array}$

\begin{tabular}{|c|c|c|c|c|c|c|}
\hline c) & $\begin{array}{l}i \text { - panels } \\
1968-1981\end{array}$ & $\begin{array}{l}\text { ii - Mathieson } \\
\text { Jaffrey Pt. }\end{array}$ & $\begin{array}{l}\text { et al. (1981) } \\
\text { all sites }\end{array}$ & $\begin{array}{l}\text { iil - Sc } \\
\text { total }\end{array}$ & $\begin{array}{l}\text { hneider } \\
25^{\circ} \mathrm{C}>\end{array}$ & $\begin{array}{l}1981) \\
30^{\circ} \mathrm{C}\end{array}$ \\
\hline Rhodophyta & $55(50)$ & 59 (48) & $76(47)$ & 19 (45) & $13(50)$ & $12(57)$ \\
\hline Phaeophyta & 24 (22) & $33(26)$ & $45(28)$ & $10(24)$ & $3(12)$ & $1(5)$ \\
\hline Chlorophyta & $30(28)$ & $33(26)$ & 41 (25) & $13(31)$ & $10(38)$ & $8(38)$ \\
\hline tal & 109 & 125 & 162 & 42 & 26 & 21 \\
\hline
\end{tabular}


divisions, with proportions similar to ours (Table lciii). However, he also reported the range of temperatures over which each species was found; extracting from his data the number of species present when water temperatures exceeded $25^{\circ} \mathrm{C}\left(77^{\circ} \mathrm{F}\right)$ and $30^{\circ} \mathrm{C}\left(86^{\circ} \mathrm{F}\right)$ shows a greatly different pattern. With elevated temperatures, the number of brown algal species decreases rapidly, concomitantly decreasing the proportion of browns relative to the other groups. This phenomenon has also been noted in the Millstone Exposure Panel Program (NUSCo 1982).

Our data show that few local algae are found exclusively in the quarry, or never found there. However, many species that are common elsewhere (e.g. Fucus vesiculosus) are rare in the quarry, or species characteristic of quarry collections (e.g. Agardhiella subulata) are seldom found outside of the discharge cut. Additionally, the heated effluent has an effect on seasonal patterns of occurrence and reproduction; the present sampling program will enable us to determine the degree and extent of this effect.

The qualitative collections will also be particularly important for predicting and assessing the impact of widening the quarry cut and of Unit 3 operation. The sampling sites provide a full range of potential thermal stress; the two Seaside stations and Giants Neck are beyond MNPS effects, and the three sites within the quarry are exposed to undiluted effluent. The two Fox Island stations, White Point, Twotree Island, Millstone Point, and Bay Point are potentially impacted, and bracket the predicted plume; the sampling site in the quarry cut represents a transition zone between the quarry and the other stations.

In summary, the qualitative algal collections, as one facet of the rocky shore monitoring program, allow us to determine what species are 
present in the Millstone Point vicinity, and the degree of seasonal and year-to-year variability in their occurrence. Additionally, a change in the relative species composition at the intertidal stations, particularly a decrease in the number of brown algae, would be an easily observed indication of thermal incursion.

\section{Quantitative Collections}

Undisturbed transects - In terms of the stated objectives of the Rocky Shore Survey, data from the undisturbed transects are used to quantify the spatial and temporal patterns of occurrence and abundance of intertidal organisms in the Millstone Point area. Additionally, these species form a base-line community, against which communities in other studies and in future years may be compared.

Results of three years of percent cover measurements (from March 1979 through February 1982) are presented in Table 2. Each month, 339 quadrats are sampled: to condense this large volume of data into a more clearly understandable and presentable form, some generalizations are made. Each transect is divided into three zones: upper, mid, and low intertida1.

Data from all five transects at each station are pooled to generate an average percent cover for each organism in each zone; then each organism and substratum type is assigned to one of eight habit categories: (see NUSCo 1982).

The upper intertidal (Zone I) at most stations was dominated by bare rock, at times greater than 99 percent. The ephemeral class was most commonly represented by a blue-green algal turf (primarily a Calothrix - Lyngbya association) that was present in winter and early 
spring, disappeared in summer, and refurned in autumn. At the more exposed stations, Ulothrix, Bangia, and Blidingia were also common in spring and autumn. The Fox Island-Exposed station was unique in having approximately 30 percent each of Fucus and barnacles, and 1ess than 25 percent rock; all other stations had a least 45 percent rock and much lower coverage by barnacles and Fucus (Table 1). In general, the development of a high intertidal (Zone I) community was primarily dependent on degree of desiccation, on a seasonal basis and according to degree of exposure; and secondarily, on abundance and distribution of predators and grazers, which also varied seasonally and with exposure.

Zone II was largely covered by fucoids. In general, Fucus vesiculosus was the dominant alga, but given more protection from surf, Ascophyllum nodosum became more abundant. Bay Point was atypical because of high exposure and concomitant low fucoid coverage; it was dominated by mussels and barnacles. At most stations, barnacle set into Zone II was heavier than that in Zone I and survival was higher (Table 2).

Zone III was characterized by high coverage of Chondrus crispus (34 percent), and fucoids and ephemerals (approximately 13 percent each). Because Fox Island-Sheltered was subjected to more severe ice scouring, this station differed from the others by having less Chondrus in Zone III (1ess than 5 percent), but more Fucus and bare rock (30 and 47 percent, respectively).

The abundances of the perennial algae (e.g., Fucus, Ascophyllum, Chondrus) are not as variable seasonally as those of ephemeral algae or intertidal invertebrates, but changes in percent coverage of these species do occur with time. Coverage can increase as young plants are recruited into the population, or growth and branching of older plants 


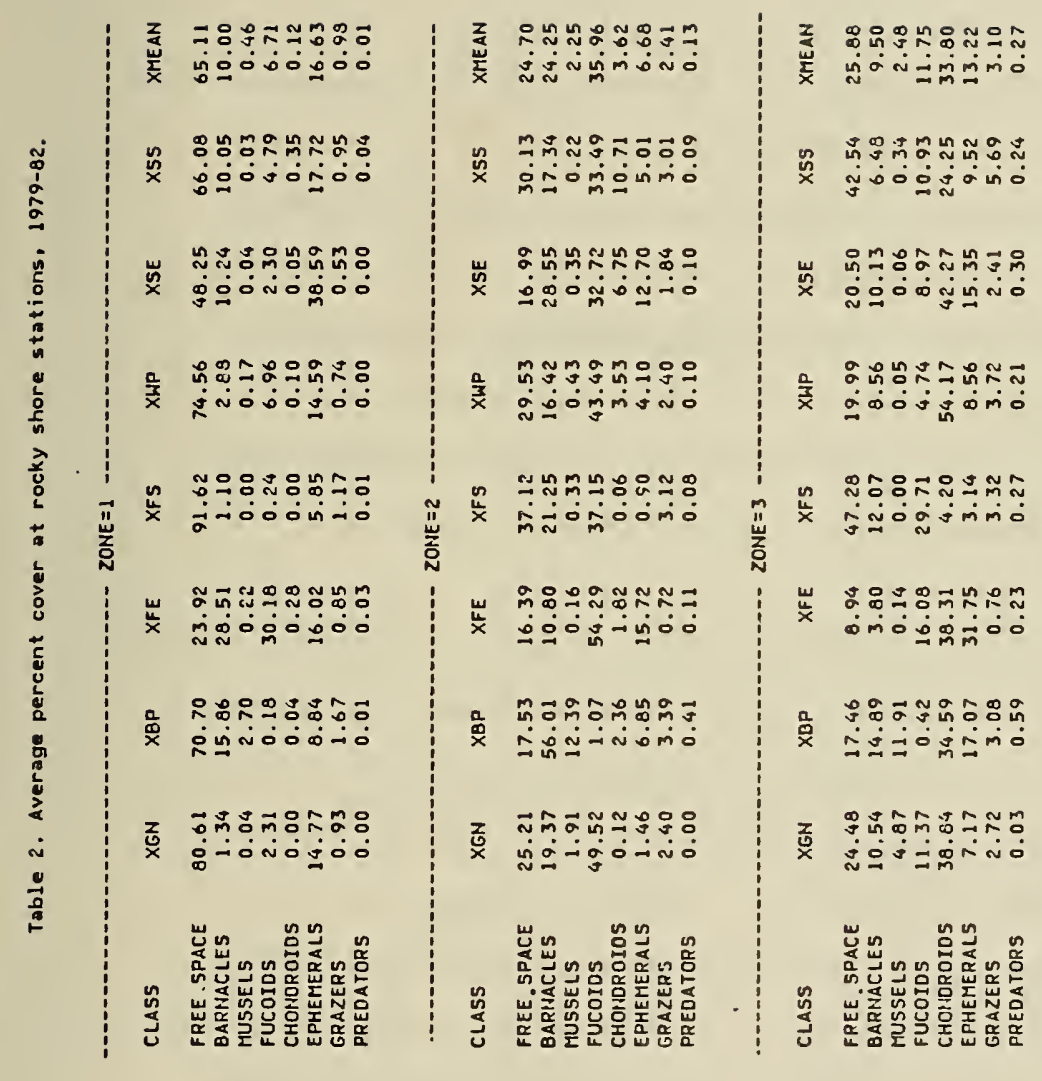


takes place. Coverage can decrease as plants are lost due to senescence or storms, especially in winter and early spring. These phenomena will be discussed in a later section. Aside from the actual loss of plants, apparent (canopy layer) percent coverage decrease can occur as a result of overgrowth of the host plants by ephemeral algae. In Zone III, for example, at most stations Chondrus experienced a decrease in percent coverage in late spring, followed by an increase through the summer, then a decrease in early autumn, and another increase during late autumn and winter. These fluctuations were inversely related to percent coverage of the ephemeral class; since the percentages given represent canopy coverage, the variations represent overgrowth of Chondrus by other species. In the spring, Monostroma pulchrum was the dominant ephiphyte; it disappeared by summer, and Polysiphonia harveyi became the most common ephemeral unt1l autumn. This epiphytism did not appear to produce enough shading to harm the Chondrus, which maintained a high understory percentage, contrary to the findings of Menge (1975) and Lubchenco and Menge (1978).

Another illustration of the spatial and temporal variability associated with intertidal communities is shown when percent standardized BrayCurtis similarity coefficients are represented as clustering dendrograms. Numerical classification was applied to the data, using a hierarchical clustering algorithm (Boesch 1977). Figure 4 represents data from 3 years of monthly percent cover determinations (March 1979 - February 1982), analyzed by station and zone. Three groups are apparent at the 50 percent level and correspond to the three designated shore zones. The inclusion of FEl and FS3 in a cluster otherwise made up of Zone II stations is caused by the high proportion of Fucus in the high intertidal 


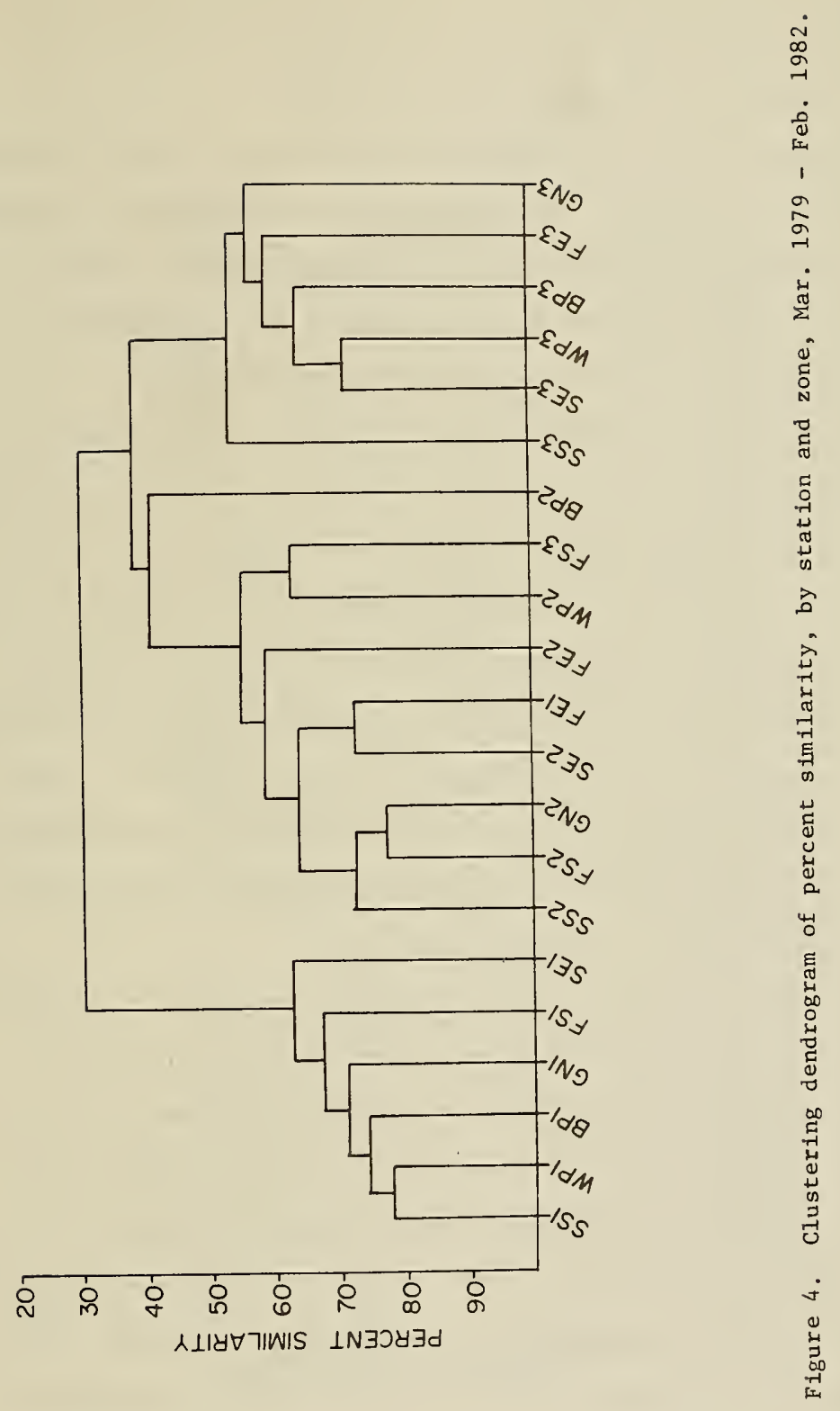


at Fox Island-Exposed and the low abundance of Chondrus in the low intertidal at Fox Island-Sheltered. Bay Point, Zone II, is not closely associated with the other zone II stations because of the high mussel coverage and scarcity of Fucus plants at this site.

When the same data are analyzed by month (Figure 5), three distinct clusters are apparent at the 67 percent level, corresponding to seasonal groupings. Cluster A represents a late spring-early sumer flora, roughly April - June. Cluster B is winter-early spring (December March), and Cluster C is late summer-autumn (July - November).

As mentioned in the section on qualitative algal collections, the thermal effluent has an effect on the seasonal occurrence and reproductive phenology of the algae growing in the quarry. If this effect were to extend to one or more of the intertidal stations, it would decrease this station's (or stations') similarity, relative to the control stations and to previous years. An advantage of the present quantitative sampling methods, particularly the representation of percent similarity in the form of clustering dendrograms, is the ease with which we could detect such a change; the affected collection would no longer be included in the appropriate spatial or temporal group.

To sumarize the results of the Rocky Shore Program, the intertidal communities in the Millstone Point area show considerable variability between and within themselves. However, these fluctuations may occur on a seasonal basis, or with degree or exposure to waves and tides; they could be attributed to natural cycles as well as to man-induced impact. Characterization of these cycles, particularly of abundance of the perennial macroalgae (Chondrus, Fucus, Ascophyllum) and barnacles, is a major goal of the monitoring program. Because of their important role 


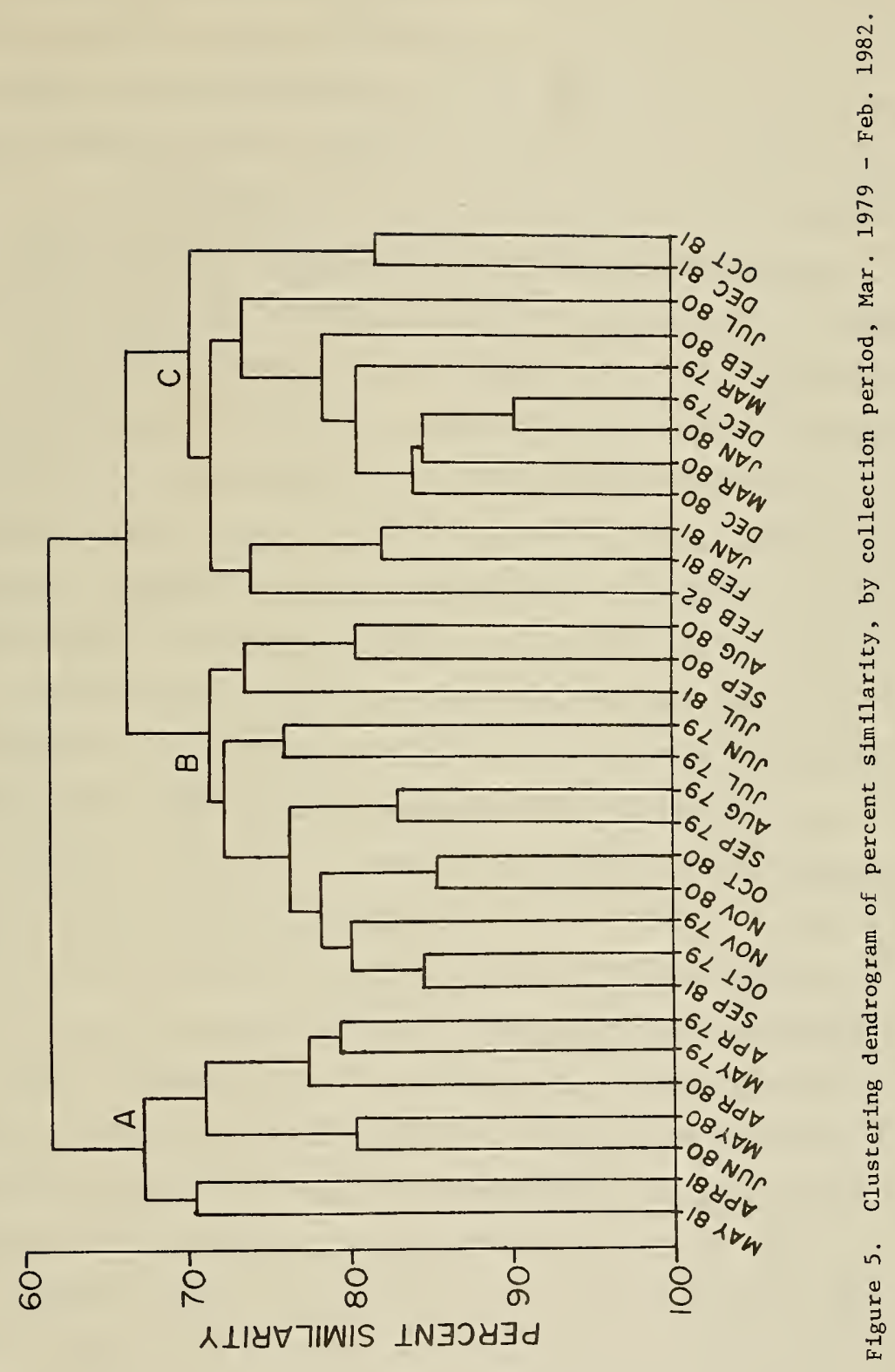


in maintaining the physical structure of the intertidal community, a loss or reduction of any of these species would have a dramatic effect on the appearance and stability of the intertidal region. Should any of them disappear, there are no other organisms that are capable of filling those functional niches (Vadas et a1. 1976; Price 1980).

Recolonization studies - The recolonization studies described earlier were designed to determine the patterns and rates of recovery of intertidal communities (particularly the species mentioned above) following substratum denudation. Presumably, colonizing germling and juvenile stages would be more susceptible to environmental impact. and therefore could detect a more subtle alteration of conditions (Bird and McLachlan 1974). The denudings simulated the worst possible impact (i.e., total removal of biota); hence, they represent a much more severe perturbation than any expected power plant effect. Exclusion cage experiments were included to assess the effect of grazing and predation on recolonization. In the Millstone area, Urosalpinx cinerea is the dominant predator; Littorina spp., especially L. 1ittorea, are the dominant grazers. Predators and grazers can exert a profound influence on the structure of the intertidal community (Southward 1964; Menge 1978; Peterson 1979), although they are not dominant in terms of percent cover. In fact, the relationships between the abundance of algae and sessile animals, and the numbers and activity of the snails suggest that the latter have a direct effect on the abundance of the former, in terms of percent coverage. Many intertidal organisms have life histories that include relatively short reproductive periods at a specific time of year; therefore, the initial stages of recolonization are dependent on the time of denuding. For example, if substrata are cleared in early spring (March), one of 
the earliest colonizers may be Balanus; barnacles have a major settlement period around April - May. As the barnacles grow, they provide surface heterogeneity that allows attachment and survival of Fucus germlings; as the Fucus canopy develops, it provides protection for other elements of the recolonization community. If the rock is cleared in June, subsequent to the major barnacle set, Fucus germlings that settle in sumer are more vulnerable to grazing; recovery is usually delayed until the following year. If grazers are excluded from the cleared areas (e.g., by the wire cages), Fucus may grow without prior establishment of a barnacle population. Sometimes, however, exclusion of grazers can actually retard Fucus development; if sufficient moisture is available, ephemeral algae (e.g., Enteromorpha, Porphyra) may grow so densely that they reduce the settlement of other organisms beneath them (Menge 1975; NUSCo 1982). Once barnacles are established, in the absence of predation they may crowd themselves into 'hummocks' and become detached (Grant 1977). Alternatively, mussels may settle into a barnacle patch; particularly in the low intertidal, given protection from predation, they may grow so rapidly that they outcompete the barnacles for attachment space.

The above discussion was included to describe some of the many possible stages an intertidal community might go through in recovering from a severe perturbation. The same stages may be found in unperturbed communities as well; the denudation that I called 'severe' is actually a commonly occurring process throughout the intertidal. Biological and physical factors (e.g., grazing, predation, storms, ice-scouring) may clear substrata at almost any time of the year. Therefore, recolonization cannot be regarded as a precise series of successional stages; rather, the intertidal community is continually undergoing dynamic processes. 
Despite the apparent randomness, several generalizations may be drawn from the recolonization studies to date. Recovery is more rapid in the low intertidal than in the upper intertidal, and faster and more complete at exposed stations than at sheltered ones. Predators and grazers have a profound effect on recolonization (Lubchenco 1978); they ma: retard development of some species (e.g., Fucus), but they also prevent the monopolization of space by one or a few species (e.g., mussels, Enteromorpha). Depending upon time of year, some components of the community (e.g., barnacles, ephemeral algae) may recolonize almost immediately, and others (e.g., Fucus) recover more slowly ( 8 mo at an exposed station, up to 30 mo at a sheltered one). Some species (e.g., Chondrus, Ascophyllum) may require many years to re-establish populations (Prince and Kingsbury 1973; Sundene 1973).

The slow recovery rates for Chondrus and Ascophyllum in our study are partly an artifact of the experimental design. The method of experimental denuding (i.e., scraping and burning) was far more drastic than would be natural removal (e.g., ice-scouring), which would typically remove only the upright thalli, and permit regrowth from the basal or crustose holdfasts. Additionally, the areas denuded were not optimal for the growth of these species; Ascophyllum was not dominant even before the denudation, and Chondrus is more of a subtidal alga, and is usually found intertidally under a fucoid canopy.

To get a more representative idea of recolonization rates for these species, we propose clearing some areas in established Chondrus and Ascophyllum beds, with denudation to consist of scraping and burning, and scraping only. These experiments should allow us to better determine the ability of these algae to recover from perturbation. The Ascophyllum 
denudings in particular will add information on growth and mortality rates to the data that have been collected in the Ascophyllum growth studies.

Because of the importance of Fucus vesiculosus in the structure and function of the intertidal community, particular attention has been given to the abundance and recolonization patterns of this alga in the Rocky Shore Survey. The present sampling procedures are well designed for detecting changes in abundance of intertidal organisms, in terms of percent cover. More importantly, they allow us to identify long-term trends, and to determine whether these trends can be attributed to thermal impact or are part of a widespread natural cycle. As an example, Figure 6 illustrates percent cover values for the fucoid canopy in Zone 2 of six rocky shore stations for the past three years (Bay Point was omitted, due to consistently low coverage).

There is a general tendency for the highest values to occur in late summer (July-Aug.); coverage decreases as older plants are removed by storms, and occasionally, by ice-scouring. Values generally begin to increase around March, as the survivors resume growth, and new plants settle and are recruited into the population. At all stations but Seaside Exposed, there was a decrease in mean annual percent cover of fucoids from spring 1979 to spring 1981, with minima occurring in April of 1981. This decrease was attributed to natural mortality of Fucus. Fucus vesiculosus is a perennial alga; its lifespan is estimated at 2-4 years (Nienburg 1930; Knight and Parke 1950; Keser 1978). O1der plants are susceptible to epiphytism (Menge 1975), storm damage, and ice-scouring (Vadas et al. 1977); their removal makes space avallable for settlement and growth of new germlings to continue the cycle. The 

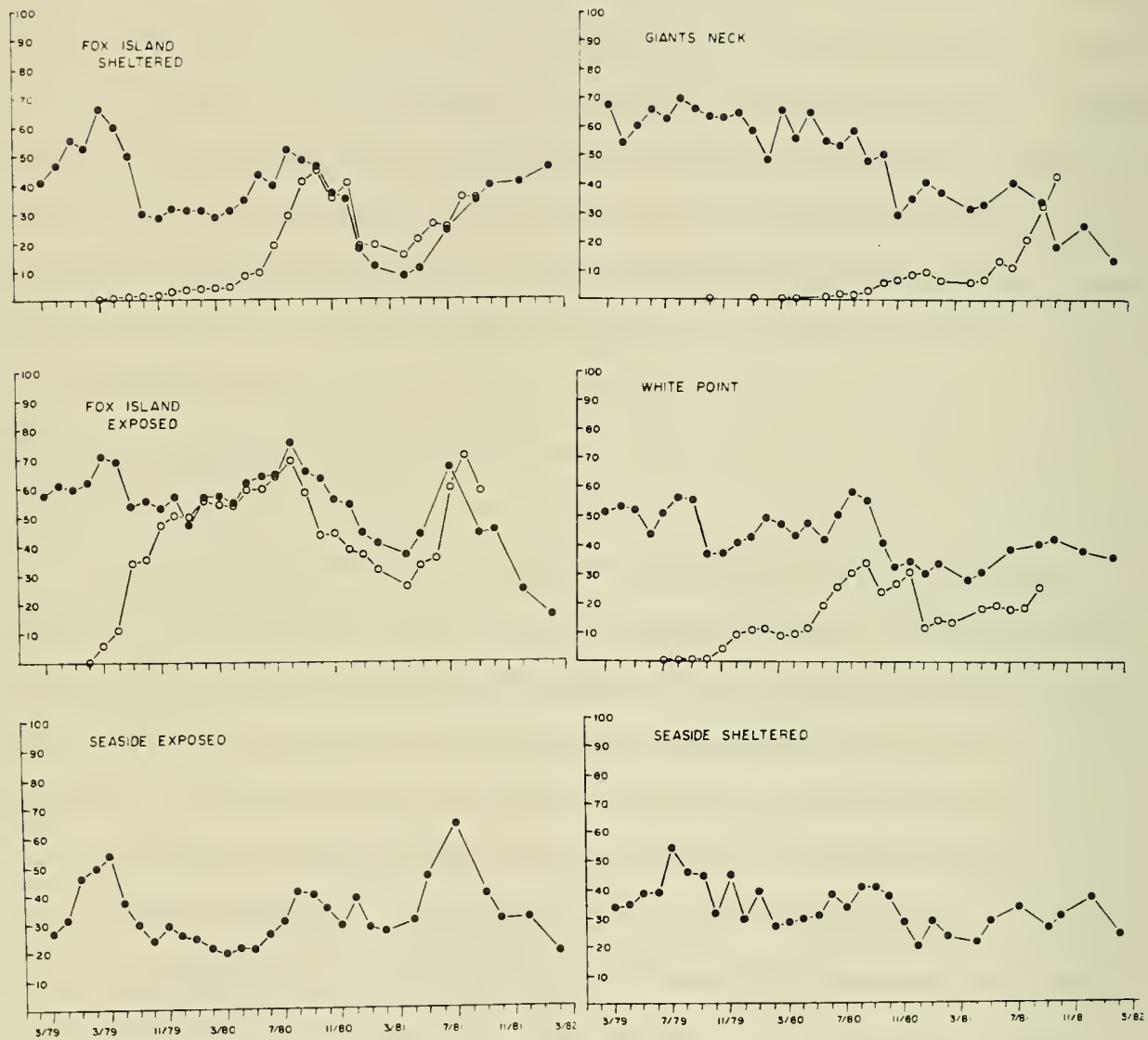

Figure 6. Percent cover of fucoid canopy in mid-intertidal of rocky shore stations, Mar. 1979 - Feb. 1982. 
assumption that the observed declipe is part of a natural cycle rather than the result of a man-induced impact is supported by the fact that it occurs throughout the study area, even at control stations beyond the influence of MNPS. The cyclic nature is particularly clear at the Fox Island-Sheltered station, where fucold percent cover values of $11 \%$ in April 1981 increased to $46 \%$ by the following spring (Fig. 6). In August 1982, Fucus cover at this station was up to $60 \%$, a three year maximum.

Figure 6 also presents Zone 2 Fucus canopy cover at the recolonization stations, in the strips denuded in April 1979 (except for Fox IslandSheltered, where the recolonization transects were burned and cleared in June 1978). Further evidence that the loss of Fucus in the undisturbed transects was natural mortality of older plants is seen in the fact that over the same time span (1979-1981), coverage increased in the recolonization transects. The recovery of Fucus populations (particularly rapid at Fox Island-Exposed, potentially the most impacted site) indicates that enviromental conditions necessary for Fucus growth have not deteriorated over the past three years.

The comparison of recolonization to undisturbed transects also indicates one of the advantages of the present multi-faceted monitoring program; data from one study can support hypotheses presented in another facet

Ascophyllum growth studies - Ascophyllum nodosum is a particularly effective monitoring tool, especlally for studying thermal impacts (Vadas et al. 1976; Keser and Foertch 1982). The abundance, longevity, and mode of growth of this alga permit easy measurement of response to changes in environmental conditions; the growth rate of Ascophyllum has been shown to be particularly sensitive to temperature changes (Strömgren 1977; Vadas et a1. 1978; Wilce et al. 1978). 
Ascophyllum in our area has proven to be a particularly sensitive indicator of thermal incursion. Analyses of data from three growing seasons show year-to-year variability in total growth, but extremely consistent seasonal and station-to-station trends. At all stations, growth starts in March - April; maximum growth rates occur July - August, and growth is very low in late autumn and winter. Ascophyllum is not present within $25 \mathrm{~m}$ of the discharge, but plants at the experimental stations (FL, $70 \mathrm{~m}$ from discharge and $\mathrm{FH}, 100 \mathrm{~m}$ ) grew significantly faster than at the control stations (WP, $2 \mathrm{~km}$ from discharge and GN, 6 $\mathrm{km}$ ). Average growth is illustrated in Figure 7. The ability of Ascophyllum to respond to a slight thermal enhancement emphasizes its applicability as a monitoring tool. Ascophyllum mortality, measured as plant loss and tip loss, is also variable between years; however, no station-to-station trends are evident, and mortality is not correlated with proximity to discharge.

The Ascophyllum growth studies, together with the proposed Ascophyllum recolonization experiments, will provide base-1ine data that will be particularly useful in assessing the impact of the quarry cut widening and Unit 3 operation." If the increased volume of heated effluent has any biological impact on the rocky shore, it will be evidenced first in the Ascophyllum populations near Fox Island.

\section{SUMMARY AND CONCLUSIONS}

The present rocky shore sampling program was designed to assess the effects of operation of Millstone 1 and 2 and the construction of Millstone 3 upon the intertidal community in the vicinity of Millstone Point. The sampling sites (Fig. 2 and 3) were selected to represent a range of exposure to prevailing wind and waves, from relatively high exposure 


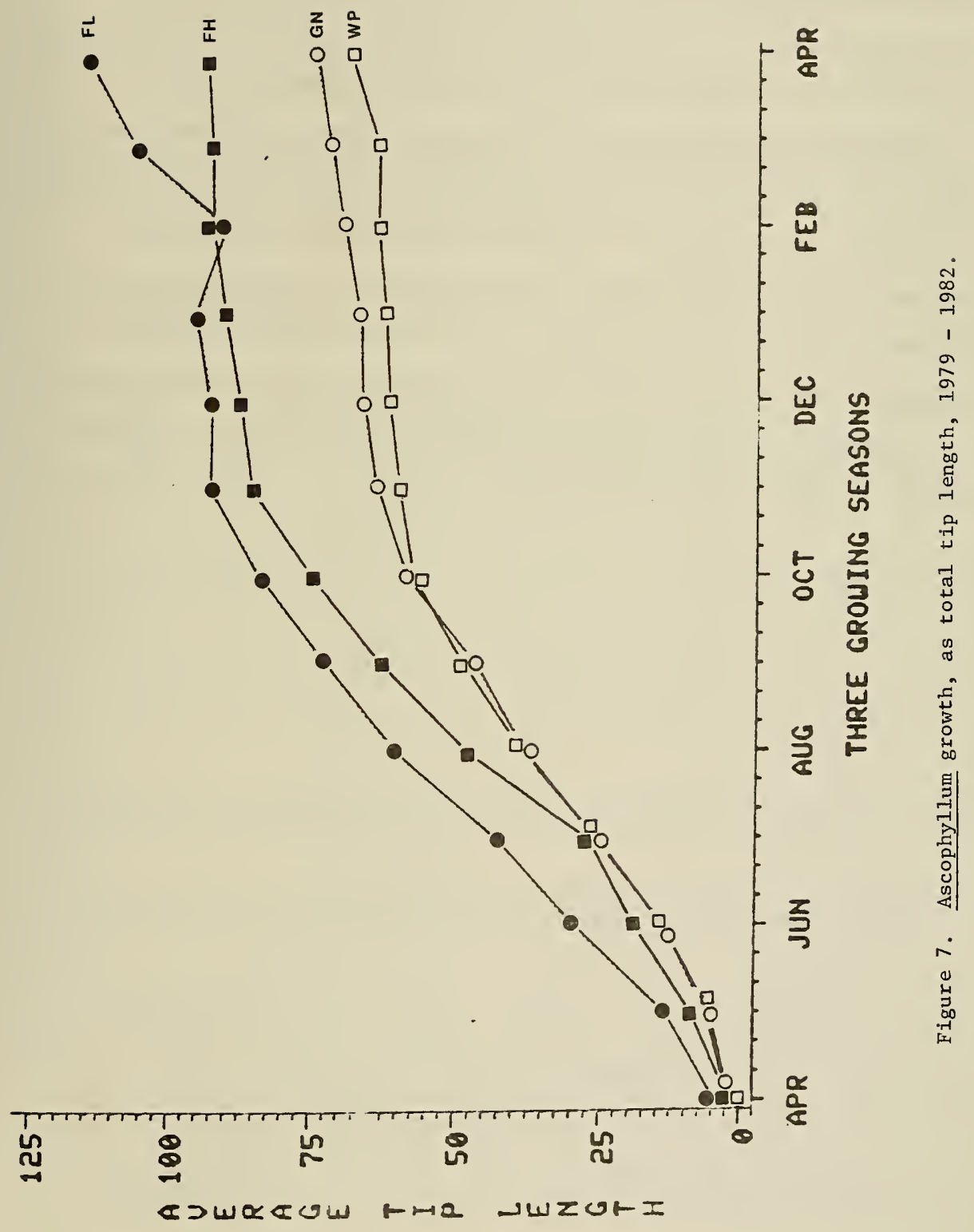


(BP, TT), to moderate exposure (FE, MP, WP, SE), to relatively sheltered conditions (SS, GN, FS, quarry sites). Also represented is the full range of exposure to thermal stress, from undiluted effluent (quarry sites) to uninfluenced controls (GN, SE, SS), with the other stations at intermediate levels. The sampling methodology effectively, efficiently monitors the intertidal community with state-of-the-art techniques. We feel that continuation of the present program is necessary and sufficient to assess the additional impact due to operation of Milstone 3. The program should permit achievement of the stated objectives of the Rocky Shore Survey, namely, to characterize the rocky intertidal regions in the vicinity of Millstone Nuclear Power Station, to identify the attached plant and animal species at these sites, and to determine if differences in the biota of these sites exist that could be attributed to the operation of the power station. 
Bird, C.J. and J. McLachlan. 1974. Cold-hardiness of zygotes and embryos of Fucus (Phaeophyceae, Fucales). Phycologia 13:212-225.

Boesch, D.F. 1977. Application of numerical classification in ecological investigations of water pollution. EPA-600/3-77-033, 114 p.

Bold, H.C. and M.J. Wynne. 1978. Introduction to the algae. Prentice-Hall, Inc., Englewood Cliffs, N.J., 706 p.

Edwards, D.C., D.0. Conover and F. Sutter, III. 1982. Mobile predators and the structure of marine intertidal communities. Ecology 63:1175-1180.

Grant, W.S. 1977. High intertidal community organization on a rocky headland in Maine, U.S.A. Mar. Biol. 44:15-25.

Josselyn, M.N. and A.C. Mathieson. 1978. Contribution of receptacles from the fucoid Ascophyllum nodosum to the detrital pool of a north temperate estuary. Estuaries $1: 258-261$.

Keser, M. 1978. Ecological effects of harvesting on the growth of Ascophyllum and the growth dynamics of Fucus. Ph.D. thesis, Univ. of Maine, 138 p.

, and J. Foertch. 1982. Colonization and growth of Ascophyllum nodosum in New England. Presented at First International Phycological Congress, St. John's, Newfoundland. August 9, 1982.

Knight, M. and M.W. Parke. 1950. A biological study of Fucus vesiculosus L. and F. serratus L. J. Mar. Biol. Assoc. U.K. 29:437-514.

Lubchenco, J. and B.A. Menge. 1978. Community development and persistence in a low rocky intertidal zone. Ecol. Monogr. 59:67-94.

Mann, K.H. 1973. Seaweeds: their productivity and strategy for growth. Science 182:975-981.

Mathieson, A.C., J.W. Shipman, J.R. O'Shea and R.C. Hasevlat. 1976. Seasonal growth and reproduction of estuarine fucoid algae in New England. J. Exp. Mar. Biol. Ecol. 25:273-284.

Menge, B.A. 1978. Predation intensity in a rocky intertidal community. Effect of an algal canopy, wave action and desiccation on predator feeding rates. Decologia $34: 17-35$.

- 1982. Reply to a comment by Edwards, Conover, and Sutter. Ecology $63: 1180-1184$.

Menge, J. 1975. Effect of herbivores on community structure on the New England rocky intertidal region: distribution, abundance, and diversity of algae. Ph.D. thesis, Harvard Univ. 164 p.

Nienburg, W. 1930. Die Besiedelung des Felsstrandes und der Klippen von Helgoland. Teil II. Die Algen. Wiss. Meeresunters., Helgoland, N.F. Bd. 15, 19:1-15. 
NUSCo (Northeast Utilities Service Company). 1980. Annual Report, 1979. Monitoring the marine environment of Long Island Sound at Millstone Nuclear Power Station, Waterford, CT.

1981. Annual Report, 1980. Monitoring the marine environment of Long Island Sound at Millstone Nuclear Power Station, Waterford, CT.

- 1982. Annual Report, 1981. Monitoring the marine environment of Long Island Sound at Millstone Nuclear Power Station, Waterford, CT.

Peterson, C.H. 1979. The importance of predation and competition in organizing the intertidal epifaunal communities at Barnegat Inlet, New Jersey. Decologia 39:1-24.

Price, J.H. 1980. Niche and community in the inshore benthos, with emphasis on the macroalgae. Pages 487-564 in Price, J.H., D.E.G. Irvine and W.F. Farnham (eds). The shore environment. Vol. 2: Ecosystems. Academic Press, New York.

Prince, J.S. and J.M. Kingsbury. 1973. The ecology of Chondrus crispus at Plymouth, Massachusetts. I. Ontogeny, vegetative anatomy, reproduction, and life cycle. II. Field studies. Am. J. Bot. 60:956-975.

Schneider, C.W. 1981. The effect of elevated temperature and reactor shutdown on the benthic marine flora of the Millstone thermal quarry, Connecticut. J. Therm. Biol. $6: 1-6$.

Southward, A.J. 1964. Limpet grazing and the control of vegetation on rocky shores. Pages 165-273 in Crisp, D.J. (ed). Grazing in terrestrial and marine environments. Blackwell Scientific Publications, Oxford.

Stephenson, T.A. and A. Stephenson. 1972. Life between tidemarks on rocky shores. W.H. Freeman and Co., San Francisco.

Stromgren, T. 1977. Short-term effects of temperature upon the growth of intertidal fucales. J. Exp. Mar. Biol. Ecol. 29:181-1985.

Sundene, 0. 1973. Growth and reproduction in Ascophyllum nodosum (Phaeophyceae). Norw. J. Bot. 20:249-255.

Vadas, R.L., M. Keser and B. Larson. 1977. Marine algae. Pages 227-251 in Semi-annual environmental surveillance report $X$, Maine Yankee Atomic $\overrightarrow{\text { Power }}$ Co.

- 1978. Effects of reduced temperatures on previously stressed populations of an intertidal alga. Pages 434-451 in Thorp, J.H. and J.W. Gibbons (eds). DOE Symposium Series, Springfield, VA.

Vadas, R. L., M. Keser and P.C. Rusanowski. 1976. Influence of thermal loading on the ecology of intertidal algae. Pages 202-212 in Esch, G.W. and R.W. MacFarlane (eds). Thermal Ecology II. ERDA Symposium Series, Augusta, GA.

Wilce, R.T., J. Foertch, W. Grock1, J. Kilar, H. Levine and J. Wilce. 1978. Flora: Marine algal studies. Pages 307-656 in Benthic studies in the vicinity of Pilgrim Nuclear Power Station, 1969-1977. Summary Report, Boston Edison Co., Boston, MA. 



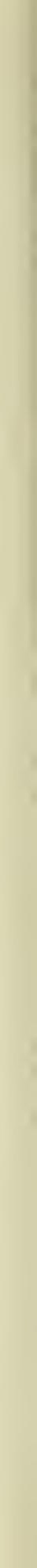


MILLSTONE INFAUNAL SAND STUDIES:

A REVIEW AND EVALUATION 



\section{INTRODUCTION}

Investigations of benthic infaunal communities are frequently included in ecological surveillance programs at electrical generating stations that use once-through cooling systems (ConEd 1977; LILCo 1980, 1981; Boston Edison Co. 1981). The reasons for this are two-fold. First, benthic organisms remain fairly stationary and thus are continuously exposed to any physical or chemical changes in the overlying water caused by plant operation. The sensitivity and response of benthic communities to various enviromental perturbations have been well documented (Boesch 1973; Reish 1973; Loi and Wilson 1979; Reish et al. 1980) and this information provides a solid framework within which any man induced changes in community composition and abundance may be detected and their ecological significance evaluated.

The second justification for monitoring benthic communities in areas potentially impacted by man's activities is that these organisms play an integral role in the function of marine ecosystems. Benthic animals provide a valuable food source for demersal fish populations (Longhurst 1958; Arntz 1980). Additiona11y, their activities (tube building, burrowing, feeding) contribute to energy recycling and nutrient regeneration processes essential to maintaining the high productivity characteristic of estuarine and coastal ecosystems (A1ler 1978a, b; Goldhaber et a1. 1977; Tenore 1977).

Quantitative infaunal studies have been conducted at the Millstone Nuclear Power Station since 1968, with an overall objective of assuring that construction and operation of the facility results in no significant changes in the ecology of local marine communities. The program has been designed to detect changes in community structure that have been 
characteristically associated with envirommental stress. These changes include reductions in the numbers of species or individuals, shifts in community trophic structure, or changes in the overall community composition. Stressed communities generally contain a few species of ten with one or two occurring in very high density. Additionally, the types of species that flourish under these conditions are well known and further enhance our ability to identify any plant induced changes in benthic ecology

Our program examines within station structural and compositional changes relative to those that occur naturally over time (and thus the need for long term data). Also, potentially impacted and non-impacted stations are sampled to provide spatial comparisons necessary for separating more short term, i.e. less than one year, natural fluctuations from those potentially caused by plant operations. This evaluation is intended to present a historical overview of the infaunal sand program at Millstone, summarize prior evaluations upon which program changes were based, and evaluate the necessity of the present and any future studies relative to the startup of Unit 3 .

\section{CHRONOLOGY OF PAST EVALUATIONS}

Over the years, the collection and analysis procedures used to obtain infaunal samples have been modified to improve the quality of data and increase our ability to assess plant impacts. These modifications (Tables 1 and 2) were generally based on evaluations of existing Millstone data or on the results of special studies that addressed specific collection techniques. The freezing of samples as a preservation method (prior to June 1976) most severely affected the quality of data; a 


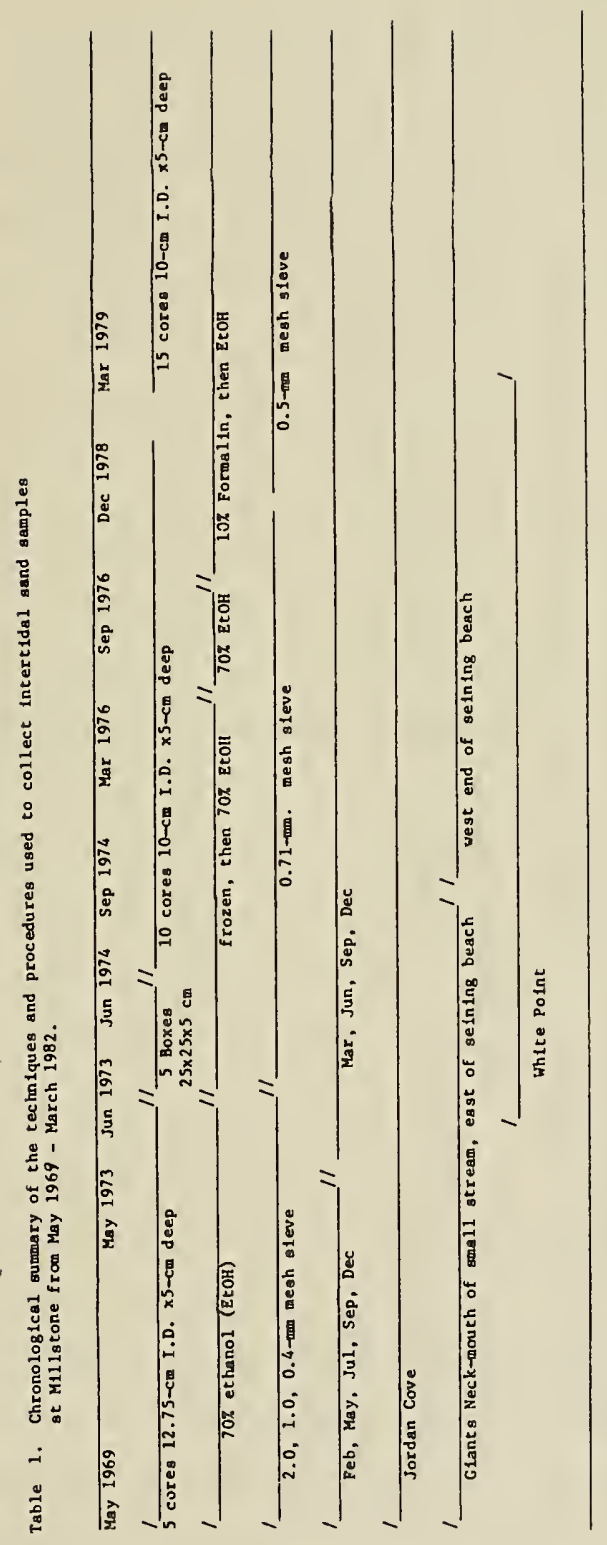




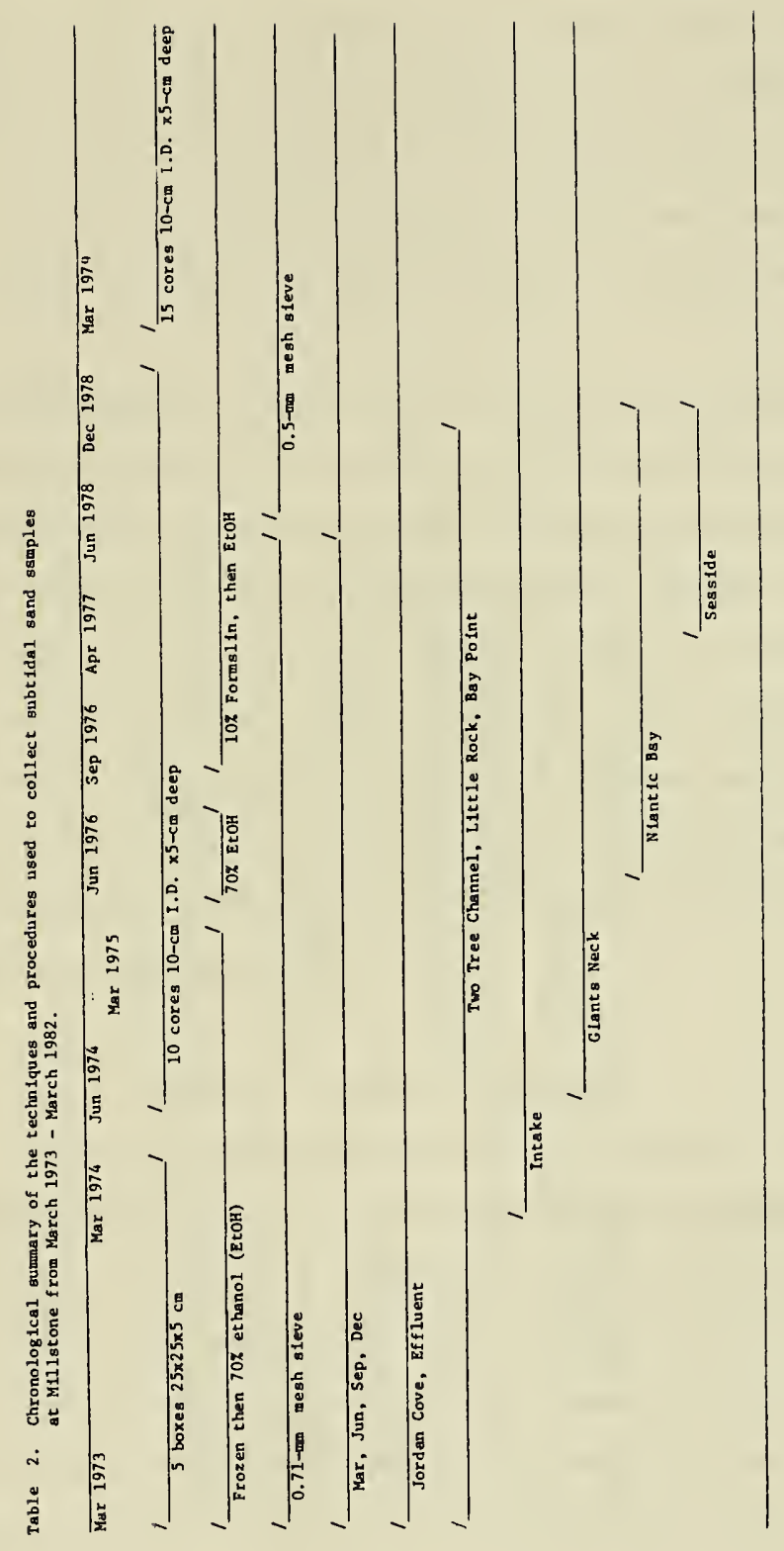


special study (letter to Paul Jacobson from John Dickinson dated September 12,1977 ) estimated loss of up to $75 \%$ of the organisms when samples were frozen (Table 3). This loss precludes quantitative analysis of data collected prior to June 1976.

Infaunal data obtained from June and September 1976 (samples not frozen) were evaluated by Battelle to determine the adequacy of ten replicate cores (sieve mesh $0.7 \mathrm{~mm}$ ) for sampling infaunal communities (Battelle 1977). Indicies of dispersion, species area curves, cumulative information curves, and frequency distributions were used to evaluate estimates of density, species diversity, and dominance. These analyses illustrated the patchy distribution of infaunal organisms and the influence of this distribution on the various community parameters. The study recommended increasing the number of replicates to help integrate small scale patchiness and thus provide better estimates of density, species diversity and dominance.

Following this initial evaluation, a more intensive study was performed to examine the effect of sampling area size on estimates of descriptive community parameters (Battelle 1978). This study compared species area curves, community composition, and diversity based on samples obtained using hand-held corers of $25 \mathrm{~cm}$ (i.d.) $\times 10 \mathrm{~cm}$ deep and $10 \mathrm{~cm}$ (i.d.) $\times 5 \mathrm{~cm}$ deep. Total surface area for large cores was $0.5 \mathrm{~m}^{2}$ and $0.078 \mathrm{~m}^{2}$ for small cores. A $0.7 \mathrm{~mm}$ mesh sieve was used to process all samples.

Results of this study indicated that species area curves based on large cores reached an asymptote at 7 replicates. Curves based on small cores failed to reach an asymptote after 10 replicates; the pooled small cores included $66 \%$ of the taxa collected by the large cores. Comparisons 
Table 3. Comparison of replicate samples preserved in formalin or frozen. (excerpt from letter to Paul Jacobson from John Dickinson dated September 1977).

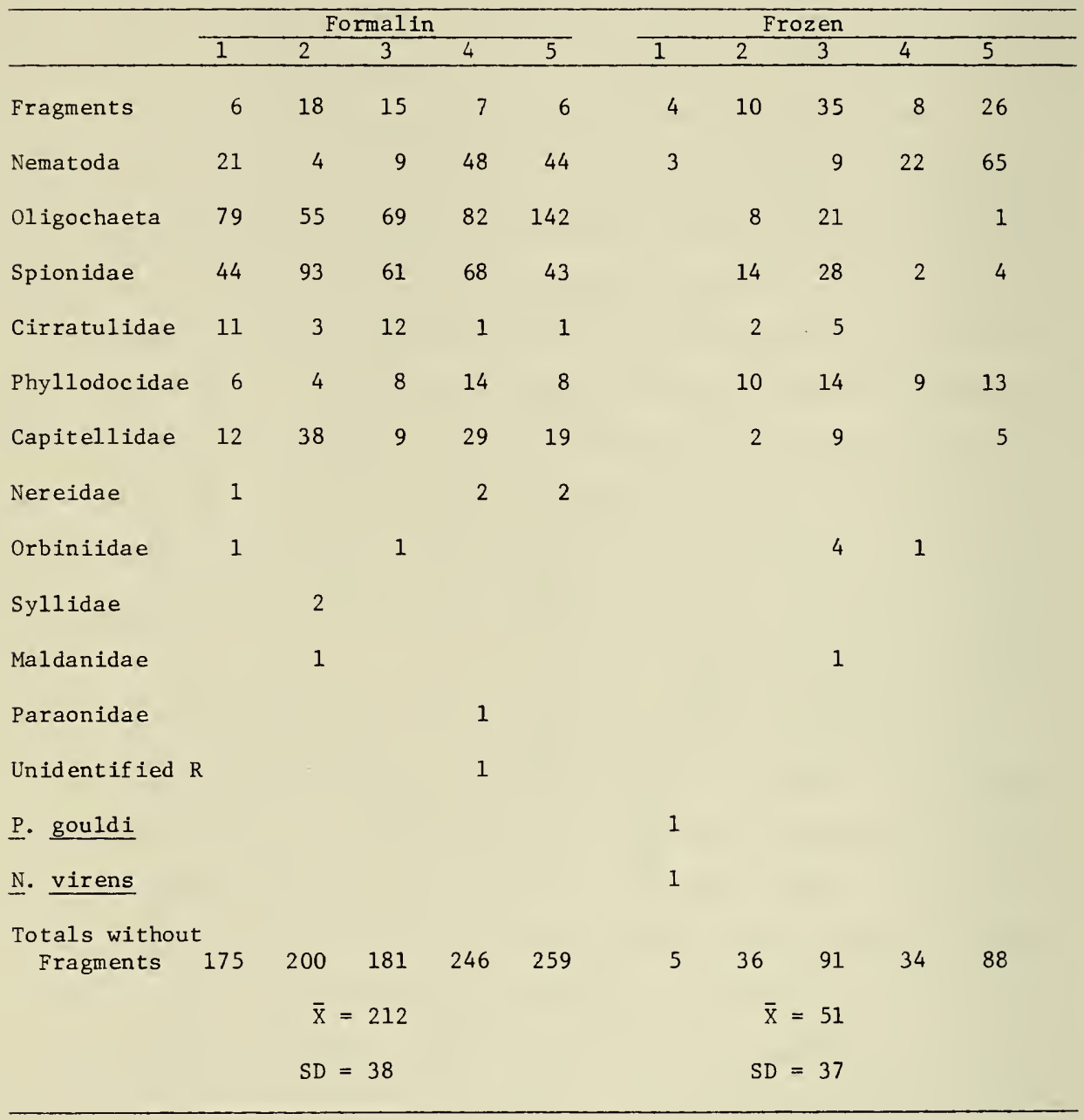


of community composition based on a sample area of $0.5 \mathrm{~m}^{2} \mathrm{vs} 0.078 \mathrm{~m}^{2}$ yielded significant differences in estimated density for only 3 species. Overall, the percent contribution of each species was similar between the two sampling methods. A total of 36 taxa were found in the large core samples and not in the small corer; however, over half of these were represented by only 1 individual.

Based primarily on species area curves presented in the 1978 study, it was recommended that our program should increase the total surface area sampled from $0.078 \mathrm{~m}^{2}$ to at least $0.1 \mathrm{~m}^{2}$. A reduction in sieve mesh size $(0.7 \mathrm{~mm}$ to $0.5 \mathrm{~mm})$ was also suggested but not evaluated. Program changes submitted and approved as Technical Specifications in April 1981 included increased surface area and decreased sieve mesh size. In addition, five subtidal and one intertidal sampling station were deleted from the program; this permitting collection and analysis of 15 replicates without increasing manpower requirements.

Since March 1979,15 replicates $\left(0.117 \mathrm{~m}^{2}\right.$ surface area) have been collected quarterly at the Millstone benthic sites and processed using a $0.5 \mathrm{~mm}$ mesh sieve. An evaluation of increased surface area sampled and reduced sieve mesh was performed in 1981 since the sample comparison in 1978 did not compare the same sample volume $(25 \mathrm{~cm}$ (i.d.) $\mathrm{x} 10 \mathrm{~cm}$ deep for large cores vs $10 \mathrm{~cm}$ (i.d.) x $5 \mathrm{~cm}$ deep small cores). In addition, the previous study used a $0.7 \mathrm{~mm}$ sleve rather than a $0.5 \mathrm{~mm}$ sieve.

Species area curves were generated for each month and station sampled and the results are summarized as the percent of species found in 10 of 15 replicates (Table 4). At all sites, over $90 \%$ of the total species collected by 15 replicates were also collected by only 10 replicates. On a seasonal basis, percentages obtained in June and December were more consistent between years than those of March and September. 
The mean number of individuals per core and $95 \%$ confidence intervals were plotted for each station and collection using 10 and 15 replicates (Figs 1 and 2). Of the 54 densities plotted, only the March 1979 Intake estimates (10 vs 15 replicates) were significantly different $(p<0.05)$ based on the overlap of the $95 \%$ confidence intervals. Although variances associated with mean densities generally decreased by collecting 15 vs 10 replicates, the magnitude of the variance was still closely associated to the size of the mean. Additionally, variance remained higher than the mean in all cases, whether 10 or 15 samples were collected.

Mean infaunal densities $/ \mathrm{m}^{2}$ and percent composition at each station and for each species were calculated from September 1979 to June 1980 and results for the 10 dominant taxa are presented in Tables 5 and 6 . The use of 15 replicates did not add nor delete any species from the 10 dominants based on 10 replicates. Species rankings at each site were nearly identical for both replicate groups. Differences in a species ranking usually occurred between adjacent species, i.e., rank of Polycirrus eximius was 2 nd with 15 replicates and 3 rd with 10 replicates. The rank of Caulleriella spp. collected at the Giants Neck subtidal site changed more than any other taxon; this change involved a decrease in rank from 8 (15 replicates) to 10 (10 replicates).

Results of this 2 year study have shown that increased sample area size (from $0.078 / \mathrm{m}^{2}$ per quarter to $0.117 \mathrm{~m}^{2}$ per quarter) has not significantly changed estimates of infaunal density nor substantially altered observed patterns of community composition. Collection of additional replicates did not reduce the variance associated with species counts and thus has not increased the statistical power of our infaunal monitoring program. 


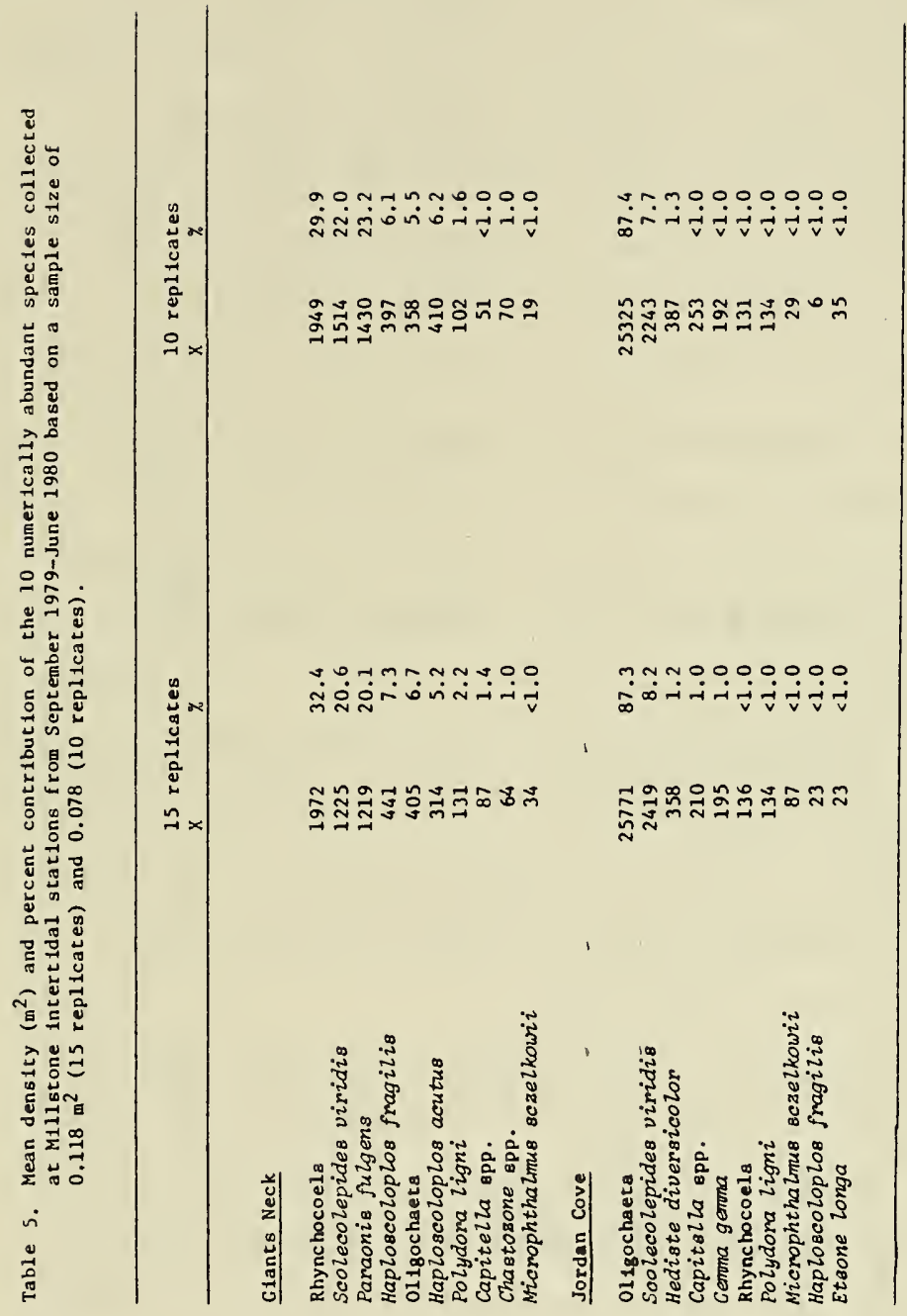


Table 6. Mean density $\left(w^{2}\right)$ and percent contribution of the 10 numerically obundant speciea collected t Mllstone abtidal stations from September 1979-June 1980 based on sample alze of $0.118 \mathrm{~m}^{2}$ (15 replicatea) and 0.078 ( 10 replicatea).

\begin{tabular}{ll}
\hline 25 repl1cates & 10 replicates \\
\hline
\end{tabular}

\section{Effluent}

Chatozone spp.

Polycirrus eximius

011 gochaeta

Aricidea catherinas

caulleriella spp.

Microphthalmus aberrane

Tellina agilis

Capitella spp.

Protodorviliea gaspeensis

Rhynchocoela

G1ants Neck

011 gochaeta

Aricidea catherinae

Chaetozone spp.

Tharyx spp.

Mediomastus ambiseta

Polycirrus eximius

phorocephalus holbolli

Caulleriella spp.

protodorvillea gaspeensis

nombrinerio impatiens

Intake

Ol1gochaeta

Capitella spp.

Chatozone spp.

Aricidea catherinae

Sabellaria vulgaris

Tellina agilis

Mediomastus combiseta

Exogone hebes

Spiophanes bombyx

Amplisea verrili

Jordan Cove

01180 chaeta

Mediomastue onbiesta

Aricidea catherinas

Polyeirrus eximius

Lumbrineris impatiens

[umbrineris tenuis

Cheetozone spp.

Capitella epp.

Parapionosyllis longicirrata Tharyx BPP.

$\begin{array}{rrrr}7819 & 27.7 & 8070 & 32.1 \\ 4861 & 17.2 & 3123 & 12.4 \\ 4800 & 17.0 & 4704 & 18.7 \\ 3316 & 11.8 & 2746 & 10.9 \\ 1925 & 6.8 & 1693 & 6.7 \\ 407 & 1.4 & 310 & 1.2 \\ 405 & 1.4 & 397 & 1.6 \\ 400 & 1.4 & 365 & 1.4 \\ 394 & 1.4 & 310 & 1.2 \\ 307 & 0.9 & 237 & 0.9\end{array}$

9033

24.5

8506

7037

11.5

4238

3284

3205

1760

1117

772

640

351

8.9

8.7

4.7

3.0

2.1

1.7

1. 5

4448

3411

2602

1661

1190

234

717

573

23.9

19.8

12.5

9.6

7.3

4.7

3.3

0.7

2.0

1.6

899

15.9

1011

794

16.8

466

13. 3

8. 3

8.1

$360 \quad 6.4$

554

397

368

352

5.5

329

314

259

138

13.2

9.2

6.6

6.1

5.8

5.5

5.2

4.3

4. 3

2.3

242
165

2.9

25224

9298

51.0

24995

8157

3680

1526

1804

939

890

816

719

613

449
19.0

3.7

1.9

1.8

1.6

1.5

1.2

0.9
52.8

17.2

7.8

3.2

1.7

1.5

1.7

1.4

1.4

1.1 


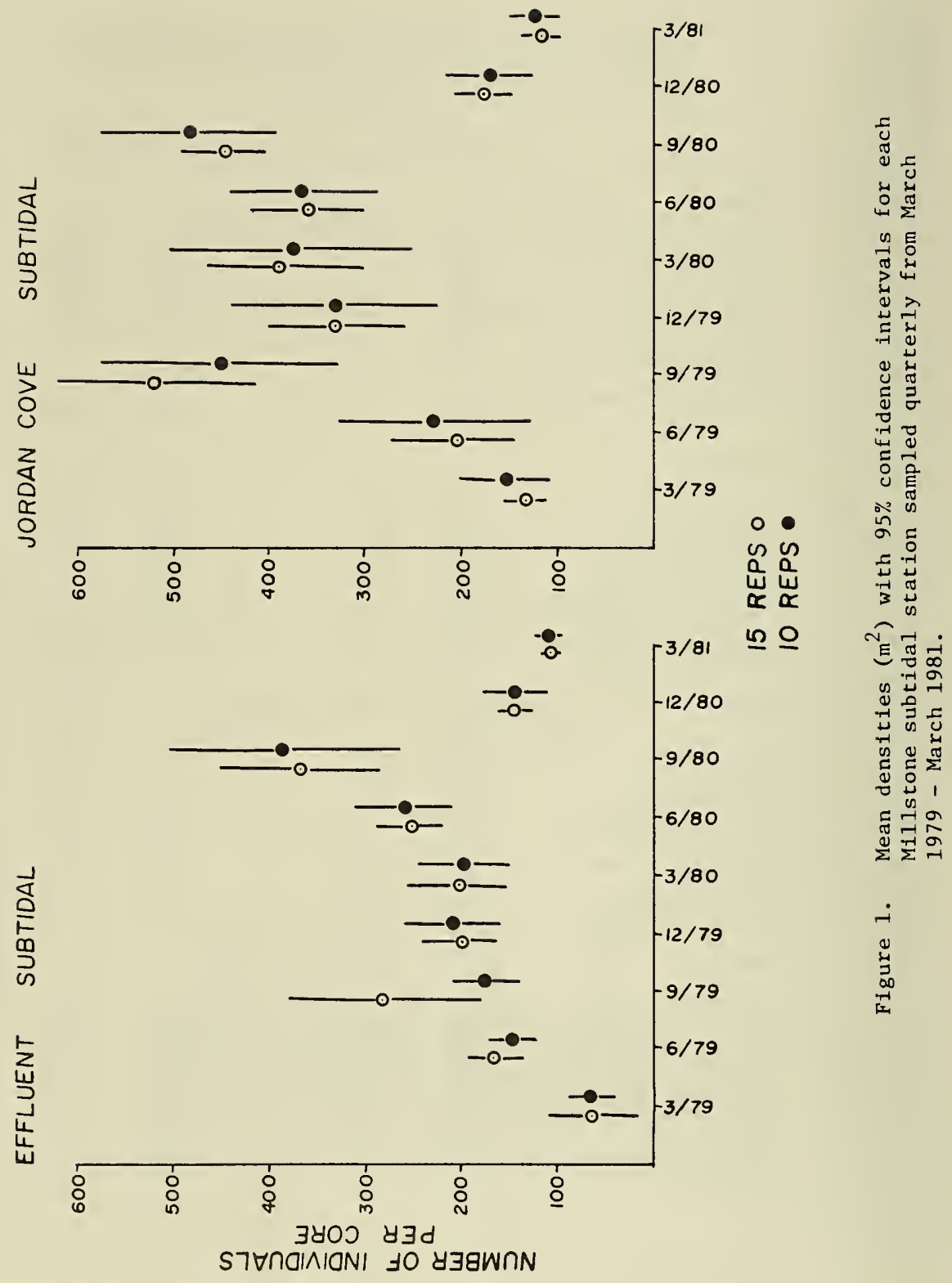




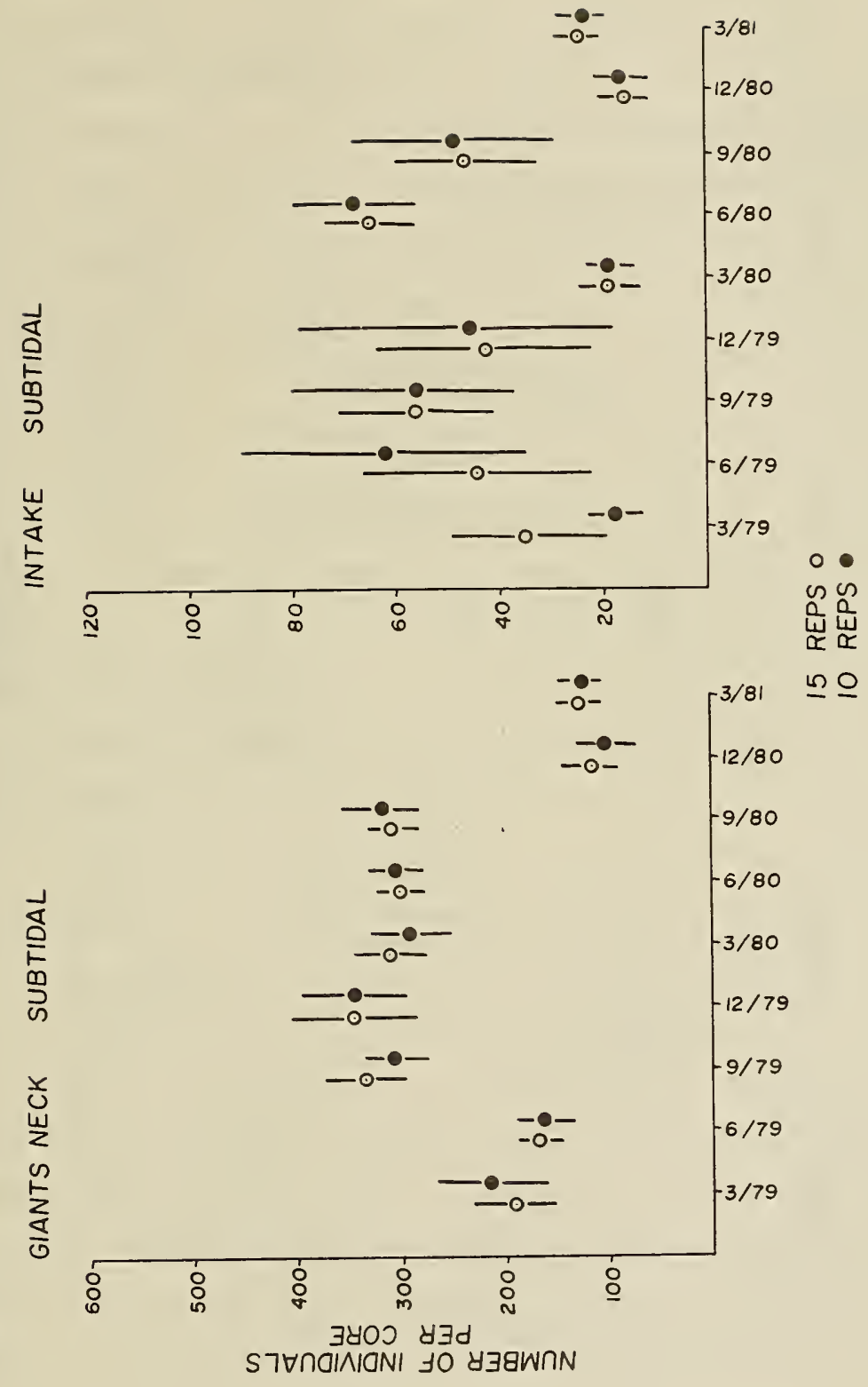




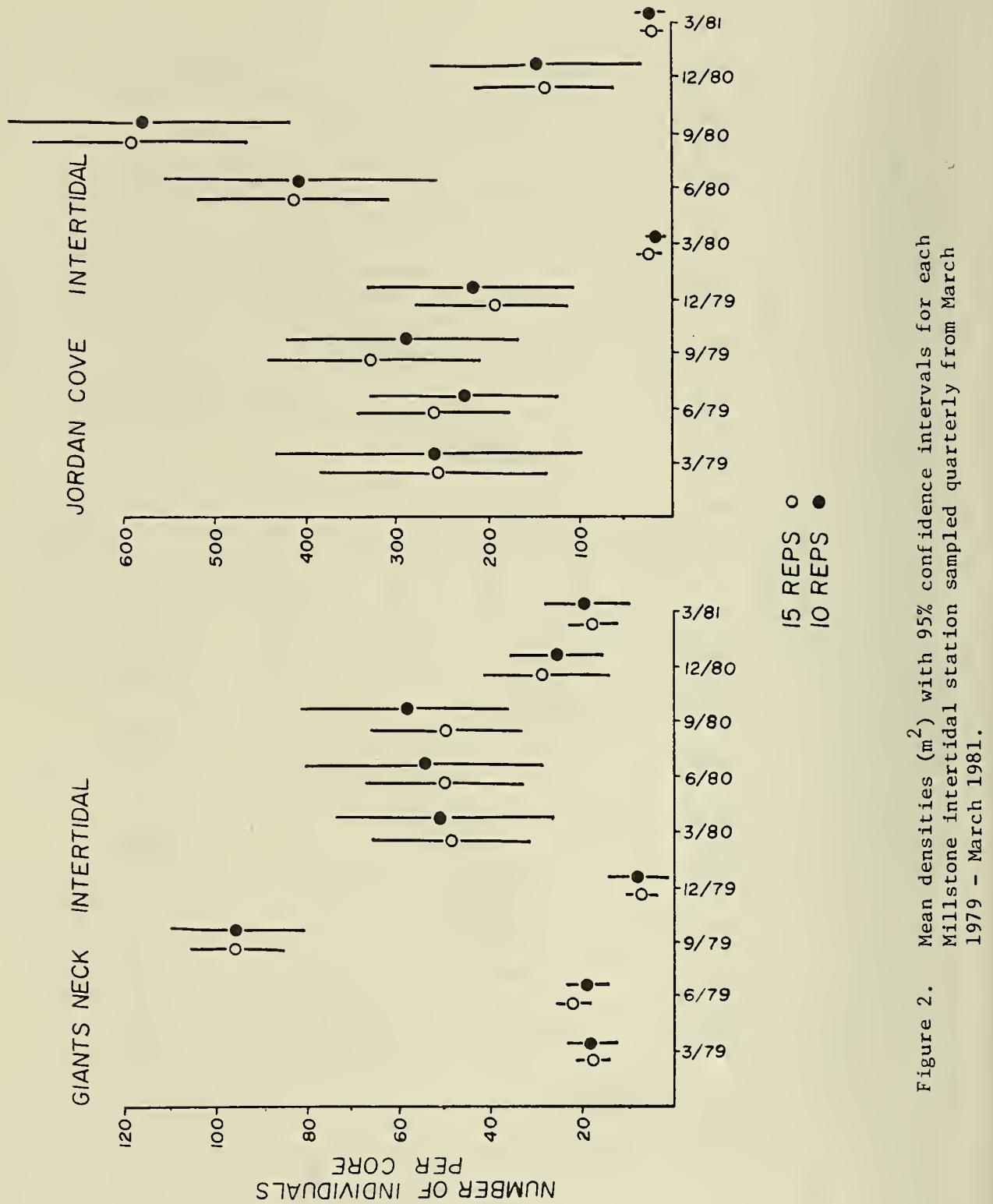


Our conclusion, therefore, is that collection of the additional five replicates has not significantly enhanced our ability to detect power plant impacts. The conclusion reached in this study is contrary to that of the 1978 study for two reasons. The use of a smaller mesh $(0.5 \mathrm{~mm})$ has attenuated some of the influence of sample area size exerted on community parameters reported in 1978 when a larger mesh sieve (0.7 mm) was used for sample processing. Secondly, the 1978 study did not compare 10 vs 15 replicates directly, rather conclusions were based on data resulting from collection of $0.078 \mathrm{~m}^{2}$ vs $0.5 \mathrm{~m}^{2}$. Since samples of $0.5 \mathrm{~m}^{2}$ were economically impossible to analyze over a long term, a sample size of at least $0.1 \mathrm{~m}^{2}$ was proposed; however, no evidence was available to conclude that increasing sample size from $0.078 \mathrm{~m}^{2}$ ( 10 replicates) to $0.117 \mathrm{~m}^{2}$ (15 replicates) would enhance data quality. It has become apparent after two years that the increased sample size does not significantly improve the data, and a request to reduce the number of replicates back to 10 was prepared and submitted to the Nuclear Regulatory Commission (NRC).

\section{PRESENT PROGRAM}

Since March 1979, the infaunal program has consisted of quarterly collection of 15 replicates at 4 subtidal and 2 intertidal sites with all samples processed using a $0.5 \mathrm{~mm}$ mesh sieve. The 3 years of data collected since March 1979 represents the longest period of consistent collection techniques (coupled with adequate analysis procedures) since the infauna1 program was begun in 1968. Since these data are directly comparable, analyses can be performed to establish patterns of density and community composition as well as determine the extent of year to year change. This type of information provides a strong basis for determining both short and long term power plant impacts. 
In 1982, numerical classification techniques could be applied to a long term ( 3 yrs) data base for the first time (NUSCo 1982). Classification of intertidal and subtidal communities (stations) fllustrated high within-site community similarity (Figs. 3 and 4); the relationship among and between-sites provides strong comparative data against which future changes in overall community structure will be evaluated. Additionally, classification of species that numerically dominated over three years has revealed recurrent groups of species characteristic of the infaunal communities around Millstone Point (e.g. taxa in Group I in Figs. 5 and 6). Further long term information on specific populations will enhance our ability to detect more subtle impacts which might otherwise be impossible to detect at the community level.

Other quantitative measures used to describe infaunal communities have also become more appropriate, given the longer data base now available. Over three years, seasonal patterns in community density (Fig. 7) and numbers of species (Fig. 8) that were previously masked by within-year variability, have become recognizable.

The benthic program is now providing long term data that is directly comparable to previous years. The overall result is that we are now able to characterize these communities in terms of the "consistency" and relative "stability" over years rather than in terms of the "variability" observed within any single year.

Since much of the data collected prior to 1979 and nearly all collected prior to 1976 (when samples were frozen) do not provide long term continuity, we believe that our current program should be continued through the Unit 3 operational phase. This study will provide the long term data base needed to quantitatively assess any changes in infaunal density or composition caused by the addition of Unit 3 . 


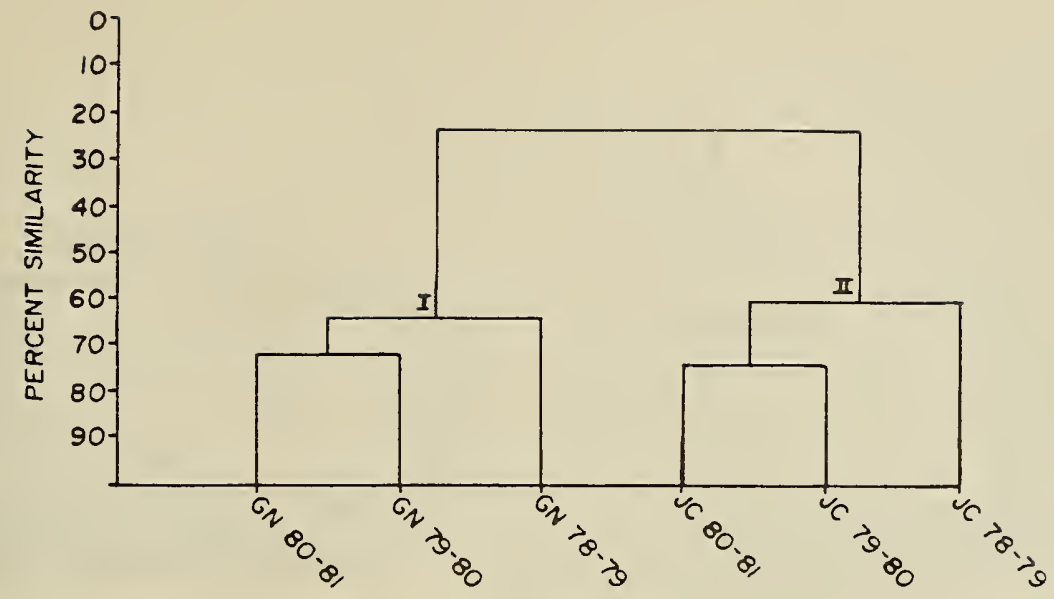

Fig. 3. Dendrogram resulting from classification of annual collections at the Millstone intertidal stations, September 1978-June 1981.

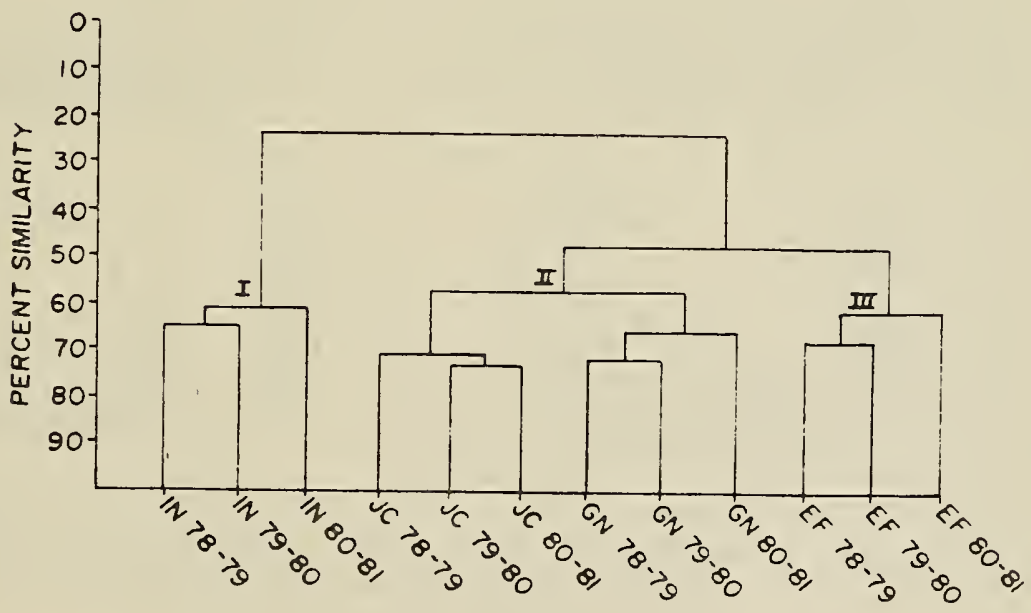

Fig. 4. Dendrogram resulting from classification of annual collections at the Millstone subtidal stations, Septerber 1978-June 1981. 

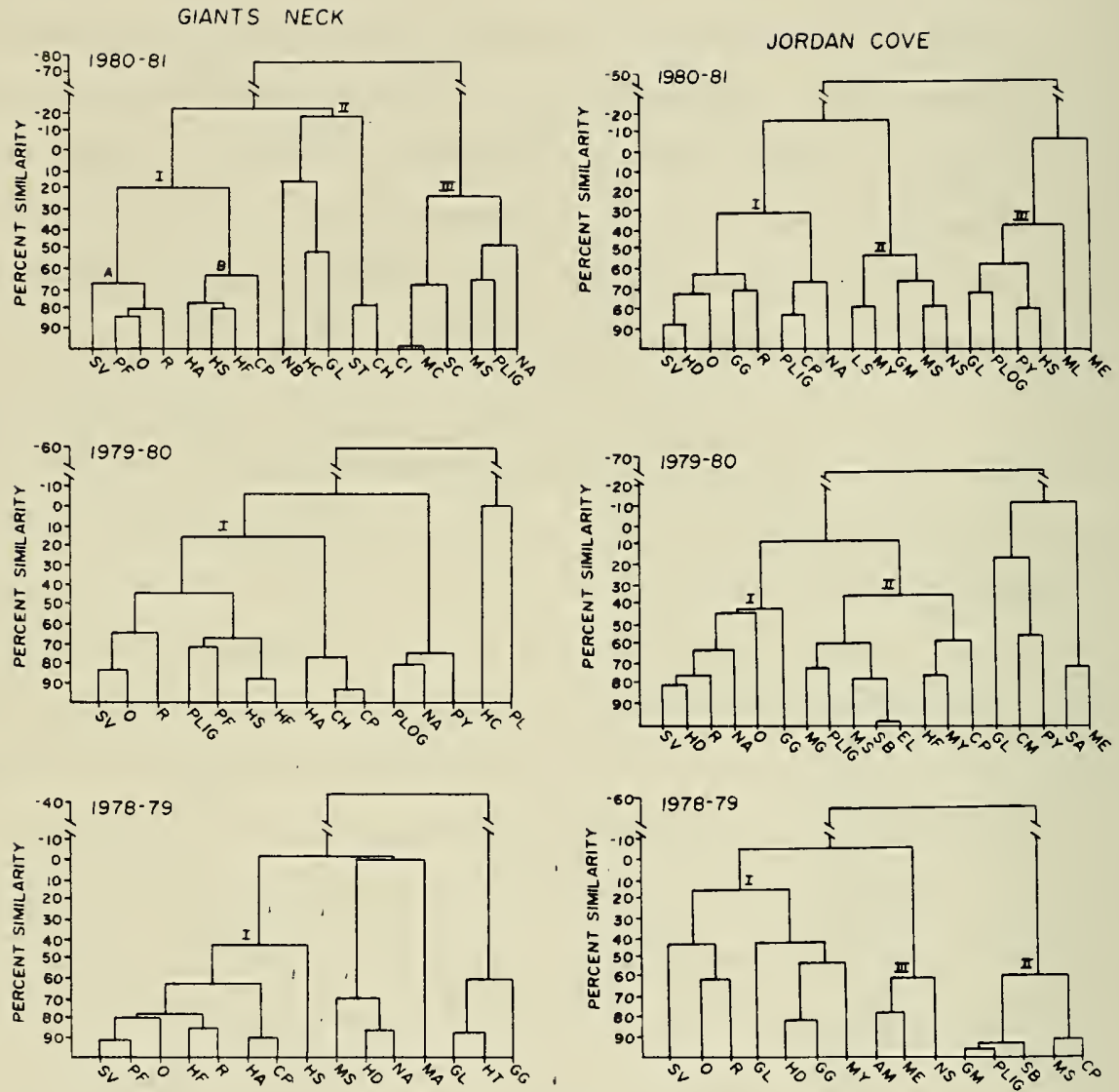

Fig. 5. Dendrograms resulting from classification of dominant taxa collected at each Millstone intertidal station for each sampling year from September 1978-June 1981. 

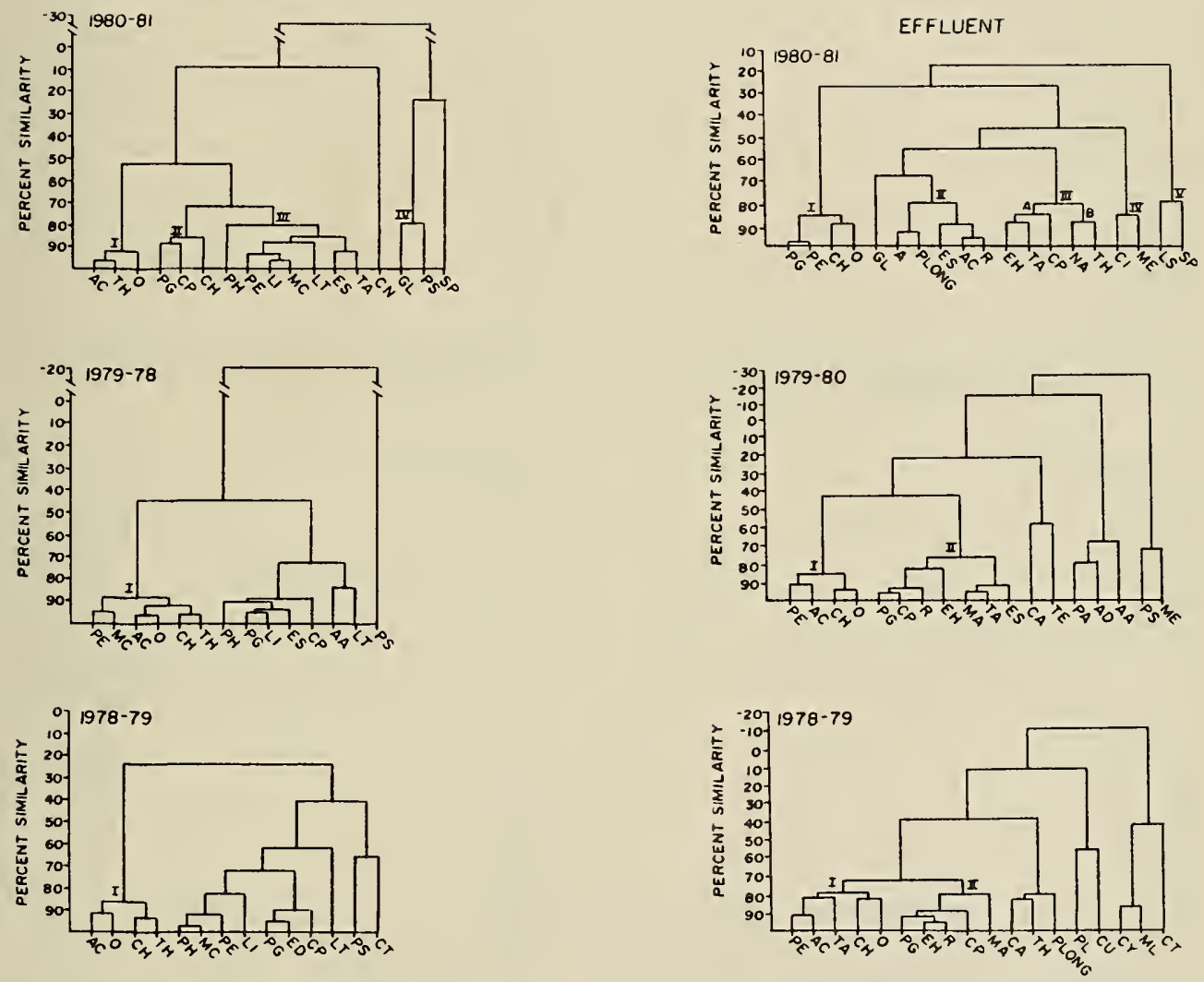

Fig. 6. Dendrograms resulting from classification of dominant taxa collected at each Millstone subtidal station for each sampling year from September
1978-June 1981. 
FIGURE 6 CONTINUED

INTAKE
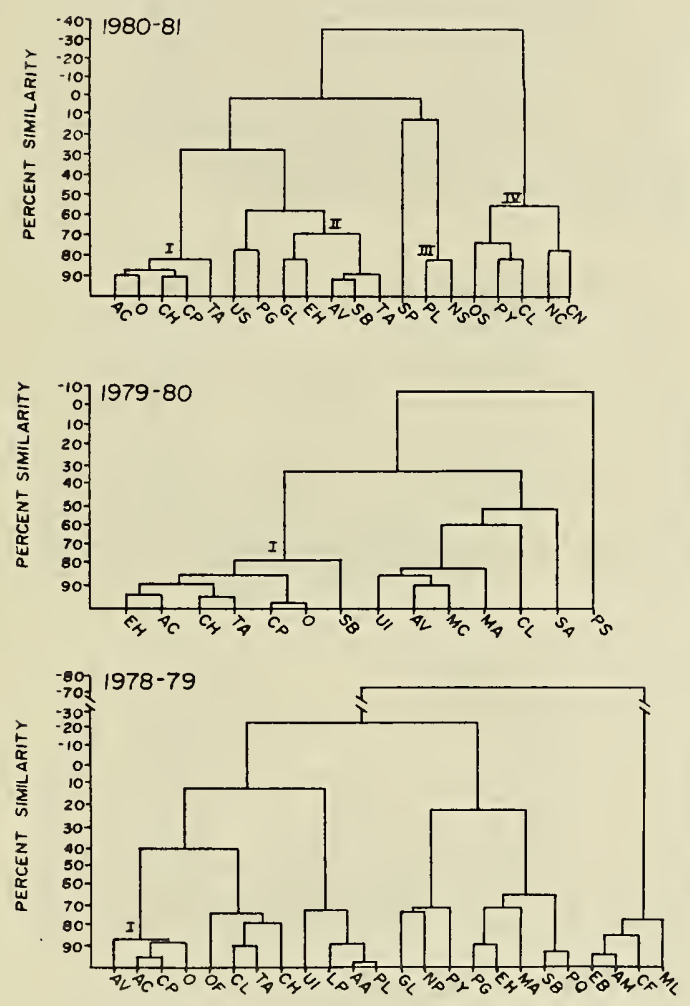
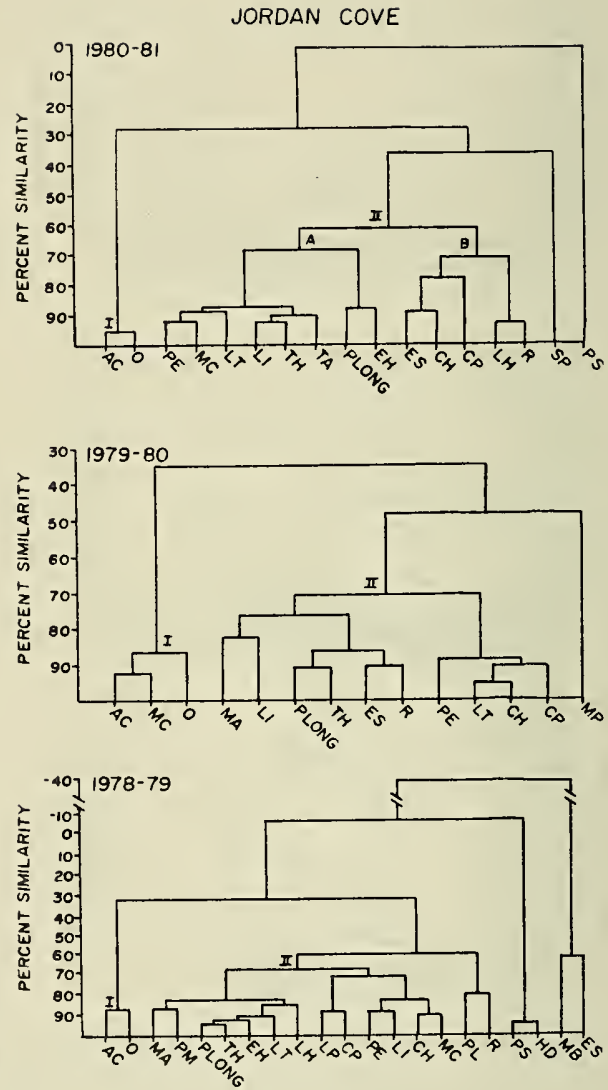

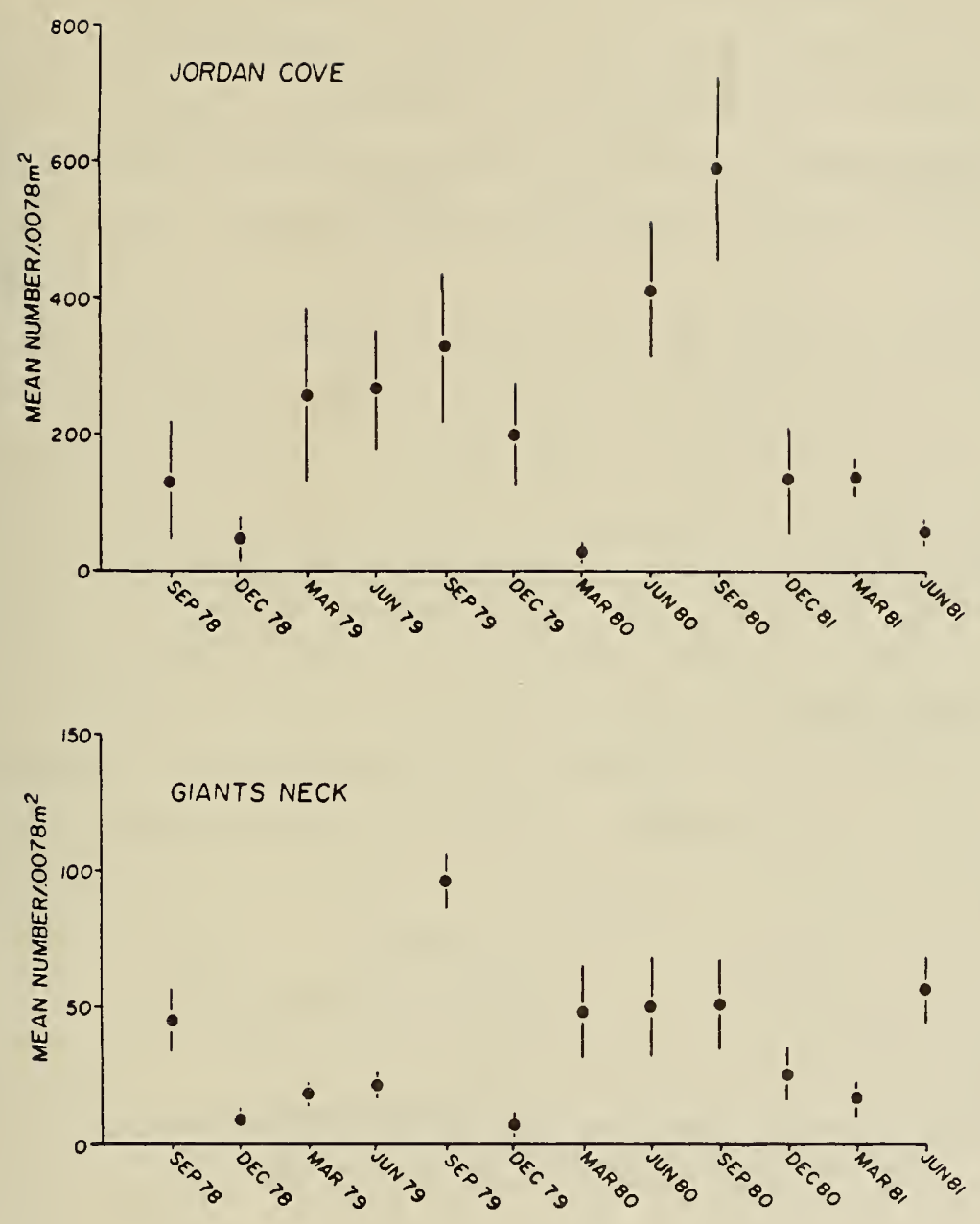

Fig. 7. Mean ( $\pm 95 \%$ confidence interval) number of individuals per core at the Millstone intertidal stations, September 1978-June 1981. 

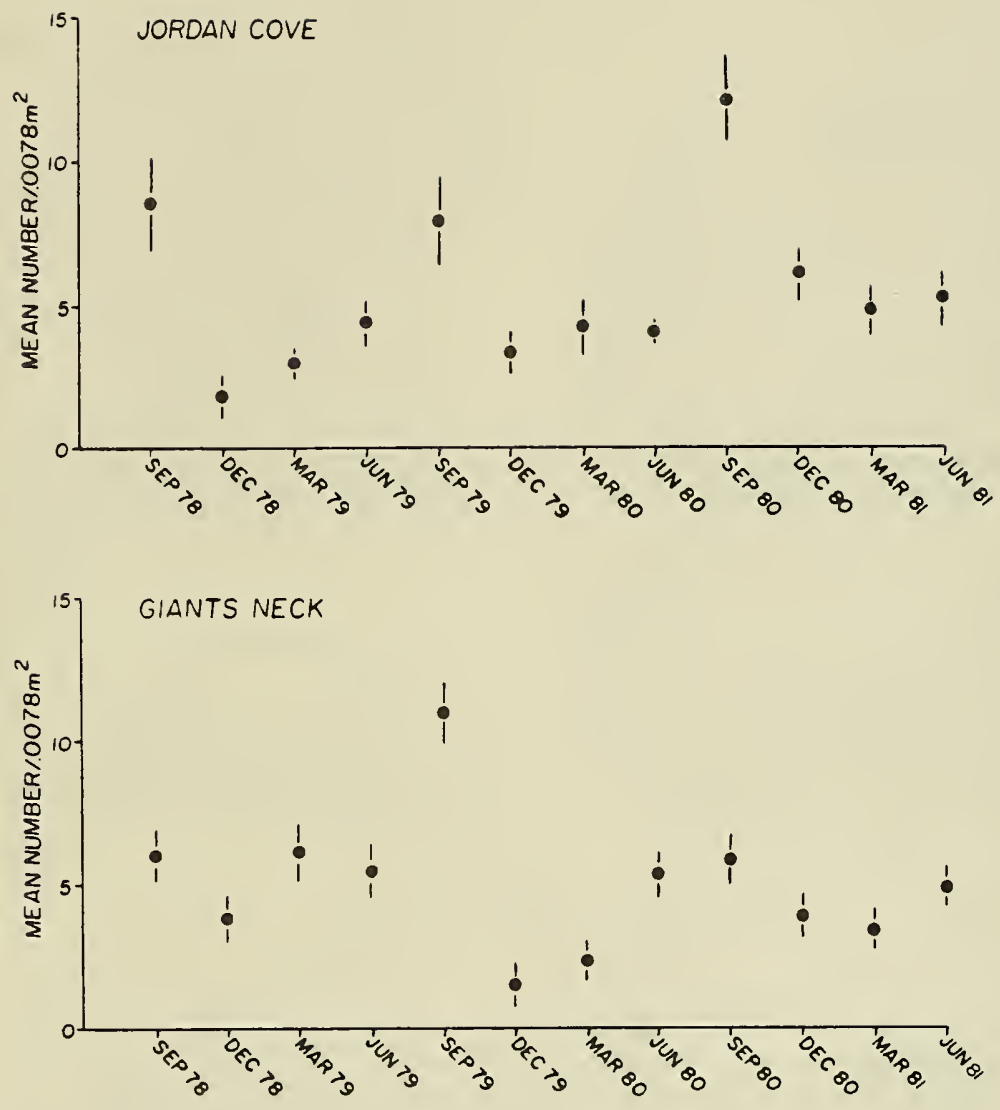

Fig. 8. Mean ( $\pm 95 \%$ confidence interval) number of species per core at the Millstone intertidal stations, September 1978-June 1981. 
PROGRAM CHANGES

No major modifications to the long-term monitoring program are presently being considered. However, prior to Unit 3 operation a new Effluent site will be established since discharge currents created during 3 unit operation will probably preclude sampling of our present Effluent site. Sampling of this additional site was begun in March 1982.

In addition, we believe that the White Point intertidal site should be reestablished as a long term monitoring site, given the most recent predictions of the 3 unit thermal plume. This site was deleted from the Technical Specifications in December 1978; however, it has been continually sampled at reduced effort (10 replicates). The infaunal community inhabiting the White Point beach is similar in composition and density to our reference community at Giants Neck, thus monitoring the White Point site will provide an excellent comparison between potentially impacted (White Point) and non impacted sand communities.

\section{FUTURE STUDIES}

If the proposed reduction in sampling effort (15 to 10 replicates) is approved by the NRC, manpower must be available to perform additional work designed to yield information that complements the long term impact analysis program. Additional studies would be of short duration and of limited scope such that they may be completed in one year or less. Major emphasis of this work will be within the Jordan Cove - White Point area, since this shallow area would most likely show thermal effects (if any) caused by 3 unit operation. Studies being considered include an eelgrass (Zostera) mapping study and a comparative infaunal study of 
sandflats and eelgrass beds located on the east and west sides of Jordan Cove. A food habits study of winter flounder is also being considered. This species sustains an important recreational and commercial fishery in our area and is considered potentially impacted by plant operations. These programs will obtain information concerning communities not sampled by our present long term program.

In addition, studies are being considered for the Intake, Effluent, and the discharge quarry. Objectives of these studies will be to evaluate plant impacts in areas receiving the most direct environmental perturbations (Thermal, Scouring, Chemical) caused by plant operation. Sampling along transects running seaward from the Effluent and Intake will allow demarcation of any areas impacted by 2 unit operation and thus provide the basis for evaluation of 3 unit impacts. Preliminary temperature data and infaunal samples along Effluent transects were collected in August 1981. Sampling in the discharge quarry was performed in August 1981 and again in June 1982. Preliminary analysis of August 1981 samples revealed an assemblage typical of stressed environments. Capitella spp. and Polydora ligni were codominants in our samples; both are considered opportunistic and able to flourish in environmentally stressed habitats. Since this community receives the most severe plant impacts (at least in terms of temperature, biocides, heavy metals, and chemicals) it provides an "impacted community" against which we can judge potential impacts or the severity of realized impacts at stations further removed from plant influence. Should June 1982 samples reveal a seasonal shift in community composition we will consider a sampling effort coordinated with the quarterly sampling of long term sites. 


\section{CONCLUSIONS AND RECOMMENDATIONS}

We believe that the infaunal program performed over the last three years has been of sufficient magnitude to assess impacts of Millstone Units $1 \& 2$ and is providing powerful long term baseline data necessary for 3 unit impact assessment. Since modifications in program design have reduced comparability and validity of data collected prior to 1979 , we believe the present long term program should be continued without modification through the operational period of Unit 3 .

Additional work should be concentrated in the shallow-water areas of Jordan Cove, where potential impacts of the 3 unit discharge appear to be greatest. These studies should investigate communities not sampled by our long term program and thus will provide data that complement the present long term impact assessment studies.

The proposed special studies near the Intake, Effluent discharge, and particularly within the Quarry are of particular importance. These "maximally" impacted communities will yield information on a "worst case" basis and thus will provide the critically needed frame of reference for evaluating impacts during 3 unit operation. 



\section{REFERENCES CITED}

Aller, R.C. 1978a. Experimental studies of changes produced by deposit feeders on pore water, sediment, and overlying water chemistry. Am. J. Sci. 278:1185-1234.

- 1978b. The effects of animal - sediment interactions on geochemical processes near the sediment water interface. Pages 157-172 in M.L. Wiley, ed. Estuarine interactions. Academic Press, New York.

Arntz,.W.E. 1980. Predation by demersal $\mathrm{f}$ ish and its impact on the dynamics of macrobenthos. Pages 121-149 in K.R. Tenore and B.C. Coul1, eds. Marine benthic dynamics. University of South Carolina Press, Columbia, South Carolina.

Battelle, 1977. Benthic Program Evaluation. Prepared by John Dickinson and presented at the Millstone Ecological Advisory Committee Meeting, November 7 and 8, 1977 .

- 1978. Investigation on the effects of sample size on estimates of community parameters for subtidal sand fauna. Submitted to Northeast Utilities Service Company. 27pp. William F. Clapp Laboratories.

Boesch, D.F. 1973. Classification and community structure of the Hampton Roads area, Virginia. Mar. Biol. 21:226-244.

Boston Edison Electric Co. 1981. Marine ecology studies, Pilgrin Nuclear Power Staion. January 1980 - December 1980. Prepared by Taxon, Inc.

ConEd (Consolidated Edison Company of New York). 1977. Near-field effects of once through cooling system operation on Hudson River biota. Indian Point Units 2 and 3.

Goldhaber, M.B., R.C. Aller, J.K. Cochran, J.K. Rosefield, C.S. Martens, and R.A. Berner. 1977. Sulfate reduction, diffusion, and bioturbation in Long Island Sound sediments: Report of the FOAM Group. Am. J. Sci. 277:193-237.

LILCo (Long Island Lighting Company). 1980. Preoperational aquatic ecology study, Shoreham Nuclear Power Station, Unit 1. Prepared by GeoMet for LILCO. 1979.

- 1981. Preoperational aquatic ecology study, Shoreham Nuclear Power Station, Unit 1. Prepared by GeoMet for LILCo. 1980.

Loi, T-N. and B.J. Wilson. 1979. Macroinfaunal structure and effects of thermal discharges in mesohaline habitat in Chesapeake Bay, near a nuclear power plant. Mar. Biol. 55:3-16. 
Longhurst, A.R. 1958. The food of the demersal fish of a West African estuary. J. Anim. Ecol. 26:369-387.

Reish, D.J. 1973. The use of benthic animals in monitoring the marine environment. J. Environ. Plann. Pollut. Control 1:32-38.

, D.F. Soule, and J.D. Soule, 1980. The benthic biological conditions of Los Angeles-Long Beach Harbors: Results of 28 years of investigations and monitoring. Helgolander Meeresunters. 34:193-205.

Tenore, K. 1977. Food chain pathways in detrital feeding benthic communities: A review, with new observations on sediment resuspension and detrital recycling. Pages 37-53 in B.C. Coull, ed. Ecology of marine benthos. University of South Carolina Press, Columbia, South Carolina. 


LOBSTER POPULATION DYNAMICS:

A REVIEW AND EVALUATION 



\section{INTRODUCTION}

The lobster is the most valuable commercial species within Long Island Sound (LIS), yielding 500,000 - 900,000 pounds annually with a retail value in excess of 2 million dollars (Smith 1977; Connecticut DEP Marine Fishery Statistics 1975-80, unpublished). Monitoring of such a commercially valuable species at power generating stations is essential; by evaluating annual stock recruitment patterns and long-term cyclic variations in abundance, we can discern power plant induced impacts from naturally occurring fluctuations in the lobster population (Capuzzo and Reynolds 1980).

Power plant induced stresses may affect survival of lobster larvae and juveniles or alter the behavior of adults possibly resulting in a decline in the inshore fishery. Potential effects on the lobster population attributable to the operation of the Millstone Nuclear Power Station (MNPS) are impingement of lobsters on the intake traveling screens, entrainment of larvae through the cooling water systems, and thermal effects by the discharge.

\section{CHRONOLOGY}

The collection of information on the abundance of lobsters in the Millstone area began in February 1969, when a commercial lobsterman turned in his catch information; the number of legal, short, and berried lobsters was recorded (Table 1 ).

During the period 1970-73 lobster pot sampling was conducted in February, May, July, September and December. Six wood pots were set for a week around Fox Island (at the fringe of the plume) and six around Seaside Point (an area far from the plant) as controls; in May 1973 the Bartlett's Reef station was added. These pots were checked daily, 


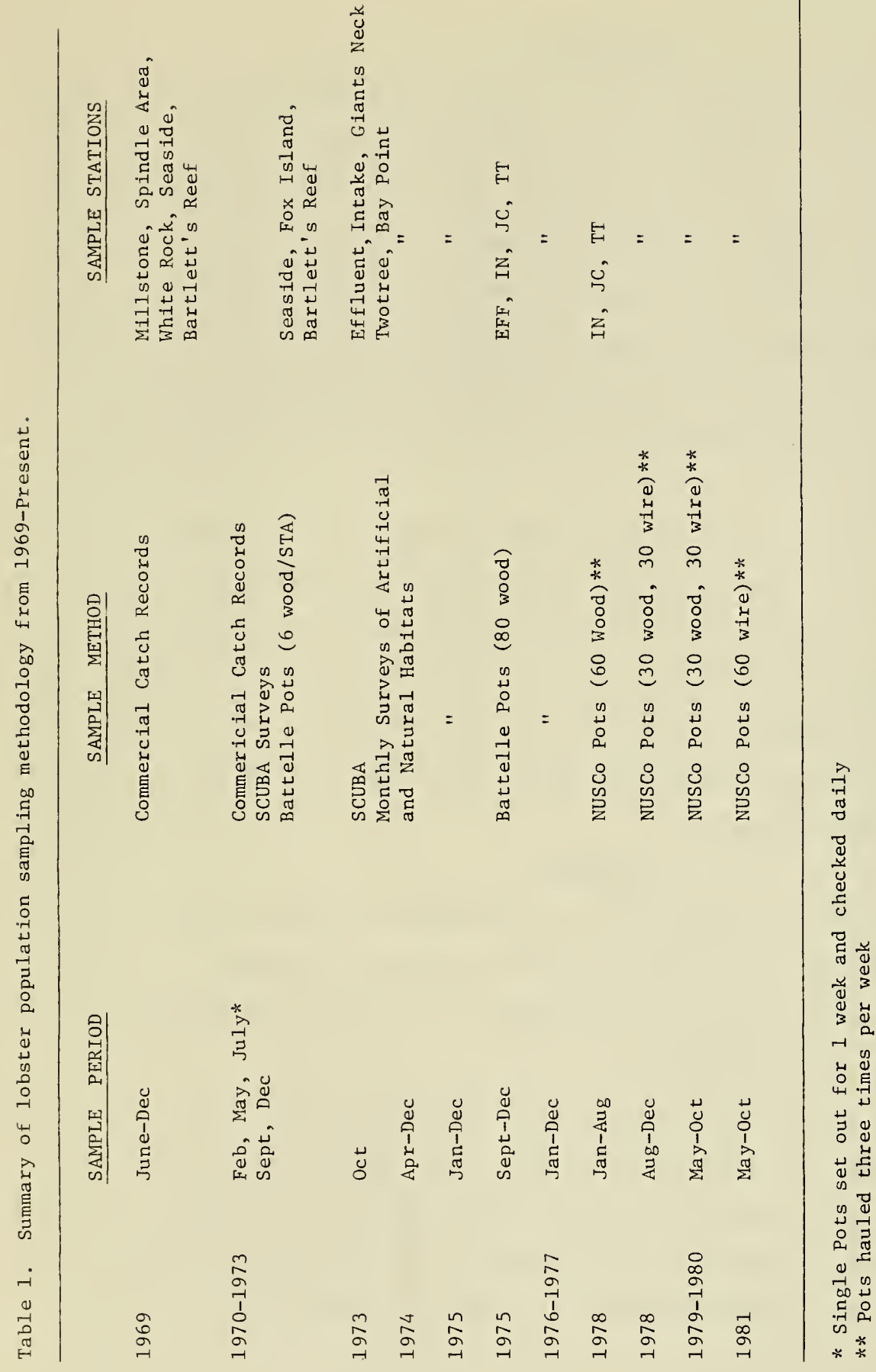


weather permitting, during the week that the Rocky Shore surveys took place. In addition to the lobster pot surveys, several SCUBA dives were made annually to determine the abundance of lobsters in these areas. Artificial habitats, consisting of an array of 36 concrete blocks (16" $\times 24^{\prime \prime} \times 10^{\prime \prime}$, with three burrows each, were installed during the summer of 1973 to provide additional habitat in front of the quarry-cut effluent, in Jordan Cove, near the intake structures, and adjacent to Bartlett's Reef. Natural lobster areas chosen for observation in conjunction with the artificial areas were located south of the discharge, between Twotree and Bartlett's Reef, near Bay Point, and south of Giant's Neck. Each artificial habitat and natural area were checked monthly using SCUBA. Monitoring of these areas continued through December 1975, when artificial habitat monitoring was terminated in lieu of a more intense tagging program using lobster pots.

From September 1975-81, pot trawls were used to collect lobsters. Pot trawls consisted of five double entry pots $(3-5 \mathrm{~cm}$ lath spacings) strung along a 50-75 $\mathrm{m}$ line bouyed at both ends. Four pot trawls were placed at Jordan Cove, Intake, Effluent and Twotree (Fig. 1). Al1 pots were checked and rebaited three times each week. Lobsters $\geq 55 \mathrm{~mm}$ carapace length (CL) were banded to restrain chelipeds, brought to the $1 \mathrm{ab}$, and maintained in flow through seawater tanks. On Fridays, lobsters caught that week were examined and pertinent data recorded; sex, presence of eggs (berried), carapace length (CL), crusher claw position, missing claws and molt stage (Aiken 1973); tagged with a serially numbered international orange sphyrion tag (Scarrett and Elson 1965; Scarrett 1970); returned to the site of capture and released. Recaptured tagged lobsters, severely injured or newly molted lobsters and those < $55 \mathrm{~mm}$ CL 


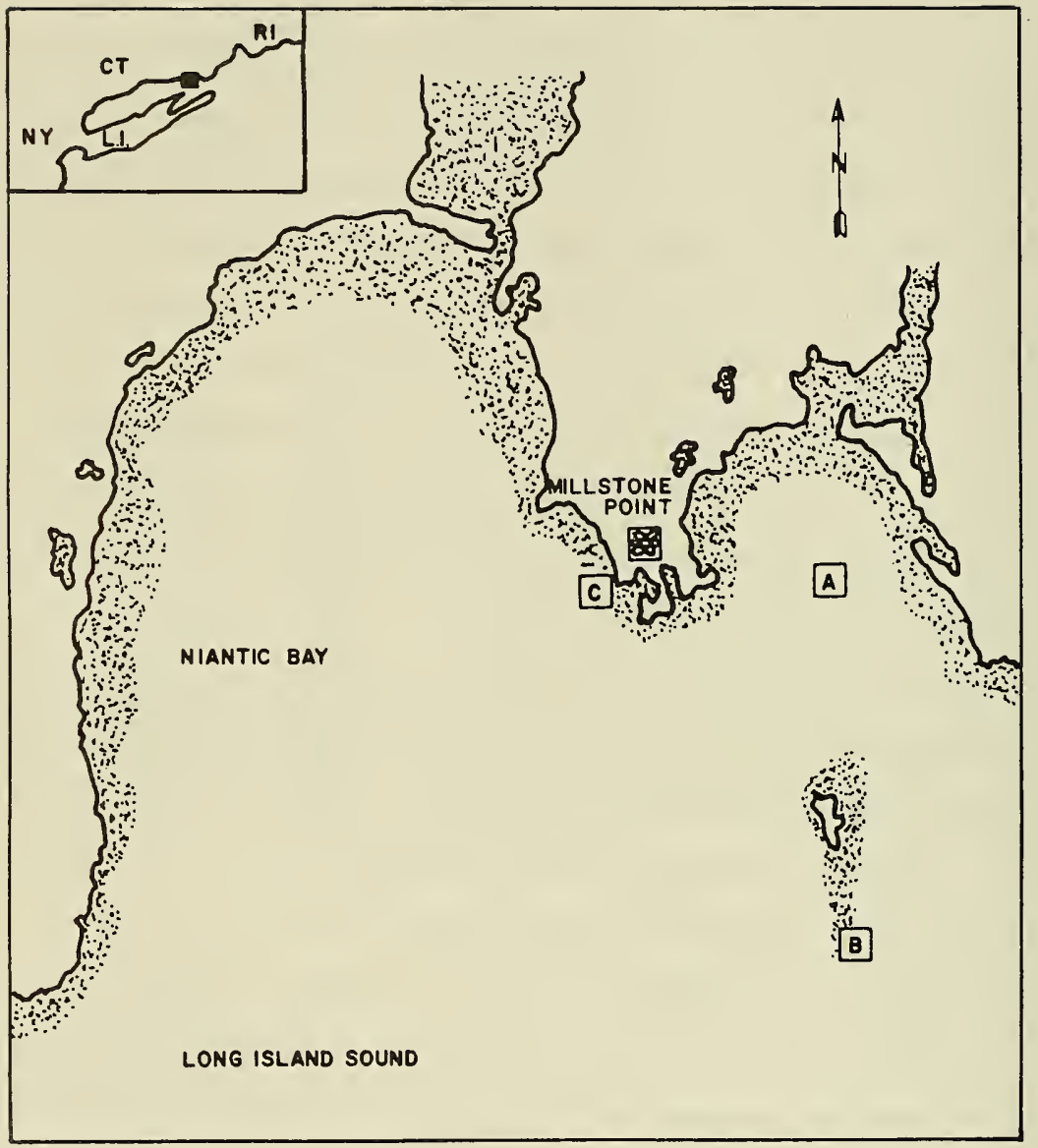

FIGURE 1. Map of Millstone Point area showing the location of the lobster sampling stations (A-Jordan Cove, B-Twotree, C-Intake). 
were immediately returned to the water after recording the data mentioned above.

In 1978 the effluent station was discontinued due to the difficulty in hauling and keeping pots set properly in that area. Strong currents and large boulders greatly increased the number of snagged trawls and lost pots.

To obtain more information on smaller sized lobsters half of the wood pots were replaced with wire mesh pots $\left(2.5 \mathrm{~cm}^{2}\right)$ in August 1978 . The wire pots caught greater numbers of smaller lobsters which were unable to escape through the small mesh. Estimating abundances of these small individuals (particularly those from the 70-76 mm CL) is important since they constitute a large proportion of the prerecruits whose abundance largely determines the size of the legal catch. To further increase catch, starting in 1982, all wood pots were replaced by wire pots.

From 1975-78 sampling was conducted from January to December and from 1979 - present during the months of highest catch, May through November. Starting in 1979, surface and bottom water temperatures and salinities were recorded at each station.

Since 1973 , a $\$ 2.00$ reward has been paid as an incentive for the return of information on tagged lobsters by commercial and recreational lobstermen.

In addition to the population data mentioned above ( $C L$, sex, molt stage etc.), we are collecting data to determine the size (CL) at which female lobsters reach maturity. The maximum outside width of the second abdominal segment of all females was measured to the nearest mm and by dividing the mean abdominal width by the mean CL for each $5 \mathrm{~mm} \mathrm{CL}$ 
interval a female index of maturity was obtained (Briggs and Mushacke 1979; Ennis 1980; NUSCo 1981a).

The size of the local lobster population was estimated using the method of Jolly (1965) as modified by Seber (1965). This multiple census method uses tag and recapture data collected from an open population in which recruitment, immigration, mortality, and permanent emigration are operable.

\section{RESULTS AND DISCUSSION}

\section{Physical Measurements}

Water temperature and salinity were measured from May through October (1979-81). Bottom temperatures ranged from $7^{\circ} \mathrm{C}$ in early May to $22^{\circ} \mathrm{C}$ in summer, and were up to $2.1^{\circ} \mathrm{C}$ lower than corresponding surface temperatures (Table 2). Temperatures (surface and bottom) at Jordan Cove and Intake ( $4-6$ m in depth) were similar to each other, but consistently warmer than at Twotree $(12 \mathrm{~m})$.

Salinity was constant between stations and between surface and bottom; values ranged from 29.1 - 32.0\%.. Due to the spring freshwater runoff, salinities were $1.2 \%$. lower in May and June than in the rest of the sampling period.

Abundance and Catch Per Unit Effort

A total of 27,019 lobsters was collected in the study area from 1975-81 (Table 3). The data collected prior to 1975 is not presented due to inconsistencies in sample design which render it uncomparable to the 1975 - present data base. The increased catches from 1978-81 were the result of the addition of wire pots into the sampling program ( Table 4). 
Table 2. Mean monthly surface $(S)$ and bottom (B) water temperature $\left({ }^{\circ} \mathrm{C}\right.$ ) at each station (1979-81).

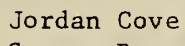

$\mathrm{S}$

B
Intake

$\mathrm{S}$
Twotree

S B

\section{9}

\begin{tabular}{|c|c|c|c|c|c|c|}
\hline May & 10.3 & 9.5 & 10.5 & 9.5 & 9.9 & 9.2 \\
\hline June & 15.0 & 14.2 & 15.2 & 14.4 & 14.5 & 13.9 \\
\hline July & 19.9 & 17.8 & 19.2 & 18.3 & 18.3 & 17.7 \\
\hline Aug & 20.6 & 19.6 & 20.2 & 19.8 & 19.7 & 19.2 \\
\hline Sept & 19.8 & 19.2 & 19.8 & 19.3 & 19.2 & 18.9 \\
\hline Oct & 17.0 & 15.9 & 15.8 & 15.7 & 15.6 & 15.5 \\
\hline \multicolumn{7}{|c|}{1980} \\
\hline May & 10.8 & 9.8 & 10.6 & 9.7 & 9.9 & 9.4 \\
\hline June & 14.8 & 14.1 & 14.7 & 14.3 & 14.4 & 13.9 \\
\hline July & 19.6 & 17.8 & 19.2 & 18.3 & 18.4 & 17.7 \\
\hline Aug & 21.2 & 19.9 & 21.0 & 20.1 & 20.2 & 19.7 \\
\hline Sept & 20.7 & 19.8 & 20.5 & 20.0 & 20.1 & 19.9 \\
\hline Oct & 16.1 & 15.9 & 16.1 & 16.0 & 16.2 & 16.1 \\
\hline \multicolumn{7}{|c|}{1981} \\
\hline May & 9.8 & 9.0 & 9.6 & 9.1 & 9.3 & 8.8 \\
\hline June & 16.0 & 14.1 & 15.3 & 14.6 & 14.6 & 14.0 \\
\hline July & 19.9 & 19.0 & 19.8 & 19.2 & 19.3 & 18.6 \\
\hline Aug & 21.8 & 20.5 & 21.2 & 20.7 & 20.6 & 20.3 \\
\hline Sept & 20.4 & 19.5 & 19.8 & 19.6 & 19.7 & 19.4 \\
\hline Oct & 15.2 & 14.6 & 14.7 & 14.5 & 14.2 & 14.1 \\
\hline
\end{tabular}


TABLE 3. Summary of lobster mark-recapture program from 1975 - 81 .

\begin{tabular}{lccccc}
\hline $\begin{array}{c}\text { Sampling } \\
\text { Months }\end{array}$ & $\begin{array}{c}\text { Period } \\
\text { Year }\end{array}$ & $\begin{array}{l}\text { Number } \\
\text { Caught }\end{array}$ & $\begin{array}{c}\text { Number } \\
\text { Tagged }\end{array}$ & \multicolumn{2}{c}{ Recaptures } \\
Sept-Dec & 1975 & 1501 & 1501 & $97(6.5)$ \\
Jan-Dec & 1976 & 3498 & 2962 & $341 \quad(11.5)$ \\
Jan-Dec & 1977 & 3242 & 2876 & $240(8.3)$ \\
Jan-Dec & $1978^{\text {a }}$ & 4371 & 3199 & $378(11.8)$ \\
May-Oct & 1979 & 5031 & 3732 & $674 \quad(18.1)$ \\
May-0ct & 1980 & 4266 & 3634 & $485 \quad(13.3)$ \\
May-0ct & 1981 & 5110 & 4246 & $571 \quad(13.4)$ \\
\hline
\end{tabular}

a Wire pots added to sampling scheme in August. 
TABLE 4. Monthly catch per unit effort (CPUE per 100 pots hauled) for wood and wire pots from $1978-81$.

\begin{tabular}{|c|c|c|c|c|c|}
\hline & \multicolumn{2}{|c|}{ Total Catch } & & \multicolumn{2}{|c|}{ Legal Catch } \\
\hline & Wood & Wire & & Wood & Wire \\
\hline & & & $\underline{1978}$ & & \\
\hline Aug & 55 & 215 & & 8 & 18 \\
\hline Sept & 96 & 177 & & 14 & 19 \\
\hline Oct & 54 & 132 & & 8 & 15 \\
\hline Nov & 98 & 162 & & 16 & 12 \\
\hline & & & 1979 & & \\
\hline May & 86 & 132 & & 6 & 6 \\
\hline June & 103 & 183 & & 18 & 15 \\
\hline July & 124 & 195 & & 23 & 25 \\
\hline Aug & 95 & 164 & & 15 & 12 \\
\hline Sept & 69 & 151 & & 10 & 9 \\
\hline Oct & 55 & 112 & & 9 & 9 \\
\hline & & & $\underline{1980}$ & & \\
\hline May & 79 & 180 & & 15 & 15 \\
\hline June & 65 & 170 & & 14 & 12 \\
\hline July & 69 & 177 & & 18 & 17 \\
\hline Aug & 56 & 131 & & 13 & 12 \\
\hline Sept & 69 & 84 & & 12 & 8 \\
\hline Oct & 78 & 74 & & 6 & 3 \\
\hline & & & $\underline{1981}$ & & \\
\hline May & 118 & 134 & & 8 & 8 \\
\hline June & 153 & 116 & & 15 & 8 \\
\hline July & 157 & 124 & & 21 & 13 \\
\hline Aug & 122 & 100 & & 13 & 11 \\
\hline Sept & 122 & 73 & & 11 & 10 \\
\hline Oct & 112 & 66 & & 13 & 9 \\
\hline
\end{tabular}


Catch per unit effort for wood pots was similar in magnitude from 1976-81 but peaked at different times within each year (Fig. 2). In general, lobster activity (i.e. feeding, movements, molt frequency) increased at temperatures $>10^{\circ} \mathrm{C}$. Catch began to increase and peaked between $15-20^{\circ} \mathrm{C}$ (Fig. 3). A relationship between catch and water temperature has also been documented by other researchers (McLeese and Wilder 1958; Dow 1966, 1969, 1976; Flowers and Saila 1972).

Results from the $1978-80$ sampling period indicated that wire pots caught significantly more lobsters than wood pots. However, this was not the case in 1981 when the parlor entry funnel for wire pots was closer to the rear of the trap than in previous years. Our data (experiments in progress) confirm the above observations and further demonstrate the degree to which slight changes in parlor head design can affect trap efficiency. Similarly, Spurr (1972) reported that the principal factor affecting pot efficiency was parlor head design; Thomas (1959) found that high-rigged heads deterred escape.

\section{Size Frequencies}

The yearly size distributions of lobsters caught in the Millstone Point area from $1975-81$ are presented in Figures 4 and 5. The relatively larger proportion of smaller sized individuals in 1975 was attributed to sampling methodology. During 1975, lobsters were acquired using SCUBA from artificial habitats, from fish trawls and from impingement studies at Units 1 and 2 intake structures. Pecci et al. (1978) reported that lobsters in surface-hauled pot catches were larger than ones caught by divers. After 1975, lobsters were captured using commercial pots, which do not sample small individuals as effectively. 


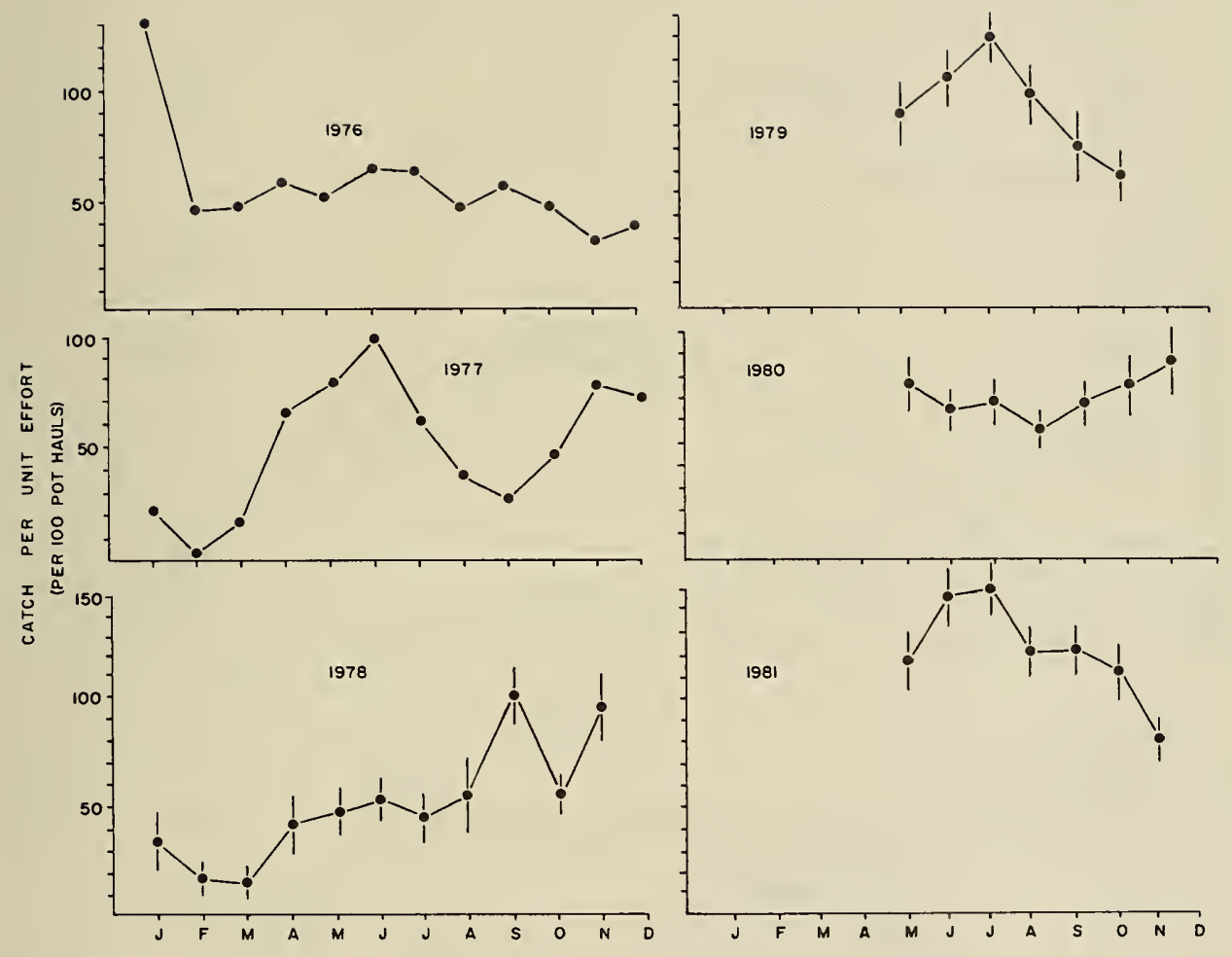

FIGURE 2. Mean Monthly lobster catch per unit effort (per 100 pot hauls) and $95 \%$ confidence interval for wood pots $1976-81$. 


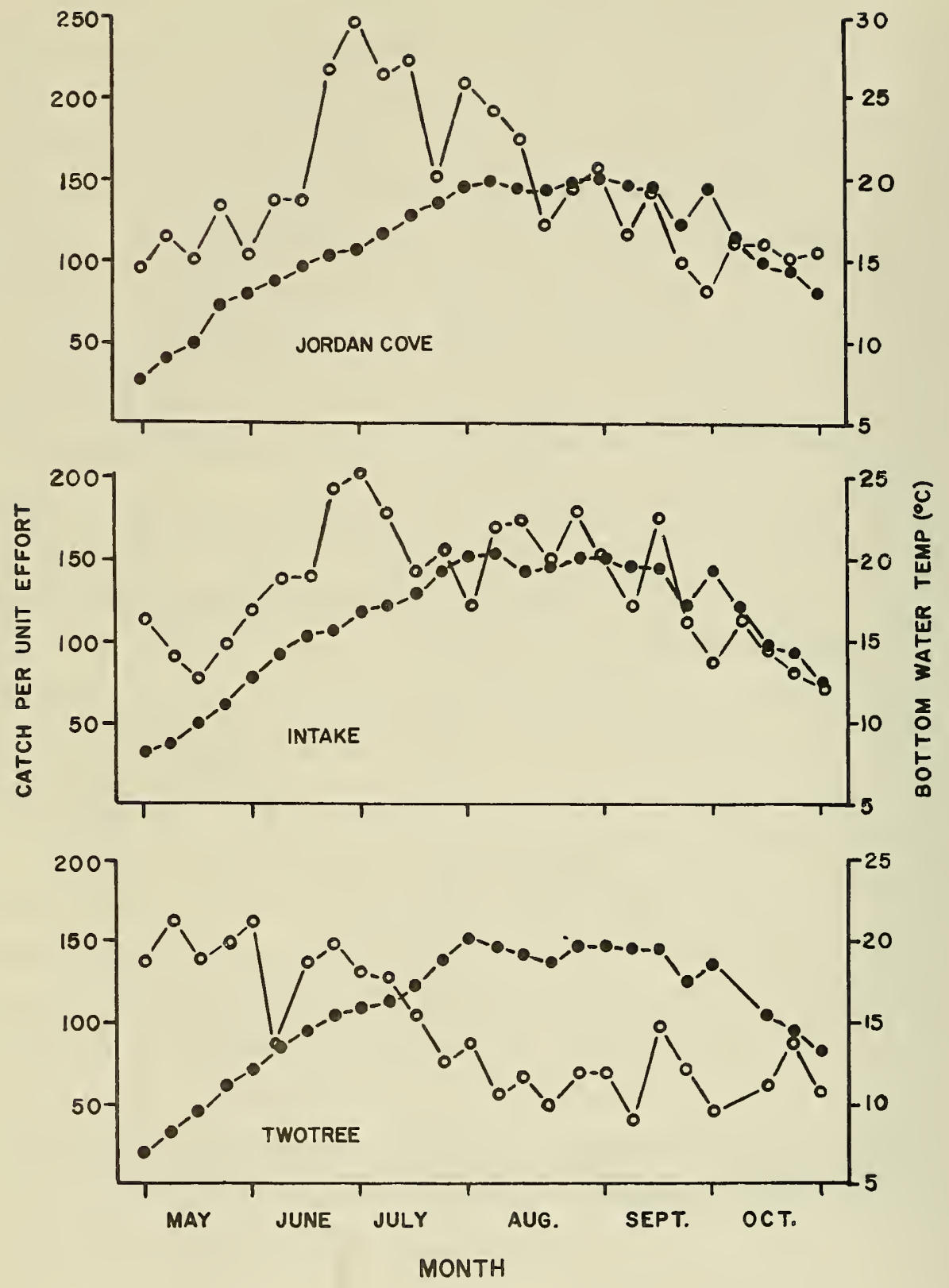

FIGURE 3. Catch per unit effort (o-o) (per 100 pot hauls) and bottom water

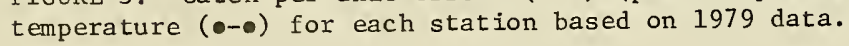



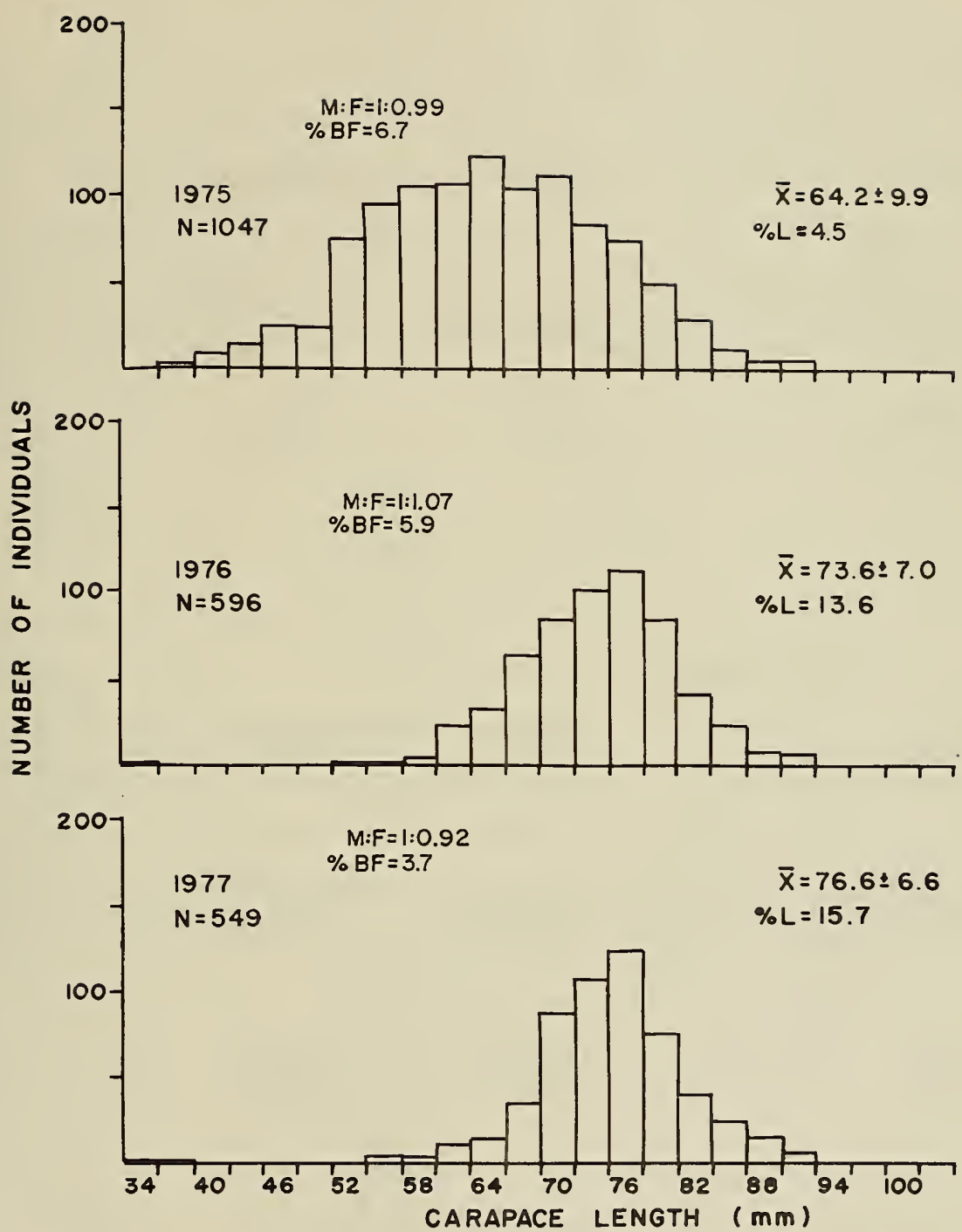

FIGURE 4. - Annual size distribution of lobsters in the Millstone Point area, 1975-1977 (wood pots). Values for male:female sex ratios (M:F), percent of berried females (\% BF), mean carapace length $(\bar{X})$, and percent legal catch (\% L) are also presented. 


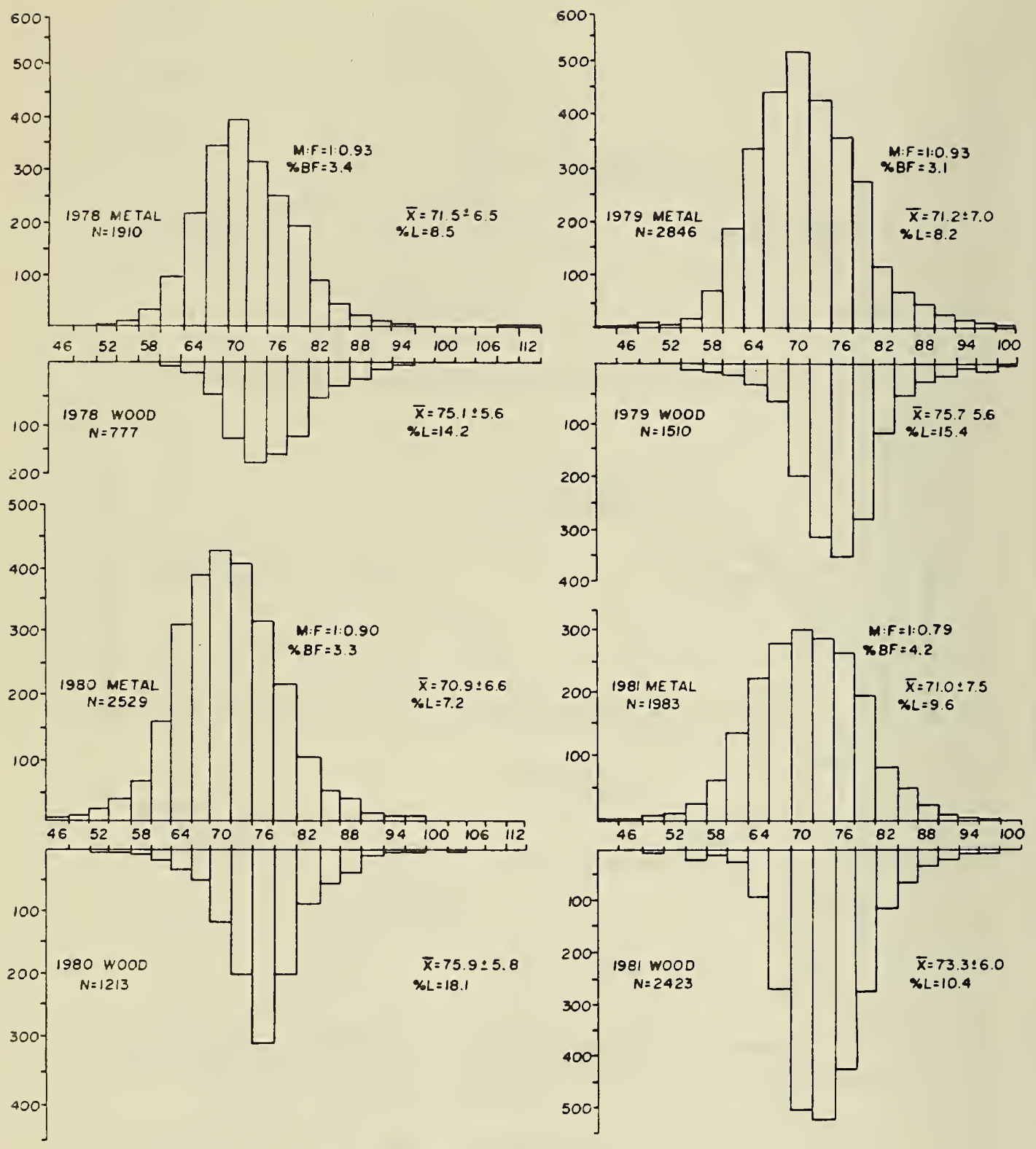

FIGURE 5. Annual size distribution of lobsters in the Millstone Point area caught in wood and wire pots, 1978-81. Values of male:female sex ratios ( $M: F)$ and percent of berried females ( $\%$ BF) represent combined pot type data. mean carapace length $(\bar{X})$, and percent legal catch (\% L) values are presented for each pot type. 
Since lobsters have been collected using wood pots, yearly mean carapace length and percent legal catch have not varied greatly; average CL ranged from $73.3-76.6 \mathrm{~mm}$ from 1976-81. Two other investigations within LIS that used wood pots found larger lobsters; mean CL of $78.9 \mathrm{~mm}$ was reported by Smith (1977), for an area east of the Connecticut River, and $78.2 \mathrm{~mm}$ was reported for western LIS (Briggs and Mushacke 1979). Our study also used wire pots since 1978, and yearly mean CL for these traps ranged from $70.9-71.5 \mathrm{~mm}$. Marcello et al. (1979), using wire pots (2.5 $\mathrm{cm}^{2}$ mesh) in Block Island Sound (BIS), calculated an average CL of $74 \mathrm{~mm}$.

From 1976-81, the percent of legal-sized (CL $\geq 81 \mathrm{~mm}$ ) individuals in our catch ranged from 7.2 to $18.1 \%$ (Figs. 4 and 5). The values reported by other area investigators ranged between $16.7-34.0 \%$ (Smith 1977; Briggs and Mushacke 1979; Marcello et a1. 1979). Over $92 \%$ of the legal-sized lobsters in our study were newly recruited from the sublegal size class (assuming $13 \%$ growth per molt).

Our study area has a higher proportion of small lobsters and a smaller proportion of legal sized individuals than has been reported from surrounding areas. Over $75 \%$ of the legal-sized individuals that we tagged and released were subsequently caught by commercial fishermen, and removed from the population. These data attest to the high exploitation of the local lobster population, especia1ly in the summer when recreational fishing increases.

\section{Sex Ratios}

Since 1975 , the yearly mean sex ratio of males to females was close to $1: 1$ (Figs. 4 and 5). However, when three stations were compared, Twotree had consistently higher proportions of females, whereas Intake 
and Jordan Cove had slightly more males. Sex ratios close to $1: 1$ were also reported by other researchers working in near shore waters (Herrick 1911; Templeman 1936; Ennis 1971, 1974; Stewart 1972; Krouse 1973;

Thomas 1973; Briggs and Mushacke 1980). However, Smith (1977), working in four different areas of LIS, found male to female ratios ranging from $1: 1.06-1: 1.81$. Dominance of females in the catch was also reported by Marcello et al. (1979) and by Briggs and Mushacke (1979). Predominance of females is often associated with depth of water, size of catch, and sampling method. Ratios close to $1: 1$ occur up to the size at which females are sexually mature, after which females tend to predominate in the catch due to the legal restrictions of landing egg-bearing females and the fact that mature females molt less frequently then males (Skud and Perkins 1969; Cooper et al. 1975; Ennis 1980).

Growth

As a result of the mark and recapture tagging program, growth expressed as percent increase in CL between molts, was calculated for 270 individuals that molted between the time of release and the time of recapture. The growth per molt ranged from $12.1-13.4 \%$ (1978-

81). There was no significant difference in growth between males and females. Stewart (1972) reported growth per molt of $15.8 \%$ for males and 15.4\% for females from eastern LIS and Briggs and Mushacke (1979) reported $10.4 \%$ from western LIS. In inshore waters, growth per molt has been reported from 12.0 - 17.5\% (Wilder 1953; Cooper 1970; Ennis 1972; Fair 1977). Cooper and Uzmann (1971) found growth increments of $16.7 \%$ for females and $18.7 \%$ for males caught in deep offshore waters. Smaller growth of inshore lobsters has been attributed to their relative inactivity (feeding) during the colder months of the year (Cooper and Uzmann 1980). 
From 1975-81, the percentage of females that were bearing eggs ranged from $3.1-6.7 \%$ (Table 5). However, the 1975-76 values were based on small sample sizes so the $1977-81$ values of about $3 \%$ are more representative. Twotree had a significantly $(\mathrm{p}<0.05)$ greater proportion of berried females of the three stations (Duncan's Multiple Range Test). Other investigators in eastern LIS and BIS have reported percentages of berried females ranging from 2.5 - 8.2\% (Stewart 1972; Smith 1977; Marcello et a1. 1979). These values differ considerably from those in western LIS, where Smith (1977) reported $27.3 \%$ and Briggs and Mushacke (1979) $27.8 \%$ of females berried.

The mean CL of berried females in our study ranged between 79.1 $82.9 \mathrm{~mm}$. Other investigators in our area reported average sizes of berried females from $80.0-86.2 \mathrm{~mm}$. The smallest berried female caught during our study ( $64 \mathrm{~mm} \mathrm{CL}$ ) was smaller than has been reported by most of the area investigators. Female lobsters in LIS and BIS apparently mature at a smaller size than those off the coast of Maine (Krouse 1973; Thomas 1973), the outer shelf (Skud and Perkins 1969), or along the south shore of Long Island (Briggs and Mushacke 1980).

$\underline{\mathrm{Cu} 11 \mathrm{~s}}$

The percentage of culled lobsters (missing either one or both claws) has ranged from $9.0-17.4 \%$ (Table 6). Smith (1977) reported $26.4 \%$ culled in LIS, east of the Connecticut River, and Briggs and Mushacke (1979) reported culls varying between $7.4-22.8 \%$ in western LIS.

Percent culled in wood pots (range $14.0-17.4 \%$ ) was slightly greater than that observed in wire pots (range 12.1-15.5\%) 1978-81. Trap related 
TABLE 5. The percentage, number, size range, and mean carapace length $(\mathrm{CL})+$ S.D. of egg-bearing females collected from $1975-81$.

\begin{tabular}{cccccccc} 
& Intake & Jordan Cove & Twotree & Overall & $\mathrm{N}$ & Range & CL \\
\hline $1975^{\mathrm{a}}$ & 3.5 & 4.5 & 9.7 & 6.7 & 7 & $73-84$ & $79.1 \pm 3.7$ \\
1976 & 3.3 & 1.9 & 11.2 & 5.9 & 16 & $70-102$ & $82.9 \pm 7.7$ \\
1977 & 3.5 & 1.4 & 6.2 & 3.7 & 35 & $68-92$ & $79.7 \pm 6.4$ \\
$1978^{\mathrm{b}}$ & 2.8 & 1.7 & 5.4 & 3.4 & 58 & $74-88$ & $80.1+4.0$ \\
1979 & 2.8 & 1.7 & 5.2 & 3.1 & 67 & $64-93$ & $80.6 \pm 5.4$ \\
1980 & 1.8 & 2.8 & 5.0 & 3.3 & 71 & $72-93$ & $79.2 \pm 5.1$ \\
1981 & 2.6 & 1.6 & 6.7 & 4.2 & 82 & $70-97$ & $81.2 \pm 6.1$
\end{tabular}

a Wood pots only (1975-77).

b Wood and wire pots (1978-81).

TABLE 6. The percentage of catch missing one claw, two claws, and total percent cull for both wood and wire pots from 1975 - 81 .

\begin{tabular}{|c|c|c|c|c|c|c|}
\hline & \multicolumn{2}{|c|}{$\begin{array}{l}\text { Percent Missing } \\
\text { One Claw }\end{array}$} & \multicolumn{2}{|c|}{$\begin{array}{l}\text { Percent Missing } \\
\text { Two Claws } \\
\end{array}$} & \multicolumn{2}{|c|}{ Percent Cull } \\
\hline & Wood & Wire & Wood & Wire & Wood & Wire \\
\hline 1975 & 7.8 & $-{ }^{a}$ & 1.9 & - & 9.0 & - \\
\hline 1976 & 13.5 & - & 2.0 & - & 15.4 & - \\
\hline 1977 & 10.4 & - & 1.2 & - & 11.7 & - \\
\hline 1978 & 14.1 & 14.0 & 1.9 & 0.9 & 15.9 & 15.0 \\
\hline 1979 & 15.0 & 14.4 & 2.4 & 1.2 & 17.4 & 15.5 \\
\hline 1980 & 14.7 & 11.9 & 2.2 & 1.4 & 16.9 & 13.4 \\
\hline 1981 & 12.6 & 11.2 & 1.4 & 0.9 & 14.0 & 12.1 \\
\hline
\end{tabular}

a

Wire pots not used. 
injuries resulting in claw loss are of ten associated with water temperature, handling by lobstermen, trap set over days, and physical condition (i.e. its nearness to molt) of the lobster (Pecci et al. 1978).

\section{Molting Patterns}

Molting was first noted in May, although at low levels $(<1 \%$ ) (Fig. 6). Incidence of molters reached a peak in June (6-8\%), coinciding with bottom water temperatures of $14-16^{\circ} \mathrm{C}$. Subsequently, molting continued at a low level (1-4\%) from July to October and ceased in January. Although Lund et al. (1973) and Russel et al. (1978) reported a distinct autumn molt, most lobsters in the Millstone Point area apparently molt in June or July. A single molting peak per year has been described in Maine and in offshore waters (Dow 1966; Skud and Perkins 1969; Krouse 1973).

\section{Movement}

The majority $(95.2 \%)$ of our recaptures and commercial returns (95.0\%) were caught at the station where they were released (Fig. 7). These data support the conclusion that inshore lobsters tend to form localized populations (Wilder and Murray 1958; Wilder 1963; Cooper 1970). However, at the Effluent station (1976-77) only $58 \%$ of the lobsters released there were subsequently recaptured there (Fig. 8). The lobsters that did move from the Effluent station moved to the nearby Jordan Cove $(30.7 \%)$ and Intake $(8.6 \%)$ stations, suggesting movement of lobsters in and out of the discharge area, possibly for feeding or temperature avoidance. Additional thermal loading by Unit 3 may increase lobster movement between Jordan Cove and Intake for the same reasons lobsters moved from the effluent. Lobsters that move outside our area > $5 \mathrm{mi}$. tend to move easterly as suggested by Lund et al. (1973), several were caught on the outer continental slope, Hudson and Block canyons. 


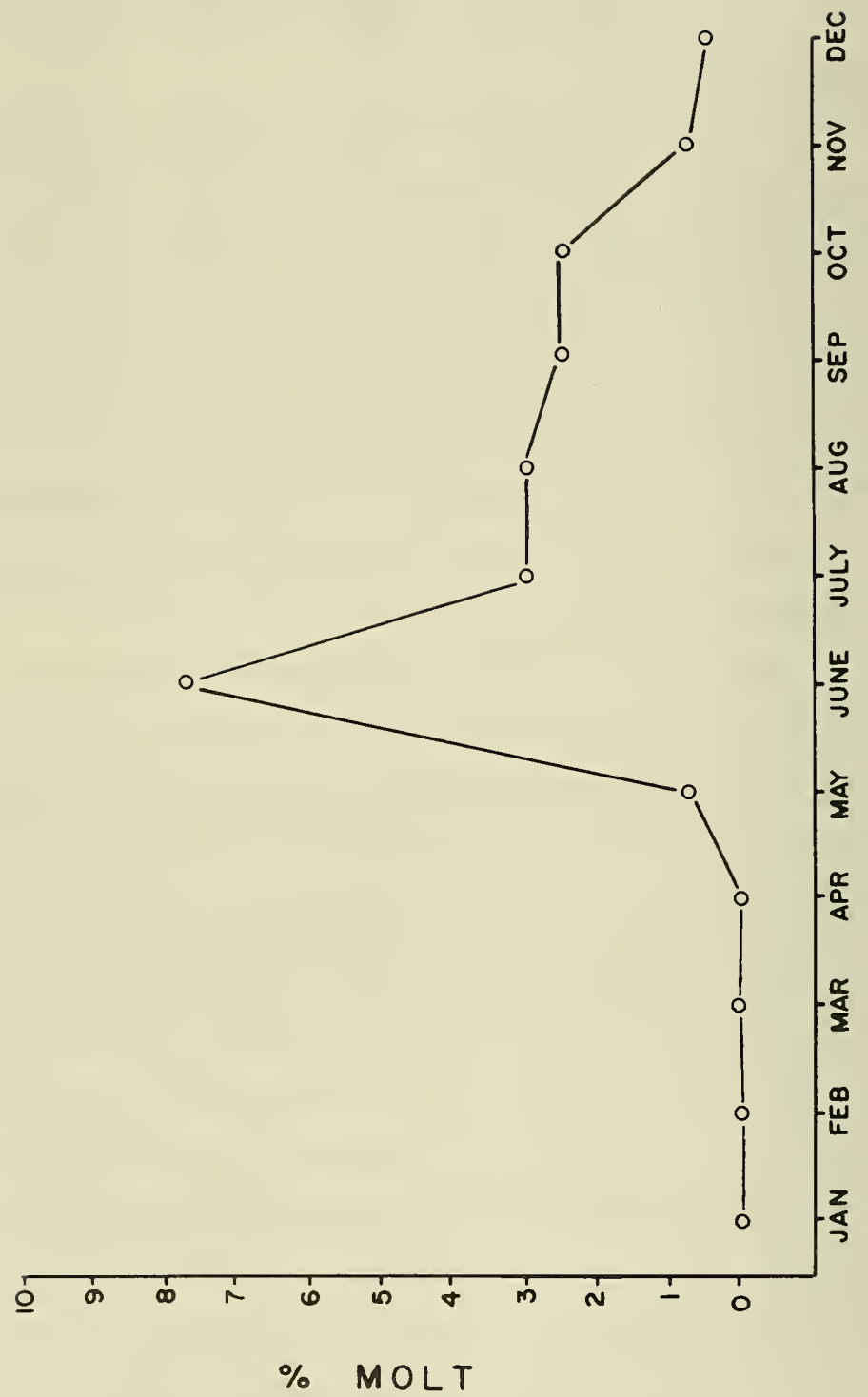

FIGURE 6. Molting patterns for lobsters in the Millstone Point area based on data from 1975-81. 


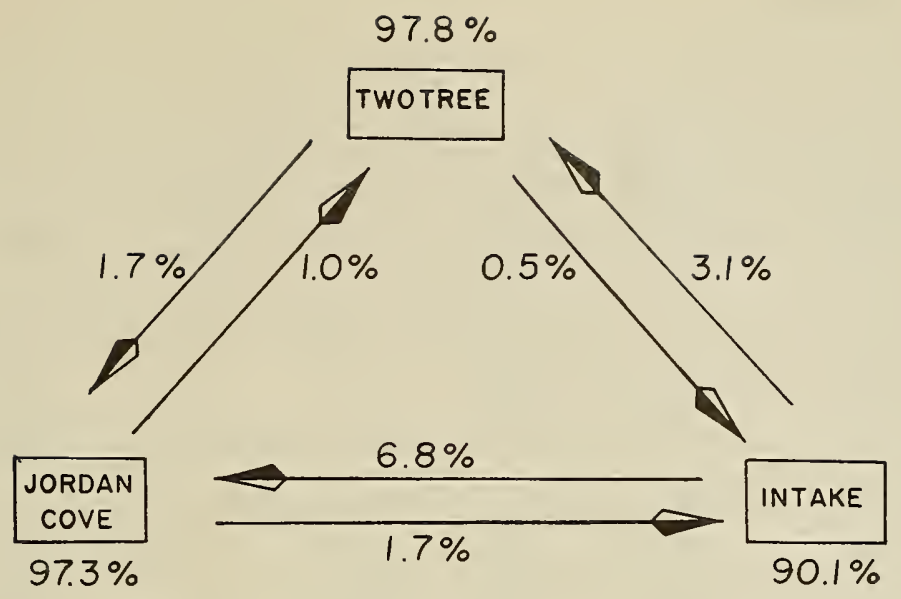

FIGURE 7. Interstation movement as shown by the percent of recaptured lobsters that moved from the station where released 1978-81.

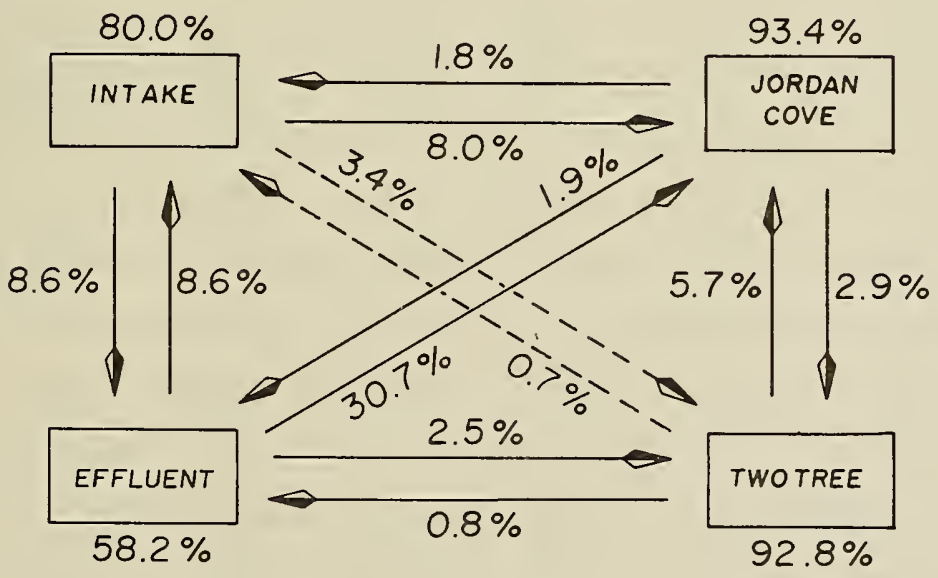

FIGURE 8. Interstation movement as shown by the percent of recaptured lobsters that moved from the station where released 1976-1977. 
The annual population sizes from 1975-81 are presented by month in Table 7. The total population size (initial population size $\mathrm{Ni}+$ recruits Bi) ranged from 16,506 (1978) to 29,697 (1976). Highest recruitment occurred in June, reflecting the spring molt. The maximum population estimatc occurred in July, but as fishing pressure increased in the late summer, population estimates decreased.

Since our estimates are comprised of mostly sublegal size classes, not affected by commercial fishing, and since inshore lobsters are apparently nonmigratory, low population estimates in late summer and early fall were most likely due to the decreased catchability of lobsters associated with decreasing water temperature.

\section{Entrainment}

From 1976 - 1981, the number of lobster larvae counted in entrainment and offshore ichthyoplankton samples ranged from 19 (1977) to 71 (1978). Densities ranged from $.002 / \mathrm{m}^{3}-.07 / \mathrm{m}^{3}$ and the majority of larvae were stage $1(88 \%)$. The larvae were found in our area from May to July with peak abundance occurring in June. If these densities were extrapolated based on total flow rates with both units operating $100 \%$ during the period larvae are found, the number of lobster larvae entrained would be high. However, we believe this method of estimation is inappropriate since the present sampling technique is not designed to sample lobster larvae. Generally more lobster larvae were found in night samples and no correlations were found with tidal stages. Knowledge of larval distribution is 1 imited (Cooper and Uzmann 1980). Lund and Stewart (1970) indicated that the major source of larvae in LIS comes from the western portion of the Sound; this correlates well with the number and 
Table 7. Monthiy Instantaneous Population Estimates for Lobsters in the Millstone Point Area 1975 - 81

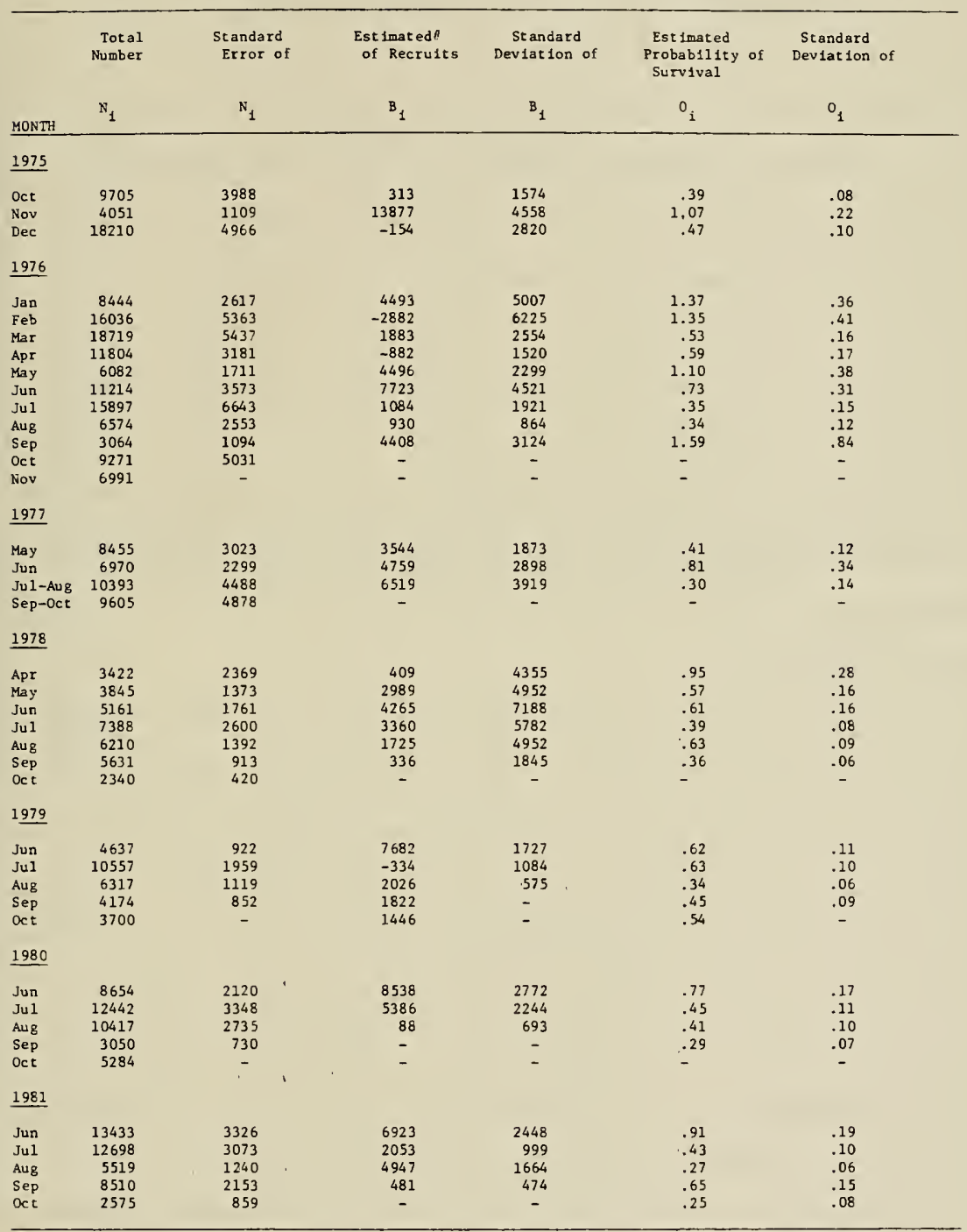


size of berried females found in the western portion (see Smith 1977;

Briggs and Mushacke 1979).

Impingement

The total estimated number of lobsters impinged from 1975-81 was 6,184 (Table 8). Unit 1 impinged 3,054 lobsters and Unit 2, 3,130. The size distributions of impinged lobsters from 1975-81 are presented in Figure 9. The mean CL ranged from $48.6 \mathrm{~mm}$ (1975) to $64.9 \mathrm{~mm}$ (1977). The number of lobsters impinged varied seasonal1y; highest impingement occurred during the summer months concomitant with increased water temperature. Estimated survival rates for the past three years averaged $65 \%$ for lobsters returned to the lab for impingement counts. Lobsters not removed for counts experience $100 \%$ mortality thus, the actual survival is about $28 \%$ of the total number impinged. Proposed sluiceways at Units 1 and 3 will increase our total percent annual survival to about $68 \%$ (NUSCo 1981b).

\section{Gear Effectiveness}

An important objective of the lobster study was to gather information on as large a segment of the local lobster population as possible. Through the use of wire pots $\left(2.5 \mathrm{~cm}^{2}\right.$ mesh) we anticipated increased catch of smaller sized lobsters capable of escaping through the $3-5 \mathrm{~cm}$ gap between the laths of the commerical wood pots. There was no significant difference (ANOV $\mathrm{p}<0.05$ ) in the CPUE of lega1-sized lobsters caught in wood (286) and wire (266) pots. A Kolmogorov-Smironov test on the size distribution of lobsters caught in the two pat types indicated that wire pots caught significantly $(\mathrm{p}<0.05)$ more of the $<75 \mathrm{~mm} \mathrm{CL}$ size class than did the wood pots. These results are similar to those of Krouse (1973) who found that CL of the catch from wire pots averaged 
Table 8. Yearly impingement of lobsters at Millstone Units 1 and 2, from 1975 - 81.

\begin{tabular}{lccc} 
YEAR & UNIT 1 & UNIT 2 & BOTH UNITS \\
\hline $1975 *$ & 734 & 56 & 790 \\
$1976 *$ & 479 & 663 & 1142 \\
1977 & 240 & 310 & 550 \\
1978 & 245 & 261 & 506 \\
1979 & 323 & 426 & 749 \\
1980 & 368 & 405 & 773 \\
1981 & 665 & 1009 & 1674 \\
\hline Total & 3054 & 3130 & 6184 \\
\hline
\end{tabular}

$\star 1975-76$ values are based on 7 days of sampling per week. The 1977-81 values are based on 3 days of sampling per week and are extrapolated based on flow rates to represent the estimated total number impinged. 


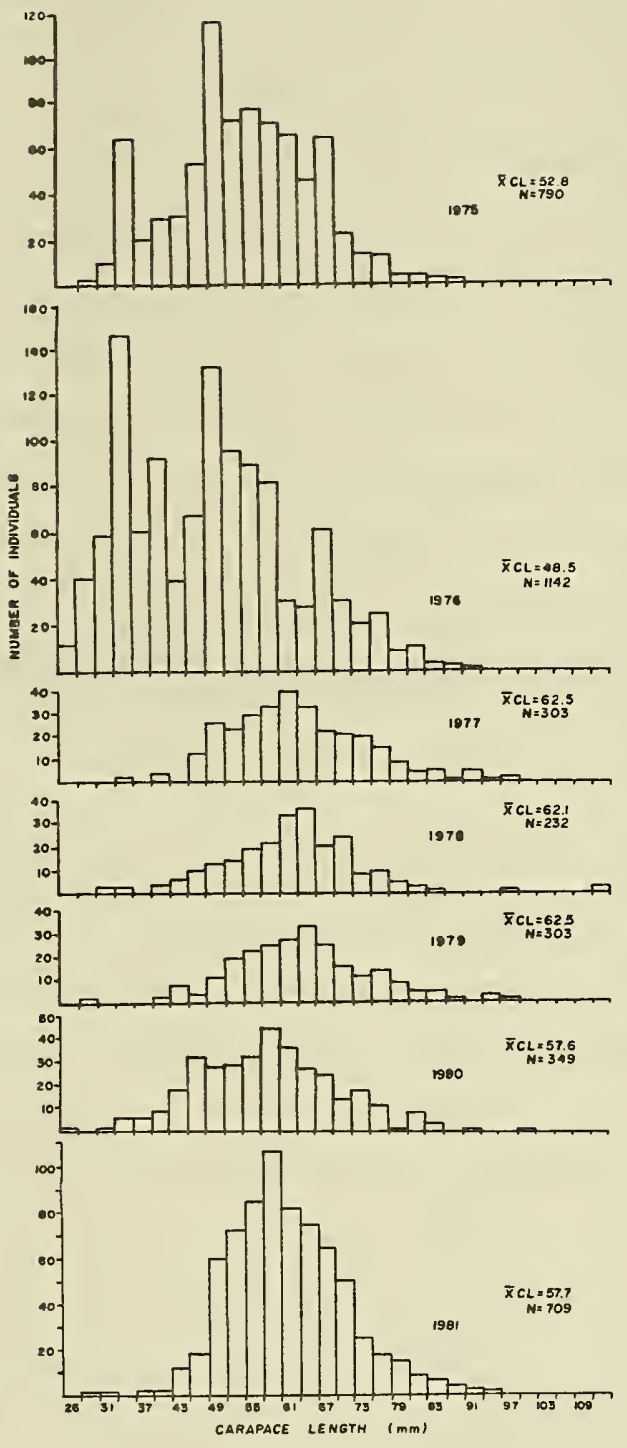

FIGURE 9. The number, mean carapace length and size distribution of impinged lobsters from 1975-81. 
between 67.9 and $70.5 \mathrm{~mm}$. He considered the modal size of his catch (70 mm CL) to be the size at which lobsters are less apt to escape the traps; using the same reasoning, we belleve lobsters in our study are vulnerable to the wire pots at $70 \mathrm{~mm} \mathrm{CL}$ and to the wood pots at about 76 mm CL.

In addition to capturing larger numbers of individuals (to improve population estimates) the use of wire pots was also economically advantagous. Wire pots were more easily hauled, required less maintenance, and were capable of fishing effectively up to 3 years. Wood pots required more ballast, travelled through the water slowly thus require more effort to haul, and could only be $\mathrm{f}$ ished for one season $(<1 \mathrm{yr}$ ) because of wood borer attack.

\section{CONCLUSION AND RECOMMENDATIONS}

Results indicated that the local lobster population was highly exploited, with the commercial and recreational catch ( $\geq 81 \mathrm{~mm} \mathrm{CL}$ ) being highly dependent on the prerecruit size class. The seasonal variation in catch was shown to be a function of molting patterns and changes in catchability, induced by the seasonal change in water temperature. Based on these findings and the fact that the present thermal plume does not reach the bottom sediments at any station, adverse effects on the local lobster population during the operation of Units 1 and 2 have not been observed. 'However, no long-term preoperational population data were collected prior to Unit 1 and 2 start up, therefore, no conclusive statements as to the impacts of Units 1 and 2 can be made in regard to lobster population characteristics prior to their operation. Since lobsters require 4 years of growth before they are vulnerable to our 
traps, and an additional 2-3 years to reach marketable size, there is a lag of at least 6 years between the time of a potential impact on larvae and the time at which we can detect that impact. Therefore, plant induced effects (if any) on larval and juvenile stages that have occurred since 1975 would only now be apparent in the 1981-82 catch. Thus, the information collected since 1975 is providing long-term population data needed to quantitatively assess any changes in the lobster population due to Unit 3 .

To evaluate the effects of Millstone Units 1,2 and potential impact of Unit 3, the changes in the population will be detected by the alteration of the basic population parameters now being collected. The population size, and growth and movement of individuals can be compared by station over time as a result of our tagging program. Sex ratios, size frequencies, CPUE, the number of culls and berried females can be evaluated over years and between stations. The stability of these parameters during Unit 1 and 2 operation and after the start up of Unit 3 will demonstrate the effects (if any) of operating plants on Millstone Point.

We believe the present program should be continued through the operational phase of Unit 3. In addition, we stress the commercial and recreational importance of lobsters in our area and the favorable channel of communication between our staff and these local lobstermen as a result of our tagging program. 
AIKEN, D.E.

1973. Proecdysis, setal development, and molt prediction in the American lobster (Homarus americanus). J. Fish. Res. Board Can. 30:1337-1344.

BRIGGS, P.T. AND F.M. MUSHACKE.

1979. The American Lobster in Western Long Island Sound. New York Fish and Game J. 26:59-86.

BRIGGS, P.T. AND F.M. MUSHACKE.

1980. The American Lobster and the pot fishery in the inshore waters off the south shore of Long Island, New York. New York Fish and Game J. $27: 156-178$.

CAPUZZO, J.M. AND W.W. REYNOLDS

1980. Lobster Behavior in Relation to Power Plants. Pages 227-240 in C.H. Hocutt, J.R. Stauffer Jr., J.E. Edinger, L.W. Hall Jr. and R.P. Morgan III eds. Power Plants Effects on Fish and Shellfish Behavior, Academic Press, Inc., New York.

COOPER, R.A.

1970. Retention of marks and their effects on growth, behavior, and migration of the American lobster, Homarus americanus. Trans. Amer. Fish. Soc. 99:409-417.

COOPER, R.A., R.A. CLIFFORD AND C.D. NEWELL.

1975. Seasonal abundance of the American lobster, Homarus americanus, in the Boothbay Region of Maine. Trans. Am. Fish. Soc. 104:669-674.

COOPER, R.A. AND J.R. UZMANN.

1971. Migrations and growth of deep-sea lobsters, Homarus americanus. Science $171: 288-290$.

COOPER. R.A. AND J.R. UZMANN.

1980. Ecology of Juvenile and Adult Homarus. Pages 97-141 in J.S. Cobb, and B.F. Phillips eds. The Biology and Management of Lobsters, Vol. II, Academic Press, Inc., New York.

DOW, R.L.

1966. "The use of biological, environmental and economic data to predict supply and to manage a selected marine resource," The Amer. Biol. Teacher 28:26-30.

DOW, R.L.

1969. "Cyclic and gepgraphic trends in seawater temperature and abundance of American lobster," Science, Vo1. 164:1060-1063.

DOW, R.L.

1976. Yield trends of the American lobster resource with increased fishing effort. Mar. Techno1. Soc. 10:17-25. 
ENNIS, G.P.

1971. Lobster (Homarus americanus) fishery and biology in Bonavista Bay, Newfoundland. 1966-70. Fish. Mar. Serv. Tech. Rep. 289, 46p.

ENNIS, G.P.

1972. Growth per molt of tagged lobsters (Homarus americanus) in

Bonavista Bay, Newfoundland. J. Fish. Res. Board Can. 29:143-148.

ENNIS, G.P.

1974. Observations on the lobster fishery in Newfoundland. Fish.

Mar. Serv. Tech. Rep. 479; 21p.

ENNIS, G.P.

1980. Size-maturity relations and related observations in Newfoundland populations of the lobster (Homarus americanus). Can. J. Fish. Aquat. Sci. 37:945-956.

FAIR, J.J., JR.

1977. Lobster investigations in management area I; Southern Gulf of Maine. Mass. Div. of Mar. Fish. 8p.

FLOWERS, J.M. AND S.B. SAILA.

1972. An analysis of temperature effects on the inshore lobster fishery. J. Fish. Res. Board Can. 29:1221-1225.

HERRICK, F.H.

1911. Natural History of the American lobster. Bull. U.S. Bureau

Fish. 29:149-408.

JOLIY, G.M.

1965. Explicit estimates from capture-recapture data with both death and immigration-stochastic model. Biometrika 52:225-247.

KROUSE, J.S.

1973. Maturity, sex ratio, and size composition of the natural population of American lobster, Homarus americanus, along the Maine coast. Fish. Bu11. 71:165-173.

LUND, W.A. AND L.L. STEWART

1970. Abundance and distribution of larval lobsters, Homarus americanus, off the coast of southern New England. Proc. Nat. Shellfish. Assoc. $60: 40-49$.

LUND, W.A., L.L. STEWART, AND C.J. RATHBUN.

1973. Investigation on the lobster. NOAA Technical Report, NMFS Project No. 3-130-R, 189p.

MARCELLO, R.A., JR., W. DAVIS III, T. O'HARA AND J. HARTLEY.

1979. Population statistics and commercial catch rate of American lobster (Homarus americanus) in the Charlestown-Matunuck, Rhode Island region of Block Island Sound. Yankee Atomic Electric Company. Submitted to New England Power Company. YAEC1175, 40p. 
MCLEESE, D.W. AND D.G. WILDER

1958. The activity and catchability of the lobster (Homarus americanus) in relation to temperature. J. Fish. Res. Board Can. 15:1345-1354.

NUSCo.

1981a. Lobster Population Dynamics. Pages 1-21 in the annual report on Ecological and Hydrographic Studies at the Millstone Nuclear Power Station. Northeast Utilities Service Company, Waterford, CT.

NUSCo .

1981b. Feasibility of Modifying the Millstone Units 1 and 2 Cooling Water Intake Screen Wash System to Improve the Return of Fish to Long Island Sound. $67 \mathrm{p}$ Northeast Utilities Service Company, Waterford, CT.

PECCI, K.J., R.A. COOPER, C.D. NEWELL, R.A. CLIFFORD, AND R.J. SMOLOWITZ.

1978. Ghost fishing of vented and unvented lobster, Homarus americanus, traps. Mar. Fish. Rev. 40:9-43.

PHILLIPS B.F., J.S. COBB, AND R.W. GEORGE

1980. General Biology. Pages 1-82 in J.S. Cobb, and B.F. Phillips eds. The Biology and Management of Lobsters, Vol. I, Academic Press, Inc. New York.

RUSSEL, H.J.,C.V.D. BORDEN, AND M.J. FOGARTY.

1978. Management studies of inshore lobster resources completion

report. No. L074-1-RI(1):1. R.I. Fish and Game, 75p.

SCARRATT, D.J.

1970. Laboratory and field tests of modified sphyrion tags on lobsters

(Homarus americanus). J. Fish. Res. Board Can. 27:257-264.

SCARRATT, D.J. AND P.F. ELSON.

1965. Preliminary trials of a tag for salmon and lobsters. J. Fish.

Res. Board Can. 2:421-432.

SEBER, G.A.F.

1965. A note on the multiple-recapture census. Biometrika 52:249-259.

SKUD, B.E. AND H.C. PERKINS.

1969. Size composition, sex ratio and size at maturity of offshore northern lobsters. U.S. Fish Wildl. Serv. Spec. Sci. Rept. Fish. $598,10 p$.

SMITH, E.M.

1977. Some aspects of catch/effort, biology, and the economics of the Long Island Sound lobster fishery during 1976. NOAA Technical Report, NMFS Project No. 3-253-R-1, 97p.

SPURR, E.

1972. Lobster research project: Final report of 3-105-R, July 1969June 1971. Fish. Div., N.H. Fish Game Dep., 22p.

STEWART, L.L.

1972. The seasonal movements, population dynamics and ecology of the lobster, Homarus americanus (Miline-Edwards), off Ram Island, Connecticut. Ph.D. Thesis, University of Connecticut. 112p. 
TEMPLEMAN, $W$.

1936. Local differences in the life history of the lobster (Homarus americanus) on the coast of the maritime provinces of Canada. J. Biol. Board Can. 2:41-88.

THOMAS, H.J.

1959. A comparison of some methods used in lobster and crab fishing. Scott. Fish. Bu11, 12:3-8.

THOMAS, J.C.

1973. An analysis of the commercial lobster (Homarus americanus)

fishery along the coast of Maine, August $196 \overline{6 \text { through December }} 1970$. NOAA Technical Report, NMFS SSRF-667, 57p.

WILDER, D.G.

1953. The growth rate of the American lobster (Homarus americanus).

J. Fish. Res. Board Can. 10:371-412.

WILDER, D.G.

1963. Movements, growth, and survival of marked and tagged lobsters liberated in Egmont Bay, Prince Edward Island. J. Fish. Res. Board Can. 20:305-318.

WILDER, D.G. AND R.C. MURRAY

1958. Do lobsters move offshore and onshore in the fall and spring? Pages 12-15 in Fish. Res. Board Can. Atlantic Prog. Rpt. No. 69. 


EXPOSURE PANELS 1968-1981:

A REVIEU AND EVALUATIOI 



\section{L:TRODUCTION}

The destructive activities of marine fouling and wood-boring organisms has caused coastal communities to pay a high price for their control (WHOI 1952; Pritchard 1980). Boat bottoms require coatings of expensive antifouling paints or frequent scrapings. Lobstermen and dock owners either have to replace their wooden traps and pilings regularly or use more expensive materials which have been chemically treated. Users of seawater cooling systems must chlorinate, flush with hot water, or build redundant systems to maintain cooling efficiency. Therefore, industries and individuals become justifiably concerned with changes in the abundances of these organisms.

Artificial substrates (exposure panels) have been used to study community structure and temporal variability of fouling and wood-boring organisms. A variety of materials such as glass, plexiglass, ceramic tiles, asbestos cement, artificial sponges and various types of wood have been used for collecting these organisms. The use of exposure panels in environmental monitoring studies has increased over the years because this approach, in comparison to monitoring naturally occurring substrates, provides several advantages, which include: obtaining a known age for the community, standardization of habitat on which to collect organisms, flexibility in locating sites for sampling, which depends more on the ingenuity of the investigator than the availability of natural substrates, and easy method for obtaining replicate samples (Cairns 1982). 
Several monitoring studies have used exposure panels to assess environmental impacts of thermal effluents (Frame 1968; Cory and Nauman 1969; Nauman and Cory 1969; Hillman 1975, 1977; Young and Frame 1976; NAI 1979; Maciolek-Blake et a1. 1981; Osman et al. 1981). The types of impacts attributed to thermal effluents from such studies include increases in biomass (Cory and Nauman 1969; Nauman and Cory 1969) and woodborer activity (Naylor 1965; Turner 1973; Maciolek-Blake, et al. 1981), extension of breeding seasons (Naylor 1965; Young and Frame 1976), and attraction of non-native species (Naylor 1965; Hoagland and Turner 1980; NUSCo 1982).

The exposure panel program at the Millstone Nuclear Power Station (MNPS), Waterford, Connecticut has sampled fouling and wood-boring communities, since 1968. The objective has been to characterize fouling and wood-boring communities at sites within and beyond the thermal effluent. Species composition and abundance have been used to assess temporal and spatial differences between sites and years. This evaluation is intended to present a historical overview of the program, summarize prior evaluations upon which program changes were based, and evaluate our approach to future work relative to the startup of Unit 3 .

\section{HISTORICAL REVIEW OF METHODOLOGY}

\section{Overview of Program}

During 1968-1981, one change in the general approach to collecting data and several minor changes in methods were made to improve the data base. From 1968-1978, one long and one short term exposure panel were collected monthly from each of six stations. Long term panels were exposed for 12 months and short term panels were exposed for one month. 
In 1979, the sampling approach was changed to six replicate samples collected at five of the original six sites. Instead of making monthly collections of these panels, they were collected in four overlapping six month exposure periods. This program change resulted from recommendations of Brown and Moore (1977) and Battelle (1978, 1979). Minor changes from 1968-1981 included relocation of panels at sites, sample storage techniques, and refining of panel processing methods. These latter changes were made to reduce losses of panels from storms, increase the similarity in deployments between stations, improve the condition of specimens used for identification, and generally improve our understanding of community structure on exposure panels.

Battelle (1979) began a special study monitoring the gonad development of shipworms in 1976. They examined a total of 636 shipworms, Teredo navalis, from eight locations around MNPS during the two year study. It was concluded that shipworms in our area could spawn from June through September.

Exposure panel studies have monitored fouling and wood-boring organisms during three phases of power plant operation: 1) two and one half years before operation, 2) five years of one unit operation, and 3) six years of two unit operation. These data provide an adequate data base for assessing any impact three unit operation might have in the future (Appendix I). For this reason, the Nuclear Regulatory Agency (NRC) permitted us to suspend the monitoring of these communities until two years prior to three unit operation (Appendix II). This action has provided us with the opportunity to concentrate our research efforts on shipworms, Teredo navalis and Teredo bartschi, and increase our understanding of how power plant operation will affect their life histories. 
A series of changes in collection and analysis procedures for exposure panels have occurred during the history of this program (Table 1). Changes were made to enhance data collection and increase our ability to discern power plant effects from natural variability in community parameters.

In 1977, Brown and Moore evaluated the exposure panel program at Millstone using 1968-1974 data. An array of statistical methods were applied to the data to determine strengths and weaknesses of the program. They concluded that the major weakness of the data was the lack of replicate sampling and the most meaninful parameter analyzed was the number of species collected per panel. In fact, Brown and Moore concluded that a signficant impact by power plant operation would require an addition or loss of at least three spectes per site. Therefore, they recommended replicate sampling to account for interpanel variability of species and their abundances, which would provide a more quantified basis for making decisions. In addition, they recommended a reduction in the exposure period from 12 months to $7-9$ months. They suggested that the shorter exposure period would reduce the destructive effects of woodborers, which in the past had frequently resulted in the loss of entire panels, and reduce any time lapse in data caused by a storm destroying an entire rack of panels.

Battelle subsequently conducted a two year pilot study (February 1977 - February 1979) to assess interpanel variability in community composition and species abundance (Battelle 1978, 1979a). They concluded that a minimum of six replicate panels at each site was needed to adequately account for natural variability. These results were based on the deployment 


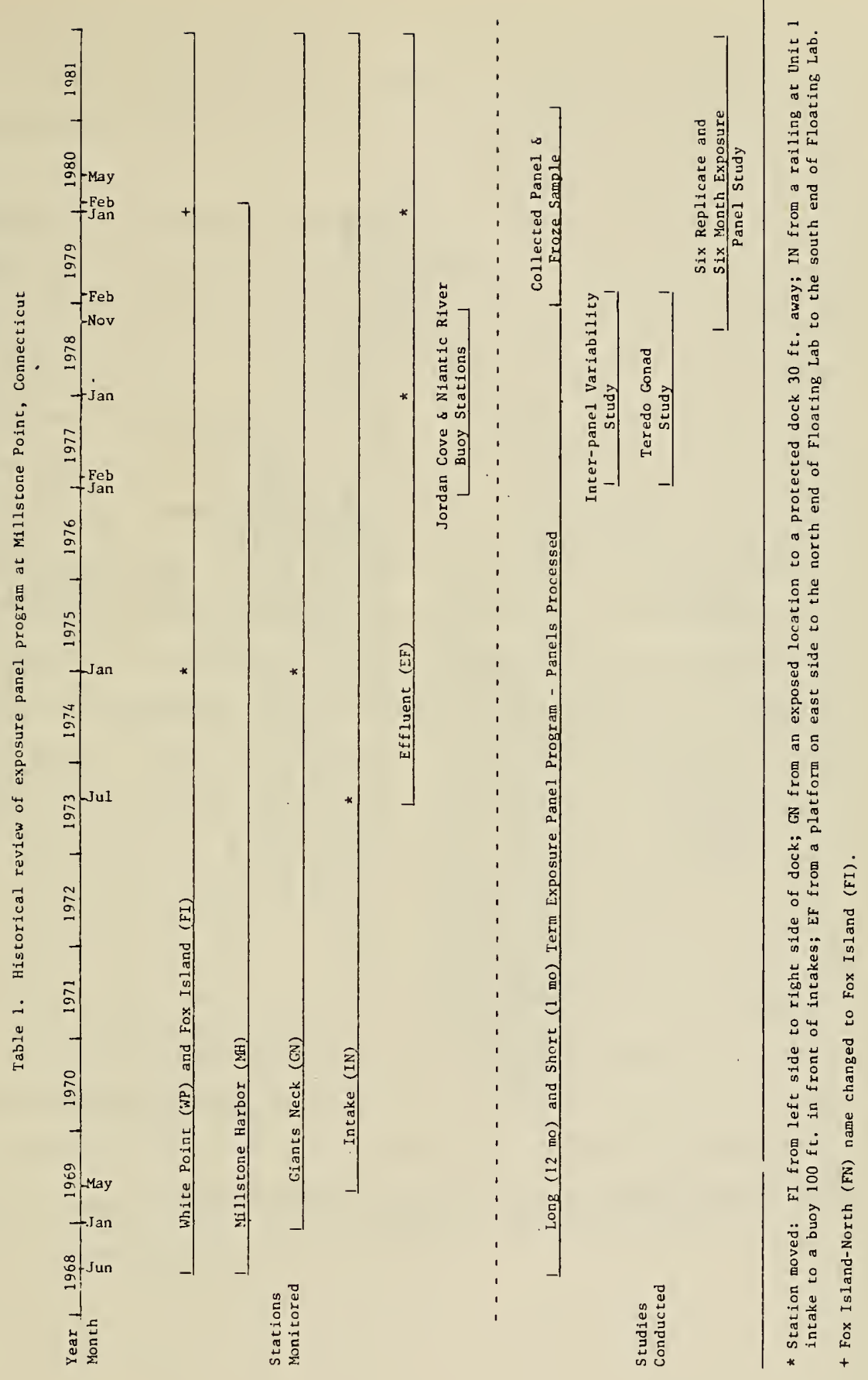


of 12 replicate panels exposed for six months at two sites (Fox Island and Giants Neck). The shorter exposure period effectively sampled the fouling and wood-boring species over the year and allowed the communities to be compared on a seasonal basis.

We adopted the six replicate and six month exposure period sampling method in November 1978, collecting the first samples in May 1979. Four overlapping six month exposure periods (February, May, August, and November) were collected each year from 1979-1981. To further improve Hata collection, four changes were made in processing exposure panels. First biota on asbestos and wood panels were considered different assembages and were processed separately. Second, the additional parameters of canopy cover (panel surface covered by an organism beyond its direct attachment, primary cover, on the panel), freespace (panel surface not covered by the direct attachment of live or dead organisms), and dead Balanus (panel surface covered by empty tests and basal plates of barnacles) were added in February 1980 to the data collected. Third, to avoid any bias caused by the vertical displacement of panels which were collected from overlapping exposure periods, the placement of three replicate panels on the top and three replicate panels on the bottom level of a rack was begun in May 1980 (Fig. 1). Prior to this time, panels from overlapping collection periods were placed on different levels. Fourth, the use of radiographs for counting shipworms and estimating percent destruction was also initiated in May 1980. This latter method considerably reduced the amount of time needed for processing wood panels and provided a permanent record of the infestations (Table 2). 


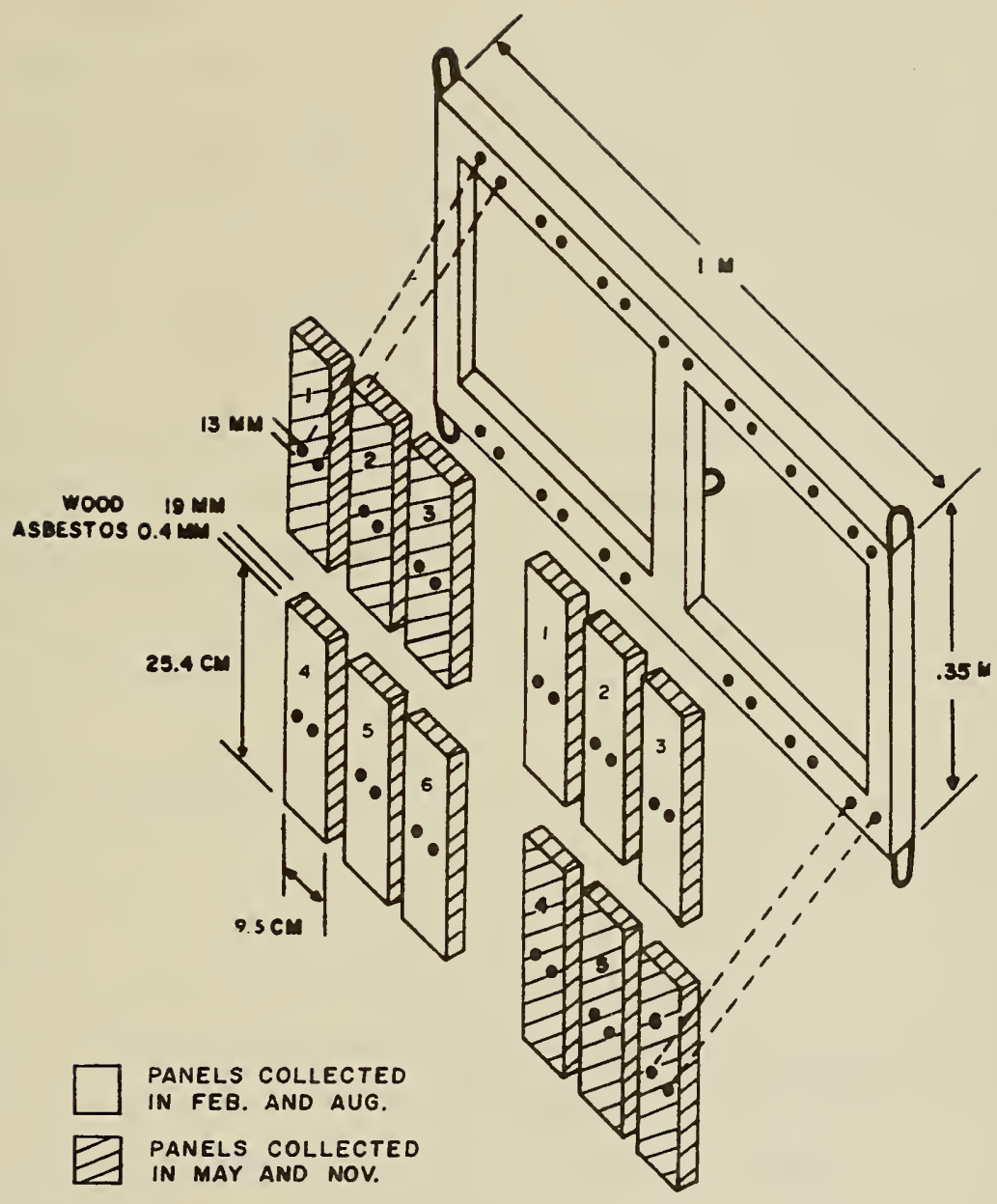

Figure 1. Exposure panel rack and position of panels for sampling the fouling and wood-boring communities in the Millstone Point area during 1980-81. 
Table 2. X-ray Inspection verses Actual Picking of Wood Panels for Shipworms.

\begin{tabular}{|c|c|c|c|c|}
\hline Station/Rep. & $\begin{array}{c}\text { Type of } \\
\text { Assessment }\end{array}$ & $\begin{array}{c}\text { Percent } \\
\text { Destruction }\end{array}$ & $\begin{array}{c}\text { Number of } \\
\text { Teredo }\end{array}$ & $\begin{array}{c}\text { Size } \\
\text { Range }(\mathrm{mm})\end{array}$ \\
\hline \multirow[t]{3}{*}{ Effluent/3 } & $\begin{array}{r}\text { Actual } \\
\text { Count }\end{array}$ & 50 & 86 & $1.5-350$ \\
\hline & $\mathrm{X}$-ray (A) & 40 & 91 & $2-354$ \\
\hline & $\mathrm{X}$-ray (B) & - & 85 & $6-345$ \\
\hline \multirow[t]{3}{*}{ Effluent/5 } & $\begin{array}{r}\text { Actual } \\
\text { Count }\end{array}$ & $35-40$ & 83 & $3.5-308$ \\
\hline & $\mathrm{X}$-ray (A) & 50 & 84 & $10-340$ \\
\hline & $X-$ ray (B) & - & 76 & $13-320$ \\
\hline \multirow[t]{3}{*}{ Intake/3 } & $\begin{array}{l}\text { Actual } \\
\text { Count }\end{array}$ & 5 & 6 & $9-190$ \\
\hline & $\mathrm{X}$-ray (A) & 5 & 6 & $10-195$ \\
\hline & $\mathrm{X}-\mathrm{ray}(\mathrm{B})$ & - & 6 & $9-190$ \\
\hline \multirow[t]{3}{*}{ * Giants Neck/5 } & $\begin{array}{r}\text { Actual } \\
\text { Count }\end{array}$ & 75 & 125 & $4-120$ \\
\hline & $\mathrm{X}$-ray $(\mathrm{A})$ & 80 & 100 & $5-95$ \\
\hline & $X-$ ray (B) & - & 93 & $7-100$ \\
\hline \multirow[t]{3}{*}{${ }^{*}$ Giants Neck/6 } & $\begin{array}{r}\text { Actua } 1 \\
\text { Count }\end{array}$ & 75 & 74 & $5-135$ \\
\hline & $\mathrm{X}$-ray (A) & 75 & 96 & $11-110$ \\
\hline & $X$-ray (B) & - & 93 & $18-115$ \\
\hline
\end{tabular}

*Left half of panel picked and $r i g h t$ half $x$-rayed. $A \& B=$ Counts by two different people. 
EVALUATION OF THE EXPOSURE PANEL PROGRAM, 1979-1981

\section{Sources of variability}

At least five potential sources of variability have influenced the data collected during this program. Station location, substrate type, and placement of panels on the racks can be standardized. Seasonal cycles in reproduction and dispersal of organisms and year to year changes in the dominance of species can only be assessed through repetitive sampling.

Station location. Five stations have been sampled during the last three years (Fig. 2). Giants Neck is beyond the influences of the thermal effluent and is considered a reference station. Effluent is in the undiluted effluent of MNPS where the greatest thermal impacts are observed. The other three stations are located in the waters surrounding Millstone Point.

Community structure and abundance of individuals at White Point, Fox Island, and Intake have been compared to those at Giants Neck and Effluent for the last three years (NUSCo 1982). Giants Neck, White Point, and Fox Island have had consistently high interstation similarities, which were attributed to their locations at docks. Intake has been the least similar to the other ambient water stations; a factor attributed to its exposed location and deployment near the surface in deep water. Effluent communities have consistently been least similar to the other four (Fig. 3). These trends in similarities between stations are important because a change in the similarity of a community from one most similar to those at Giants Neck to one more similar to those at Effluent would suggest power plant impacts. 


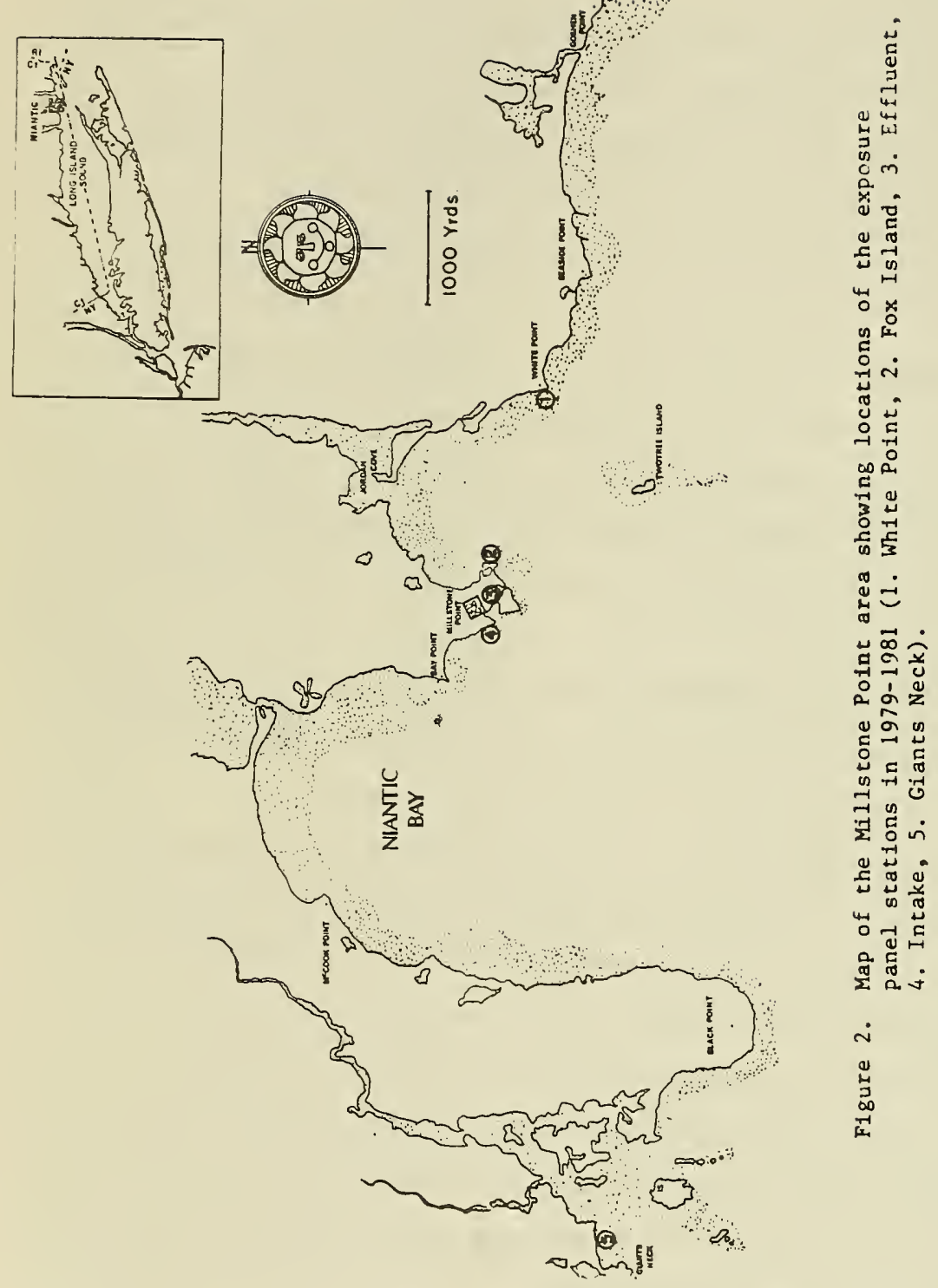




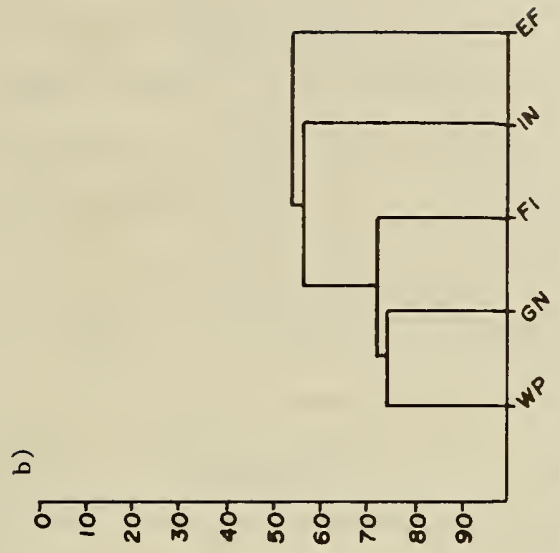

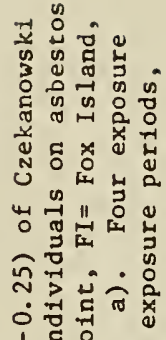
II ๑ 4 ำ $\infty$ 대 है 폴 क 43 क क ซ

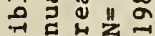
들 出 飞一 क ळ 山 4 I o o $\infty<\infty$ 4 \& 1 出 $\infty$ 类 동용. म 5 का के क

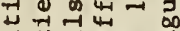

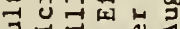
के ज्ञ 걸 \& む

a मे क

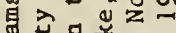
क्ष

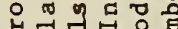
ग क्त 是早艺岕?
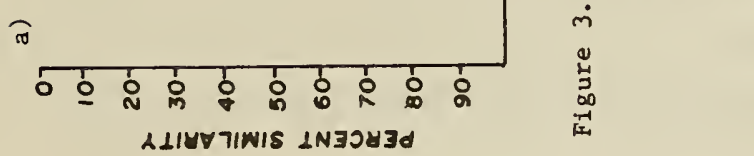
For the purpose of this evaluation, two of the five stations, Giants Neck and Effluent, have been selected to describe the variability and adequacy of estimates associated with the community and population parameters monitored. Communities at Giants Neck in the last three years have had the greatest number of species collected and have been representative of communities at White Point and Fox Island. Communities at Effluent in the last three years have had the fewest numbers of species collected and have been the least similar to communities of the other four stations. Therefore, these two stations are representative of the range in data which is potentially affected by station location and should bracket the variability and adequacy of estimates associated with the community and population parameters monitored.

Substrate type. Battelle (1978) concluded that communities collected on asbestos and wood panels were different based on 12 replicates panels exposed at Giants Neck and Fox Island from August 1977 through August 1978. Reexamining this difference, we calculated Czekanowski similarity coefficients for 1980 data collected at Giants Neck and Effluent. Dendrograms for these similarity values reconfirmed that communities developing on asbestos and wood panels were distinct (Fig. 4). These differences were maximized in February and November at Giants Neck and in August at Effluent. At Giants Neck, differences between panel types were primarily caused by 6 of 39 taxa collected in February and 9 of 50 taxa collected in November (Table 3). At Effluent, these differences were primarily caused by 7 of 16 taxa collected in August. Of the 18 species 1 isted in Table 3 , eight had significantly different abundances (based on the overlap of the $95 \%$ confidence limits) on the two pane1 types. 

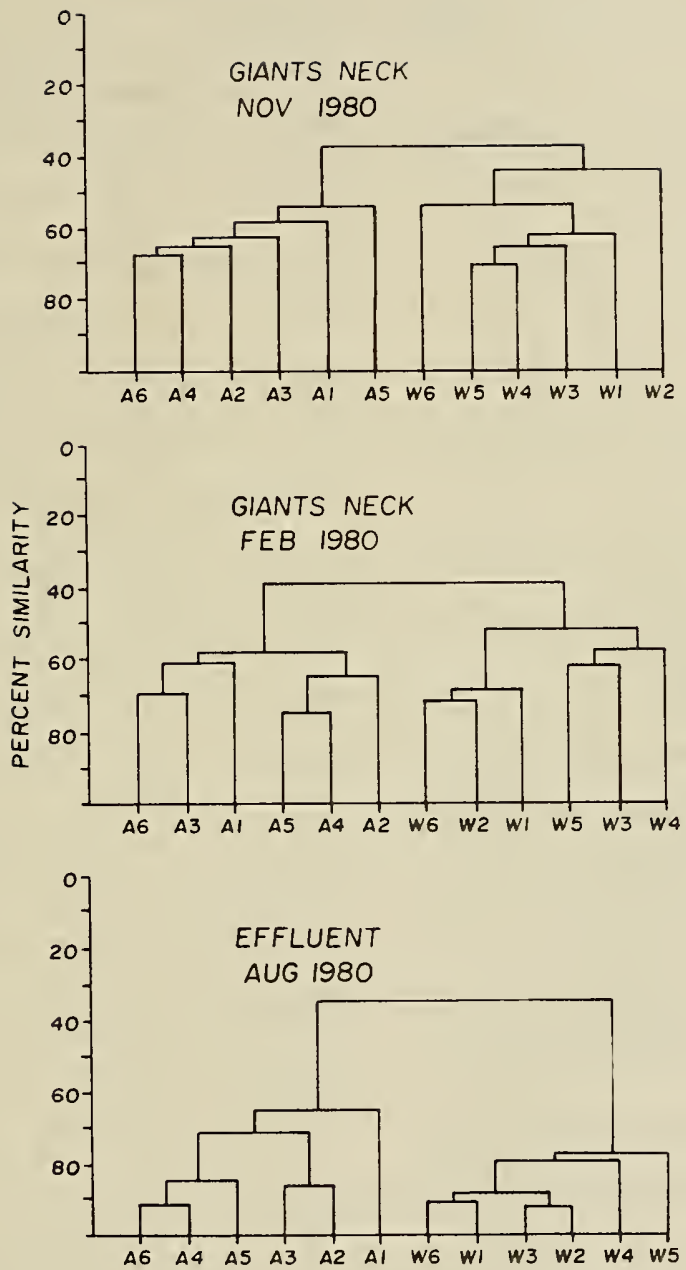

Figure 4. Dendrograms resulting from flexible sorting $(g=-0.25)$ of Czekanowski similarity coeficients using replicate counts of individuals on asbestos and and $W=$ wood). 
Table 3

Abundance (Counts of Individuals) of Individual Species, which had Distinctly Different Abundances on Asbestos and wood Panels at Giants Neck (GN) and Effluent (EF) in 1980

\begin{tabular}{|c|c|c|c|c|}
\hline & \multirow[b]{2}{*}{ Station } & \multirow{2}{*}{$\begin{array}{c}\text { Collection } \\
\text { Date }\end{array}$} & \multicolumn{2}{|c|}{$\overline{\mathrm{X}}$ Abundance \pm 95 Confidence Limits } \\
\hline Taxa & & & Asbestos Panels & Wood Panels \\
\hline * Sabellaria vulgaris & $\mathrm{GN}$ & $2 / 80$ & $16 \pm 9$ & $1.2 \pm 1.2$ \\
\hline * Spirorbid worms & GN & $2 / 80$ & $11 \pm 6$ & $0.2 \pm 0.4$ \\
\hline Spirorbid worms & GN & $11 / 80$ & $19 \pm 20$ & $0.2 \pm 0.4$ \\
\hline * Spirorbid worms & $E F$ & $8 / 80$ & $7 \pm 3$ & 0 \\
\hline * Serpulid worms & GN & $2 / 80$ & $28 \pm 8$ & $1.0 \pm 1.3$ \\
\hline Serpulid worms & GN & $11 / 80$ & $15 \pm 17$ & $2.7 \pm 3.6$ \\
\hline * Nicloea venustula & GN & $2 / 80$ & $11 \pm 7$ & $4.7 \pm 3.9$ \\
\hline * syllis qracilis & EF & $8 / 80$ & $4.5 \pm 3.3$ & $51 \pm 24$ \\
\hline * Balanus juveniles & EF & $8 / 80$ & $22 \pm 18$ & $142 \pm 51$ \\
\hline * Balanus improvisus & GN & $2 / 80$ & $17 \pm 9$ & $3.5 \pm 2.6$ \\
\hline * Balanus improvisus & EF & $8 / 80$ & $21 \pm 13$ & $128 \pm 63$ \\
\hline Balanus eburneus & GN & $11 / 80$ & 0 & $0.8 \pm 0.8$ \\
\hline Caprella penantis & GN & $2 / 80$ & $67 \pm 115$ & $6.8 \pm 17.0$ \\
\hline Corophium acherusicum & EF & $8 / 80$ & $12 \pm 20$ & $148 \pm 152$ \\
\hline Corophium tuberculatum & EF & $8 / 80$ & $11 \pm 20$ & 0 \\
\hline Corophium tuberculatum & GN & $11 / 80$ & $136 \pm 159$ & $31 \pm 26$ \\
\hline Corophium acutum & GN & $11 / 80$ & $266 \pm 265$ & $59 \pm 62$ \\
\hline Microdeutopus anomalus & GN & $11 / 80$ & $20 \pm 26$ & $0.2 \pm 0.4$ \\
\hline Microdeutopus gryllotalpa & GN & $11 / 80$ & $37 \pm 52$ & 0 \\
\hline Dexamine thea & GN & $11 / 80$ & $51 \pm 77$ & $5.7 \pm 6.3$ \\
\hline Amphithoe valida & $\mathrm{EF}$ & $8 / 80$ & $110 \pm 67$ & $19 \pm 48$ \\
\hline * Ciona intestinalis & GN & $11 / 80$ & $2.0 \pm 1.5$ & 0 \\
\hline Styela partita & GN & $11 / 80$ & $12 \pm 20$ & 0 \\
\hline
\end{tabular}

*958 Confidence Limits do not overlap the means suggesting the abundances are significantly different $(p>0.05)$. 
Observed differences between asbestos and wood communities might be influenced by species preferences, or woodborer activity. For example, spirobid and serpulid worms have exhibited a preference for setting on asbestos cement over wood panels. In contrast, the abundance of a species may be altered between panel types due to the severity of the woodborer activity, since it occurs only on wood panels. Battelle (1977) found that severe infestations of Limnoria spp. reduced the abundance of shipworms and it would seem reasonable that it would effect the distribution of other species as well. As Limnoria spp. populations increase the surface of the wood begins to crumble and attached species are sloughed off. Such effects occurred at Giants Neck, where the lowest asbestos/wood affinities coincided with periods of peak woodborer abundance (February and November).

Placement of panels on rack. The location of a panel on a rack can effect the distribution or abundance of an organism (Fig. 5). In May 1980, the location of panels was changed from all replicates being at the same level to three on the top of the rack and three on the bottom (Fig. 1). The objective was to minimize any sampling bias that might create an artificial seasonal effect by having panels from overlapping exposure periods vertically displaced. Woodborer attacks often become more severe as a substrate approaches the bottom sediments, as observed in 1980 and 1981 (NUSCo 1982). Even though there is only $0.6 \mathrm{~m}$ from the bottom of a lower panel to the top of an upper one, the variance for a single species can be considerably increased over the six replicates (Fig. 6). However, fouling species as a group have had only a slight tendancy toward this vertical displacement. For example, the most extreme case of this vertical bias for fouling species occurred in 

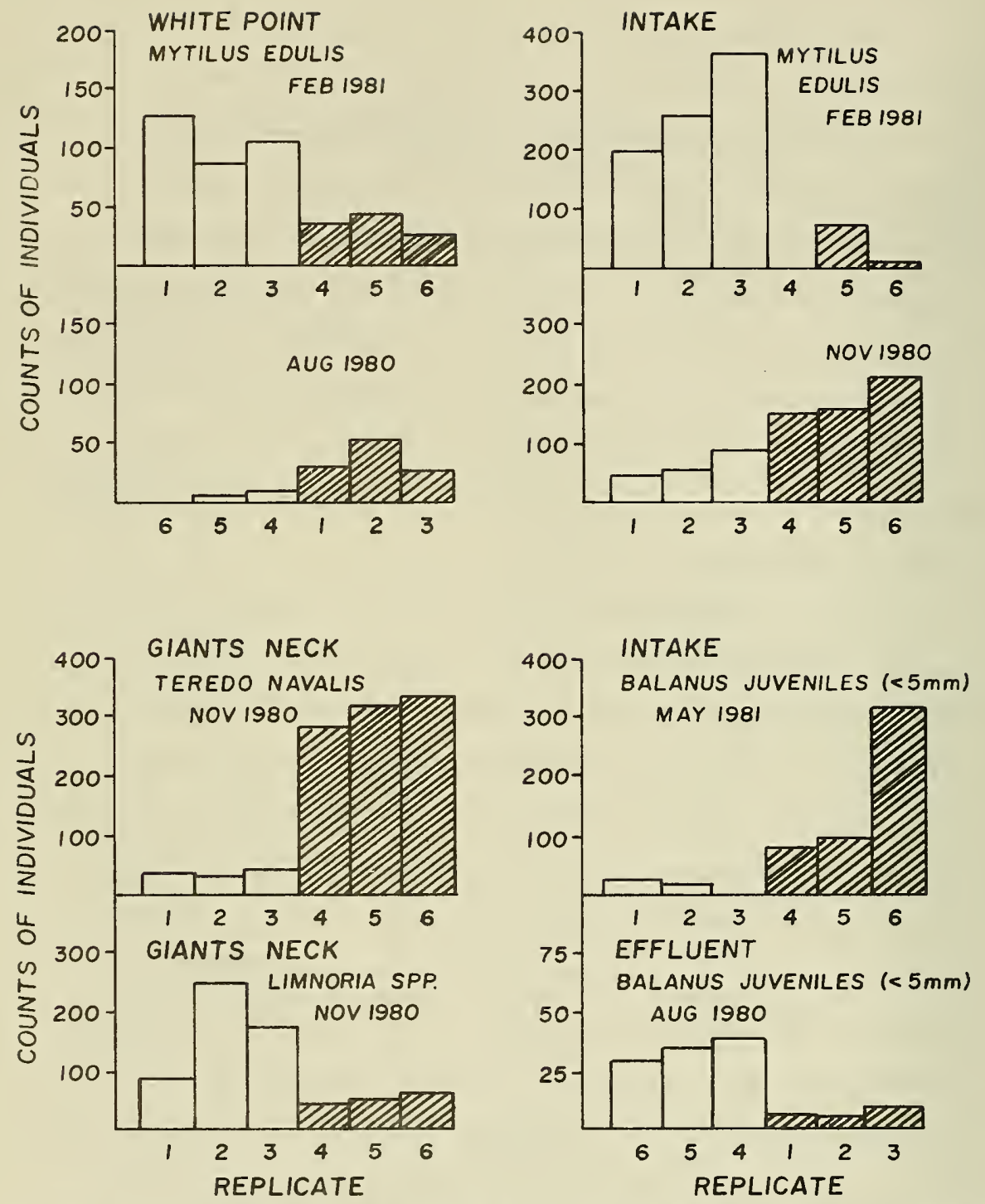

Figure 5. Histograms of the abundance for individual species on exposure panels, showing the bias in abundance between (replicates 1-3) on the upper level and panels (replicates 4-6) on the lower level of a rack. Note: In August 1980 replicates $1-3$ re on the lower level and replicates 4-6 were on the upper level. 


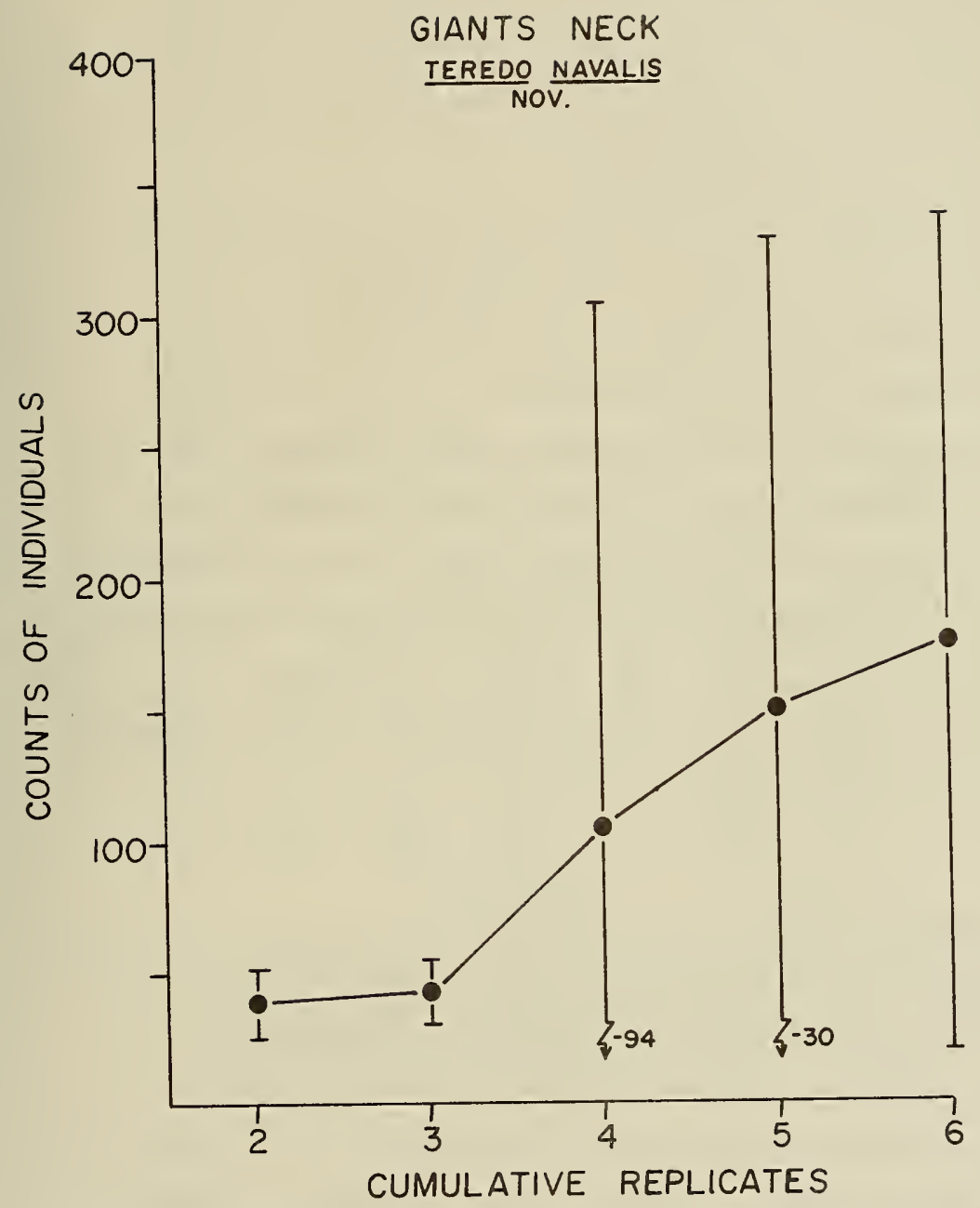

Figure 6. Cummulative mean abundance of Teredo navalis (shipworm) over six replicate panels at Giants Neck in November 1980, illustrating the increase in the $95 \%$ confidence interval around the mean (variance) due to the vertical displacement of panels (replicates 1-3 on top and 4-6 on bottom of rack). 
August 1981 at Giants Neck and resulted in a similarity dendrogram where there is only a $3.2 \%$ difference between the replicates on the upper level of the rack and those on the lower level (Fig. 7). Therefore, the vertical bias in the distribution and abundance of species can affect replicated data in a variable way depending on which species, stations, and exposure periods are considered. In extreme cases true replication has been lost for a series of six panels.

Natural variability. Variability in the data caused from seasonal effects and year to year trends has been reported since 1968. Since 1979, the assessment of quantitative data from quarterly collection periods has helped to define seasonal effects. Four well colonized samples, whose consecutive exposure periods are over lapped by three months, have established seasonal trends in community composition and abundance over the last three years (Fig. 8). These trends are based on the seasonal reproduction periods of the various fouling and woodboring organisms in the Millstone Point area. Three years of sampling have provided data concerning how these seasonal trends in species composition and abundance can vary from year to year.

\section{Adequacy of six replicates}

For this evaluation, the adequacy of six replicate panels for sampling fouling and woodboring organisms will be assessed based on the effectiveness with which species are collected and the percision with which their abundances can be estimated. Species area curves will be used to illustrate how many replicate panels are necessary to adequately sample the community. The $95 \%$ confidence 1 imits surrounding the mean will be used to describe the precision with which abundances can be estimated. 


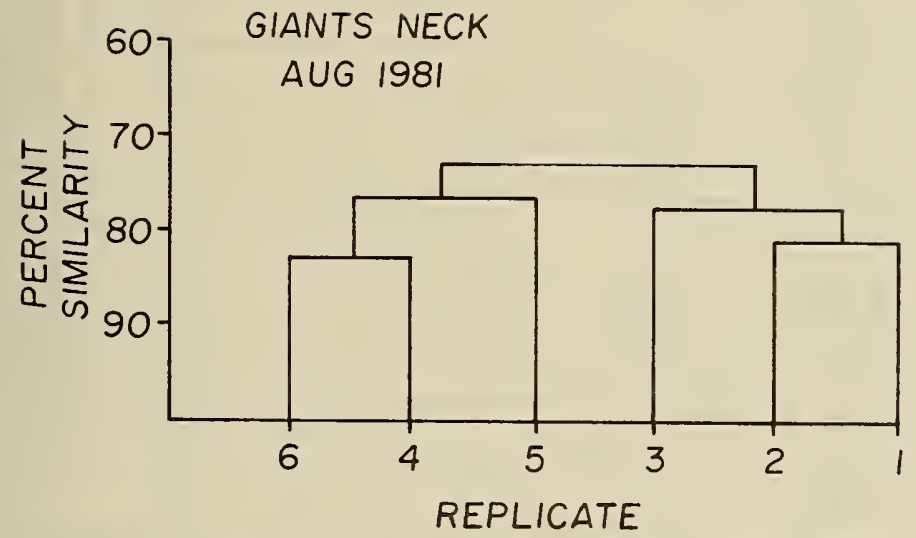

Figure 7. Dendrogram resulting from flexible sorting $(\beta=-0.25)$ of Czekanowski similarity coeficients using replicate counts of individuals on asbestos panels at Giants Neck in August 1981, illustrating the similarities in abundance between replicates $1-3$ on the upper level and replicates 4-6 on the lower level of the rack. 

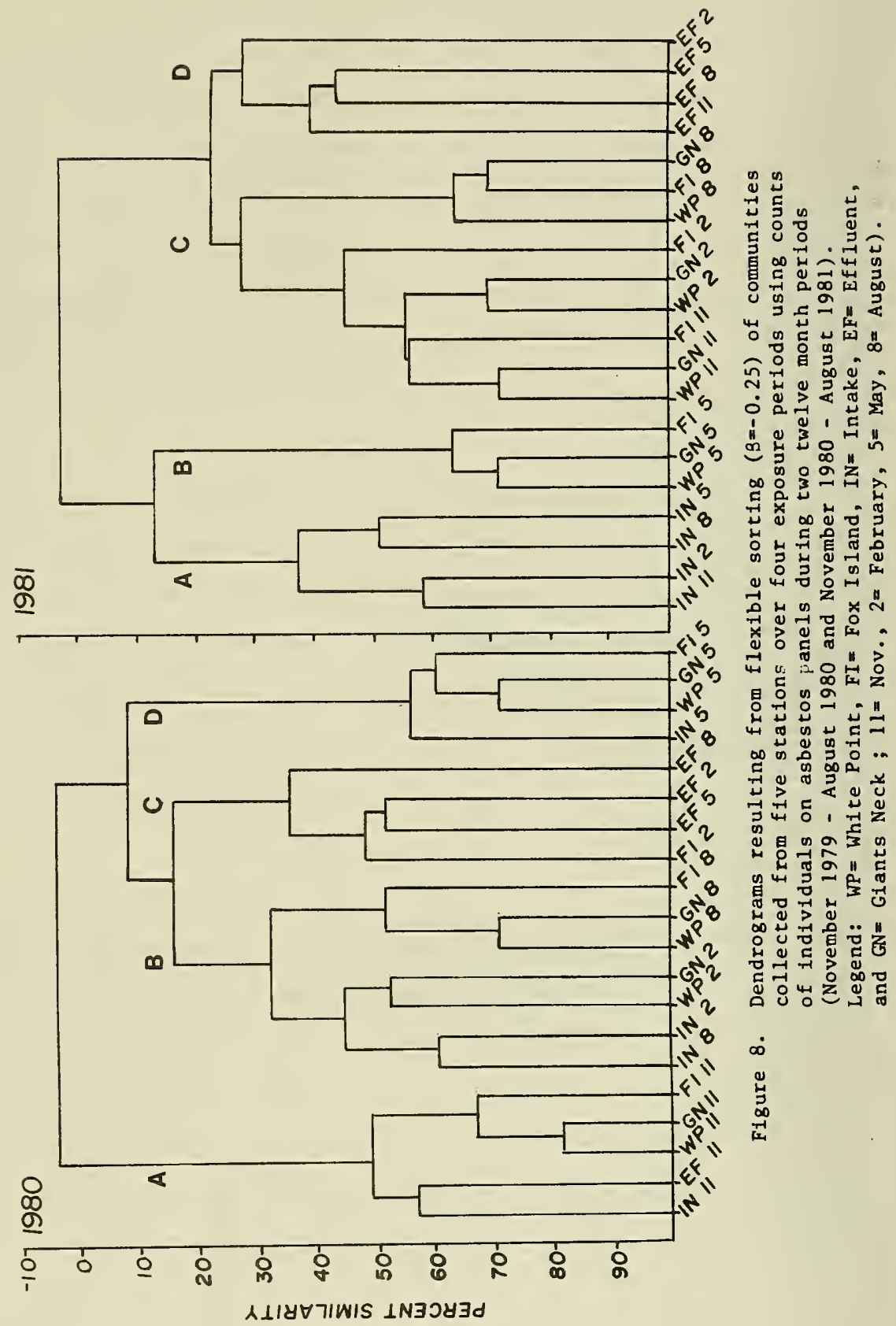
Species area curves. A general leveling off in the accumulation of species over the six replicate panels is illustrated by species area curves for communties collected at Giants Neck and Effluent (Fig. 9). Similar trends occur at all stations in May and August, when the numbers of species peaked for the year at Effluent and Giants Neck (Fig. 10). Three replicate panels accounted for a low of $74 \%$ of the species on six replicate panels in August at Effluent to a high of $95 \%$ in August at Giants Neck. Over the year, three replicate panels generally accumulated $82 \%$ of the species on the six replicate panels and four replicates accumulated approximately $90 \%$.

Total community estimates. Variance associated with the estimate of total abundance for the parameters canopy cover, primary cover, and density is reduced quickly with the accumulation of the first three replicates and more slowly over the last three (Fig. 11). These trumpet diagrams were created by plotting the $95 \%$ confidence interval (CI) about the mean as a percent of the mean $\left(\%=\frac{\text { mean } \pm C I}{\text { mean }} \times 100\right)$. The collection periods in 1980 and 1981 were selected because they represented peak periods for each measurement.

Canopy cover is the percentage of a panel surface which is covered (shaded) by the vertical growth of an attached organism and the CI is reduced to $61-74 \%$ of the mean after six replicates. Primary cover is the percentage of a panel surface which is directly obscured by an organism's attachment and the CI is reduced to $28-40 \%$ of the mean after six replicates. Density refers to the total number of solitary organisms, both free and attached, on a panel and has the greatest precision of the three parameters with the CI reduced to within $21-23 \%$ of the mean after six replicates. In comparison, after three replicates these CI's are reduced to $94-163 \%, 57-58 \%$, and $37-64 \%$, respectively. 

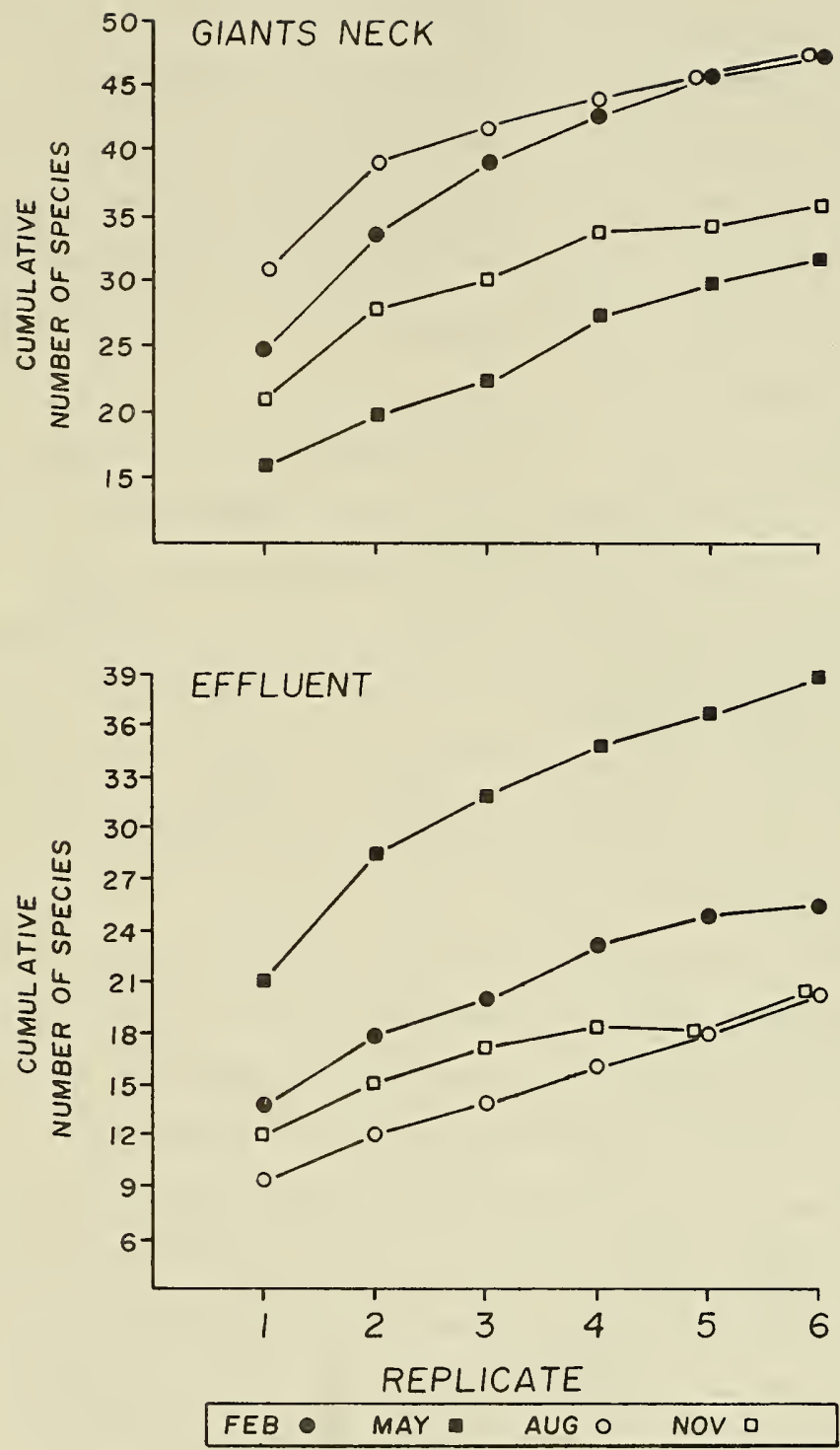

Figure 9. Species area curves based on a three year average of $10 \mathrm{random}$ assortments of six replicate panels, showing how the numbers of species are accummulated over six replicates during each exposure period at Giants Neck and Effluent. 

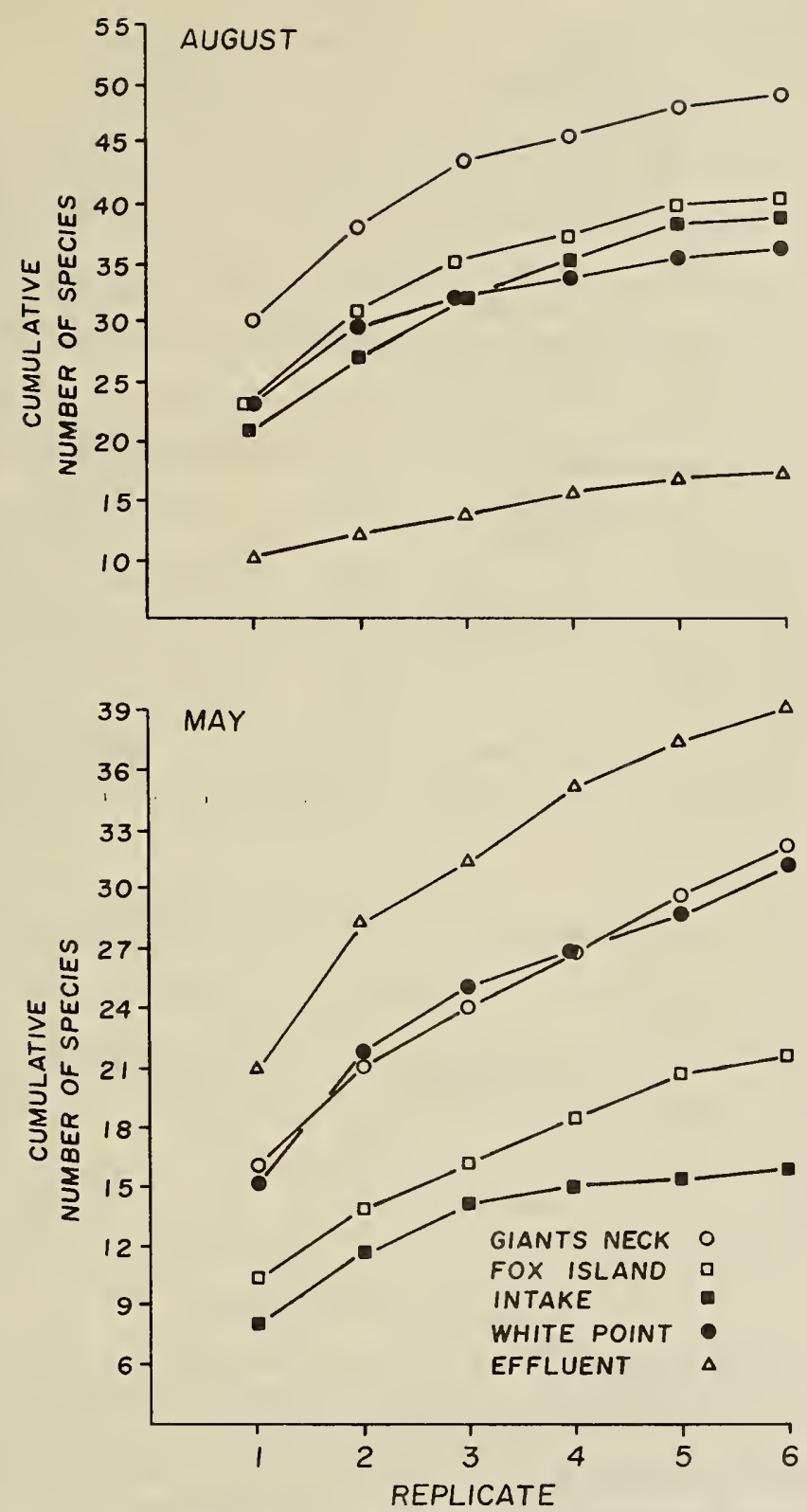

Figure 10. Species area curves based on a three year average of 10 random assortments of six replicate panels, showing how the numbers of species are accummulated over six replicates during the August and May exposure periods for all stations. 


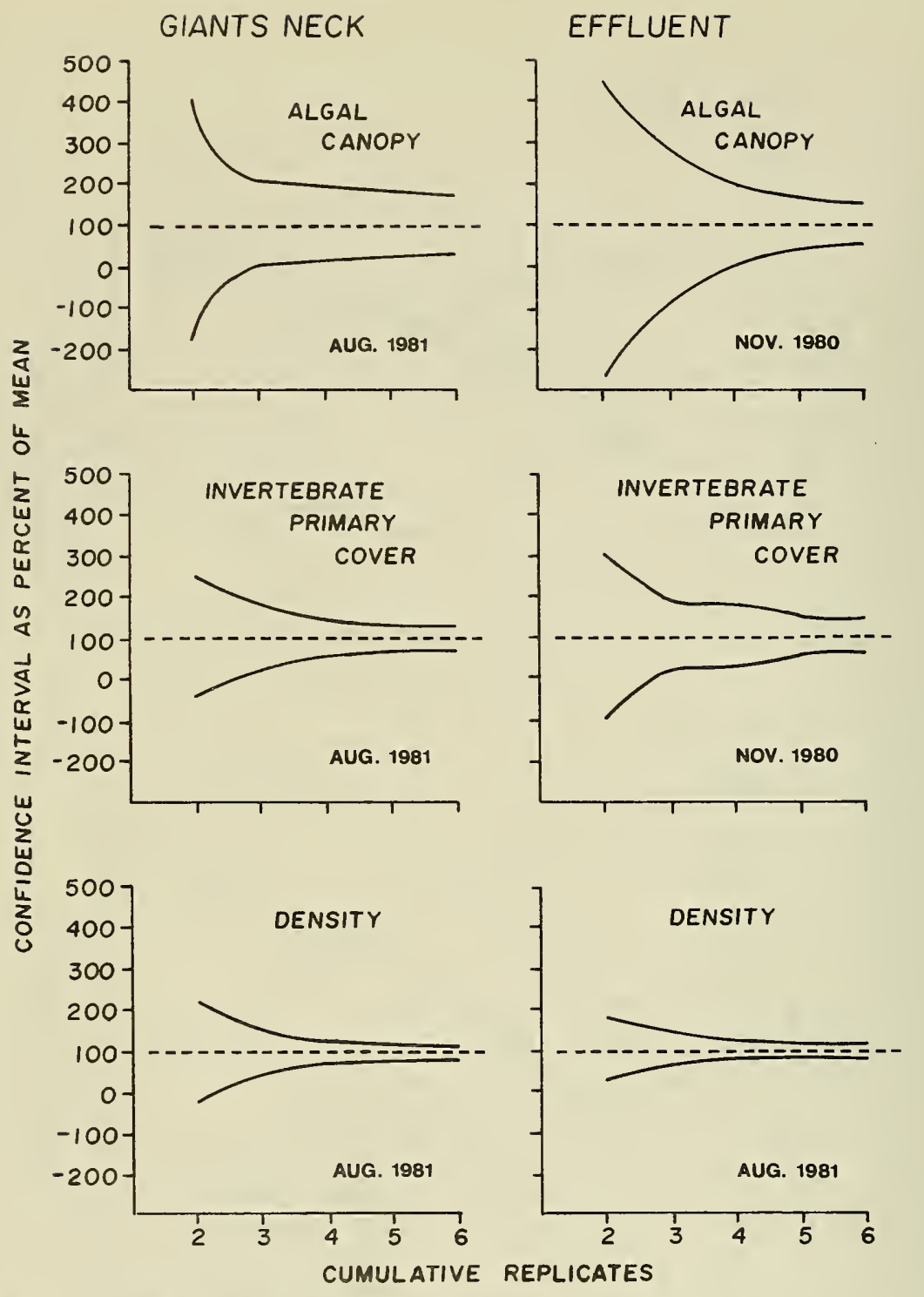

Figure 11. Trumpet diagrams of the upper and lower $95 \%$ confidence interval (CI), expressed as a percent of the mean ( $\%=$ (mean \pm CI/ mean) $x 100)$, and plotted versus sample size, based on the average of 10 random samples of six replicate panels at Giants Neck and Effluent. The data represents mean percent canopy cover, mean percent primary cover and mean percent density during peak occurrences. 
Individual speciés estimates. Variance associated with abundance (counts) estimates for individual species is greater than that described for total community density. Three species, Teredo navalis, Balanus crenatus, and Mytilus edulis, collected at Giants Neck and Effluent in 1980 were selected to illustrate the range in the precision of the estimates for single species ( $\mathrm{Fig} .12$ ). The $95 \%$ confidence interval about the mean of six replicates for these species ranged from $119 \%$ of the mean for I. navalis at Giants Neck in November 1980 to $20 \%$ of the mean for $\underline{M}$. edulis at Giants Neck in August 1980.

Four rather than three replicates appear most approprlate for maintaining the precision of these estimates with a reduction in sampling effort. After six replicates the confidence interval for $\underline{T}$. navalis is within $73-119 \%$ of the mean; that for $\underline{B}$. crenatus is within $35-93 \%$ of the mean, and $\underline{M}$. edulis is within $20-23 \%$ of the mean. In comparison, after four replicates these percents are $105-200 \%, 49-101 \%$, and $27-35 \%$, respectively.

The differences in precision between total community estimates of abundance and individual species estimates of abundances might be related to panel location, low abundance, or species subtitution. Panel location was previously shown to affect individual species abundances by increasing inter-panel variance. For example, the distribution of $\underline{T}$. navalis at Giants Neck in November 1980 was shown to have considerable bias due to panel location, which resulted in the low precision of the six replicate mean. However, the low precision of the abundance estimates for $\underline{T}$.

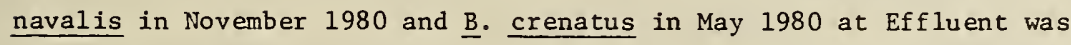
primarily caused by their low abundances (or patchiness) on the panels. Species substitution from one replicate to the next has not been identified 


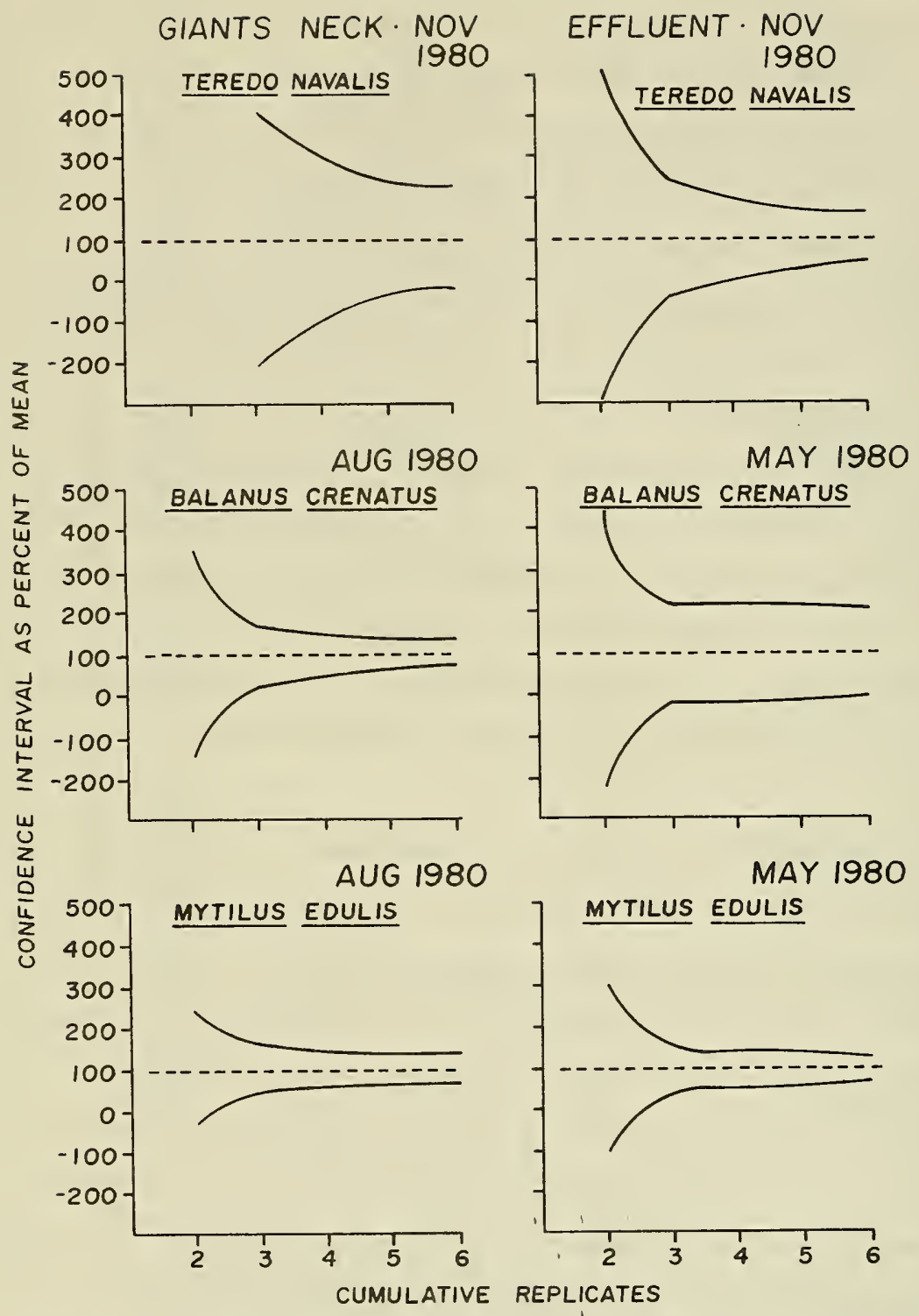

Figure 12. Trumpet diagrams of the upper and lower $95 \%$ confidence interval (CI), expressed as a percent of the mean (\%=(mean $\pm \mathrm{CI} /$ mean) $\times 100)$, and plotted versus sample size, based on the average of 10 random samples of six replicate panels at Glants Neck and Effluent. The data represents peak abundances of three species in 1980. 
in our study, but Schoener (1982) suggests it is related to the higher precision of total community abundances versus those for individual species. The similarity in niches of the species (e.g. Corophid and Caprellid amphipods, barnacles, and sponges) collected on exposure panels supports her theory. The availability of freespace on panels is an important factor in colonization (Osman 1977) and how quickly this is occupied eventually determines the abundances of individual species from one replicate to the next.

Although trumpet diagrams describe the tightening of the confidence interval about the mean, they do not indicate how the estimate of the mean changes as the number of replicates is increased. Two species common between replicate panels and exhibiting large differences in abundances were selected from communities collected on asbestos panels at Giants Neck and Effluent in August and May to illustrate how the mean fluctuates as the number of replicates is increased (Figs. 13 and 14). Similarly, the fluctuation in means were also compared for woodborers common to each station (Fig. 15). Even though there were fluctuations in the value of the means as the number of replicates was increased, significant changes (based on overlap of the $95 \% \mathrm{CI}$ ) did not occur in this estimate in any of the eight species considered. In fact, the cumulative mean of four replicates closely approximates that of six. A similar case might be made for three replicates, but the effects of patchiness on species of low abundance make four replicates a better choice.

\section{Adequacy of data base}

Three years of qualitative and quantitative data have been collected using the six replicate and six month exposure period method and provide 


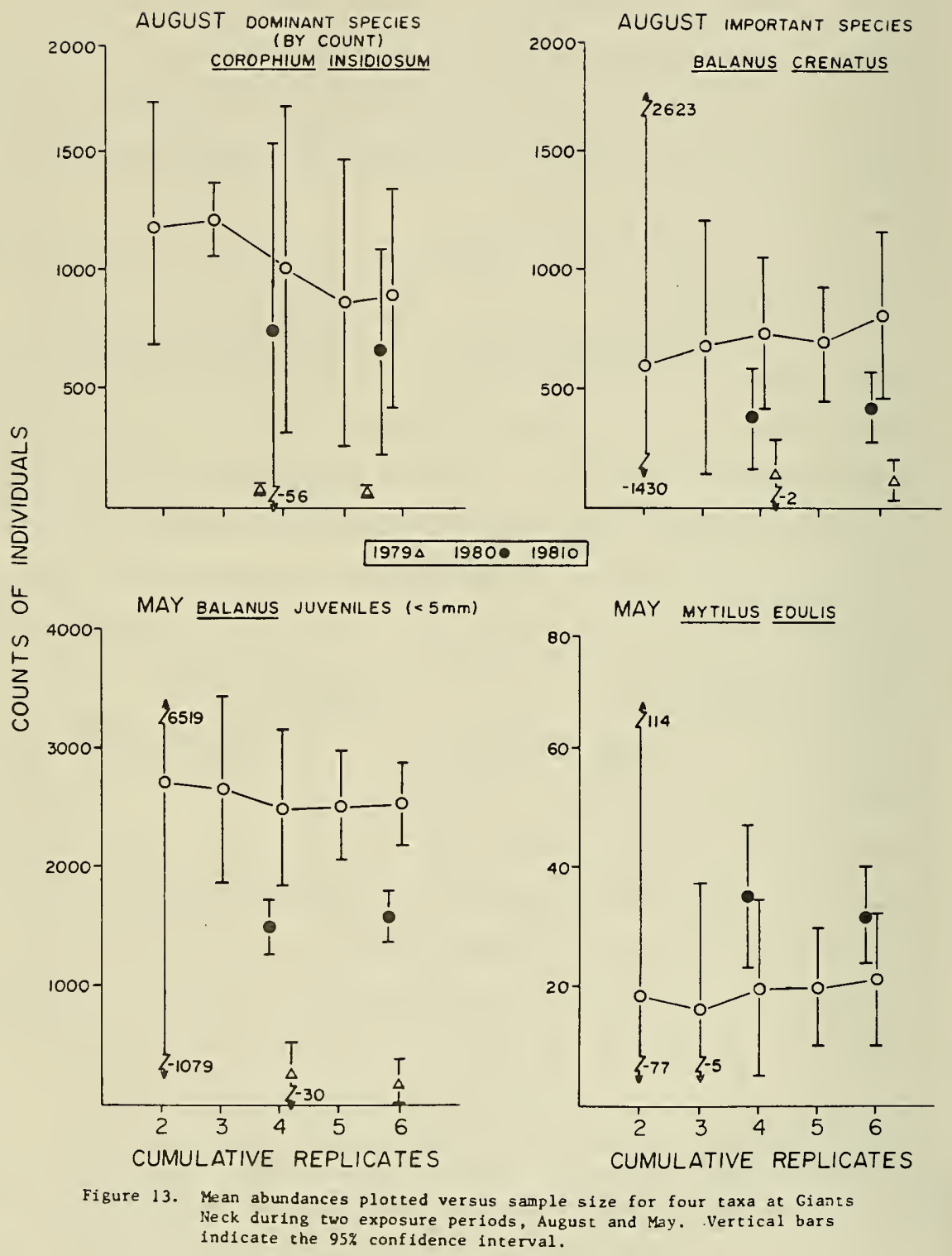




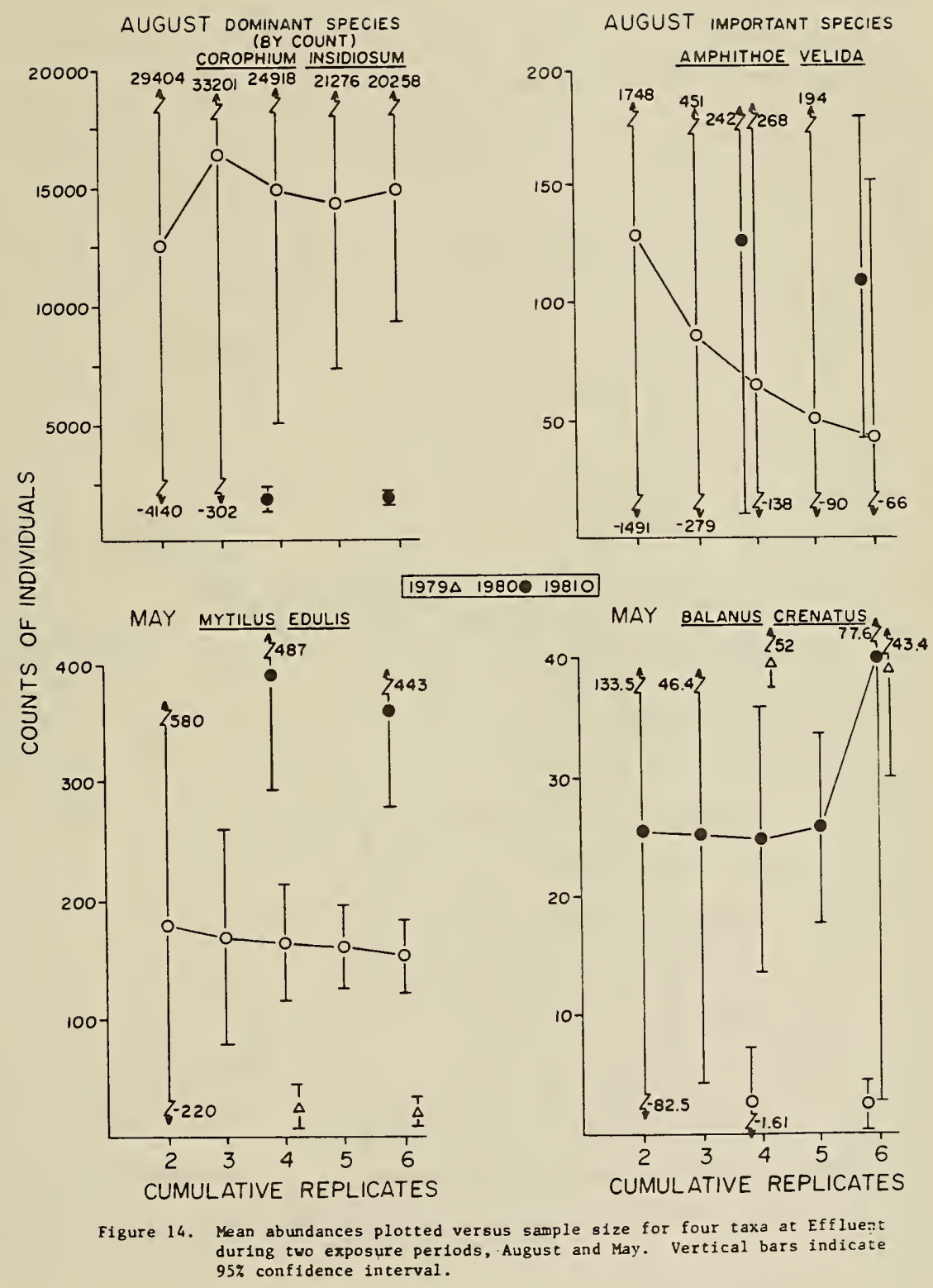



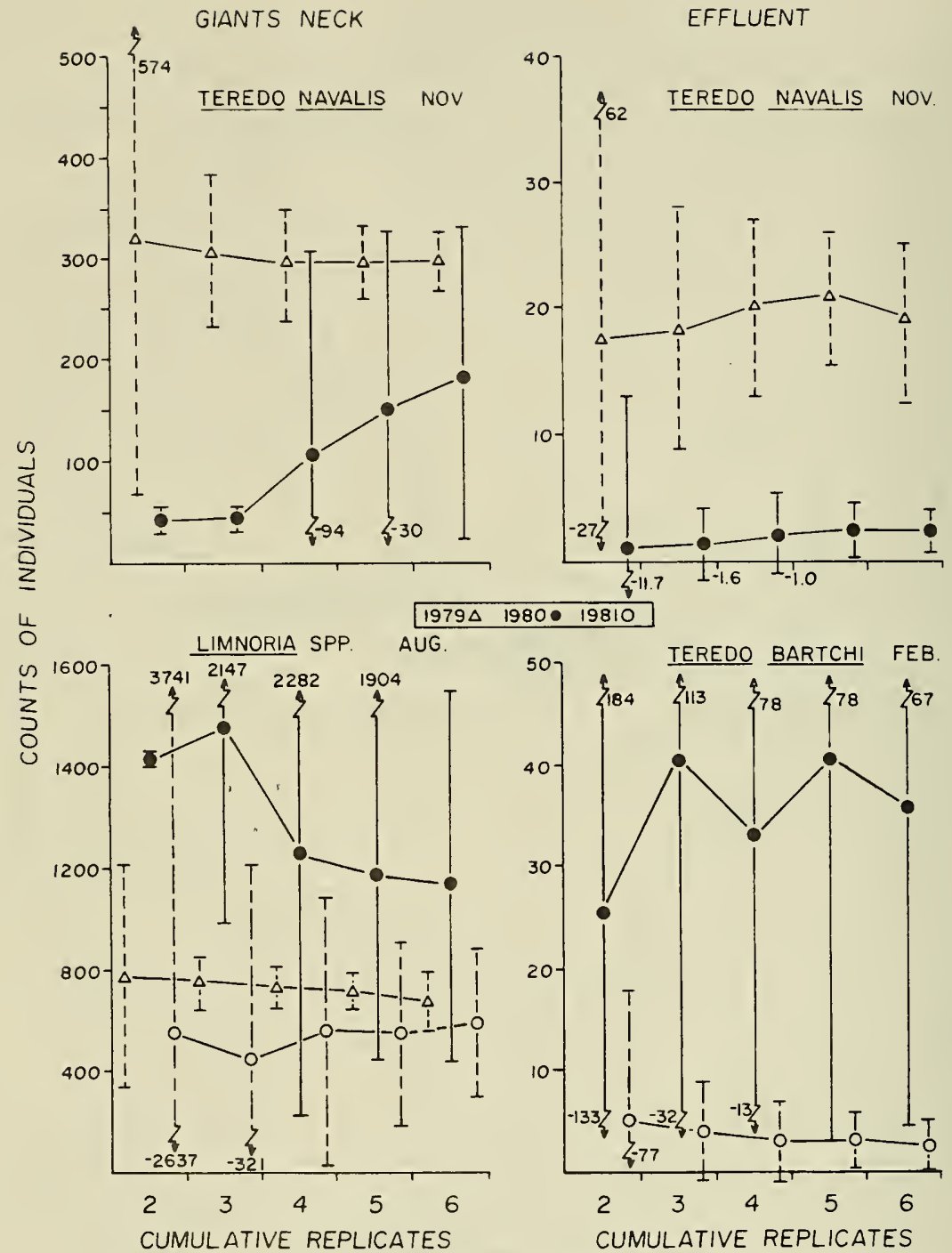

$980 \cdot 19810$
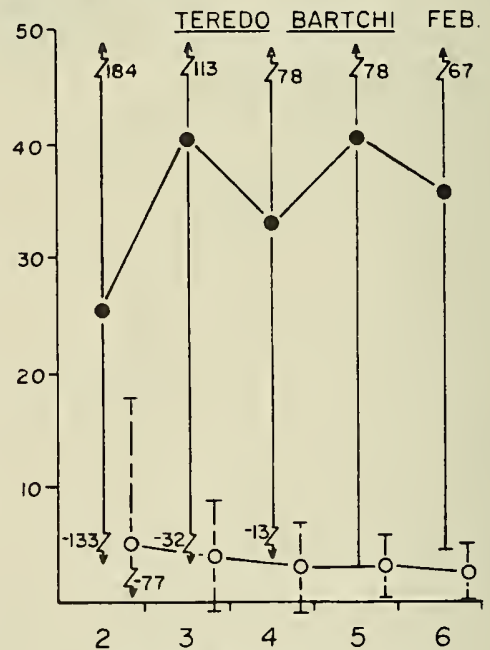

CUMULATIVE REPLICATES

Figure 15. Mean abundances plotted versus sample size for three species of woodborers at Giants Neck and Effluent during their peak abundances. Vertical bars indicate $95 \%$ confidence interval. 
the data base for making future assessments of power plant impacts. These impact assessments eventually depend on how well our present data base def ines the natural varlablity assoclated with communty composition and abundance. Interstation similarities have been identified from 1979-1981 and there is an annual pattern to these relationships (Fig. 3). Seasonal trends in community composition and abundance have also been consistent from year to year (FIg. 8). However, the abundances of individual species have been found to fluctuate significantly from year to year (Figs. 13, 14, and 15). Even so, three years of data have provided an assessment of the natural variance associated with these trends and fluctuations and are considered adequate for quantitatively evaluating the ecological significance of future changes in species composition and abundance.

In summary, the evaluation of exposure panel data collected from 1979-1981 suggests that future assessments of power plant impacts can be quantitatively defined. Species area curves indicate that four to six replicate panels can effectively collect fouling and wood-boring species. Trumpet diagrams show a higher degree of confidence in the abundance estimate for total community density than that for individual species. However, the latter statistic is probably more sensitive to environmental impacts. Four replicate samples, appear sufficient to account for interpanel variability using abundance data. Mean abundances for individual species did not significantly change with an increase in the number of replicate samples. Three years of data have been used to assess natural variability associated with seasonal trends and yearly fluctuations in community composition and abundance. 


\section{FUTURE STUDIES}

Without a doubt, woodborers remain the most important species monitored by exposure panels, given the economic consequences should power plant operation cause increases in their abundances. Teredo bartschi, a non-native species common to subtropical coastal waters, has been collected from our undiluted effluent since 1975. The presence of this immigrant species raises the question as to its potential impact on local environments with a doubling of the flow rate of the thermal effluent at MNPS during three unit operation. The litigation resulting from the destruction of docks and pilings by woodborers in Oyster Creek, New Jersey and the eventual out-of-court settlement of Jersey Central Power and Light Company for 2.5 million dollars with marina owners created the present concern for power plant impacts on woodborers. The Oyster Creek Nuclear Generating Station (OCNGS) changed the salinity of two previously freshwater creeks and raise the temperature of these poorly circulated areas by 3 to $6^{\circ} \mathrm{C}$, which caused a severe increase in destruction of wooden structures within the Oyster Creek and Forked River areas (Turner 1973; Maciolek-Blake et al. 1981). At MNPS, the thermal effluent is discharged into a well circulated, open coastal area, where docks and pilings are scarce. However, the species most responsible for wood destruction in the Oyster Creek area is $\underline{T}$. bartschi, the same non-native species collected in the MNPS undiluted effluent (Hoagland and Turner 1980). This concern for potential power plant impacts caused by woodborers was reflected in the NRC's request for us to specifically address this problem in the Millstone Point area prior to three unit operation (Appendix III). 
Since we have established the data base needed for assessing future power plant impacts on fouling and wood-boring communities, we propose to begin a concentrated study on shipworms to learn more about their Iffe histories in this area. In 1978, a two year gonad development study on shipworms, $\underline{T}$. navalis and $\underline{\mathrm{T}}$. bartschi, was completed by Battelle (1979). They described the state of gonad developement of shipworms throughout the year, but obtained little data concerning $T$. bartschi. Growth data and fecundity data for these two species in the Millstone area are still poorly understood. Therefore, a study is plannned to obtain data concerning their thermal tolerances, growth rates, and fecundity (Appendix IV).

In addition, a field study will be conducted to determine the present rate of destruction of common types of wood used in building docks and lobster traps (Appendix IV). Several species of wood and chemical treatments of them will be placed in areas around the Millstone Point and monitored once a year over a period of five years to detect changes in their rates of destruction. This study will more directly answer whether or not power plant operation will affect the natural rate of property damage currently experienced by dock owners and lobstermen. Approximately two years prior to the operation of Millstone Unit 3 , we will resume the $s i x$ replicate and $s i x$ month exposure period study. This program includes subtidal species and woodborers which are not sampled by other Millstone programs. The dominant species comprising these communities have proved to be useful ecological indicators of water quality. Resuming these studies two years prior to three unit operation will increase our data base and provide a continuum between before and after operation studies. To improve the exposure panel study four modifications should be considered. 
1. Reduction of replicate samples from six to four panels, which can be accomplished without significant losses in information.

2. Speciation of algae should be curtailed because these species are more intensively treated within the Rocky Shore Study.

3. Asbestos and wood panels should be deployed separately to reduce as much variability as possible in collecting fouling and wood-boring species, respectively.

4. Depending on the results of the woodborer life histories studies in the next two years, additional research may be required to field vertfy conclusions drawn from laboratory studies.

\section{CONCLUSIONS}

We believe the past program has established an adequate historical base from which future power plant effects can be detected. In addition, proposed studies concerning the temperature tolerance, growth, and fecundity of shipworms will refine our ability to assess any impacts which thermal incursions could have on indigenous and non-native woodboring species. Data on the rates of destruction of common building materials caused by woodborers will provide an important link between our monitoring studies and the actual concerns of local residents. Finally, resumption of the exposure panel studies prior to three unit operation will provide an update of our present data base and continuity between the preoperational and operational phases of the investigation. 
Battelle. 1978. Exposure panel variability study Millstone. A special report to Northeast Utilities Service Company. $13 \mathrm{pp}$.

- 1979a. Exposure panel variability study Millstone. A special report to Northeast Utilities Service Company. $9 \mathrm{pp}$.

- 1979b. A monitoring program on the ecology of the marine environment of Millstone Point, Connecticut area. Annual Report for the year 1978. Presented to Northeast Utilities Service Company.

Brown, R.T. and S.F. Moore. 1977. An analysis of exposure panel data collected at Millstone Point, Connecticut. MIT, Cambridge, MA. Rep No. MIT-EL 77-015. $119 \mathrm{pp}$.

Cairns, J. Jr. (ed.). 1982. Artificial substrates. Ann Arbor Science Publisher, Inc., Ann Arbor, MI. 279pp.

Cory, R.L. and J.S. Nauman. 1969. Epifauna and thermal additions in the upper Patuxent River estuary. Chesapeake Sci. 10:210-217.

Frame, D.W. 1968. Epibiota attached to wooden panels on the Cape Cod Canal, Sandwich, Massachusetts. M.S. Thesis, Univ. of MA., Amherst. 146pp.

Hillman, R.E. 1975. Environment monitoring through the use of exposure panels. Pages 55-76 in S.B. Saila ed. Fisheries and energy production. Lexington Books, D.C. Heath Co., Lexington MA.

- 1977. Techniques for monitoring production and growth of fouling organisms at power plant intakes. Pages 5-9 in L.D. Jensen ed. Biofouling control procedures, technology and ecological effects. Marcel Dekker, Inc. NY.

Hoagland, K.E. and R.D. Turner. 1980. Range extensions of teredinids (shipworms) and polychaetes in the vicinity of a temperate zone nuclear generating station. Mar. Biol. 58:55-64.

Maciolek-Blake, N., R.E. Hillman, P.I. Feder and C.I. Belmore. 1981. Annual report for the period December 1, 1979 to November 30, 1980, on study of woodborer populations in relation to the Oyster Creek Generating Station to Jersey Central Power and Light Company. Battelle-William F. Clapp. Laboratories. Report No. 15040. 15pp.

NAI (Normandeau Associates, Inc.). 1979. Seabrook ecological studies 19761977. Estuarine panel studies. Coastal panel studies. Tech. Rep. VII-5: Pages 311-436 prepared for Public Service Company of New Hampshire.

Nauman, J.K., and R.L. Cory. 1969. Thermal additions and epifaunal organisms at Chalk Point, MD. Chesapeake Sci. 10:218-226

Naylor, F. 1965. Effects of Heated effluents upon marine and estuarine organisms. Adv. mar. Bio1. 3:63-103. 
NUSCo (Northeast Utilities Service Co.). 1982. Annual report, 1981. Monitoring the marine environment of Long Island Sound at Millstone Nuclear Power Station, Waterford, CT.

Osman, R.W. 1977. The establishment and development of a marine epifaunal community. Ecol. Monogr. 47:37-63.

, R.W. Day, J.A. Haugsness, J. Deacon, C. Mann. 1981. Final report, The effects of San Onofre Nuclear Generating Station on sessile invertebrate communities inhabiting hard substrata (including experimental panels). Hard Benthos Project, Mar. Sci. Inst., Univ., S.B. 223pp.

Pritchard, A.M. 1980. Fouling-science or art. Effluent Water Treat. J. $20: 172-174$.

Schoener, A. 1982. Artificial substrates in marine envirọnments. Pages 1-22 in J. Jr. Cairns ed. Artificial substrates. Ann Arbor Science Publishers, Inc., Ann Arbor, MI. 279pp.

Turner, R.D. 1973. In the path of a warm saline effluent. Amer. Malacol. Union Bul1. 39:36-41.

WHOI (Woods Hole Oceanographic Institution). 1952. Marine fouling and its prevention. Contribution, 580. U.S. Naval Inst., Annapolis, MD. 388pp.

Young, J.S., and A.B. Frame. 1976. Some effects of a power plant effluent on estuarine epibenthic organisms. Int. Revue ges. Hydrobiol. 61:37-61. 


FISH ECOLOGY :

TRAIL AND SEINE EVALUATION . 



\section{INTRODUCTION}

The Millstone Nuclear Power Station (MNPS) located in Waterford, Connecticut, consists of two operating electric generating plants and a third plant scheduled to begin operation in 1986. The MNPS currently uses $5.3 \times 10^{6} \mathrm{~m}^{3}$ of water per day for cooling purposes and returns this water to Long Island Sound with an increased temperature $(\Delta-t)$ of $12{ }^{\circ} \mathrm{C}$ (NUSCo 1982). During three-unit operation, the volume of cooling water requried by MNPS will increase to $10.2 \times 10^{6} \mathrm{~m}^{3} /$ day but the $\Delta-t$ will drop to $10^{\circ} \mathrm{C}$ above ambient (NUSCo 1982). Northeast Utilities Service Company (NUSCo) has established an extensive monitoring program at their Environmental Laboratory (NUEL) to assess the impact of construction and operation of the power plants on indigenous fish populations. Impacts from MNPS may be expected to arise from several sources. Larger adult fish may be removed from the population by impingement on the intake screens. Larvae and small fish may be removed during entrainment through the cooling water system. Those populations experiencing such losses would, then, be subject to increased mortality rates. The effects of increased mortality rates on finfish abundances are varied (Ricker 1975) and the magnitude of the effects depends on the size of the increased mortality as well as on the size and age structure of the affected population and any compensatory mechanisms in the reproductive cycle. Additionally, the geographical distribution of local fish populations may be altered in response to thermally or physically altered habitats. Localized water temperature increases could either attract fish to or exclude fish from areas that did not meet their thermal requirements. Physical alteration by rip rap accumulation or bottom 
scouring or dredging could also attract or exclude fish depending on the species' habitat preferences.

To meet the purpose of the monitoring program and assess potential impacts 1 isted above, the data collected should allow us to:

1) describe the occurrence, distribution and relative abundance of potentially impacted finfish in the Greater Millstone Bight

2) contribute information with which to distinguish naturally occurring changes in such populations from those resulting from power plant related impacts

3) describe changes in community composition with respect to power plant impacts (EAC meeting, May 1979).

The trawl sampling program was established in April 1973 to monitor the demersal fish. Initially, one $15 \mathrm{~min}$ haul was taken biweekly from each of seven stations. The program expanded to 11 sampling stations in 1976. By October of 1977 it had evolved into the current program of triplicate hauls covering $0.69 \mathrm{~km}$ taken biweekly at six representative stations.

The seine sampling program was established in 1969 to monitor the shore-zone fish. A preliminary study (Battelle 1973) indicated that there was no difference in the numbers of fish collected from the shore zone at different tidal stages and thus all samples have been collected in the two hours preceding high tide. Initially, samples were collected in February, May, July, September and December at four stations. The program was expanded to include June, August and October samples at a total of six stations. 
To determine if the data from the trawl and seine programs were, in fact, providing adequate information to meet the objectives, an evaluation of these programs was undertaken. The results from this evaluation are presented in this report along with recommendations for changes necessary to more efficiently meet the objectives.

\section{A. Trawls}

\section{MATERIALS AND METHODS}

Sampling sites

A total of eleven different sites have been sampled at one time or another since 1973. They were designated 1, N2, 4, NB, JC, 7, TT, 9, 10, IN, and $B R$ and are shown in Fig. 1.

\section{Co11ections}

Beginning in March, 1973, 15-minute hauls were made biweekly using a $9.1 \mathrm{~m}$ Wilcox otter trawl with a $0.6 \mathrm{~cm}$ codend 1 iner at stations 1,4 , JC, 7, TT, 9 and 10. From March through May a single $15 \mathrm{~min}$ tow was made at each station. In an attempt to increase the precision of the catch estimates, replication was begun in June 1974. During June and July duplicate hauls were made at one station chosen randomly. In August, three tows were taken at one randomly chosen station.

About this time, investigations were being pursued to determine the best location for the proposed intake of Unit 3. In September of 1974 station IN was added and duplicate tows were begun at TT, 10 and IN (all 


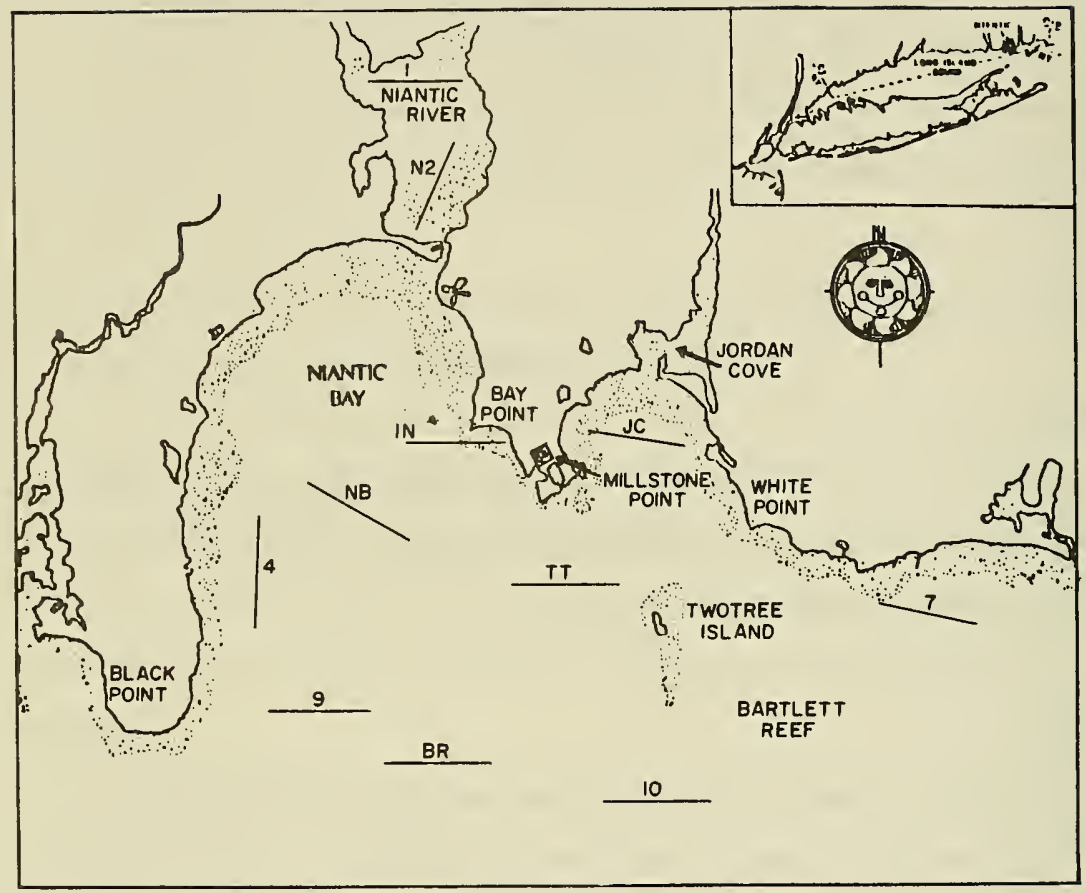

Figure 1. Location of trawling stations. 
potential locations for the Unit 3 intake) while one tow was collected at all other stations. This program continued through January 1975.

In February 1975, NB was added to get a more representative sampling of Niantic Bay. Duplicate hauls were made here and at TT, 10 and IN and at one randomly chosen station. Sampling began at N2 in June of 1975 to obtain more information on the demersal finfish community in the Niantic River. Through January, 1976, two tows were made at NB, TT, 10, IN and one randomly chosen station, and single hauls were made at the other stations.

In February 1976, BR was added because the area was being considered as another potential site for the Unit 3 intake. Since that time three tows have been made at N2, NB, JC, TT, IN and BR. These 6 stations are believed to be representative of the different demersal environs around Millstone Point. Through the end of 1976, a single 15-minute tow was completed at the remaining 5 stations. These stations $(1,3,7,9$ and 10) were dropped for several reasons. Station 1 was dropped because the bottom cover of algae and eelgrass had increased to the point where the traw1 was no longer efficient. Additionally, N2 was felt to better represent the Niantic River system. Station 4 was dropped because it was similar to NB. Station 7 and 10 were dropped because the bottom was too rocky and the trawl efficiency was low. Station 9 was dropped because it was very close to BR.

In October 1977, the current sampling program was adopted. The unit of effort was changed from $15 \mathrm{~min}$ to $0.69 \mathrm{~km}$ over the bottom. While unit-effort for trawls is conventionally a unit of time, it was felt that the demersal finfish population levels would be better estimated by an area swept clear unit-effort. The distance of $0.69 \mathrm{~km}$ was used because 
it was the maximum distance that could be covered at N2 and JC. Additionally, this was approximately the distance covered in 15 minutes when the boat was hauling a trawl net with the engine at idle speed and no influence of tidal current. These changes in methodology have been summarized in Table 1.

Fish in each haul were identified to lowest practical taxon, counted, and measured (total length) to the nearest $\mathrm{mm}$.

Analytical Methods

Several methods were used to analyse the demersal data. Preliminary data reduction provided such summary statistics as the percent species composition, and total and species catch per unit effort. These statistics were scrutinized and those data collected since October 1977 were used to characterize the trawl data. Subsequently, various methodologies were used to determine if any changes had occurred in these descriptive statistics. Included were tests for determining the underlying probability distribution of the data, analyses of variance, time-series analyses, and the Krumbein and Tukey (1956) method of analyzing proportions.

Historically, the trawl data were used to estimate catch per unit effort (CPUE) based on a $15 \mathrm{~min}$ tow. So that the longest possible series of data could be established, catches in a region and sampling period were summed and divided by the sum of the total time spent trawling. This number was then multiplied by 15 to give CPUE (NUSCo 1982). However, for the data collected since October 1977 (when the actual unit-effort was changed from a time basis to a distance basis) these data manipulations may have contributed undesirable variance to the catch statistics. Thus the first aspect to be investigated was the effect of changing from time 


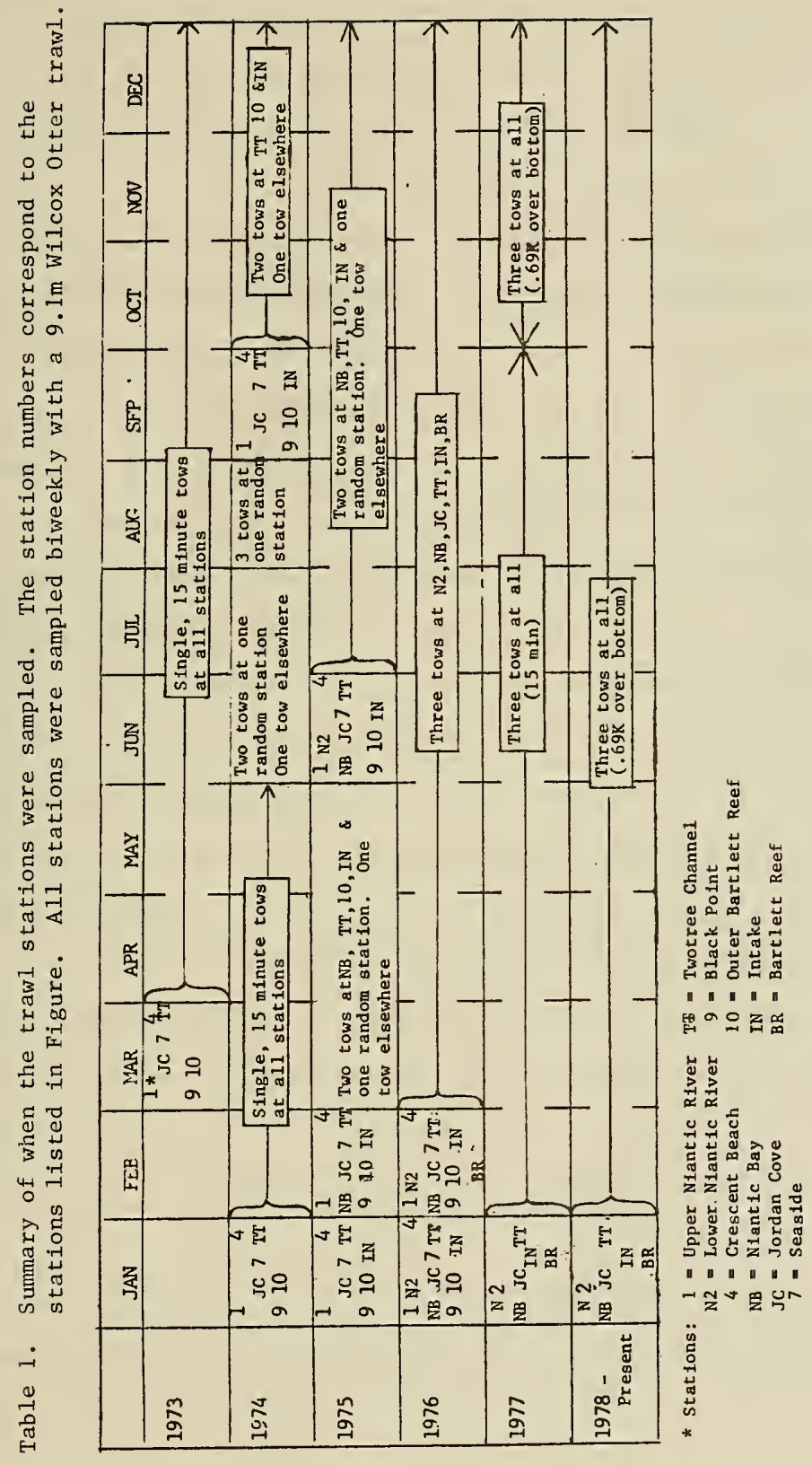


to distance as the unit-effort. This was evaluated qualitatively by comparing the frequency distributions of the tow times and the timebased CPUE statistics for before and after October 1977. Since the extant program (unchanged since 1977) was distance-based, these were the data primarily used in the evaluation analyses.

Several approaches were used on the traw1 catch data to elucidate the underlying probability distribution. The frequency distributions of the distance based CPUE were evaluated visually. The highly skewed data were suspected of having come from a negative binomial distribtuion and this possibility was investigated. To do this the mean, $m$, and a parameter, $\hat{k}$, must be known (Poole 1974). The mean was estimated by the sample mean $\bar{x}$, while $\hat{k}$ was estimated by the maximum 1ikelihood method (Bliss and Fisher 1953). Scores, $\mathrm{Z}$, were computed from trial values of $\hat{k}$ until $\mathrm{Z}=0$ in the following equation:

$$
\begin{aligned}
& Z=\Sigma\left(\frac{\left.A_{x}\right)}{\bar{k}+x}-N \log _{e}(1+(\bar{x} / \hat{k}))\right. \\
& \text { where } A_{X}=\text { accumulated frequency in all units containing } \\
& \text { more than } \mathrm{x} \text { organisms } \\
& \overline{\mathrm{x}}=\text { sample mean }
\end{aligned}
$$


The values of $\hat{k}$ were used in the probability distribution function,

$$
\begin{aligned}
P_{x} & =\frac{(\hat{k}+x-1) !}{x !(\hat{k}-1) !} \cdot \frac{R_{\hat{k}}^{x}}{q^{k}} \\
\text { where } R & =p / q \\
P & =\bar{x} / \hat{k} \\
q & =1+p
\end{aligned}
$$

to calculate the expected frequency of samples containing $\mathrm{x}$ organisms $\left(P_{x}\right)$. A chi-square statistic:

$$
\begin{aligned}
X^{2} & =\frac{\left(F_{X}-P_{X}\right)^{2}}{P_{X}} \\
\text { where } F_{X} & =\text { actual frequency of } x \text { organisms }
\end{aligned}
$$

was used to test the fit of the actual catch distribution against a negative binomial.

The adequacy of the trawl program was determined by transforming the catch $(\ln (\operatorname{catch}+\hat{\mathrm{k}} / 2))$ and using the pooled variances to determine the number of samples required to detect specified changes in the means. Typically, testing for differences between arithmetic means requires a simple subtraction:

$$
\text { Ho: } \mu 1-\mu 2=0 \text { vs } \mathrm{Ha}: \mu 1-\mu 2=\mathrm{d}
$$

For In transformed data this specified difference (d) is the ratio of the geometric means $(R)$ or $d=\ln (R)$. The following analysis of variance model:

$$
\begin{aligned}
\log _{e}(\operatorname{catch}+\hat{k} / 2)=\bar{X}+\mathrm{YR}+\mathrm{MO}+\mathrm{YR} * \mathrm{MO}+\mathrm{STA}+\mathrm{YR} * \mathrm{STA}+ \\
\text { STA } * \mathrm{MO}+\mathrm{YR} * \mathrm{MO} * \mathrm{STA}+\varepsilon
\end{aligned}
$$

was used to estimate the variances assoclated with each main and crossed effect. These were pooled to produce an estimate of the underlying variance, 
$\sigma^{2}$. The sample size, $N$, required to detect a specified difference, $d$, at various $\alpha$ and $\beta$ levels was given by Snedecor and Cochran (1967):

$$
\begin{aligned}
\mathrm{N}= & \left(\mathrm{Z}_{\alpha}+\mathrm{Z}_{\beta}\right) * 2 \sigma^{2} / \mathrm{d}^{2} \\
\text { where } \mathrm{Z}_{\alpha}= & \text { normal deviate such that the area from }-\infty \text { to } \mathrm{Z} \\
& \text { is }(1-\alpha) \\
\mathrm{Z}_{\beta}= & \text { normal deviate such that the area from }-\infty \text { to } \mathrm{Z} \\
& \text { is }(1-\beta) \\
\mathrm{d}= & \log _{\mathrm{e}} \mathrm{R} \\
\sigma^{2}= & \text { variance estimated from ANOVA }
\end{aligned}
$$

The In transformed catch data were analysed as time series. The autocorrelation structure of the data was investigated by visually evaluating the autocorrelation function (ACF) generated by the PROC ARIMA procedure of SAS. The general hypotheses being considered were that the catch did not change over time (i.e., no power plant effect). A "change" could be an increase or decrease in the average values (trend), or an alteration of the frequency or amplitude of the fluctuations (cyclical components) of the values over time. While these specific changes can be tested with time series methodology (Box and Jenkins, 1976), as a first step an alternate approach was taken. The monitoring data collected prior to the current year were used to construct autoregressive models. Because long term constant values were hypothesized, the data were not detrended (long term trend removed from the data by regression). Detrending data that are primarily the results of stochastic processes is a procedure that may give misleading results in forecasting models (Box and Jenkins, 1976). Autocorrelations between the catch at time ' $i$ ' and ' $n$ ' time units away (up to 26 in this case) were calculated. If any correlations were significantly different from zero at $\alpha=0.05$, autoregressive terms of "An" were included in the model. For example, 
if the catch of a species was found to be positively correlated with its value a year away, the forecasting model would include, in addition to a constant term, an autoregressive term for 26 lags (biweekly data points), designated A26. The resulting models were used to predict the catch for the current year. The forecasted data were compared to the actual catch by using a test statistic with an $\mathrm{F}$ distribution:

$$
F_{\text {calc }}=\frac{\sum_{i=1}^{s}\left(a_{i}-f_{i}\right)^{2} /(s-1)}{\hat{o}_{m}^{2}}
$$

where $a_{i}=$ actual data point for time period $i$

$f_{i}=$ forecasted date point for thime period $i$

$s=$ number of time periods forecasted

$\sigma_{\mathrm{m}}^{2}=$ least square estimate of the model varfance

which has $(s-1)$ and $(n-p)$ degrees of freedom where $n$ is the number of observations used to build the time series model and $\mathrm{p}$ is the number of terms estimated by the model.

To determine if the relative proportions of selected important demersal species differed in the current year from previous years (19731980), an expansion of the Krumbein and Tukey (1956) analysis of proportions was applied to the relative proportions of the 12 most abundant demersal taxonomic groups. A similar approach was used by Briggs and O'Connor (1971). The analysis consisted of using the arcsine square root transformation of the relative proportions and distributing the sums of squares as in the following analysis of variance model:

$$
\begin{aligned}
X= & x+P_{1}+Y_{i j}+S_{i j k}+T_{m}+(T Y)_{1 j m}+(T S)_{i j k m}+ \\
& R_{1}+(R P)_{i l}+(R Y)_{i j 1}+(R S)_{i j k 1}+(T R)_{1 m}+ \\
& (T R P)_{k l m}+(T R Y)_{i j l m}+(T R S)_{i j k l m}
\end{aligned}
$$


where the model components are defined in Table 2. There is no error term in this model because proportion data are multinomial. The theoretical variance (BV) is approximately $821 / \mathrm{n}$ where $\mathrm{n}$ is the average number of individuals in each sample (Bartlett 1947). The total sum of squares was apportioned following Krumbein and Tukey (1956) and the expected mean squares determined. Because changes in the relationship among taxa were of interest, $F$ values for significance tests were calculated only for terms that included taxon crossed with some other factor. The F ratios for testing the significance of the taxon $\mathrm{x}$ period and taxon $\mathrm{x}$ year interactions were "manufactured" by taking the ratio of the sum of two mean squares. The appropriate degrees of freedom were calculated using the method given by Snedecor and Cochran (1967). Table 3 summarized the effects of interest and composition of the F ratios. Determination of expected mean squares and all calculations were completed using the computer program PROC ANOVA from SAS79.

\section{RESULTS}

Since 1973, 152,223 fish representing 82 taxa have been collected from the trawl hauls. The species caught, their actual catch and relative percent composition are presented in Table 4.

The following 12 taxonomic groups were considered 'important' and were selected for further analysis. Winter flounder (Pseudopleuronectes americanus) was the dominant demersal species, making up $42 \%$ of the total catch. Scup (Stenotomus chrysops) was the second most abundant 
Table 2. Definition of percent species composition AOV model components.

\begin{tabular}{|c|c|}
\hline Component & Definition \\
\hline$x_{i j k I m}$ & $\operatorname{arcsine}\left(p_{i j k l m} / n_{i j k l}\right)^{\frac{1}{2}}$ for $p$ individuals of species $m$ in $n$ total \\
\hline & mean \\
\hline $\mathbf{P}$ & effect due to period i for the period before or after September 1979 \\
\hline Y & effect due to year $j$ (October through September) within period i \\
\hline s & effect due to season (month or quarter) $k$ within year $j$, period $i$ \\
\hline $\mathrm{T}$ & effect due to being assigned to a taxon (species) $m$ \\
\hline TP & interaction effect of taxon by period \\
\hline TY & interaction effect of taxon by year (within period) \\
\hline TS & interaction effect of taxon by season (within year and period) \\
\hline R & effect due to region (station) 1 \\
\hline RP & interaction effect of region by period \\
\hline RY & interaction effect of region by year (within period) \\
\hline RS & interaction effect of region by season (within year and period) \\
\hline TR & interaction effect of taxon by region \\
\hline TRP & interaction effect of taxon by region by period \\
\hline TRY & linteraction effect of taxon by region by year (within period) \\
\hline TRS & interaction effect of taxon by region by season (within year and period) \\
\hline
\end{tabular}


Table 3. Summary of percent species composition AOV effects of interest, mean squares (MS), derivation of $\mathrm{F}$ statistic and corresponding degrees of freedom $\left(v_{1}, v_{2}\right)$.

\begin{tabular}{|c|c|c|c|c|}
\hline Source & d. $f$. & MS & F statiotic & ${ }^{v} 11$ \\
\hline Taxon $\mathrm{X}$ Period & tp & TP & $\frac{T P+T R Y}{T Y+T R P}$ & $\frac{(T P+T R Y)^{2}}{\frac{T P^{2}}{t p}+\frac{T R Y^{2}}{t r y}} \cdot \frac{(T Y+T R P)^{2}}{\frac{T Y^{2}}{t y}+\frac{T R P^{2}}{t r p}}$ \\
\hline Taxon $\mathrm{X}$ Year & ty & TY & $\frac{T Y+T R S}{T S+T R Y}$ & $\frac{(T Y+T R S)^{2}}{\frac{T Y^{2}}{t y}+\frac{T R S^{2}}{t r s}} \cdot \frac{(T S+T R Y)^{2}}{\frac{T S}{t s}+\frac{T R Y^{2}}{t r y}}$ \\
\hline Taxon $X$ Season & ts & TS & TS/TRS & ts, trs \\
\hline Taxon X Region & $\operatorname{tr}$ & TR & TR/TRP & tr, trp \\
\hline Taxon X Region X Period & $\operatorname{trp}$ & TRP & TRP/TRY & trp, try \\
\hline Taxon $X$ Region $X$ Year & try & TRY & TRY/TRS & try, trs \\
\hline Taxon X Region X Season & trs & TRS & $\operatorname{TRS} /(821 / n)$ & trs, $n$ \\
\hline Binomial variance & $\mathrm{n}$ & $821 / n$ & & \\
\hline
\end{tabular}


Table 4. Actual catch and percent species composition of fish collected with trawts in long lsland Scurd rear the Millstone Power Station, 1973-1981.

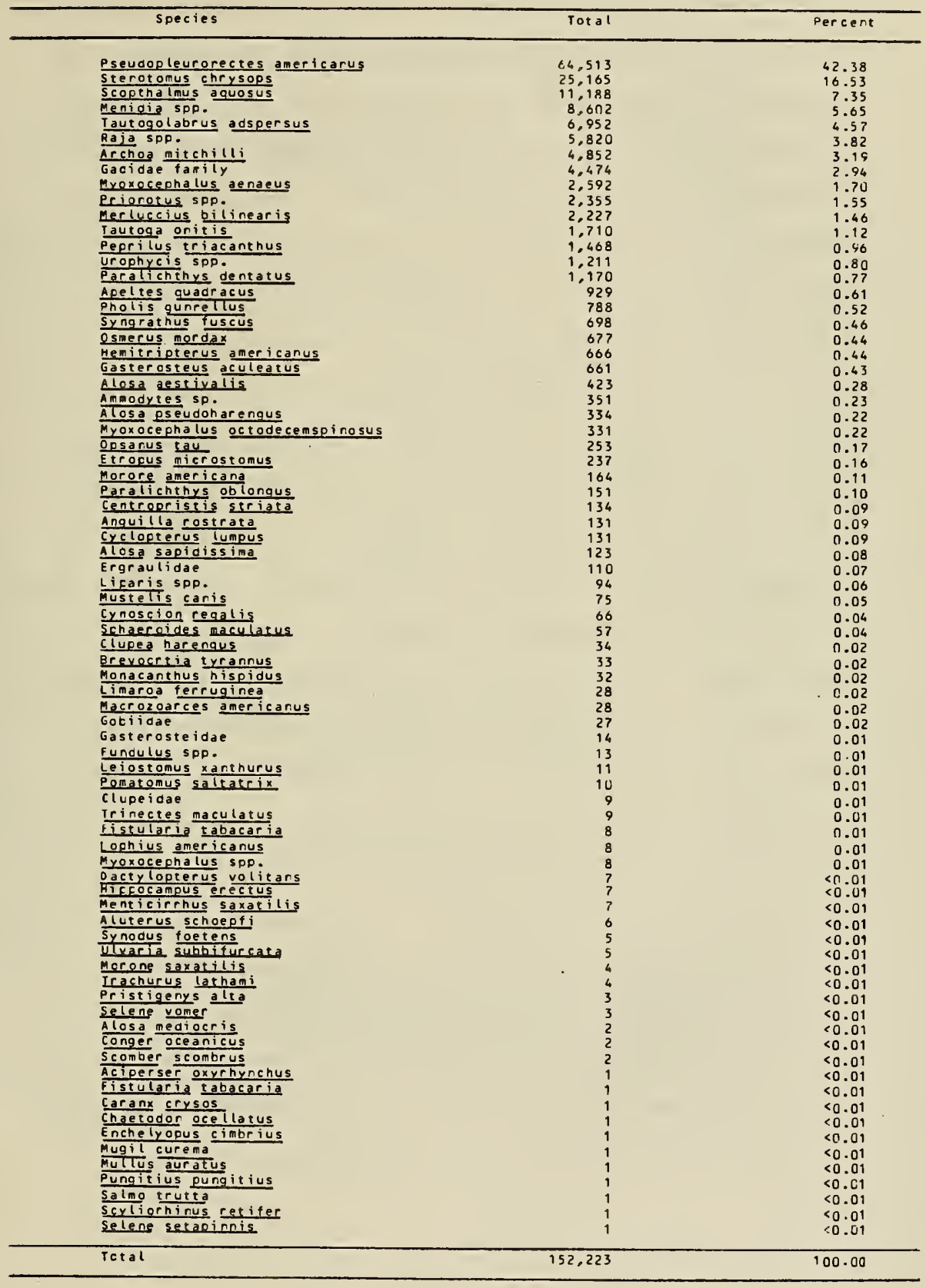


trawl-caught fish, even though it is known to school in waters above the bottom. Another flatfish species, the windowpane (Scophthalmus aguosus) was the third most abundant demersal finfish from the Millstone Bight. Silversides, typically found in the shore zone in the summer (Bigelow and Schroeder 1956), were the fourth most abundant trawl-caught taxon, and were caught primarily in the winter hauls. This group includes representatives from two species, the inland silverside (Menidia beryllina) and the Atlantic silverside (M. menidia), because they were not differentiated during some times of the study. The fifth ranked traw1-caught fish was the cunner (Tautogalabrus adspersus), described by 01la et al. (1975) to be a reef fish. Several species of skates (Raja spp.), are found in Long Island Sound and these were the sixth ranked demersal taxon. The seventh most abundant trawl-caught species, bay anchovy (Anchoa mitchilli), is a schooling summer transient, not really a demersal resident. The eighth ranked taxon, Gadidae, consisted of juvenile cod (Gadus morhua) and Atlantic tomcod (Microgadus tomcod) which are difficult to distinguish. Because the older specimens examined were primarily Atlantic tomcod, this species was probably the major component of the Gadidae taxon. The grubby (Myoxocephalus aenaeus), searobins, (Prionotus spp.), silver hake (Merluccius bilinearis) and tautog (Tautoga onitis) separately also contributed at least $1 \%$ to the total catch since 1973 . The species composition of the demersal catch was compared to that reported from the impingement and entrainment sampling programs (Table 5). Of the 12 selected trawl-caught species, all but 2 (scup and searobins) could be considered 'potentially impacted' by entrainment or impingement as they contributed at least $1 \%$ to those collections as well. 


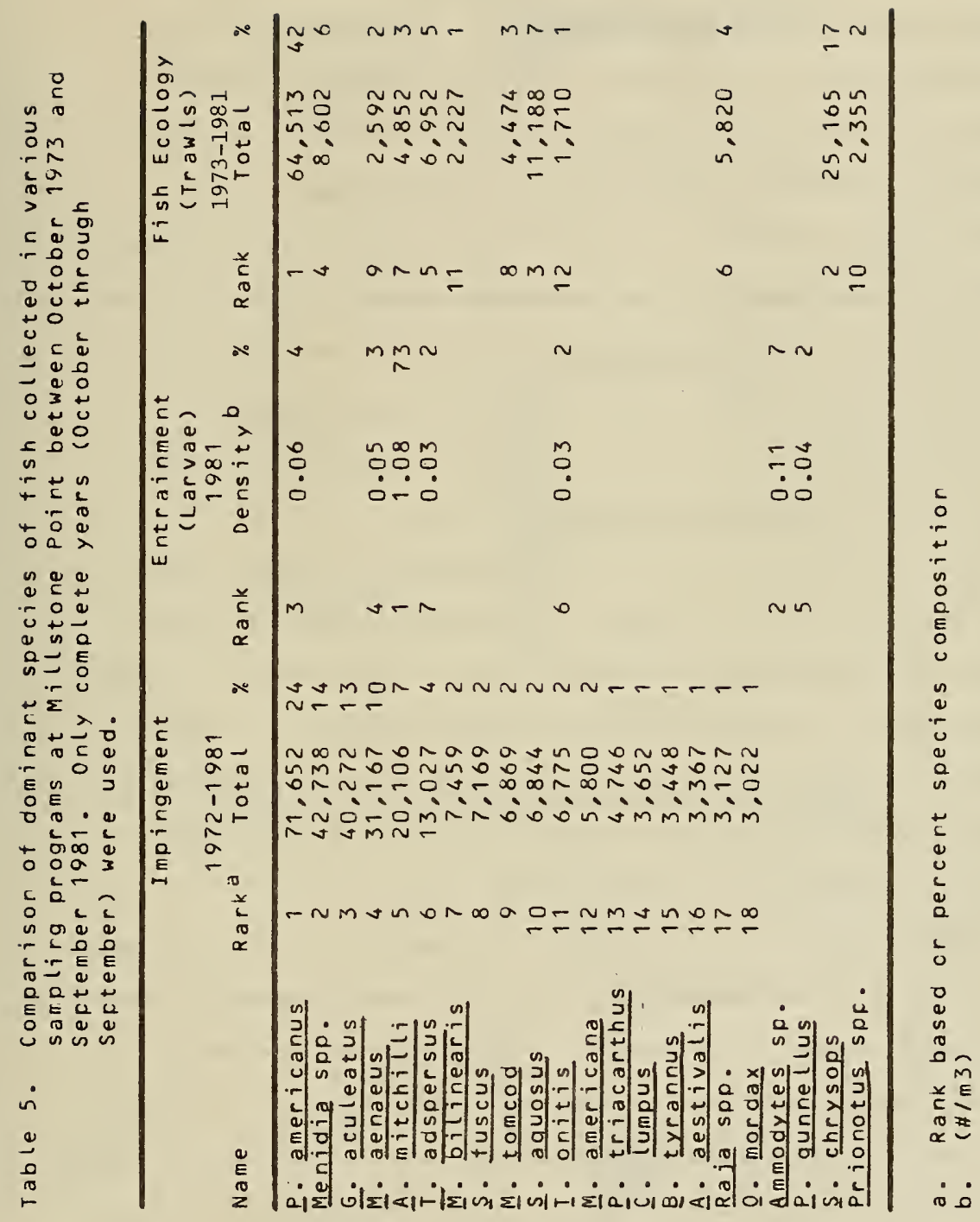


Because the catch data were historically converted to a CPUE based on a 15 min tow, a qualitative evaluation of this procedure was made prior to any critical analyses of the data. The frequencies of the catch per haul were fairly similar regardless of whether a 'tow' was $15 \mathrm{~min}$ or $0.69 \mathrm{~km}$. Winter flounder and scup (Fig. 2 and 3) were representative of the catch distributions of the trawl-caught species. However, the distribution of the tow durations (Fig. 4) were distinctly different after the change to a distance basis. The effect of dividing the catches by the durations would be to increase the variance of the time-based CPUE collected after October 1977 so that AOV tests for comparisons before and after this data would be inappropriate. Thus, the data used in the AOV of catch statistics were limited to those collected since October 1977 and were expressed as 'catch per $0.69 \mathrm{~km}$ '. The trawl catches varied with date, station and species. Two extreme patterns of catch are exhibited by the winter flounder, a yearround resident of the greater Millstone Bight, and the scup, a summer migrant to the area. While a seasonal pattern is more obvious from the scup catch, both of these species exhibit fairly repeatable annual patterns at some if not all stations (Fig. 5-6).

Specific patterns of distribution over time and space were typical of the selected trawl species, and resulted in some species being absent from certain seasons and stations. Threshold criteria were used to select the data from those times and places where a species was caught. If a species' catch was uniformly distributed over all months and stations, $8 \%$ of the catch would occur in each of 12 months and $16 \%$ would be found in each of 6 stations. A species was considered 'absent' if it did not contribute at least half of these percentages ( $4 \%$ or $8 \%$ ) to a given 


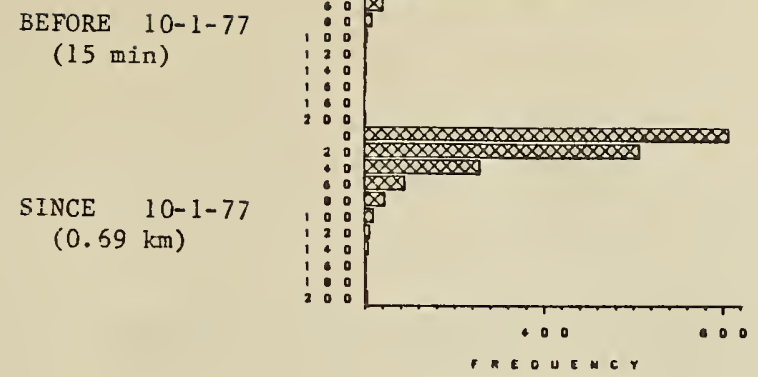

Figure 2. Frequency distribution of catch of $P$. americanus

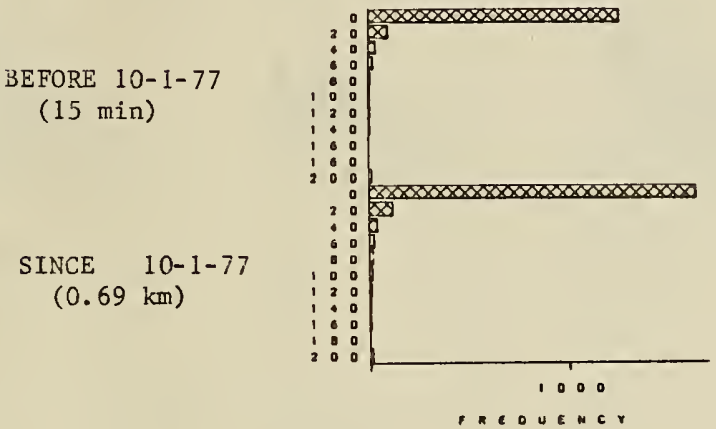

Figure 3. Frequency distribution of catch of S. chrysops

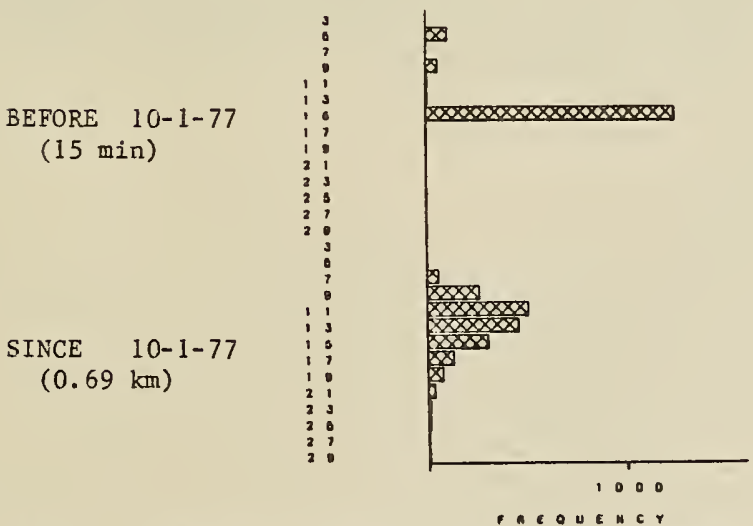

Figure 4. Frequency distribution of tow durotion in minutes 


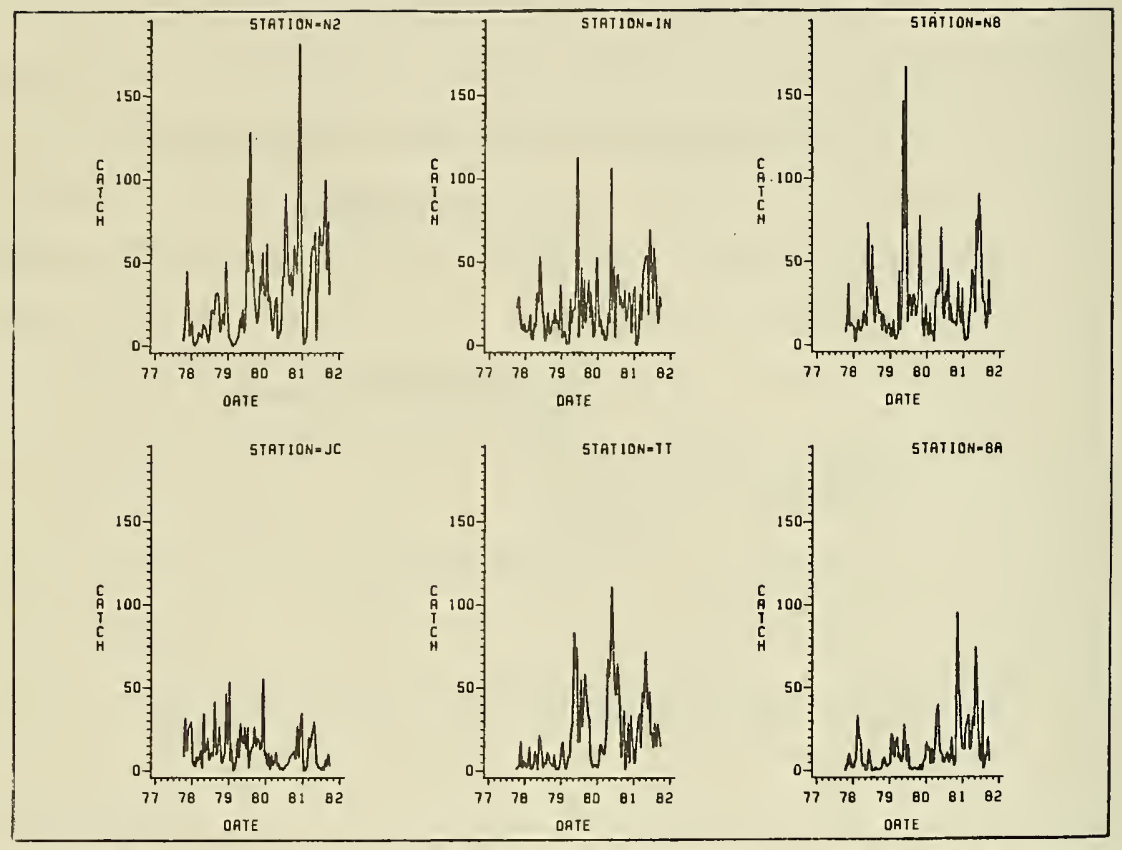

Figure 5. Catch of winter flounder since October 1977 at six stations around Millstone Point.

20 


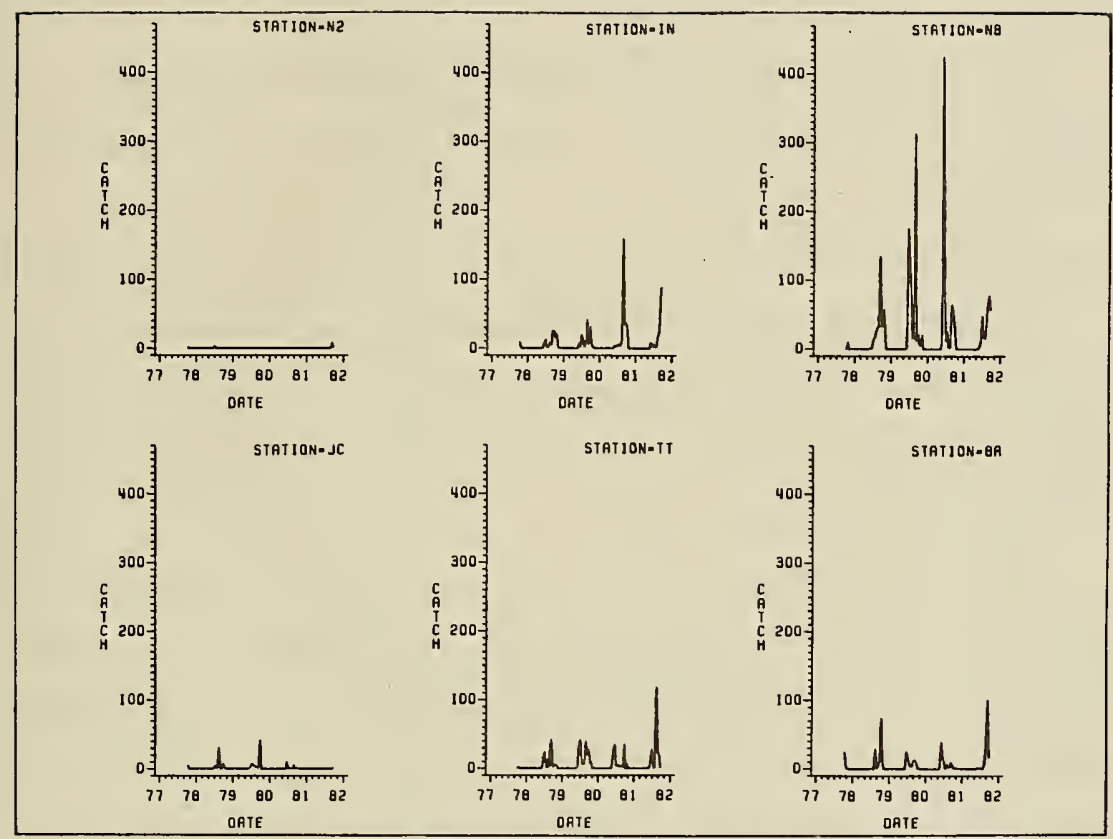

Figure 6. Catch of scup since October 1977 at six stations around Millstone Point. 
month or station. Only those months and stations where a species was 'present' by the above criteria were used in the AOV. The stations and months selected for each species are listed in Table 6. Even with these restrictions, the frequency distributions of the catches were highly skewed toward small catches and were non-normal, typical of biological data (Poole 1964) (see Fig. 2-3).

Highly skewed distributions frequently approximate a negative binomial distribution (Poole 1974), and this possibility was investigated. A goodness-of-fit (chi-square) test of the selected data to negative binomial distributions predicted from the maximum likelihood estimators of $\hat{k}$, indicated that eight of the 12 selected species' catch data did come from this type of distribution (Table 7). Thus, after transforming the data $(\ln ($ catch $+\hat{k} / 2))$, they could be used in normal theory based statistical tests.

The autocorrelation structure of the data can be determined by plotting the autocorrelation function (ACF) which represents the pattern of correlations between data points at various lags. The ACF plots for selected species catch at JC were representative of all stations and are presented in Figures 7 and 8 . It was apparent that significant serial dependence existed among the data points. Glass et al. (1975) have concluded that the effect of autocorrelations on probability statements cannot be designated.

The last aspect of the data to be examined was the ability of the current program to detect changes and the number of samples required to improve the detectability. Based on the analysis of variance model presented earlier, estimates of the variances associated with various sources are presented in Appendix 1. The variances in each cell were 


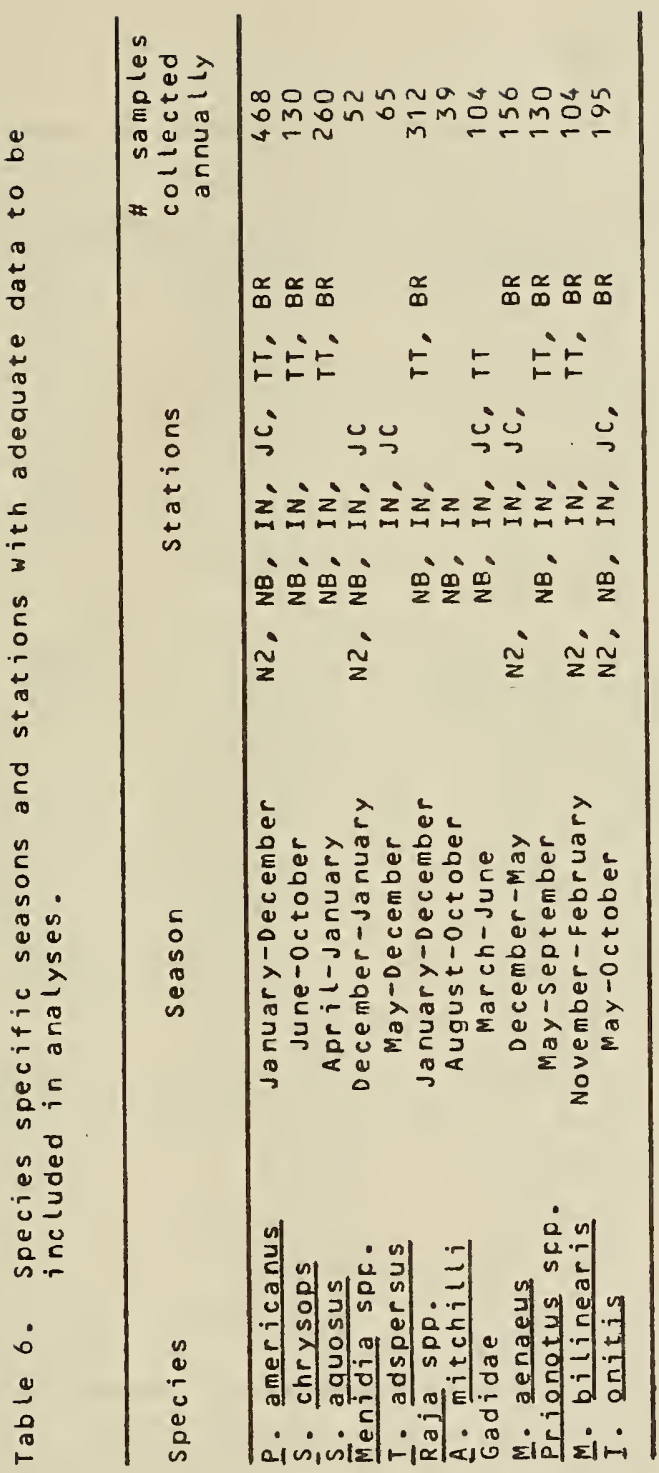


Table 7. Descriptive statistics for the catch distributions of the traut caught species.

\begin{tabular}{|c|c|c|c|c|}
\hline $\begin{array}{l}\text { Species } \\
(N)\end{array}$ & Data type & mean ( & $k^{a}$ & $\begin{array}{c}\text { Variance } \\
\text { or } \\
\text { (95\% Contidence Range) }\end{array}$ \\
\hline P. $\frac{\text { americanus }}{(1868)}$ & $\begin{array}{l}\text { Origirial } \\
\text { Transformed } \\
\text { Retranstormed }\end{array}$ & $\begin{array}{r}21.03 \\
2.41 \\
10.71\end{array}$ & $(0.83)$ & $\begin{array}{c}531.86 \\
1.82 \\
(10.05-i 1.42)\end{array}$ \\
\hline S: $\frac{\text { chrysops }}{(509)}$ & $\begin{array}{l}\text { Original } \\
\text { Trarsformed } \\
\text { Retransformed }\end{array}$ & $\begin{array}{r}17.15 \\
1.80 \\
6.12\end{array}$ & $(0.44 \pi)$ & $\begin{array}{c}612.68 \\
3.37 \\
(5.20-7.19)\end{array}$ \\
\hline$\underline{s}: \frac{a q u o s u s}{(10 S 4)}$ & $\begin{array}{l}\text { Original } \\
\text { Transformed } \\
\text { Retransformed }\end{array}$ & $\begin{array}{l}3.85 \\
0.38 \\
1.24\end{array}$ & $(0.45)$ & $\begin{array}{c}43.47 \\
2.38 \\
\left(1.11^{2}-1.38\right)\end{array}$ \\
\hline$\frac{\text { Mericia SDP. }}{(231)}$ & $\begin{array}{l}\text { Original } \\
\text { Transformed } \\
\text { Retransformed }\end{array}$ & $\begin{array}{r}10.35 \\
0.34 \\
1.32\end{array}$ & $(0.19 \star)$ & $\begin{array}{c}448.45 \\
6.03 \\
(0.94-1.83)\end{array}$ \\
\hline$I \cdot \frac{\text { adspersus }}{(254)}$ & $\begin{array}{l}\text { Original } \\
\text { Transformed } \\
\text { Retransformec }\end{array}$ & $\begin{array}{l}7.78 \\
1.31 \\
3.44\end{array}$ & $(0.54 \#)$ & $\begin{array}{c}92.32 \\
2.59 \\
(2.78-4.23)\end{array}$ \\
\hline$\frac{R a j a}{(1246)}$ SP. & $\begin{array}{l}\text { Original } \\
\text { Transformed } \\
\text { Retrarsformec }\end{array}$ & $\begin{array}{r}1.57 \\
-0.09 \\
0.63\end{array}$ & $(0.56)$ & $\begin{array}{c}5.75 \\
1.49 \\
(0.57-0.69)\end{array}$ \\
\hline A. $\frac{m i t c h i 11 i}{39)}$ & $\begin{array}{l}\text { Original } \\
\text { Transtormed } \\
\text { Retrarsformed }\end{array}$ & $\begin{array}{r}2.83 \\
-2.20 \\
0.08\end{array}$ & $(0.05 *)$ & $\begin{array}{c}101.19 \\
7.89 \\
(0.04-0.15)\end{array}$ \\
\hline $\begin{array}{l}\text { Gadidae } \\
(379)\end{array}$ & $\begin{array}{c}\text { Original } \\
\text { Transtormed } \\
\text { Retransformec }\end{array}$ & $\begin{array}{l}4.32 \\
0.23 \\
1.10\end{array}$ & $(0.31)$ & $\begin{array}{c}65.44 \\
3.74 \\
(0.99-1.36)\end{array}$ \\
\hline ㅂ. & $\begin{array}{l}\text { Original } \\
\text { Transformed } \\
\text { Retransformed }\end{array}$ & $\begin{array}{r}2.00 \\
-0.15 \\
C .65\end{array}$ & $(0.43)$ & $\begin{array}{c}11.22 \\
2.08 \\
(0.56-0.75)\end{array}$ \\
\hline$\frac{\text { Prionotus spc. }}{(523)}$. & $\begin{array}{c}\text { Original } \\
\text { Transformed } \\
\text { Retransformed }\end{array}$ & $\begin{array}{r}1.92 \\
-0.31 \\
0.55\end{array}$ & $(0.37)$ & $\begin{array}{c}10.65 \\
2.32 \\
(0.46-0.65)\end{array}$ \\
\hline 1. $\frac{\text { bilirearis }}{(40)}$ & $\begin{array}{l}\text { Original } \\
\text { Trarsformed } \\
\text { Retransformed }\end{array}$ & $\begin{array}{r}1.67 \\
-1.09 \\
0.24\end{array}$ & $(0.19)$ & $\begin{array}{c}15.14 \\
3.10 \\
\left(0.19^{-}-0.30\right)\end{array}$ \\
\hline I. $\frac{\text { onitis }}{78)}$ & $\begin{array}{c}\text { Original } \\
\text { Transformed } \\
\text { Retransformed }\end{array}$ & $\begin{array}{r}0.89 \\
-0.07 \\
0.48\end{array}$ & $(0.91)$ & $\begin{array}{c}1.64 \\
0.71 \\
(0.43-0.54)\end{array}$ \\
\hline
\end{tabular}

a. Calculated using the maximum likelihocd method

* Basec or a chi-square test, the observed distribution of cathces was significartly differert (alpha=0.05) from that expected from $k$. 


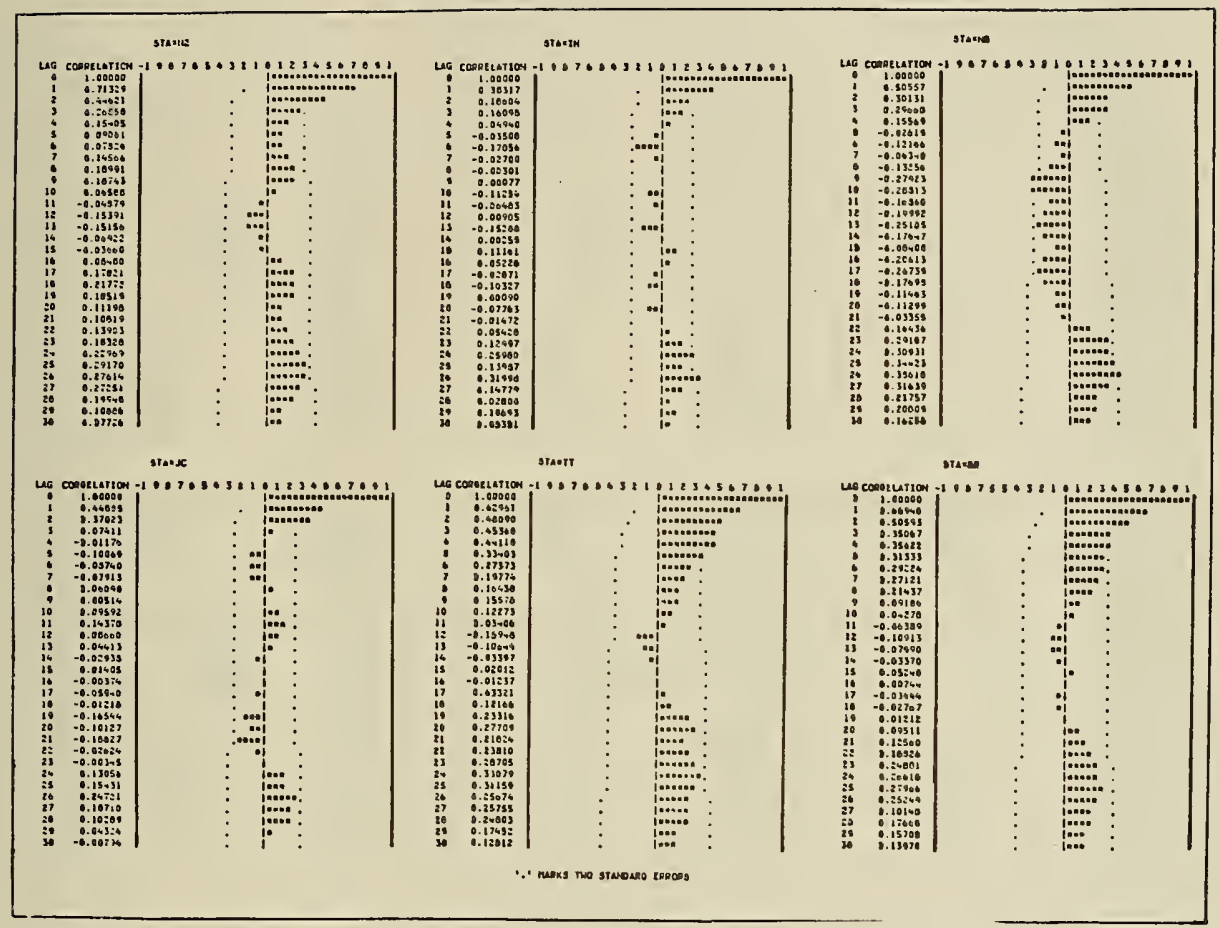

Figure 7. ACF for winter flounder caught at six stations around Millstone Point. 


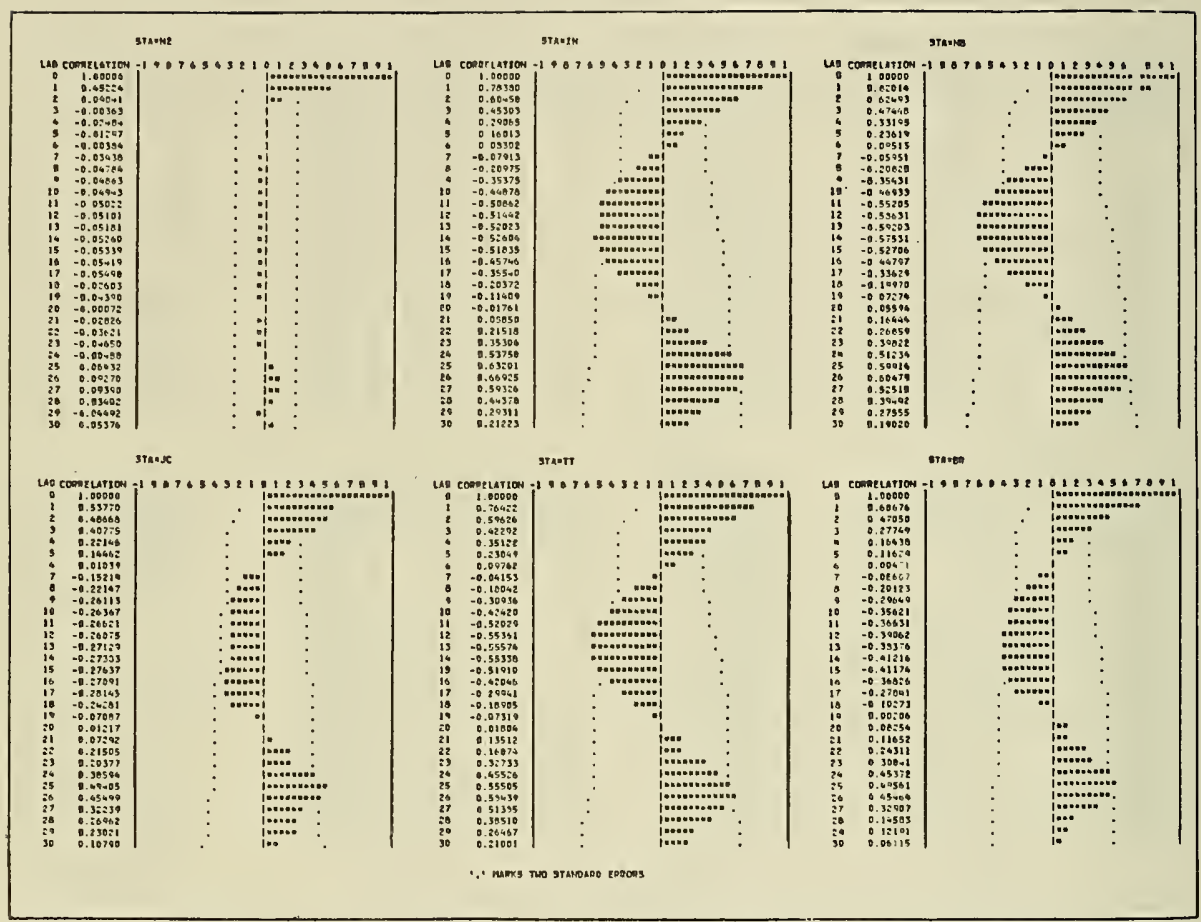

Figure 8. ACF for scup caught at six stations around Millstone Point. 
pooled and used to calculate the number of samples required to detect a specified ratio $R$ of the geometric means (corresponding to a difference of In transformed means) at certain $\alpha$ and $\beta$ levels (Table 8).

Historically, nonparametric analyses of variance based on ranks were used to test for differences between yearly, bimonthly, and station means. However, since appropriate transformations allowed the use of normal theory, and because limits of detectability were difficult to determine for nonparametric tests, this approach was not pursued further.

To determine if significant changes occurred in the demersal percent species composition, the method of Krumbein and Tukey (1956) of analysing proportions was applied to the data. Since this procedure does not involve a CPUE calculation, data collected prior to October 1977 were included. Also data from some stations were grouped into reglons. The results, presented in Table 9, indicated that the composition was significantly affected by sample period, region and the interactions of sample period with year and sample period with region.

Finally, the time series approach to the data produced models that, to some extent, described the patterns of abundance of the demersal fish. Additionally, the models produced forecasts that could be compared to actual data. The results from the time series investigations are presented in Table 10.

\section{DISCUSSION}

In order to address the first objective, i.e., describe the occurrence, distribution and relative abundance of potentially impacted demersal finfish in the Greater Millstone Bight, 'demersal' and 'potentially impacted' were defined. The demersal finfish were considered to be 
Table 8. Aumber of samples required to detect a $(R-1) * 100 \%$ change at various alpha (a) ard beta (b) levels.

\begin{tabular}{|c|c|c|c|c|c|c|c|c|}
\hline $\begin{array}{l}\text { Species } \\
\text { (Current Samples) }\end{array}$ & $\begin{array}{l}\text { Pooted } \\
\text { Variance }\end{array}$ & $R$ & $\begin{array}{l}a=05 \\
b=90\end{array}$ & $\begin{array}{l}\text { Numb } \\
a=10 \\
b=90\end{array}$ & $\begin{array}{l}a=05 \\
b=80\end{array}$ & $\begin{array}{c}\text { Sample } \\
a=10 \\
b=80\end{array}$ & $\begin{array}{l}a=05 \\
b=70\end{array}$ & $\begin{array}{l}a=10 \\
b=70\end{array}$ \\
\hline$\frac{P}{(468)} \frac{a m e r i c a n u s}{8)}$ & 0.63333 & $\begin{array}{l}1.05 \\
1.10 \\
1.15 \\
1.20 \\
1.25 \\
1.30 \\
1.35 \\
1.40 \\
1.45 \\
1.50\end{array}$ & $\begin{array}{r}4559 \\
1195 \\
556 \\
326 \\
218 \\
158 \\
120 \\
96 \\
79 \\
66\end{array}$ & $\begin{array}{r}3498 \\
917 \\
426 \\
251 \\
167 \\
121 \\
92 \\
74 \\
60 \\
51\end{array}$ & $\begin{array}{r}3291 \\
862 \\
401 \\
236 \\
157 \\
114 \\
87 \\
69 \\
57 \\
48\end{array}$ & $\begin{array}{r}2401 \\
629 \\
293 \\
172 \\
115 \\
83 \\
63 \\
50 \\
41 \\
35\end{array}$ & $\begin{array}{r}2545 \\
667 \\
310 \\
182 \\
122 \\
88 \\
67 \\
54 \\
44 \\
37\end{array}$ & $\begin{array}{r}1770 \\
464 \\
216 \\
127 \\
85 \\
61 \\
47 \\
37 \\
31 \\
26\end{array}$ \\
\hline$\frac{\text { s. }}{(130)} \frac{\text { chrysops }}{30)}$ & 1.59624 & $\begin{array}{l}1.05 \\
1.10 \\
1.15 \\
1.20 \\
1.25 \\
1.30 \\
1.35 \\
1.40 \\
1.45 \\
1.50\end{array}$ & $\begin{array}{r}11490 \\
3011 \\
1400 \\
823 \\
549 \\
397 \\
304 \\
242 \\
198 \\
166\end{array}$ & $\begin{array}{r}8817 \\
2310 \\
1074 \\
631 \\
421 \\
305 \\
233 \\
185 \\
152 \\
128\end{array}$ & $\begin{array}{l}8295 \\
2174 \\
1011 \\
594 \\
397 \\
287 \\
219 \\
174 \\
143 \\
120\end{array}$ & $\begin{array}{r}0050 \\
1585 \\
737 \\
433 \\
289 \\
209 \\
160 \\
127 \\
104 \\
88\end{array}$ & $\begin{array}{r}6415 \\
1681 \\
782 \\
459 \\
307 \\
222 \\
170 \\
135 \\
111 \\
93\end{array}$ & $\begin{array}{r}4462 \\
1169 \\
544 \\
320 \\
213 \\
154 \\
118 \\
94 \\
77 \\
65\end{array}$ \\
\hline$\frac{5}{(260)}$ & 1.13668 & $\begin{array}{l}1.05 \\
1.10 \\
1.15 \\
1.20 \\
1.25 \\
1.30 \\
1.35 \\
1.40 \\
1.45 \\
1.50\end{array}$ & $\begin{array}{r}8182 \\
2144 \\
997 \\
586 \\
391 \\
283 \\
216 \\
172 \\
141 \\
118\end{array}$ & $\begin{array}{r}6278 \\
1645 \\
765 \\
450 \\
300 \\
217 \\
166 \\
132 \\
108 \\
91\end{array}$ & $\begin{array}{r}5907 \\
1548 \\
720 \\
423 \\
282 \\
204 \\
156 \\
124 \\
102 \\
86\end{array}$ & $\begin{array}{r}4308 \\
1129 \\
525 \\
309 \\
206 \\
149 \\
114 \\
91 \\
74 \\
62\end{array}$ & $\begin{array}{r}4568 \\
1197 \\
557 \\
327 \\
218 \\
158 \\
121 \\
96 \\
79 \\
66\end{array}$ & $\begin{array}{r}3177 \\
833 \\
387 \\
228 \\
152 \\
110 \\
84 \\
67 \\
55 \\
46\end{array}$ \\
\hline$\frac{\text { Menidia }}{(52)}$ Spp. & 3.75574 & $\begin{array}{l}1.05 \\
1.10 \\
1.15 \\
1.20 \\
1.25 \\
1.30 \\
1.35 \\
1.40 \\
1.45 \\
1.50\end{array}$ & $\begin{array}{r}27034 \\
7084 \\
3295 \\
1936 \\
1292 \\
935 \\
715 \\
568 \\
466 \\
391\end{array}$ & $\begin{array}{r}20744 \\
5436 \\
2528 \\
1486 \\
992 \\
717 \\
548 \\
436 \\
358 \\
300\end{array}$ & $\begin{array}{r}19517 \\
5114 \\
2378 \\
1398 \\
933 \\
675 \\
516 \\
410 \\
337 \\
283\end{array}$ & $\begin{array}{r}14235 \\
3730 \\
1735 \\
1019 \\
681 \\
492 \\
376 \\
299 \\
245 \\
206\end{array}$ & $\begin{array}{r}15093 \\
3955 \\
1839 \\
1081 \\
722 \\
522 \\
399 \\
317 \\
260 \\
219\end{array}$ & $\begin{array}{r}10498 \\
2751 \\
1279 \\
752 \\
502 \\
363 \\
277 \\
221 \\
181 \\
152\end{array}$ \\
\hline I. adspersus & 0.98785 & $\begin{array}{l}1.05 \\
1.10 \\
1.15 \\
1.20 \\
1.25 \\
1.30 \\
1.35 \\
1.40 \\
1.45 \\
1.50\end{array}$ & $\begin{array}{r}7111 \\
1863 \\
867 \\
509 \\
340 \\
246 \\
188 \\
150 \\
123 \\
103\end{array}$ & $\begin{array}{r}5456 \\
1430 \\
665 \\
391 \\
261 \\
189 \\
144 \\
115 \\
94 \\
79\end{array}$ & $\begin{array}{r}5133 \\
1345 \\
626 \\
368 \\
245 \\
178 \\
136 \\
108 \\
89 \\
74\end{array}$ & $\begin{array}{r}3746 \\
981 \\
456 \\
268 \\
179 \\
129 \\
99 \\
79 \\
65 \\
54\end{array}$ & $\begin{array}{r}3970 \\
1040 \\
484 \\
284 \\
190 \\
137 \\
105 \\
83 \\
68 \\
57\end{array}$ & $\begin{array}{r}2761 \\
724 \\
337 \\
158 \\
132 \\
95 \\
73 \\
58 \\
48 \\
40\end{array}$ \\
\hline$\frac{\text { Raja }}{(312)}$ SPP. & 0.81055 & $\begin{array}{l}1.05 \\
1.10 \\
1.15 \\
1.20 \\
1.25 \\
1.30 \\
1.35 \\
1.40 \\
1.45 \\
1.50\end{array}$ & $\begin{array}{r}5834 \\
1529 \\
711 \\
418 \\
279 \\
202 \\
154 \\
123 \\
101 \\
84\end{array}$ & $\begin{array}{r}4477 \\
1173 \\
546 \\
321 \\
214 \\
155 \\
118 \\
94 \\
77 \\
65\end{array}$ & $\begin{array}{r}4212 \\
1104 \\
513 \\
302 \\
201 \\
146 \\
111 \\
89 \\
73 \\
61\end{array}$ & $\begin{array}{r}3072 \\
805 \\
374 \\
220 \\
147 \\
106 \\
81 \\
65 \\
53 \\
44\end{array}$ & $\begin{array}{r}3257 \\
854 \\
397 \\
233 \\
156 \\
113 \\
86 \\
68 \\
56 \\
47\end{array}$ & $\begin{array}{r}2266 \\
594 \\
276 \\
162 \\
108 \\
78 \\
60 \\
48 \\
34 \\
33\end{array}$ \\
\hline
\end{tabular}


Table 8. (cort.)

\begin{tabular}{|c|c|c|c|c|c|c|c|c|}
\hline $\begin{array}{l}\text { Species } \\
\text { (Current H Samples) }\end{array}$ & $\begin{array}{l}\text { Pooled } \\
\text { Variance }\end{array}$ & R & $\begin{array}{l}a=05 \\
b=90\end{array}$ & $\begin{array}{l}\text { Numb } \\
a=10 \\
b=90\end{array}$ & $\begin{array}{l}\text { of } \\
a=05 \\
h=80\end{array}$ & $\begin{array}{c}\text { Sample } \\
a=10 \\
b=80\end{array}$ & $\begin{array}{l}=05 \\
b=70\end{array}$ & $\begin{array}{l}a=10 \\
b=70\end{array}$ \\
\hline A. $\frac{\text { nitehilli }}{(39)}$ & 4.84340 & $\begin{array}{l}1.05 \\
1.10 \\
1.15 \\
1.20 \\
1.25 \\
1.30 \\
1.35 \\
1.40 \\
1.45 \\
1.50\end{array}$ & $\begin{array}{r}34863 \\
9136 \\
4249 \\
2497 \\
1667 \\
1206 \\
921 \\
733 \\
601 \\
505\end{array}$ & $\begin{array}{r}26752 \\
7010 \\
3260 \\
1416 \\
1279 \\
925 \\
707 \\
562 \\
461 \\
387\end{array}$ & $\begin{array}{r}25169 \\
6596 \\
3067 \\
1802 \\
1203 \\
870 \\
665 \\
529 \\
434 \\
364\end{array}$ & $\begin{array}{r}18358 \\
4811 \\
2237 \\
1315 \\
878 \\
635 \\
485 \\
386 \\
317 \\
266\end{array}$ & $\begin{array}{r}14463 \\
5100 \\
2372 \\
1394 \\
930 \\
673 \\
514 \\
409 \\
336 \\
282\end{array}$ & $\begin{array}{r}13538 \\
3548 \\
1650 \\
970 \\
647 \\
468 \\
358 \\
285 \\
233 \\
196\end{array}$ \\
\hline $\begin{array}{l}\text { Gadidaé } \\
(104)\end{array}$ & 1.43133 & $\begin{array}{l}1.05 \\
1.10 \\
1.15 \\
1.20 \\
1.25 \\
1.30 \\
1.35 \\
1.40 \\
1.45 \\
1.50\end{array}$ & $\begin{array}{r}10303 \\
2700 \\
1256 \\
738 \\
493 \\
356 \\
272 \\
217 \\
178 \\
149\end{array}$ & $\begin{array}{l}7906 \\
2072 \\
963 \\
566 \\
378 \\
273 \\
209 \\
166 \\
136 \\
114\end{array}$ & $\begin{array}{r}7438 \\
1449 \\
906 \\
533 \\
356 \\
257 \\
197 \\
156 \\
128 \\
108\end{array}$ & $\begin{array}{r}5425 \\
1422 \\
661 \\
389 \\
259 \\
188 \\
143 \\
114 \\
94 \\
79\end{array}$ & $\begin{array}{r}5752 \\
1507 \\
701 \\
412 \\
275 \\
199 \\
152 \\
121 \\
99 \\
83\end{array}$ & $\begin{array}{r}4001 \\
1048 \\
488 \\
287 \\
191 \\
138 \\
106 \\
84 \\
69 \\
58\end{array}$ \\
\hline$\frac{M}{(145)}$ & 1.14776 & $\begin{array}{l}1.05 \\
1.10 \\
1.15 \\
1.20 \\
1.25 \\
1.30 \\
1.35 \\
1.40 \\
1.45 \\
1.50\end{array}$ & $\begin{array}{r}8262 \\
2165 \\
1007 \\
592 \\
395 \\
286 \\
218 \\
174 \\
142 \\
120\end{array}$ & $\begin{array}{r}6339 \\
1661 \\
773 \\
454 \\
303 \\
219 \\
168 \\
133 \\
109 \\
92\end{array}$ & $\begin{array}{r}5964 \\
1563 \\
727 \\
427 \\
285 \\
206 \\
158 \\
125 \\
103 \\
86\end{array}$ & $\begin{array}{r}4350 \\
1140 \\
530 \\
312 \\
208 \\
150 \\
115 \\
91 \\
75 \\
63\end{array}$ & $\begin{array}{r}4612 \\
1209 \\
562 \\
330 \\
221 \\
160 \\
122 \\
97 \\
80 \\
67\end{array}$ & $\begin{array}{r}3208 \\
841 \\
391 \\
230 \\
153 \\
111 \\
85 \\
67 \\
55 \\
46\end{array}$ \\
\hline$\frac{\text { Prionotus SFP. }}{(130)}$ & 1.19509 & $\begin{array}{l}1.05 \\
1.10 \\
1.15 \\
1.20 \\
1.25 \\
1.30 \\
1.35 \\
1.40 \\
1.45 \\
1.50\end{array}$ & $\begin{array}{r}8602 \\
2254 \\
1048 \\
616 \\
411 \\
297 \\
227 \\
181 \\
148 \\
125\end{array}$ & $\begin{array}{r}6601 \\
1730 \\
804 \\
473 \\
316 \\
228 \\
174 \\
139 \\
114 \\
96\end{array}$ & $\begin{array}{r}6210 \\
1627 \\
757 \\
445 \\
297 \\
215 \\
164 \\
131 \\
107 \\
90\end{array}$ & $\begin{array}{r}4530 \\
1187 \\
552 \\
324 \\
217 \\
157 \\
120 \\
95 \\
78 \\
60\end{array}$ & $\begin{array}{r}4802 \\
1258 \\
585 \\
344 \\
230 \\
166 \\
127 \\
101 \\
83 \\
70\end{array}$ & $\begin{array}{r}3341 \\
875 \\
407 \\
239 \\
160 \\
116 \\
88 \\
70 \\
58 \\
48\end{array}$ \\
\hline$\frac{4}{(10} \frac{b i l i n e a r i s}{4}$ & 1.48810 & $\begin{array}{l}1.05 \\
1.10 \\
1.15 \\
1.20 \\
1.25 \\
1.30 \\
1.35 \\
1.40 \\
1.45 \\
1.50\end{array}$ & $\begin{array}{r}10711 \\
2807 \\
1305 \\
767 \\
512 \\
370 \\
283 \\
225 \\
185 \\
155\end{array}$ & $\begin{array}{r}8219 \\
2154 \\
1002 \\
589 \\
393 \\
284 \\
217 \\
173 \\
142 \\
119\end{array}$ & $\begin{array}{r}7733 \\
2026 \\
942 \\
554 \\
370 \\
267 \\
204 \\
163 \\
133 \\
112\end{array}$ & $\begin{array}{r}5640 \\
1478 \\
687 \\
404 \\
270 \\
195 \\
149 \\
119 \\
97 \\
82\end{array}$ & $\begin{array}{r}5980 \\
1567 \\
729 \\
428 \\
286 \\
207 \\
158 \\
126 \\
103 \\
87\end{array}$ & $\begin{array}{r}4960 \\
1090 \\
507 \\
298 \\
199 \\
144 \\
110 \\
87 \\
72 \\
60\end{array}$ \\
\hline I. $\frac{\text { enitis }}{(195)}$ & 0.45054 & $\begin{array}{l}1.05 \\
1.10 \\
1.15 \\
1.20 \\
1.25 \\
1.30 \\
1.35 \\
1.40 \\
1.45 \\
1.50\end{array}$ & $\begin{array}{r}3243 \\
850 \\
395 \\
232 \\
155 \\
112 \\
86 \\
68 \\
56 \\
47\end{array}$ & $\begin{array}{r}2488 \\
652 \\
303 \\
178 \\
119 \\
86 \\
66 \\
52 \\
43 \\
36\end{array}$ & $\begin{array}{r}2361 \\
614 \\
285 \\
168 \\
112 \\
81 \\
62 \\
49 \\
40 \\
34\end{array}$ & $\begin{array}{r}1708 \\
448 \\
208 \\
122 \\
82 \\
59 \\
45 \\
36 \\
29 \\
25\end{array}$ & $\begin{array}{r}1811 \\
474 \\
221 \\
130 \\
87 \\
63 \\
48 \\
38 \\
31 \\
26\end{array}$ & $\begin{array}{r}1259 \\
330 \\
153 \\
90 \\
60 \\
44 \\
33 \\
26 \\
22 \\
18\end{array}$ \\
\hline
\end{tabular}




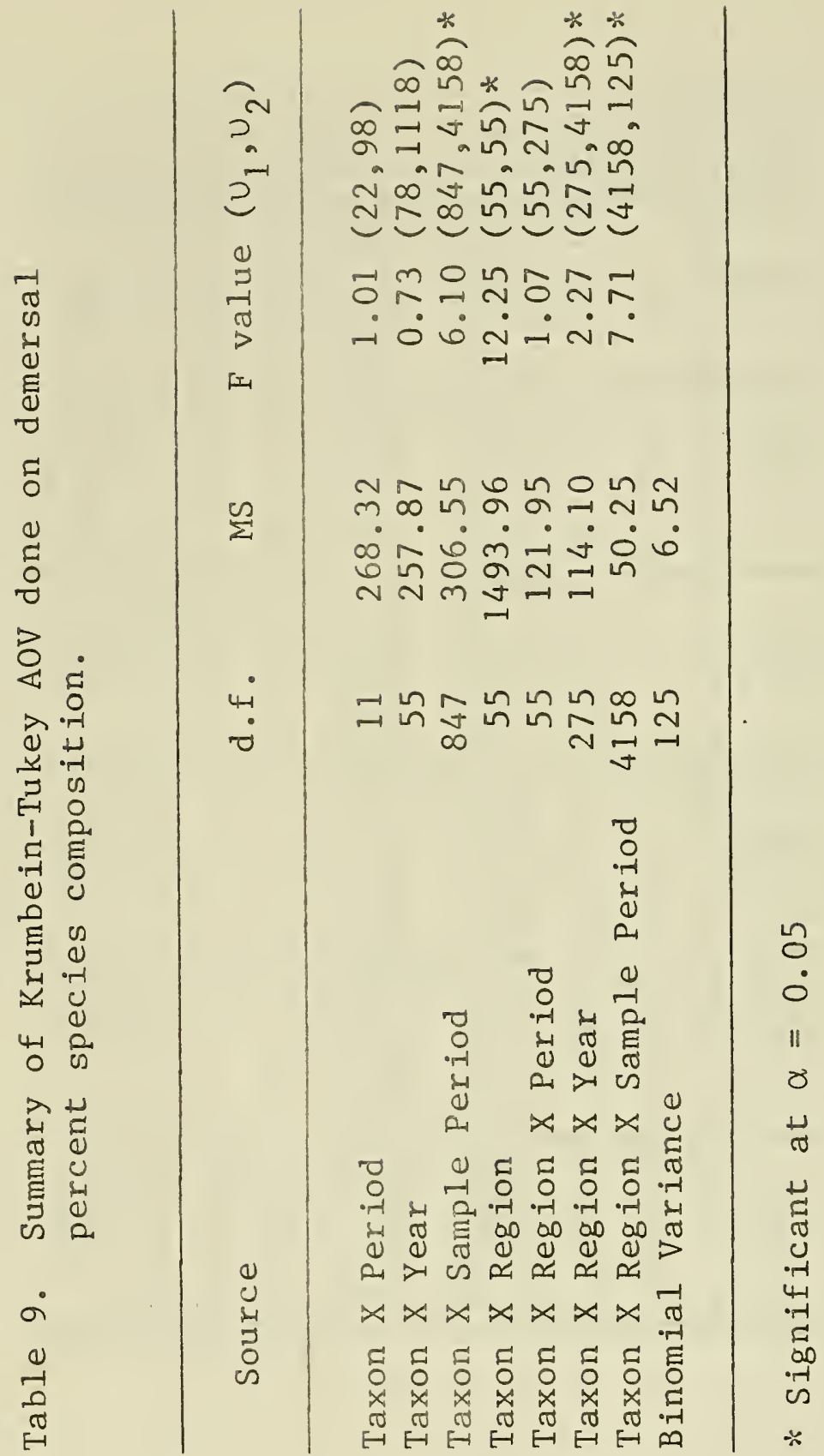




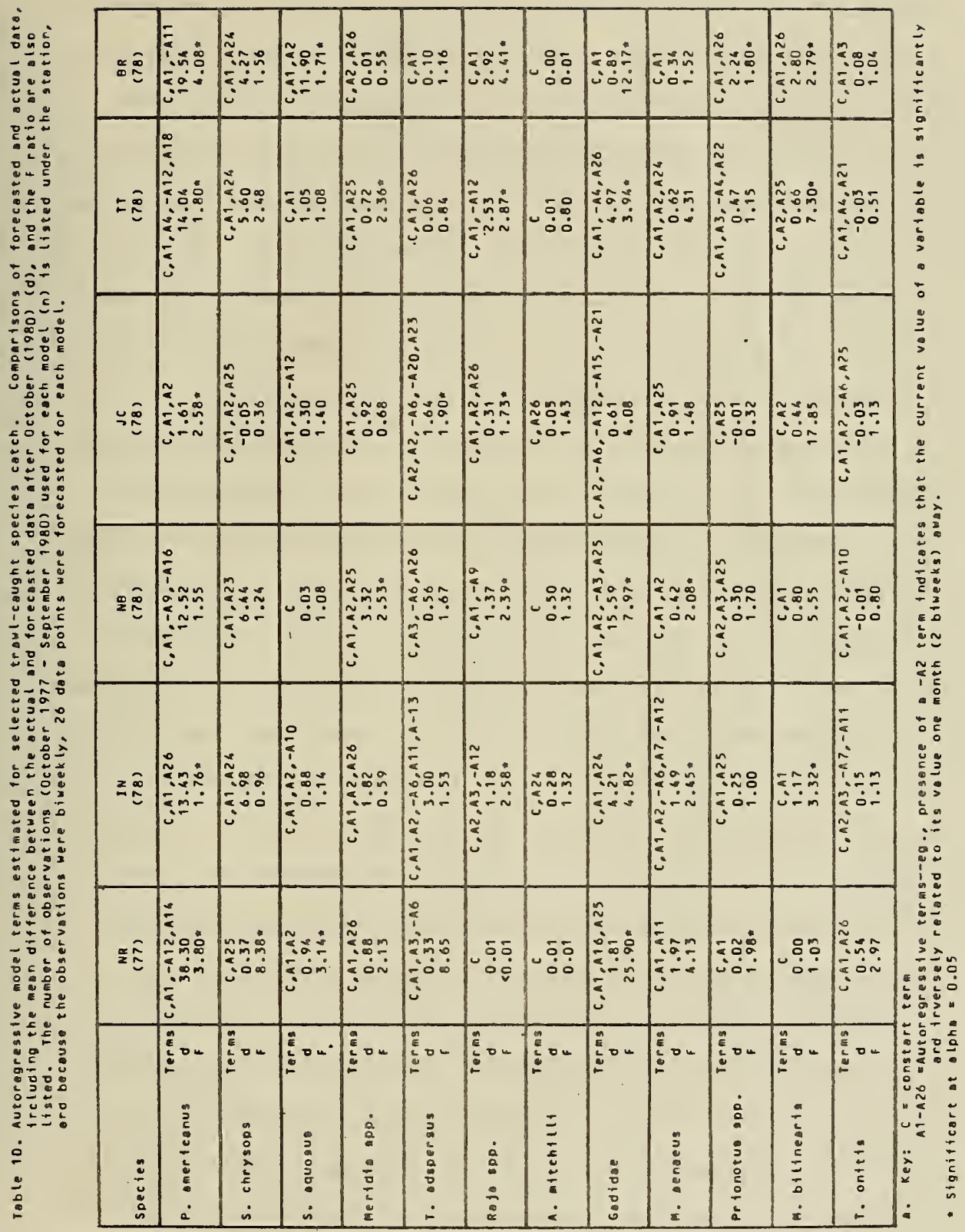


those species captured by the trawls (see Table 4). These finfish were typical of those found in demersal and near-bottom pelagic assemblages along the Northeast Atlantic Coast from New York (Briggs and $O^{\circ}$ Connor 1971) through Long Island Sound (Warfel and Merriman 1944; LILCo 1980) and the Mystic River Estuary, Connecticut (Pearcy and Richards 1962) to Rhode Island (Mulkana 1966). The patterns of fluctuations in the catches oi these fish over time, was generally seasonal (Fig, 5-6). The catch of winter flounder varied seasonally, but in different ways at different stations. Scup, on the other hand show similar seasonal patterns at all norriverine stations when they migrated into the Millstone area.

Those species whose abundance levels might change due to the removal of individuals by impingement or entrainment or whose geographical distribution might be altered by the thermal effluent could be considered potentially impacted. Since trawl-caught species are generally on or near the bottom and since the thermal effluent is primarily a surface phenomenon, this finfish assemblage would not be expected to be impacted by the thermal effluent. A comparison of those taxa either impinged or entrained to those recorded from trawls is given in Table 5. The most abundant demersal fish, winter flounder, was the most important impinged species in the time period. Of the remaining 11 selected 'important' taxa, only scup, and searobins were neither entrained nor impinged in large enough numbers to be considered potentially impacted.

The trawl sampling program extant at MNPS sampled finfish typical of the bottom and near-bottom habitats of the northeast Atlantic coast, and provided both a long term and seasonal description of the fluctuations that these assemblages experience. Additionally, potentially impacted species were represented in these collections. The next step in this 
investigation was to determine our ability to detect changes in the demersal finfish assemblages using the accumulated data, and to distinguish plant-induced changes from natural changes in the fish popularions. Hypotheses generation and statistical testing provide the most quantitative way to detect differences or changes. Standard normal theory tests assume, among other things, that the observations come from a probability distribution that is normal, that the variances are homogeneous, and that the observations are independent. A knowledge of the data base characteristics, including any changes in methodology that might effect nonbiological changes in the data, is desirable for the correct application and interpretation of various tests and results.

Several changes in the trawl program have occurred since its inception in 1973. These have been described along with the reasons for the changes in a previous section of this report. The way in which the data were manipulated in Annual Reports was one consequence of these changes. Because not all of the currently sampled stations have been sampled since 1973, but year to year comparisons were desired, some stations were grouped together into regions. The data were summed in a region and month and divided by the total tow time and multiplied by 15 to arrive at a CPUE. This allowed comparisons over time, but the information contained in the variance of the individual data points was lost. The other major changes in the trawl program affecting the data was the conversion from a time-based CPUE to a distance-based CPUE. The effect of changing unit-effort bases was not measured experimentally. The results of mathematically manipulating the data then, was to add unknown and unmeasured amounts of variance to the data collected after October 1977. Detected differences might be related to environmental or plant- 
induced factors, but could just as easily be a result of this change in technique. Thus, while the data collected between March 1973 and October 1977 are appropriate for detecting changes in that time period (perhaps related to the operations of Units 1 and 2), a more appropriate baseline for the detection of quantitative changes related to the operations of Unit 3 would begin with the October 1977 samples. Qualitative comparisons tal utilize the relative proportions of the species would still be appropriate over the whole period.

The frequency distributions of the catches of 12 selected trawlcaught species were examined after first restricting the data to those time periods and stations in which the species of interest was found (Table 6). The distributions shown in Fig. 2-3 are exemplary. These highly skewed, non-normal distributions typically had variances that were related to the means. Eight out of 12 of the distributions approximated a negative binomial distribution (Poole 1974) (see Table 7). Such data can be normalized with the transformation: In $(c a t c h+\hat{k} / 2)$. Thus, all parametric analyses utilized the appropriately transformed data from individual tows collected since October 1977.

Limits of detection and sample size were evaluated and found to be quite good for some species. The current program (consisting of three replicates taken at six stations 26 times a year) provides 468 samples per year. Considering winter flounder (Table 8), this sampling program could detect a $20 \%(R=1.20)$ change in the means of the transformed data (vs Ha: $R=1$ ) at $\alpha=0.05,90 \%$ of the time $(\beta=.90)$. Detecting a $10 \%$ change at these $\alpha$ and $\beta$ levels would require 1195 samples per year. For scup, 130 samples are currently collected from June through November at NB, IN, and JC. At this level a $50 \%$ change could be detected at $\alpha=0.05$, 
$\beta=0.80$. Since station and time of year factors provided significant contributions to the over all variances of the species considered, the ability to detect a $20 \%$ change in the annual geometric means at $\alpha=0.05, \beta$ $=0.90$ or $\alpha=0.05, \beta=0.70$ may be reasonably precise.

In addition to the assumptions of normality and homogeneous variances, data used in normal theory tests should meet the assumption of independence. The result of serial dependence in the data over time is to affect probability statements in an unpredictable way (Glass et al. 1975). Time-series analysis actually makes use of these internal autocorrelations and has been proposed as a powerful tool for statistical testing in environmental monitoring (Saila et al. 1980). The initial application of this analytical method used the autocorrelation structure to forecast fish catches a year in advance. However, techniques exist for removing the autocorrelations and then testing for differences in the remaining values. Additionally, tests can be constructed to determine if an intervention effect, like the start-up of a power plant, is detectable in the series. This approach, then, would assist in meeting both the second and the third objectives of the trawling program, that is to be able to distinguish natural changes in finfish population levels or changes in community composition from those which are power plant induced. Because 50 serial data points are needed to adequately identify a time series model (Glass et al. 1975), and results are best if at least two observations contribute to each data point (Saila, pers. comm.), it is recommended that any changes in the trawling program be considered in terms of the potential for using the extant historical data base in time series analysis. The data collected since October 1977 fulfill these requirements. Triplicate observations contributed to each of 26 data 
points per station per year or 104 points from October 1977 through September 1981 .

\section{SUMMARY}

1. The NUEL trawling program has provided both long term and seasonal estimates of the kinds and numbers of finfish inhabiting the benthic and near-bottom pelagic environs near MNPS. Their patterns of abundance are now well documented.

2. The program has provided information on trawl-caught species potentially impacted by impingement and entrainment.

3. The selected trawl-caught species data bases were characterized as having highly skewed, non-normal distributions that approximated a negative binomial distribution. Thus appropriately transformed data could be used in parametric statistical tests. Using the in (catch $+\hat{k} / 2$ ) transformed data, the program would be able to detect large (20-50\%) changes in demersal finfish populations which might be the result of power plant impact.

4. Time-series (forecasting) analysis were also found useful for analyzing trends and should be continued as a powerful measure of an intervention (power plant) effect.

\section{RECOMMENDATIONS}

1. It is recommended that the current trawl sampling program remain unchanged.

2. For detecting changes, the data collected since October 1977 , appropriately transformed, should be used as the bases for detecting potential changes related to three-unit operation. 
3. Develop time series approach to distinguish plant induced changes from natural ones.

B. Seines

\section{MATERIALS AND METHODS}

Sampling sites

A total of seven different shore zone sites have been sampled at one time or another since 1969. They were designated GN, BL, SP, IN, JC, WP and SS and are shown in Fig. 1.

The beach at Giants Neck (GN) has a southerly exposure but is protected by Black Point, Giants Neck, and some offshore islands. The bottom consists of medium to coarse sand with some large emergent rocks. Detached algae and detritus are usually present in the shore zone. The Giants Neck site, approximately three miles west of the power plant, is removed from the zone of probable MNPS impact and is considered a control site.

The Black Point site (BL) near Crescent Beach has an easterly exposure with moderate wave action. The bottom is of medium-grained sand, and there is virtually no attached vegetation in the shore zone, although some detached plant material is present in the seining area.

The site at Sandy Point (SP), in the Niantic River, is subjected to the least amount of wave action. The bottom is of medium-sized sand grains and occasionally there is a great deal of deteached plant life in the sampling area. 
The beach in front of the intake structures at Bay Point (IN) has a south-southeasterly exposure and is usually subjected to heavy surf action. The bottom consists of coarse sand and rock-rubble with no attached vegetation. Moderate amounts of unattached algal material are, however, present in the shore zone. Both the heavy surf action and adjacent construction activities related to the installation of the Unit 3 intake structure, have contributed to the regular alteration of the beach contour.

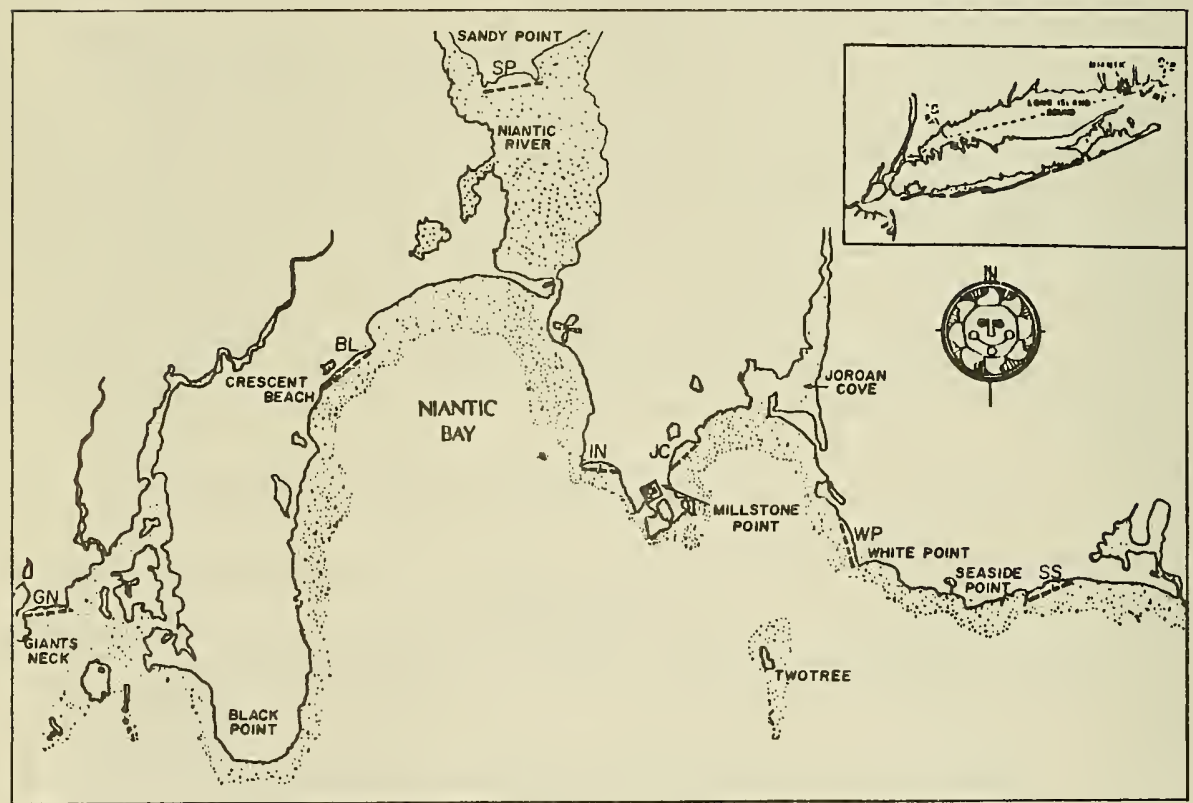

Figure 1. Location of shore-zone seine sampling stations. 
The seining area in Jordan Cove (JC) is shallow (< $1 \mathrm{~m}$ in depth for a distance of 20 to 25 meters from shore) and sheltered. The beach has a southeasterly exposure, and a freshwater stream traverses it from a nearby pond. Generally, considerable amounts of detached eel grass, Zostera marina, and algae in various stages of decomposition are present in this area. The bottom is composed of a mixture of silt, detritus, fine to coarse sand, and some emergent rocks. During the semi-monthly spring low tides, the entire seining area is frequently exposed.

The beach at White Point (WP) has a southwest exposure, but is protected by a breakwater. The bottom is medium-sized sand, and the shore zone of ten contains considerable amounts of plant material. There is a small brackish water pond located behind the beach. The stream draining this pond regularly alters the beach contour at the southern end of the area.

The Beach at Seaside Point (SS) faces due south and is exposed to direct wave action and heavy surf from Long Island Sound. The bottom substrate consists of medium to fine sand with no emerging rocks. It is completely free of attached vegetation, and only rarely are there more than small amounts of detached plant life in the surf zone.

\section{Collections}

Beginning in May, 1969, three contiguous beach seine hauls were made parallel to the beach within the two-hour period preceding high tide using a $9.2 \mathrm{~m} \times 1.2 \mathrm{~m}$ knotless nylon net with $1.3 \mathrm{~cm}$ mesh. The individual on the inshore end hauled the full length of the tow, $30 \mathrm{~m}$, while the other person arched into the beach at the end of the tow. Hauls were made in February, May, July, September and December through 1972 at 
GN, IN, JC and WP (Fig. 1.). In February, 1973, two additional stations were added: SS and BL. In 1974, the sampling frequency was increased to include collections during June, August and October. During 1975 only, SP, was sampled, and a single haul was made at IN due to construction activities. This sampling program is summarized in Table 1.

Table 1. Sumnary of frequency of seine sampling. The stations correspond to those shown in Figure 1. Triplicate hauls were made at each station in the months indicated.

\begin{tabular}{|c|c|c|c|c|c|c|c|c|}
\hline Year & February & May & June & July & August & Sept ember & October & December \\
\hline 1969 & & $\begin{array}{l}\text { GN IN } \\
\text { JC WP }\end{array}$ & & GN WP & & $\mathrm{GN}_{\mathrm{JP}}^{\mathrm{IN}}$ & & $\mathrm{GN}_{\mathrm{JC}}$ WP \\
\hline $\begin{array}{l}1970- \\
1972\end{array}$ & GN WP & GN WP & & $\mathrm{GN}_{\mathrm{JC}}^{\text {IN }}$ & & GN WP & & $\mathrm{GN}_{\mathrm{JC}}{ }^{\mathrm{IN}}$ \\
\hline 1973 & $\begin{array}{lll}G N & B L & \text { IN } \\
\text { JC } & \text { WP } & \text { SS }\end{array}$ & $\begin{array}{l}\text { GN BL IN } \\
\text { JC WP SS }\end{array}$ & & $\begin{array}{l}\text { GN BL IN } \\
\text { JC WP SS }\end{array}$ & & $\begin{array}{lll}\text { GN } & \text { BL } & \text { IN } \\
\text { JC } & \text { WP } & \text { SS }\end{array}$ & & $\begin{array}{lll}\text { GN } & \text { BL } & \text { IN } \\
\text { JC } & \text { WP } & \text { SS }\end{array}$ \\
\hline $\begin{array}{l}1974- \\
1981 \mathrm{a} .\end{array}$ & $\begin{array}{lll}\text { GN } & \text { BL } & \text { IN } \\
\mathrm{JC} & \mathrm{WP} & \mathrm{SS}\end{array}$ & $\begin{array}{lll}\text { GN } & \text { BL } & \text { IN } \\
\text { JC } & \text { WP } & \text { SS }\end{array}$ & $\begin{array}{lll}\text { GN } & \text { BL } & \text { IN } \\
\text { JC } & \text { WP } & \text { SS }\end{array}$ & $\begin{array}{l}\text { GN BL IN } \\
\text { JC WP SS }\end{array}$ & $\begin{array}{l}\text { GN BL IN } \\
\text { JC WP SS }\end{array}$ & $\begin{array}{l}\text { GN } \text { BL IN } \\
\text { JC WP }\end{array}$ & $\begin{array}{lll}G N & B L & \text { IN } \\
\text { JC } & W P & \text { SS }\end{array}$ & $\begin{array}{lll}\text { GN } & \text { BL } & \text { IN } \\
\text { JC } & \text { WP } & \text { SS }\end{array}$ \\
\hline
\end{tabular}

a. During 1975 only one haul was made at IN, three hauls were made at SP.

Fish in each haul were identified to lowest practical taxon, counted, and measured (standard length) to the nearest $\mathrm{mm}$.

Analytical Methods

Several methods were used to analyse the shore-zone seine data. Preliminary data reduction provided such summary statistics as the number of species, percent species composition, and total and species catch per unit effort (CPUE), based on a $30 \mathrm{~m}$ haul. These statistics were used to characterize the shore-zone data. Subsequently, various methodologies were used to determine if any changes had occurred in these descriptive statistics and included tests for determining the underlying probability distribution of the data, analyses of variance, 
time-series analysis, the Krumbein and Tukey (1956) method of analyzing proportions, and non-parametric tests.

A variety of techniques were used on the seine catch data to elucidate the underlying probability distribtuion. The frequency distributions of the CPUE and $\log _{10}(C P U E+1)$ transform were evaluated visually. The Kolmogorov-Smirnov D-statistic was used to test for normality. The possibility that the data came from a negative binomial distribution was investigated. To do this the mean, $m$ and a parameter, $\hat{k}$, must be known (Poole 1974). The mean can be estimated by the sample mean $\bar{x}$, while $\hat{k}$ may be estimated in one of three ways (B1iss and Fisher 1953). The simplest solution for $\hat{k}$ is:

$$
\hat{k^{2}}=\frac{\bar{x}}{s^{2}-\bar{x}}
$$

where $\bar{x}=$ sample mean

$s^{2}=$ sample variance

This estimator of $\hat{\mathrm{k}}$ is $90 \%$ efficient for small values of the mean when $(\hat{\mathrm{k}} / \overline{\mathrm{x}})>6$, for large values of $\overline{\mathrm{x}}$ when $\hat{\mathrm{k}}>13$ and for intermediate values of $\bar{x}$ when $((\hat{k}+\bar{x})(\hat{k}+2) / \bar{x}) \geq 15$.

An alternate method requires that estimates of $\hat{k}$ are iteratively replaced in the following equation until the two sides balance:

$$
\hat{k} * \log _{e}(1+(\bar{x} / \hat{k}))=\log _{e}\left(N / f_{O}\right)
$$

where $N=$ total number of samples

$f_{0}=$ number of zeros

This estimator if $90 \%$ efficient if $\left(f_{0} / N\right)>1 / 3$ and $\bar{x}<10$. For $\bar{x}>10$, $\left((\bar{x}+0.17)\left(f_{0} / N\right)-0.32\right)$ should be greater than 0.20 . 
The third and best method of estimating $\hat{k}$ is the maximum likelihood method. Scores, $\mathrm{Z}$, are computed from trial values of $\hat{\mathrm{k}}$ until $\mathrm{Z}=0$ :

$$
Z=\sum\left(\frac{A_{x}}{\hat{k}+x}\right)-N \log _{e}\{1+(\bar{x} / \hat{k})\}
$$

where $A_{x}=$ accumulated frequency in all units containing more than $x$ organisms

Al1 three estimates of $\hat{\mathrm{k}}$ were calculated for total CPUE, as well as for selected shore-zone species CPUE. Further, by using the estimates of $\hat{k}$ in the probability distribution function,

$$
P_{x}=\frac{(\hat{k}+x-1) !}{x !(\hat{k}-1) !} \cdot \frac{R^{x}}{q^{k}}
$$

$$
\text { where } \begin{aligned}
\mathrm{R} & =\mathrm{p} / \mathrm{q} \\
\mathrm{p} & =\overline{\mathrm{x}} / \hat{\mathrm{k}} \\
\mathrm{q} & =1+\mathrm{p}
\end{aligned}
$$

the expected frequency of samples containing $x$ organisms was calculated. A chi-square statistic:

$$
x^{2}=\frac{\left(\left(F_{x}-P_{x}\right)^{2}\right)}{P_{x}}
$$

where $\mathrm{F}_{\mathrm{X}}=$ actual frequency of $\mathrm{x}$ organisms

was used to teist if the seine data did in fact $f$ it a negative binomial distribution.

In order to estimate the adequacy of the seine program, the variances of the $\log _{10}($ CPUE +1 ) data were used to determine the sample size required to detect specified differences for different alpha and beta 
levels. Typically, to test for differences between arithmetic means, a simple subtraction is done, eg.,

$$
\text { Ho: } \mu 1-\mu 2=0 \text { vs } \mathrm{Ha}: \mu 1-\mu 2=\mathrm{d}
$$

where $d$ is some specified difference. For $\log _{10}$ transformed data this difference is the ratio of the geometric means. Therefore a difference, $\mathrm{d}$, in the means of $\mathrm{log}$ transformed data is equivalent to a ratio, $\mathrm{R}$, of the geometric means of the untransformed data $\left(d=\log _{10}(R)\right)$. To test against an alternate hypothesis that the geometric means differ by $30 \%$, we set $R=1.30$ and thus $d=0.114$.

To estimate the variance of the transformed data, the following analysis of variance model was used:

$$
L_{i j}=\mu+T_{i}+S_{j}+\varepsilon_{i j}
$$

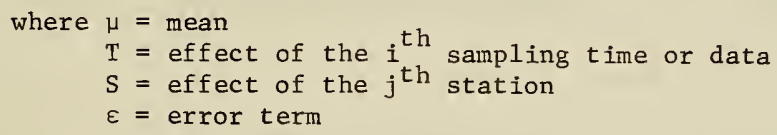

This error term was used as an estimate of $\sigma^{2}$ in determining the sample size, $N$, required to detect a specified difference, $d$, at various $\alpha$ and $\beta$ levels (Snedecor and Cochran, 1967):

$$
N=\left(z_{\alpha}+z_{\beta}\right)^{2} * 2 \sigma^{2} / d^{2}
$$

$$
\text { where } \begin{aligned}
\mathrm{Z}_{\alpha}= & \text { normal deviate such that the area from }-\infty \text { to } \mathrm{Z} \\
& \text { is }(1-\alpha) \\
\mathrm{Z}_{\beta}= & \text { normal deviate such that the area from }-\infty \text { to } \mathrm{Z} \\
\mathrm{d}= & \operatorname{iog}(10-\beta) \\
\sigma^{2}= & \text { error variance estimated from the ANOVA }
\end{aligned}
$$

The cost effectiveness of the seine program was evaluated following the method outlined by TASC (1979). The objective was to minimize the variance of the seine program within the current cost. The AOV model used was the same as equation (6). The model used to estimate yearly cost was given by: 


$$
\mathrm{c}=\mathrm{n}_{\mathrm{r}} * \mathrm{n}_{\mathrm{s}} * \mathrm{n}_{\mathrm{t}} * \mathrm{C}_{\mathrm{r}}+\mathrm{n}_{\mathrm{t}} * \mathrm{C}_{\mathrm{t}}
$$

where $C=$ yearly cost of seine program in personnel hours $(362 \mathrm{~h})$

$\mathrm{C}_{\mathrm{r}}=$ cost of processing one replicate $(2 \mathrm{~h})$

$C_{t}=$ cost of one 2 -day sampling trip $(9.25 \mathrm{~h})$

$n_{r}=$ number of replicates

$\mathrm{n}_{\mathrm{s}}=$ number of stations sampled

$n_{t}=$ number of 2-day sampling trips

while an appropriate description of the variance components was given by :

$$
s^{2}=\frac{s_{t}^{2}}{n_{t}}+\frac{s_{s}^{2}}{n_{s}}+\frac{s_{e}^{2}}{n_{r} n_{s} n_{t}}
$$

where $s^{2}=$ variance of mean $\log _{10}($ CPUE +1$)$

$\mathrm{s}_{t}^{2}=$ estimated variance component due to $t$ ime

$s^{2}=$ estimated variance component due to station

$\mathrm{s}_{\mathrm{e}}^{2}=$ estimated residual variance

To obtain the solution that minimizes the variance for a fixed cost, Lagrange multiplier techniques were followed (see TASC 1979). This gave:

$$
\begin{aligned}
& n_{s}^{\prime}=\left[\frac{s_{s}^{2} c+s_{e}^{2} c_{t} / n_{r}}{n_{r} c_{r} s_{t}^{2}}\right]^{\frac{1}{2}} \\
& n_{t}=c /\left(n_{r} n_{s}^{\prime} c_{r}+c_{t}\right)
\end{aligned}
$$

as the number of stations and times per year to sample for a given level of replication (1, 2 or 3$)$.

The $\log _{10}$ transformed catch data were analysed as time series. The autocorrelation structure of the data was investigated by visually evaluating the autocorrelation function generated by the PROC ARIMA procedure of SAS. The general hypotheses being considered were that the 
CPUE did not change over time (i.e., no power plant effect). A "change" could be an increase or decrease in the average values (trend), or an alteration of the frequency or amplitude of the fluctuations (cyclical components) of the values over time. While these specific changes can be tested with time series methodology (Box and Jenkins 1976), as a first step an alternate approach was taken. The monitoring data collected prior to the current year were used to construct autoregressive time series models of CPUE. Because long term constant values were hypothesized, the data were not detrended (long term trend removed from the data by regression). Detrending data that are primarily the results of stochastic processes is a procedure that may give misleading results in forecasting models (Box and Jenkins 1976). Autocorrelations between the catch at time, 1 , and ' $n$ ' time units, away, (up to 26 in this case) were determined. If such correlations were significantly different from zero at $\alpha=0.05$, autoregressive terms of " $A_{n}$ " were included in the model. For example, if the total catch was found to be positively correlated with its value 12 months away, the time series model for forecasting total catch would include an autoregressive term for 6 lags (bimonthly data points), designated $\mathrm{A}_{6}$. Constants and autoregressive terms were determined. These models were used to forecast the catch for the current year. The forecasted data were compared to the actual catch by using a test statistic with an $F$ distribution:

$$
F_{\text {calc }}=\frac{\sum_{i=1}^{s}\left(a_{i}-f_{i}\right)^{2} /(s-1)}{\hat{\sigma}_{m}^{2}}
$$

where $a_{i}=$ actual data point for time period $i$

$f_{i}=$ forecasted date point for thime period $i$

$s=$ number of time periods forecasted

$\sigma_{\mathrm{m}}^{2}=$ least square estimate of the model variance 
This $F$ ratio has $(s-1)$ and $(n-p)$ degrees of freedom where $n$ is the number of observations used to build the time series model and $\mathrm{p}$ is the number of terms estimated by the model.

To determine if the relative proportions of selected important shore-zone species differed in the current year from previous years, an expansion of the Krumbein and Tukey (1956) analysis of proportions was applied to the relative proportions of the five most abundant shore-zone taxonomic groups. A similar approach was used by Briggs and $0^{\prime}$ Connor (1971). The analysis consisted of using the arcsine square root transformation of the relative proportions and distributing the sums of squares as in the following analysis of variance model:

$$
\begin{aligned}
& \begin{aligned}
\mathrm{X}= & \mathrm{X}+\mathrm{P}_{i}+\mathrm{Y}_{i j}+\mathrm{S}_{i j k}+\mathrm{T}_{\mathrm{m}}+(\mathrm{TY})_{i j \mathrm{~m}}+(\mathrm{TS})_{i j k m}+ \\
& \mathrm{R}_{1}+\mathrm{HRP}_{i 1}+(\mathrm{RY})_{i j 1}+(\mathrm{RS})_{i j k l}+(\mathrm{TR})_{1 \mathrm{~m}}+
\end{aligned} \\
& { }^{(T R P)}{ }_{k l m}+(T R Y)_{i j l m}+(T R S){ }_{i j k l m}
\end{aligned}
$$

where the model components are defined in Table 2.

There is no error term in this model because proportion data are multinomial. The theoretical variance (BV) is approximately $821 / \mathrm{n}$ where $\mathrm{n}$ is the average number of individuals in each sample (Bartlett 1947). The total sum of squares was apportioned following Krumbein and Tukey (1956) and the expected mean squares determined. Because changes in the relationship among taxa were of interest, F values for significance tests were calculated only for terms that included taxon crossed with some other factor. The $\mathrm{F}$ ratios for testing the significance of the taxon $\mathrm{x}$ period and taxon $\mathrm{x}$ year interactions were "manufactured" by taking the ratio of the sum of two mean squares. The appropriate degrees of freedom were calculated using the method given by Snedecor and Cochran (1967). Table 3 summarized the effects of interest and composition of 
Table 2. Definition of percent species composition AOV model components.

\begin{tabular}{|c|c|}
\hline Component & Definition \\
\hline$x_{i j k l m}$ & $\operatorname{arcsine}\left(p_{i j k l m} / n_{i j k l}\right)^{\frac{1}{2}}$ for $p$ individuals of species $m$ in $n$ total \\
\hline & mean \\
\hline P & effect due to period i for the period before or after September 1979 \\
\hline Y & effect due to year $j$ (October through September) within period $i$ \\
\hline S & effect due to season (month or quarter) $k$ within year $j$, period $i$ \\
\hline T & effect due to being assigned to a taxon (species) $\mathrm{m}$ \\
\hline TP & interaction effect of taxon by period \\
\hline TY & interaction effect of taxon by year (within period) \\
\hline TS & interaction effect of taxon by season (within year and period) \\
\hline $\mathrm{R}$ & effect due to region (station) 1 \\
\hline $\mathrm{RP}$ & interaction effect of region by period \\
\hline RY & interaction effect of region by year (within period) \\
\hline RS & interaction effect of region by season (within year and period) \\
\hline TR & interaction effect of taxon by region \\
\hline TRP & interaction effect of taxon by region by period \\
\hline TRY & interaction effect of taxon by region by year (within period) \\
\hline TRS & |interaction-effect of taxon by region by season (within year and period) \\
\hline
\end{tabular}


Table 3. Summary of percent species composition AOV effects of interest, mean squares (MS), derivation of $F$ statistic and corresponding degrees of freedom $\left(v_{1}, v_{2}\right)$.

\begin{tabular}{|c|c|c|c|c|}
\hline Source & d.f. & MS & F statistic & $v_{1}, v_{2}$ \\
\hline Taxon X Period & tp & $T P$ & $\frac{T P+T R Y}{T Y+T R P}$ & $\frac{(T P+T R Y)^{2}}{\frac{T P^{2}}{t P}+\frac{T R Y^{2}}{t r y}} \cdot \frac{(T Y+T R P)^{2}}{\frac{T Y^{2}}{t y}+\frac{T R P^{2}}{t r P}}$ \\
\hline Taxon X Year & ty & TY & $\frac{T Y+T R S}{T S+T R Y}$ & $\frac{(T Y+T R S)^{2}}{\frac{T Y^{2}}{t y}+\frac{T R S^{2}}{t r S}} \cdot \frac{(T S+T R Y)^{2}}{\frac{T S^{2}}{t \theta}+\frac{T R Y^{2}}{t r y}}$ \\
\hline Taxon $X$ Season & ts & TS & TS/TRS & ts, trs \\
\hline Taxon X Region & $\operatorname{tr}$ & $\mathrm{TR}$ & TR/TRP & tr, trp \\
\hline Taxon $X$ Region $X$ Period & trp & TRP & TRP/TRY & $\operatorname{trp}, \operatorname{try}$ \\
\hline Taxon $X$ Region X Year & try & TRY & TRY/TRS & try, trs \\
\hline Taxon X Region X Season & $\operatorname{trs}$ & TRS & $\operatorname{TRS} /(821 / \pi)$ & $\operatorname{tra}, \mathrm{n}$ \\
\hline Binomial variance & $\mathrm{n}$ & $821 / n$ & & \\
\hline
\end{tabular}


the $\mathrm{F}$ ratios. Determination of expected mean squares and all calculations were completed using the computer program PROC ANOVA from SAS79.

Several nonparametric (distribution free) statistical tests were used to detect and/or evaluate changes in the shore-zone finfish to avoid having to assume a normal distribution. The Kruskal-Wallis nonparametric analysis of variance and a multiple range test based on ranks (Zar 1974) were also applied to the data.

\section{RESULTS}

Since 1969, 190,394 fish representing 39 taxa have been collected from the shore-zone samples. The species caught, their abundance, and relative percent composition are presented in Table 4. Silversides (Menidia spp.) were the dominant shore-zone species, making up $77 \%$ of the total catch. This group includes representatives from two species, the inland silverside (M. beryllina) and the Atlantic silverside (M. menidia), because they were not distinguished during some times of the study. Killifishes (Fundulus spp.) were the second most abundant shorezone fish. The juveniles of the mummichog (F. heteroclitus) are indistinguishable from those of the killifish (F. majalis). For this reason all killifishes were grouped together. The taxonomic literature on the third most abundant taxon, sand lance (Ammodytes sp.), is in a state of flux. Evidence indicates that only one species is present but the correct name remains obscure. Atlantic menhaden (Brevoortia tyrannus) and fourspine stickleback (Apeltes quadracus) as separate taxa have contributed at least $1 \%$ to the total catch since 1969 . These five taxonomic groups were considered 'important' and selected for further analysis. 
Table 4. Actual abundance and percent species composition of pish collected with selnes 1 I Long Island Sound near the Millstone Pover Station, 1969-1981.

\begin{tabular}{|c|c|c|}
\hline Species & Total & Percent \\
\hline 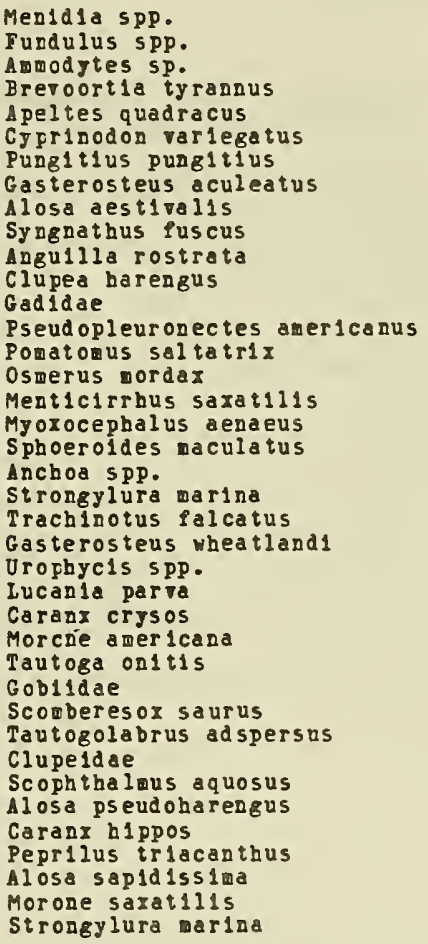 & $\begin{array}{r}147078 \\
19106 \\
10584 \\
4483 \\
4038 \\
1405 \\
810 \\
671 \\
548 \\
383 \\
231 \\
156 \\
120 \\
65 \\
63 \\
38 \\
36 \\
23 \\
19 \\
18 \\
17 \\
15 \\
14 \\
14 \\
12 \\
11 \\
9 \\
8 \\
6 \\
6 \\
6 \\
5 \\
4 \\
3 \\
2 \\
2 \\
1 \\
1 \\
1\end{array}$ & $\begin{array}{l}77.25 \\
10.03 \\
5.56 \\
2.35 \\
2.13 \\
0.74 \\
0.43 \\
0.35 \\
0.29 \\
0.20 \\
0.12 \\
0.08 \\
0.06 \\
0.03 \\
0.03 \\
0.02 \\
0.02 \\
0.01 \\
0.01 \\
0.01 \\
0.01 \\
0.01 \\
0.01 \\
0.01 \\
0.01 \\
0.01 \\
0.00 \\
0.00 \\
0.00 \\
0.00 \\
0.00 \\
0.00 \\
0.00 \\
0.00 \\
0.00 \\
0.00 \\
0.00 \\
0.00 \\
0.00\end{array}$ \\
\hline TOTAL & 190394 & 100.00 \\
\hline
\end{tabular}


The species composition of the shore-zone catch was compared to that reported from the impingement and entrainment sampling programs (Table 5). Of the five selected species collected by seine, three could be considered 'potentially impacted' by entrainment or impingement as they contributed at least $1 \%$ to those collections as well. They were silversides, At lantic menhaden and sand lance.

The catch statistics varied with time, station and species. The juveniles of Atlantic menhaden are very abundant in the shore zone only occasionally, and the CPUE exhibited a sporadic pattern, while silversides CPUE exhibited a regular, seasonal pattern at nearly all stations (Fig. 2). Even though these two species' patterns of abundance are dissimilar, in both cases, the CPUE drops to 0 many times. Such a situation produces highly skewed, non-normal sample distributions for all of the important selected species as well as for total catch (Fig. 3). The results of the Shapiro-Wilke test for normality on the total catch and for the CPUE of selected species are presented in Table 6. Also shown are the results when $\log _{10}$ transformation was used. Neither were found to normalize the data.

Frequently, highly skewed data approximate a negative binomial distribution (Poole 1974), and such a possibility was investigated. A goodness-of-fit test (chi-square) of the data to the negative binomial distribution based on the maximum likelihood estimator of $\hat{k}$, indicated that the data did not come from this type of distribution either (Table 7).

Another characteristic of the data base to be investigated was its autocorrelation structure. The correlations between data points at various lags can be represented by the autocorrelation function (ACF). 
Table 5. Comparison of dominant species of fish collected in various sampling programs at Millstone Point between October 1969 and September 1981. Only complete years (October through September) were used.

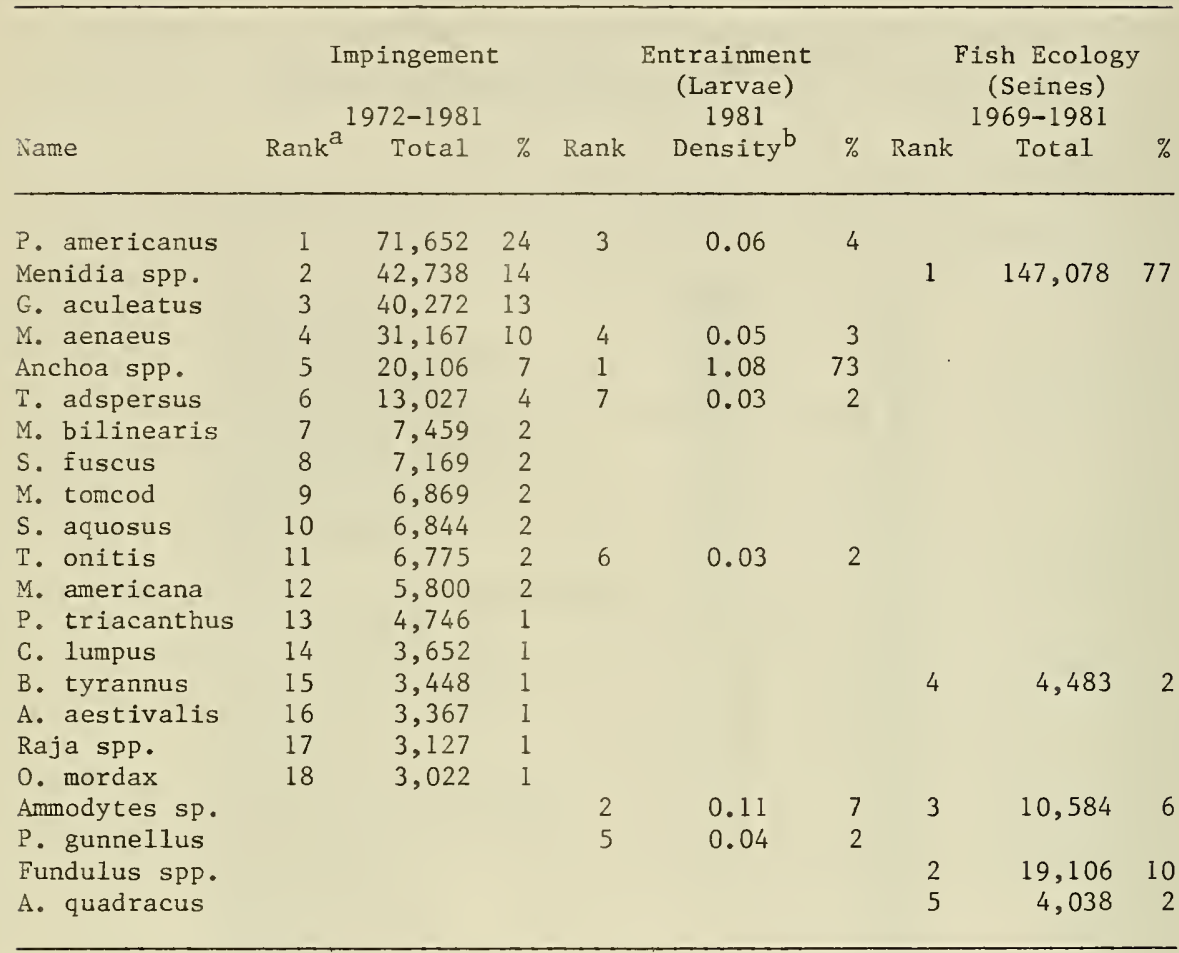

a. Rank based on percent species composition

b. $\left(\# / \mathrm{m}^{3}\right)$ 


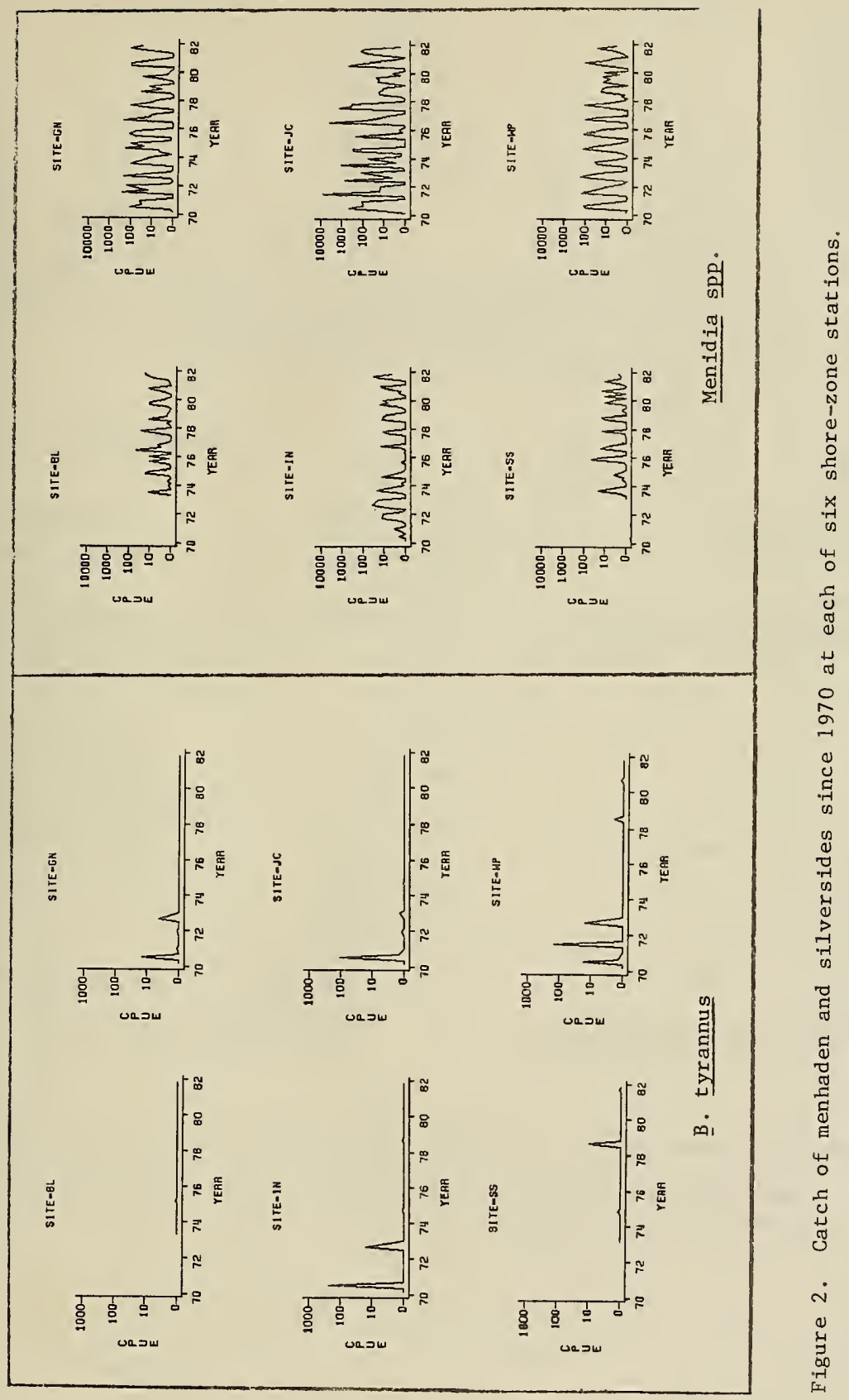




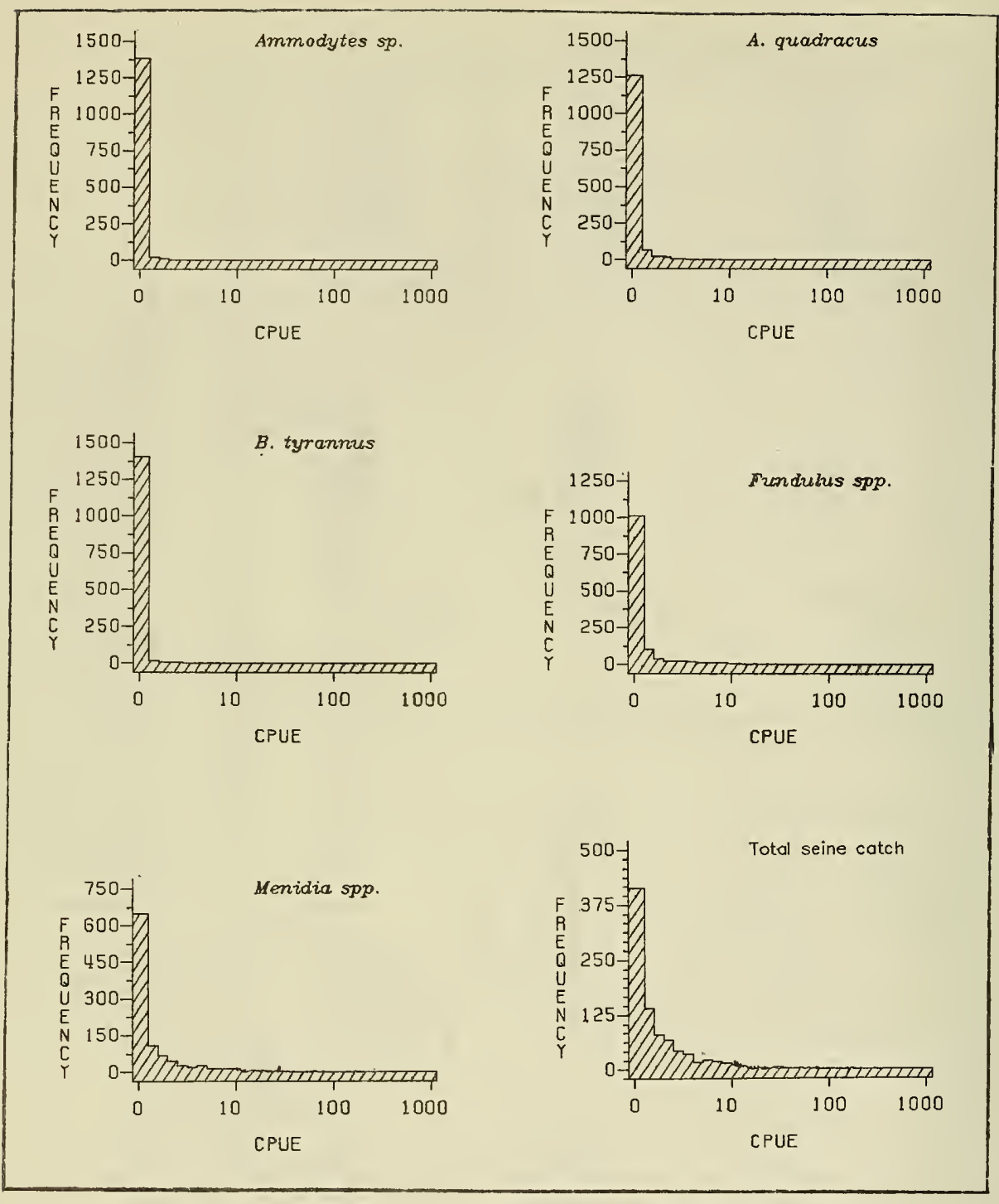

Figure 3. Frequency distribution of selected species' catch and total catch for all stations combined. 
Table 6. Results of the Kolmogorop-Smirnor test for normality using untransformed and 108 -transformed data. In order to accept the null hypothesis that the selne data $(N=1460)$ come from a normal distribution (alpha=0.10). D must be smaller than ø.e3.

\section{D-statistic}

Species

Untransformed data

Log-transformed data

Ammodytes $5 p$.

$0.49 *$

$0.52 *$

A. quadracus

$0.45 *$

0. $49 * *$

B. tyrannus

$0.50 *$

$0.52 \%$

Fundulus spp.

$0.42 *$

$0.40 *$

Menidia spp.

D. $46^{* *}$

$0.24 * *$

Total selne catch

$0.45 *$

$0.15 *$

* signiflcant at al pha $=\varnothing .01$ 
Tatle?. Results of chi-square test to determine 1 f the selne data $11 \mathrm{t}$ a negative binomial distribution based $k$ calculated in three ways (see equations 1,2 and 3 ).

\begin{tabular}{|c|c|c|c|c|c|c|c|}
\hline Species & DF & $k(1)$ & & $k(2)$ & & $k(3)$ & \\
\hline Ammodytes $\mathrm{sp}$. & 5 & 0.0503 & $71.8^{* 4}$ & 0.8259 & $30.0 \%$ & 0.0259 & $30.1 *$ \\
\hline A. quadracus & 25 & 0.0687 & $90.7 * 4$ & 0.0409 & $51.7 \%$ & 10.0407 & $51.5 *$ \\
\hline B. tyrannus & 2 & 0.0803 & $48.0 * *$ & 0.0407 & $20.8^{*}$ & 0.0410 & $21.0 * *$ \\
\hline Fundulus spF. & 126 & 0.0932 & 133.3 & 0.0736 & 115.6 & 0.0724 & 116.0 \\
\hline Mentdia spp. & 363 & 0.1278 & $543.2 * *$ & 0.1375 & $518.5 * *$ & 0.1328 & $529.2 * *$ \\
\hline Total seine catcb & 464 & 0.1411 & $688.6 *$ & 0.2168 & 501.6 & 0.1901 & $526.5 *$ \\
\hline
\end{tabular}

* slgnilicant at $\propto=0.05$

* signiflcant at $\alpha=0.01$ 
The ACFs of the total CPUE and selected species catch at JC are typical of all stations and are presented in Figure 4. It is apparent that significant autocorrelations do exist among the data points. Glass et a1. (1975) have concluded that the effect of autocorrelations on probability statements cannot be designated.

The last aspects of the data to be examined were the variance components. Based on the analysis of variance model presented earlier, estimates of the variance components, Ss, St and Se for month, station and error respectively, were calculated and are presented in Table 8 . When these variance components were divided by 8 (number of sampling months per year), 6 (number of stations sampled per sampling month), and 144 (total number of samples collected per year) respectively, the resulting variance terms were used to calculate the number of stations to sample and the number of times per year to sample to minimize the variance given the current cost of the seining program (Table 9). The error variances were used to calculate the number of samples required to detect a specified difference of the means of the log transformed catch data (d), corresponding to the indicated ratio of the geometric means (R) at certain $\alpha$ and $B$ levels (Table 10).

Al1 of the characteristics of the data base indicated that the use of standard analysis of variance tests might not be appropriate. Thus a nonparametric analysis of variance based on ranks was used to test for differences between yearly, bimonthly, and station means. The results are presented in Table 11.

To determine if significant changes occurred in the shore-zone percent species composition, the method of Krumbein and Tukey (1956) of analysing proportions was applied to the data. The results, presented 
Armodytes $\mathrm{sp}$.

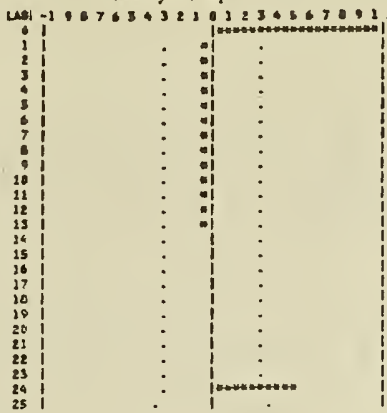

B.eyrannua

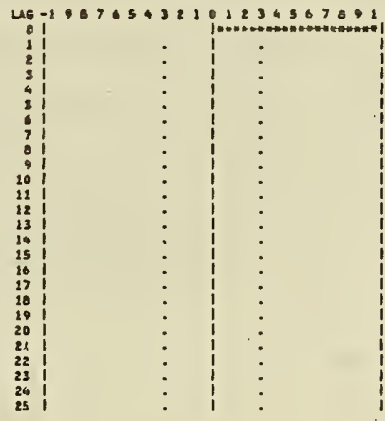

Mentd ia spp.

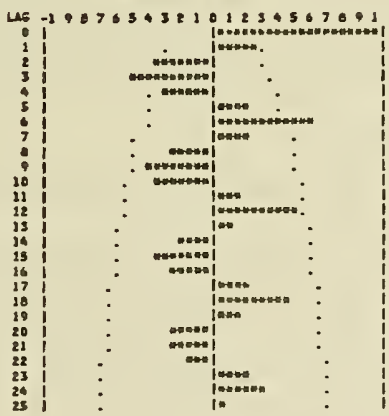

A. qusdrecus

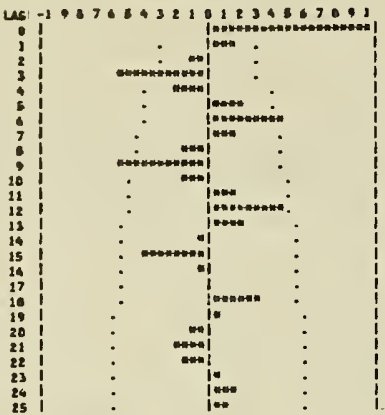

Fundulus opp.

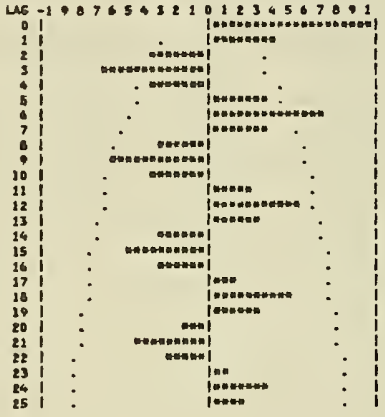

Total Catch

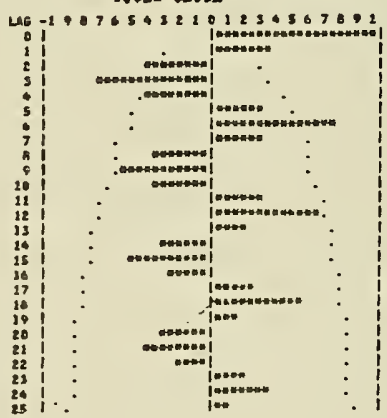

Figure 4. Autocorrelation functions of selected species' CPUE and total catch for station Jordan Cove. 


\begin{tabular}{|c|c|c|c|c|c|c|c|c|c|c|c|}
\hline 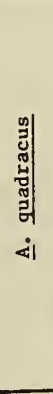 & 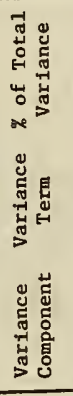 & $\begin{array}{l}\circ \\
8 \\
0 \\
0\end{array}$ & $\begin{array}{l}\text { : } \\
\text { o } \\
\dot{0} \\
\text { o } \\
\dot{0} \\
\dot{0}\end{array}$ & $\begin{array}{l}\stackrel{\circ}{\circ} \\
\vdots \\
0\end{array}$ & $\begin{array}{l}\stackrel{0}{0} \\
\stackrel{0}{0} \\
\dot{0}\end{array}$ & 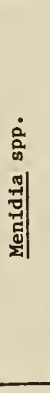 & 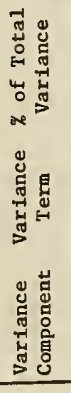 & 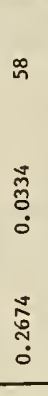 & $\begin{array}{l}\text { m } \\
\overrightarrow{\text { I }} \\
\dot{0} \\
\dot{0} \\
\stackrel{0}{0} \\
\stackrel{0}{0}\end{array}$ & $\begin{array}{l}\overrightarrow{\tilde{\delta}} \\
\dot{0} \\
\dot{0} \\
\stackrel{0}{0} \\
\stackrel{0}{0}\end{array}$ & $\begin{array}{l}\text { ईิ } \\
\text { ถุ. } \\
\dot{0}\end{array}$ \\
\hline 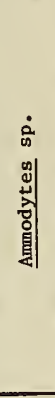 & 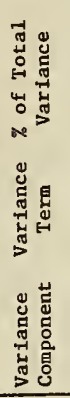 & $\begin{array}{l}\infty \\
\stackrel{0}{0} \\
\dot{0} \\
\infty \\
\stackrel{0}{0} \\
\dot{0}\end{array}$ & $\begin{array}{l}\text { ¿ } \\
\vdots \\
\dot{0}\end{array}$ & $\begin{array}{l}\stackrel{0}{0} \\
0 \\
\dot{0} \\
\\
0 \\
0 \\
0 \\
\dot{0}\end{array}$ & $\begin{array}{l}\stackrel{\infty}{8} \\
\stackrel{8}{0} \\
\dot{0}\end{array}$ & 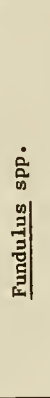 & 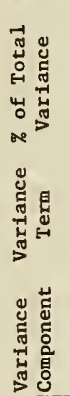 & 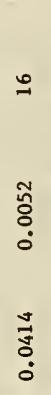 & 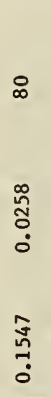 & $\begin{array}{l}\stackrel{m}{\overrightarrow{0}} \\
\dot{0} \\
\stackrel{0}{0} \\
\stackrel{0}{0} \\
\stackrel{0}{0}\end{array}$ & $\begin{array}{l}\tilde{N} \\
\dot{0} \\
\dot{0}\end{array}$ \\
\hline $\begin{array}{l}\text { ేี } \\
\text { गु } \\
\vec{J} \\
\vec{J} \\
\text { ثै }\end{array}$ & 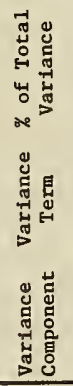 & $\begin{array}{l}\tilde{\tilde{\tilde{O}}} \\
\dot{0} \\
\stackrel{m}{m} \\
\stackrel{m}{0}\end{array}$ & $\begin{array}{l}\text { 号 } \\
\text { ô } \\
\dot{0}\end{array}$ & 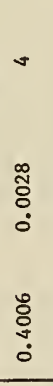 & $\begin{array}{l}\text { ț } \\
\hat{0} \\
\dot{0}\end{array}$ & 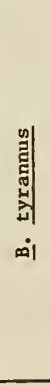 & 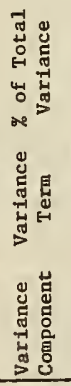 & $\begin{array}{l}\tilde{8} \\
\dot{0} \\
\dot{0}\end{array}$ & $\begin{array}{l}\vec{\delta} \\
\dot{8} \\
\dot{0} \\
\text { ஜ } \\
\dot{\delta} \\
\dot{0}\end{array}$ & $\begin{array}{l}\text { ठ } \\
0 \\
0 \\
0 \\
\overrightarrow{0} \\
\dot{0} \\
\dot{0}\end{array}$ & $\begin{array}{l}\infty \\
\delta \\
\delta \\
\dot{0}\end{array}$ \\
\hline & 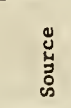 & हేّ & 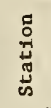 & 岕 & 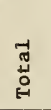 & & 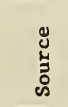 & $\begin{array}{l}\text { मี } \\
\frac{0}{2}\end{array}$ & 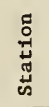 & 芦 & ثี \\
\hline
\end{tabular}


Table 9. Number of stations $\left(a_{s}\right)$ and number of times per year $\left(a_{t}\right)$ to sample the shore-zone to minlulze the varlance and maintain the current cost ( 362 personnel-hrs per year)

\begin{tabular}{|c|c|c|c|c|c|}
\hline Name & $\begin{array}{l}\text { Current } \\
\text { Varlance }\end{array}$ & $\begin{array}{l}\text { Number of } \\
\text { Reps }\end{array}$ & $\begin{array}{l}\text { Number of } \\
\text { Stations }\end{array}$ & $\begin{array}{l}\text { Number of } \\
\text { T1mes }\end{array}$ & $\begin{array}{c}\text { New } \\
\text { Varlance }\end{array}$ \\
\hline $\begin{array}{l}\text { Total Catch } \\
\text { Total Catch } \\
\text { Total Catch } \\
\text { Ammodytes } 5 p \text {. } \\
\text { Ammodytes } 5 p \text {. } \\
\text { Ammodytes sp. } \\
\text { A. quadracus } \\
\text { A. quadracus } \\
\text { A. quadracus } \\
\text { B. tyrannus } \\
\text { B. tyrannus } \\
\text { B. tyrannus } \\
\text { Fundulus spp. } \\
\text { Fundulus spp. } \\
\text { Fundulus spp. } \\
\text { Menlda spp. } \\
\text { Menldla spp. } \\
\text { Menidia spp. }\end{array}$ & $\begin{array}{l}0.0764041 \\
0.0764041 \\
0.0764041 \\
0.0018230 \\
0.0018230 \\
0.0018230 \\
0.0079319 \\
0.0079319 \\
0.0079319 \\
0.0007922 \\
0.0007922 \\
0.0007922 \\
0.0322798 \\
0.0322798 \\
0.0322798 \\
0.0576520 \\
0.0576520 \\
0.0576520\end{array}$ & $\begin{array}{l}1 \\
2 \\
3 \\
1 \\
2 \\
3 \\
1 \\
2 \\
3 \\
1 \\
2 \\
3 \\
1 \\
2 \\
3 \\
1 \\
2 \\
3\end{array}$ & $\begin{array}{l}7 \\
5 \\
4 \\
<1 \\
<1 \\
<1 \\
<1 \\
<1 \\
<1 \\
<1 \\
<1 \\
<1 \\
21 \\
1 \\
1 \\
5 \\
4 \\
3\end{array}$ & $\begin{array}{l}15 \\
12 \\
11 \\
38 \\
38 \\
37 \\
36 \\
35 \\
34 \\
39 \\
39 \\
39 \\
27 \\
24 \\
22 \\
22 \\
18 \\
15\end{array}$ & $\begin{array}{l}0.053829 \\
0.070405 \\
0.083634 \\
0.031068 \\
0.038306 \\
0.044363 \\
0.113568 \\
0.158400 \\
0.193060 \\
0.031494 \\
0.033890 \\
0.036127 \\
0.075532 \\
0.105155 \\
0.127989 \\
0.043656 \\
0.056877 \\
0.067151\end{array}$ \\
\hline
\end{tabular}


Tabie 10. Number of samples for specified do, R, at various alpha (a) and betalb) error levels.

\begin{tabular}{|c|c|c|c|c|c|c|c|c|}
\hline Name & d & $\mathbf{R}$ & $\begin{array}{l}a=0.05 \\
b=0.90\end{array}$ & $\begin{array}{l}a=0.05 \\
b=0.80\end{array}$ & $\begin{array}{c}\text { Numbi.r of } \\
a=0.05 \\
b=0.70\end{array}$ & $\begin{aligned} s a p l e s \\
a=0.10 \\
b=0.90\end{aligned}$ & $\begin{array}{l}a=0.10 \\
b=0.80\end{array}$ & $\begin{array}{l}a=0.10 \\
b=0.70\end{array}$ \\
\hline Total catch & $\begin{array}{l}0.041 \\
0.061 \\
0.079 \\
0.097 \\
0.114 \\
0.130 \\
0.146 \\
0.161 \\
0.176\end{array}$ & $\begin{array}{l}1.10 \\
1.15 \\
1.20 \\
1.25 \\
1.30 \\
1.35 \\
1.40 \\
1.45 \\
1.50\end{array}$ & $\begin{array}{r}4006 \\
1863 \\
1095 \\
731 \\
529 \\
404 \\
329 \\
264 \\
221\end{array}$ & $\begin{array}{r}2892 \\
1345 \\
790 \\
528 \\
382 \\
292 \\
232 \\
190 \\
160\end{array}$ & $\begin{array}{r}2237 \\
1040 \\
611 \\
408 \\
295 \\
226 \\
179 \\
147 \\
124\end{array}$ & $\begin{array}{r}3074 \\
1430 \\
840 \\
501 \\
406 \\
310 \\
247 \\
202 \\
170\end{array}$ & $\begin{array}{r}2110 \\
981 \\
576 \\
385 \\
278 \\
213 \\
169 \\
139 \\
117\end{array}$ & $\begin{array}{r}1556 \\
723 \\
425 \\
284 \\
205 \\
157 \\
125 \\
102 \\
86\end{array}$ \\
\hline Annooytes SP. & $\begin{array}{l}0.041 \\
0.061 \\
0.079 \\
0.097 \\
0.714 \\
0.130 \\
0.146 \\
0.161 \\
0.176\end{array}$ & $\begin{array}{l}1.10 \\
1.15 \\
1.20 \\
1.25 \\
1.30 \\
1.35 \\
1.40 \\
1.45 \\
1.50\end{array}$ & $\begin{array}{c}830 \\
386 \\
227 \\
151 \\
109 \\
84 \\
67 \\
55 \\
46\end{array}$ & $\begin{array}{r}599 \\
279 \\
164 \\
109 \\
79 \\
60 \\
48 \\
39 \\
33\end{array}$ & $\begin{array}{r}463 \\
215 \\
127 \\
85 \\
61 \\
47 \\
37 \\
30 \\
26\end{array}$ & $\begin{array}{l}637 \\
296 \\
174 \\
116 \\
84 \\
64 \\
51 \\
42 \\
35\end{array}$ & $\begin{array}{l}437 \\
203 \\
119 \\
80 \\
58 \\
44 \\
35 \\
29 \\
24\end{array}$ & $\begin{array}{r}322 \\
150 \\
86 \\
59 \\
43 \\
32 \\
26 \\
21 \\
18\end{array}$ \\
\hline A. quaoracus & $\begin{array}{l}0.041 \\
0.061 \\
0.079 \\
0.097 \\
0.114 \\
0.130 \\
0.146 \\
0.161 \\
0.176\end{array}$ & $\begin{array}{l}1.10 \\
1.15 \\
1.20 \\
1.25 \\
1.30 \\
1.35 \\
1.40 \\
1.45 \\
1.50\end{array}$ & $\begin{array}{r}822 \\
382 \\
225 \\
150 \\
108 \\
83 \\
60 \\
54 \\
45\end{array}$ & $\begin{array}{l}593 \\
276 \\
162 \\
108 \\
78 \\
60 \\
48 \\
39 \\
33\end{array}$ & $\begin{array}{l}454 \\
213 \\
125 \\
84 \\
61 \\
46 \\
37 \\
30 \\
25\end{array}$ & $\begin{array}{l}630 \\
293 \\
172 \\
115 \\
83 \\
64 \\
51 \\
41 \\
35\end{array}$ & $\begin{array}{l}433 \\
201 \\
118 \\
79 \\
57 \\
44 \\
35 \\
28 \\
24\end{array}$ & $\begin{array}{r}319 \\
148 \\
87 \\
58 \\
42 \\
32 \\
26 \\
21 \\
18\end{array}$ \\
\hline B. tyrarrus & $\begin{array}{l}0.041 \\
0.061 \\
0.079 \\
0.097 \\
0.114 \\
0.130 \\
0.146 \\
0.161 \\
0.176\end{array}$ & $\begin{array}{l}1.10 \\
1.15 \\
1.20 \\
1.25 \\
1.30 \\
1.35 \\
1.40 \\
1.45 \\
1.50\end{array}$ & $\begin{array}{r}601 \\
279 \\
164 \\
110 \\
79 \\
61 \\
48 \\
40 \\
33\end{array}$ & $\begin{array}{l}434 \\
202 \\
119 \\
79 \\
57 \\
46 \\
35 \\
29 \\
26\end{array}$ & $\begin{array}{r}335 \\
156 \\
92 \\
61 \\
44 \\
36 \\
27 \\
22 \\
19\end{array}$ & $\begin{array}{l}461 \\
214 \\
126 \\
84 \\
61 \\
46 \\
37 \\
30 \\
25\end{array}$ & $\begin{array}{l}316 \\
147 \\
86 \\
58 \\
42 \\
32 \\
25 \\
29 \\
17\end{array}$ & $\begin{array}{r}233 \\
108 \\
64 \\
43 \\
31 \\
24 \\
19 \\
15 \\
13\end{array}$ \\
\hline fundulus sFF. & $\begin{array}{l}0.041 \\
0.061 \\
0.079 \\
0.097 \\
0.114 \\
0.130 \\
0.146 \\
0.161 \\
0.176\end{array}$ & $\begin{array}{l}1.10 \\
1.15 \\
1.20 \\
1.25 \\
1.30 \\
1.35 \\
1.40 \\
1.45 \\
1.50\end{array}$ & $\begin{array}{l}1896 \\
882 \\
518 \\
346 \\
250 \\
191 \\
152 \\
125 \\
105\end{array}$ & $\begin{array}{r}1369 \\
637 \\
374 \\
250 \\
181 \\
138 \\
110 \\
90 \\
76\end{array}$ & $\begin{array}{r}1059 \\
692 \\
289 \\
193 \\
140 \\
107 \\
85 \\
70 \\
58\end{array}$ & $\begin{array}{r}1455 \\
677 \\
398 \\
265 \\
192 \\
147 \\
117 \\
96 \\
80\end{array}$ & $\begin{array}{l}998 \\
464 \\
273 \\
182 \\
132 \\
101 \\
80 \\
66 \\
55\end{array}$ & $\begin{array}{l}736 \\
342 \\
201 \\
134 \\
97 \\
74 \\
59 \\
48 \\
41\end{array}$ \\
\hline Menicie spp. & $\begin{array}{l}0.041 \\
0.061 \\
0.079 \\
0.097 \\
0.114 \\
0.130 \\
0.146 \\
0.161 \\
0.176\end{array}$ & $\begin{array}{l}1.10 \\
1.15 \\
1.20 \\
1.25 \\
1.30 \\
1.35 \\
1.40 \\
1.45 \\
1.50\end{array}$ & $\begin{array}{r}4460 \\
2074 \\
1219 \\
814 \\
589 \\
450 \\
358 \\
293 \\
246\end{array}$ & $\begin{array}{r}3220 \\
1497 \\
880 \\
587 \\
425 \\
325 \\
258 \\
212 \\
178\end{array}$ & $\begin{array}{r}2490 \\
1158 \\
680 \\
454 \\
329 \\
251 \\
200 \\
164 \\
138\end{array}$ & $\begin{array}{r}3422 \\
1591 \\
935 \\
624 \\
452 \\
345 \\
275 \\
225 \\
184\end{array}$ & $\begin{array}{r}2348 \\
1092 \\
642 \\
428 \\
310 \\
237 \\
188 \\
155 \\
130\end{array}$ & $\begin{array}{r}1732 \\
805 \\
473 \\
316 \\
229 \\
175 \\
139 \\
116 \\
96\end{array}$ \\
\hline
\end{tabular}

- R = Rario of two geometric means. An R=1.10 indicates a lox change in the means.

$d=\log (R)$ 
Table 11 Results of Kruskal-Wallis nonparametric analyola of varfance and multiple range teat oo various shore - zone community parameters. Clase varlables decrease from left to $\mathrm{r} \mathrm{Ight}_{\mathrm{B}}$ and thooe values coonected by a line are not olgnificanty different at $\alpha=0.05$.

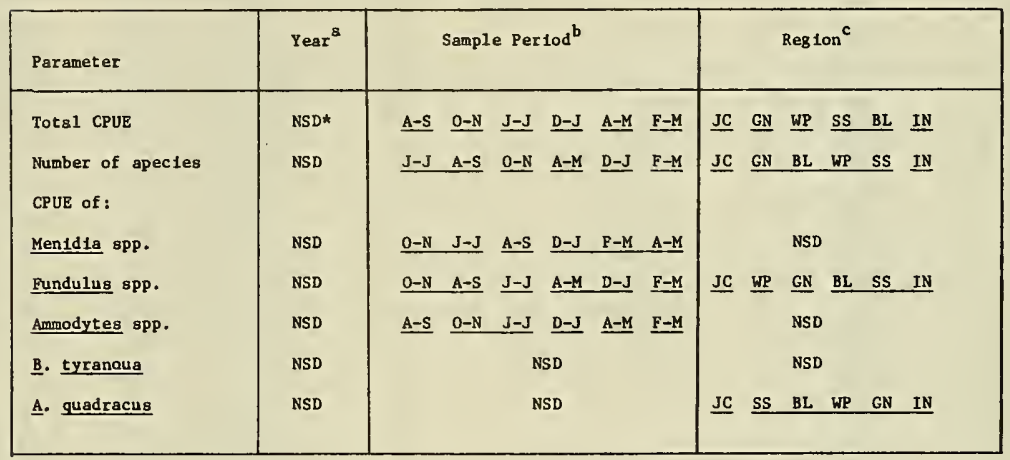

a. Values for class year: 1975-1981

b. Values for clsgs ample period: (B imonth) $0-N, D-J, F-M, A-M, J-J, A-S$

c. Values for class region: SS(Seaside), WP(White Point), JC(Jordan Cove),

* NSD - No algnificant difference IN(Intake), BL(Black Polat), GN(Glants Neck). 
in Table 12, indicated that the composition was significantly affected by season, station and the interaction of season and station.

Finally, the time series approach to the data produced models that, to some extent, described the patterns of abundance of the shore-zone fish. Additionally, the models produced forecasts that could be compared to actual data. The results from the time series investigations are presented in Table 13.

\section{DISCUSSION}

In order to address the first objective, i.e., describe the occurrence, distribution and relative abundance of potentially impacted shore-zone finfish in the Greater Milistone Bight, 'shore-zone' and 'potentially impacted' were defined. The shore-zone finfish were considered to be those species captured by the beach seines (see Table 4). These finfish were typical of those found in shore-zone assemblages along the Northeast Atlantic Coast from New York (Briggs and $0^{\prime}$ Connor 1971) through Long Island Sound (Warfel and Merriman 1944; LILCo 1980) and the Mystic River estuary, Connecticut (Pearcy and Richards 1962) to Rhode Island (Mulkana 1966). The pattern of fluctuations in the catches of these fish over time, was either seasonal (eg. silversides, Fig. 2) or occasional (eg. Atlantic menhaden, Fig. 2). Seasonally, the catch of silversides drops to zero when the shore-zone fish migrate from shallow areas to deeper regions during the winter to avoid low temperatures, wave action and turbidity (Briggs and $O^{\prime}$ Connor 1971; Hillman et al. (1977). The Atlantic menhaden population typically exhibits large fluctuations (Bigelow and Schroeder 1953) and their frequent ab'sence from the Millstone Bight shore zones was not unexpected. Thus catches of 0 fish during certain 
Table 12. Summary of Krumbein-Tukey AOV done on shore-zone percent species composition.

\begin{tabular}{|c|c|c|c|}
\hline Source & d.f. & MS & $F$ value $\left(U_{1}, U_{2}\right)$ \\
\hline Taxon X Period ${ }^{a}$ & 5 & 559.19 & $2.44(12,47)$ \\
\hline Taxon X Year ${ }^{b}$ & 30 & 260.83 & $0.48(101,303)$ \\
\hline Taxon X Sample Period ${ }^{c}$ & 195 & 753.05 & $3.36(195,980) *$ \\
\hline Taxon X Region & 30 & 1256.54 & $14.63(30,25) *$ \\
\hline Taxon X Region X Period & 25 & 85.88 & $0.35(25,155)$ \\
\hline Faxon X Region X Year & 155 & 248.32 & $1.11(155,980)$ \\
\hline Taxon X Region X Sample Period & 980 & 224.09 & $135.81(980,497) *$ \\
\hline Binomial Variance & 497 & 1.65 & \\
\hline
\end{tabular}

* Significant at $\alpha=0.05$

a. Period = October $\$ 969$ through September 1980 or Current year

b. Year(October-September) $=1969,1970,1971,1972,1973,1974,1975$, $1976,1977,1978,1979,1980$ or 1981

c. Sample Period = Bimonthly 


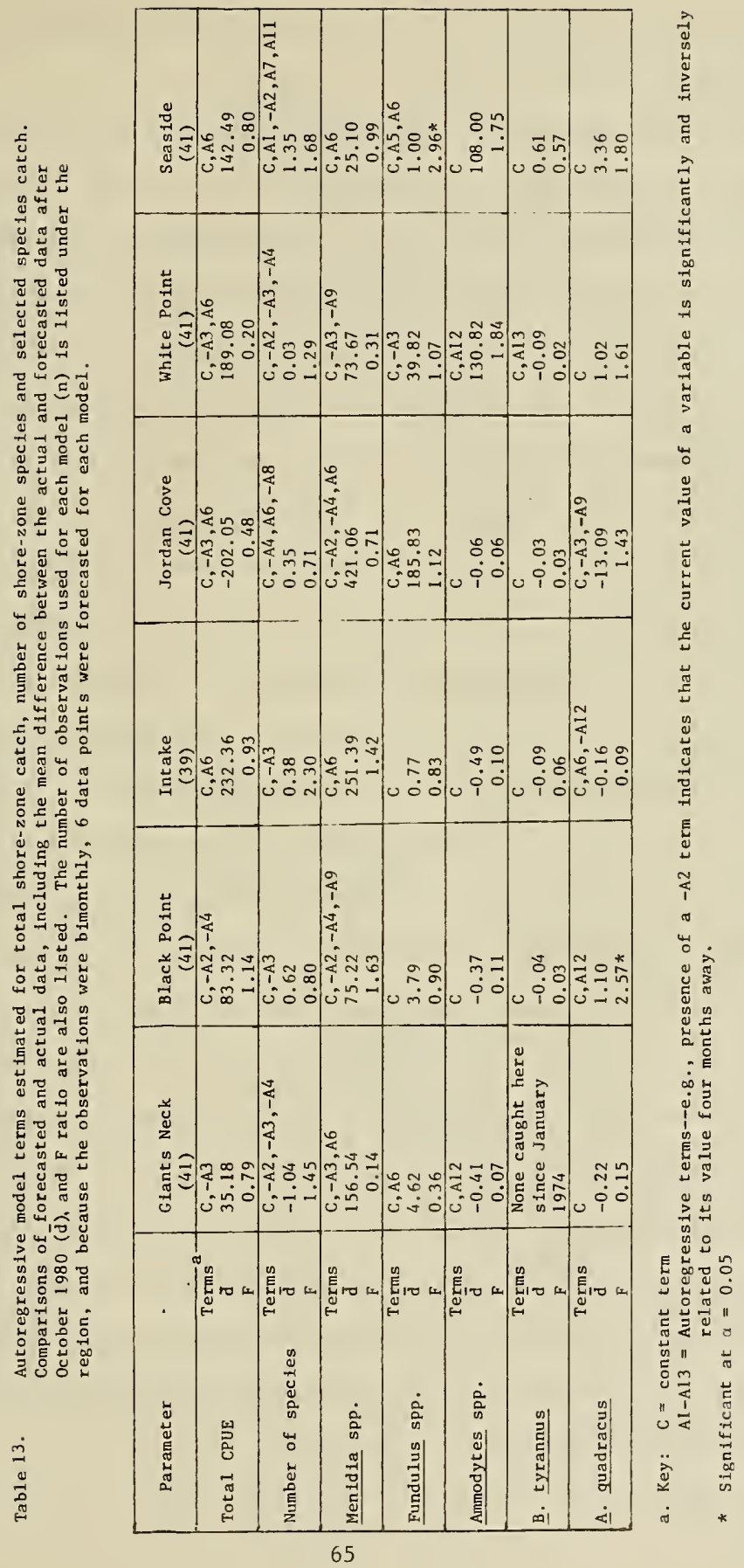


seasons or years represent real conditions, not the inadequacy of the gear to collect the desired fish.

Those shore-zone species whose abundance levels might change due to the removal of individuals by impingement or entrainment or whose geographical distribution might be altered by the thermal effluent could be considered potentially impacted. A comparison of those taxa either impinged or entrained to those recorded from seines is given in Table 5 . The most abundant shore-zone fish, silversides (Menidia spp.), was the second most important impinged species in the time period. The second most abundant shore-zone fish, sand lance (Ammodytes sp.), was the second most important entrained species. These two species along with Atlantic menhanden (Brevoortia tyrannus) (15th ranked impinged fish) could be considered as potentially impacted by entrainment or impingement effects. Additionally, with three-unit operation, shore-zone species found in Jordan Cove out to White Point may be exposed to the thermal plume on an ebb tide (Fig. 5). The more abundant representatives of the shore-zone finfish assemblage that may experience this situation include silversides, killifishes and fourspine stickleback. It is not expected that even the most extreme conditions of $28-30^{\circ} \mathrm{C}$ (maximum summer water temperature) plus the precicted surface temperature rise of $3-4^{\circ} \mathrm{C}$ would exceed the thermal tolerance limits of the more abundant shore-zone fish (Table 14) for more than two to three hours of a 12 hour tidal cycle. However, some fish might return to the shore-zone areas earlier in the spring and leave later in the fall if attracted to the warmer than ambient waters. Even though these potential impacts are expected to be transitory, the situation should be monitored in the event of some unforseen circumstances. 


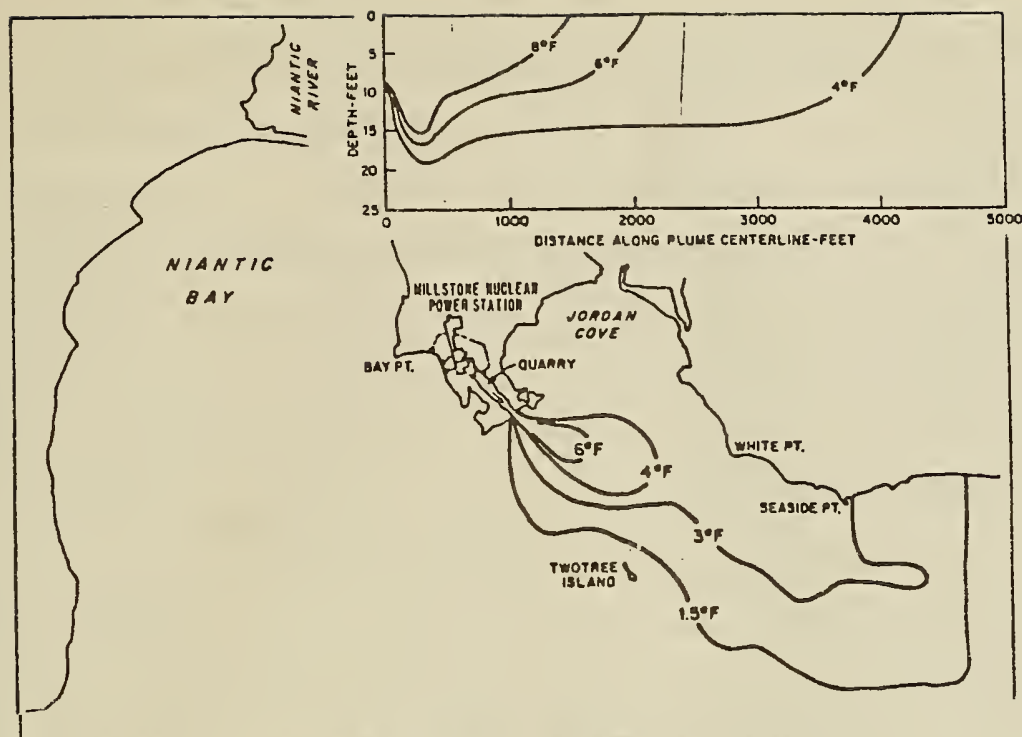

MAXIMUM EBB CONDITIONS

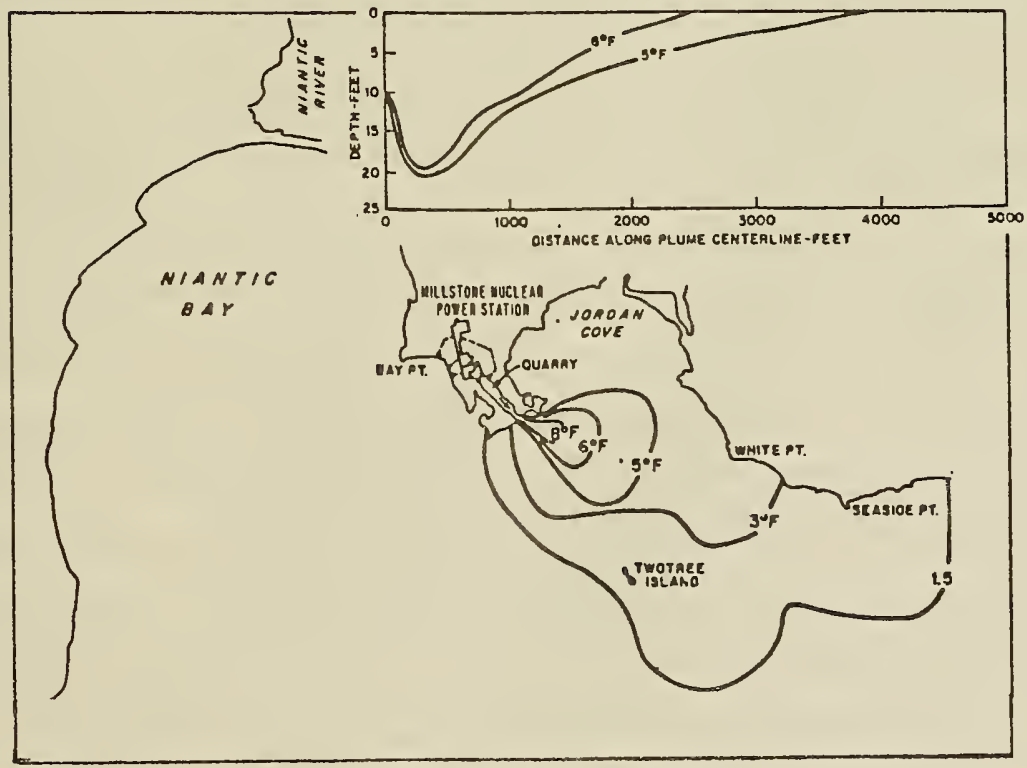

SLACK AFTER EBB CONDITIONS

Figure 5. Predicted surface temperature rise: average cases for 3-unit operation. 
Table 14. Thermal regimes tolerated by some shore-zone species found in the Greater Millstone Bight.

\begin{tabular}{|c|c|c|}
\hline Species & Regime & Reference \\
\hline Amrinodytes sp. & Prefers $0-10^{\circ} \mathrm{C}$ & Richards et al. 1963 \\
\hline F. majalis & Avoids $36.9^{\circ} \mathrm{C}$ & Gift \& Westman 1971 \\
\hline \multirow[t]{3}{*}{ F. heteroclitus } & Tolerates $37^{\circ} \mathrm{C}$ & Marcy 1976 \\
\hline & $\begin{array}{l}31.5^{\circ} \mathrm{C} \text { lethal (30\%) } \\
34.0^{\circ} \mathrm{C} \text { lethal (14\%) }\end{array}$ & Garside \& Jordan 1968 \\
\hline & $\begin{array}{l}\text { Avoids } 35.6^{\circ} \mathrm{C} \text { in March } \\
\text { Avoids } 39.2^{\circ} \mathrm{C} \text { in July } \\
\text { Avoidance breakdown: } 36.7^{\circ} \mathrm{C} \text { (March) } \\
\text { Avoidance breakdown: } 40.0^{\circ} \mathrm{C} \text { (July) }\end{array}$ & Gift \& Westman 1971 \\
\hline M. beryllina & Temperature range: 2.9 to $32.5^{\circ} \mathrm{C}$ & $\begin{array}{l}\text { Tagatz \& Dudley 1961; } \\
\text { Smith } 1971\end{array}$ \\
\hline \multirow[t]{3}{*}{ M. menidia } & Temperature range: $1^{\circ} \mathrm{C}$ to $36^{\circ} \mathrm{C}$ & $\begin{array}{l}\text { de Sylva et al. 1962; } \\
\text { Shuster } 1959\end{array}$ \\
\hline & Upper tolerance limit: $\quad 32-34^{\circ} \mathrm{C}$ & Hoff \& Westman 1966 \\
\hline & $\begin{array}{l}\text { Mean avoidance temperature: } 30.0^{\circ} \mathrm{C} \\
\text { Upper avoidance breakdown: } \quad 34.3^{\circ} \mathrm{C}\end{array}$ & Gift \& Westman 1971 \\
\hline
\end{tabular}


The seine sampling program extant at MNPS has sampled finfish typical of the shore zone along the northeast Atlantic coast, and provided both a long term and seasonal description of the fluctuations that these assemblages experience. Additionally, potentially impacted species have been represented in these collections. The next step in this investigation was to determine our ability to detect changes in the shore-zone finfish assemblages using the accumulated data, and to distinguish plant induced changes from natural changes in the fish populations.

Hypotheses generation and statistical testing provide the most quantitative way to detect differences or changes. Standard normal theory tests assume, among other things, that the observations come from a probability distrbution that is normal, that the variances are homogeneous, and that the observations are independent. A knowledge of the data base characteristics, then is desirable for the correct application and interpretation of various tests and results. After determining that there were no changes in methodology to contribute undesirable variance to the data (see Table 1), the characteristics of the underlying probability distribution were described.

The probability distributions of total catch and catches of silversides, killifishes, sand lance, menhaden and sticklebacks were characterized by first examining the frequency distributions of which Fig. 3 is an example. The high proportion of zeros result in highly skewed, non-nomal distribtuions. Such distributions typically have variances that are related to the means. The variances may be stabilized by subjecting the data to a $\log$ transformation prior to analyses. Alternatively these distributions may approximate a negative binomial distribution (Poole 1974), and can be normalized with another appropriate transformation ( 1 n(CPUEtk/2). 
However, the log transformation was found to not normalize the data

(Table 6). Additionally, based on the results in Table 7, it was concluded that the seine catch data did not come from a negative binomial distribution.

Even though the data failed to meet the assumptions of normal theory testing, these tests are fairly robust with respect to nonnormality and thus limits of detection and sample size were determined using $\log _{10}(C P U E+1)$ transformed data. The current program (consisting of three replicates taken at six stations eight times a year) provides 144 samples per year. Considering silversides (Table 10), this sampling program could detect a difference of the means of the transformed data of $d=0.146$ ( $40 \%$ change) (vs Ho: $d=0$ ) at $\alpha=0.1070 \%$ of the time, if the data were normally distributed. Detecting a d of 0.041 ( $10 \%$ change) at $\alpha=0.10, \beta=0.70$ would require $322,319,233,736,1732$ and 1556 samples per year for sand lance, fourspine stickleback, Atlantic menhaden, killifishes, silversides and total catch respectively. This difference has considerably different meanings depending on the absolute size of the catch. For example, a $d=0.114$ could represent the difference between $C P U E=10^{1 \cdot 114}$ and $C P U E=10^{1 \cdot 0}(13-10=3 \mathrm{fish})$ or between $C P U E=10^{2} \cdot 114$ and CPUE $=10^{2.0}(130-100=30 \mathrm{fish})$ but still be a $30 \%$ change. Since station and time of year combined contribute more than half of the over all variance for all species considered, being able to detect a $50 \%$ change in the annual geometric means at $\alpha=0.10, \beta=0.80$ or $\alpha=0.05, \beta=0.70$ may represent a respectable detectability.

The present seining program costs approximately 360 personnel-hours per year to complete. Over the last 11 years approximately 17,590 fish have been caught per year and this amounts to about $0.02 \mathrm{hrs} / \mathrm{fish}$. 
Based on this cost, the number of stations and times per year to sample for 1,2 or 3 replicates to minimize the variance of the annual mean was found to vary with the species under consideration (Table 9). However, it appeared that increasing the times per year and decreasing the number of stations sampled would be effective in reducing the variance.

While normal theory tests are fairly robust with respect to deviations from the assumptions of normality and homogeneous variances, the effect of non-independence or autocorrelation of the data in time on probability statements can be unsatisfactory (Glass et a1. 1975). Timeseries analysis actually makes use of the internal autocorrelations and has been proposed as a powerful tool for statistical testing in environmental monitoring (Saila et al. 1980). The initial application of this analytical method used the autocorrelation structure to forecast fish catches a year in advance. However, techniques exist for removing the autocorre-lations and then testing for differences in the remaining values. Additionally, tests can be constructed to determine if an intervention effect, like the start-up of a power plant, is detectable in the series. This approach, then, would assist in meeting both the second and the third objectives of the seining program, that is to be able to distinguish natural changes in finfish population levels or changes in community composition from those which are power plant induced. Because 50 serial data points are needed to adequately identify a time series model (Glass et al. 1975), and results are best if at least two observations contribute to each data point (Saila, pers. comm.), it is recommended that any changes in the sampling program be considered in terms of the potential for using the extant historical data base in time series analysis. 
There are several potential impacts to the shore-zone finfish assemblage posed by three-unit operation which could possibly be undetected by the current sampling scheme. Samples are currently collected in the 2-h period preceding high tide--on the flood. The thermal plume generated by three-unit operation has been modelled to encompass White Point and Jordan Cove on an ebb tide (Fig. 5). While thermal tolerance levels of shore-zone species are not expected to be exceeded, the thermal preferences of some species might be exceeded in summer when the shore-zone water temperatures are the highest, causing these species to avoid the area on an ebb tide. Also, shore-zone finfish might be attracted to an area that was warmer than normal in the spring and/or fall. While the monitoring program is more concerned with long term changes, informa-tion on potential short term changes might be helpful in elucidating a long term change, should one occur. Since samples are not collected on the ebb tides or in March, April or November when such deviations in geographical distributions most likely would occur, such changes would remain undetected. In order to sample these situations, I suggest the sampling program be increaed at least in the Jordan Cove area, to cover all months and the ebb as well as the flood tide.

Failures of the assumptions of statistical tests affect primarily probability statements and significance levels. The use of means and variances are still appropriate for descriptive purposes. Further, sampling during a shore time period when shore-zone flsh are known to be present will reduce the occurrence of zero catches which is a direct cause of the skewing of the underlying distribtuion, and reduce the serial dependence. Thus more intensive sampling during the spring, summer and fall at WP and JC to monitor shore-zone fish during these times could provide data for parametric statistical tests. 
At this time, some stations currently sampled could be dropped with no real loss in information. The Bay Point site (IN) in front of the intakes has never provided much data--the area is too exposed and rocky to provide a good habitat. Additionally, it will be non-existent after the temporary cofferdam in front of Unit 3 intake is removed. Station BL is also too exposed to provide a good shore-zone habitat. Additionally, it has a high abundance of juvenile and adult Homo sapiens during the summer months which may cause resident fish to move to other nearby shore-zone sites. While the GN site is somewhat sheltered, it is dissimilar to the JC site because it lacks vegetative cover, and thus is not a comparable control site. Because an extensive data base exists for GN, I would recommend keeping it along with JC, WP and SS and dropping IN and BL sites. The effort saved by not sampling these stations could be redistributed to more intensively sample the potentially impacted Jordan Cove sites. 
1. The NUEL seining program has provided both long term and seasonal estimates of the kinds and numbers of finfish inhabiting the shore zone near the MNPS. Their patterns of abundance are now well documented.

2. The program has provided information on species potentially impacted by impingement (silversides), entrainment (sand lance) and the thermal plume (silversides, sand lance, killifishes and fourspine stickleback).

3. The seine data base can be characterized as having a highly skewed, non-normal distribution. It cannot be characterized as having a negative binomial or a log-normal distribution. Thus appropriate transformations would not normalize the data for the application of parametric statistical tests. Even though normal-theory assumptions were violated, the program was able to detect large ( > 50\%) changes in shore-zone finfish populations which might be the result of power plant impact. Nonparametric tests and time-series (forecasting) analysis were also found useful for detecting changes in the shore-zone finfish.

4. Within the framework of the cost of the current program, modifications to the seining program would not improve the detectability of the program.

5. Under three-unit operation, conditions may exist such that the shore-zone finfish assemblages in Jordan Cove will be exposed to the thermal plume. These conditions would exist on ebb tides throughout the year, and would be unsampled under the current program of sampling two hours before high tide during only eight months. 


\section{RECOMMENDATIONS}

1. Increase the monitoring effort at the Jordan Cove (JC, WP) and control (GN, SS) sites such that these stations are sampled at least monthly. Sampling the two-hour period preceding high tide should be maintained so that the extant time series can be extended.

2. Delete the sampling effort at IN and BL.

3. Increase the sampling frequency to biweekly from May through September at JC and WP.

4. Supplement the existing high-tide sampling program at the JC and WP sites with low-tide sampling at least three times per year--April, August and November. These 'mini-experiments' should be done for two to three years prior to the start-up of Unit 3 and two to three years after Unit 3 comes on line, during periods of three-unit operation. 

Bartlett, M.S. 1947. The use of transformations. Biometrics 3:39-52.

Battelle. 1973. Summary report on a monitoring program on the ecology of the marine environment of the Millstone Point, Connecticut, area, with special attention to key indicator organisms--pre-operational phase. Prepared for Northeast Utilities Service Company.

Bigelow, H.B. and W.C. Schroeder. 1953. Fishes of the Gulf of Maine. Fish. Bull. of the Fish and Wild1. Serv. 53.

Bliss, C.I. and R.A. Fisher. 1953. Fitting the negative binomial distribtuion to biological data. Biometrics 9:176-200.

Box, G.E. and G.N. Jenkins, 1976. Time Series Analysis: Forecasting and Contro1, Revised Edition. Holden-day San Fransisco, California. 575 pp.

Briggs, P.T., and J.S. O'Connor. 1971. Comparison of shore zone fishes over naturally vegetated and sand-filled bottoms in Great South Bay. N.Y. Fish and Game J. 18:15-41.

de Sylva, D.P., F.A. Kalber, Jr. and C.N. Shuster, Jr. 1962. Fishes and ecological conditions in the shore zone of the Delaware River Estuary, with notes on other species collected in deeper water. Univ. Del. Mar. Lab., Inf. Ser., Publ. 5164 pp.

Garside, E.T. and C.M. Jordan. 1968. Upper lethal temperature at various levels of salinity in the euryhaline cyprinodontids Fundulus heteroclitus and $F$. diaphanus after isosmotic acclimation. J. Fish. Res. Bd. Can. $25(\overline{12}): \overline{2717-2720}$.

Gift, J.J., and J.R. Westman. 1971. Response of some estuarine fishes to increasing thermal gradients. Appendix 7 in Ecological Considerations for Ocean Sites of New Jersey for Proposed Nuclear Generating Stations. Vol. 2, Part 3. Ichthyological Associates Report to Public Service Electric and Gas Co. 75 pp.

Glass, G.V., V.L. Willson, and J.M. Gottman. 1975. Design and Analysis of Time-series Experiment. Colorado Associated University Press, Boulder, Colorado. $241 \mathrm{pp}$.

Hillman, R.E., N.W. Davis, and J. Wennemer. 1977. Abundance, diversity and stability in shore-zone fish communities in an area of Long Island Sound affected by thermal discharges of a nuclear power plant. Estuar. Coast. Mar. Sci. 5:355-381.

Hoff, J.G., and J.R. Westman. 1966. The temperature tolerances of three species of marine fish. J. Mar. Res. 24(2):131-140.

Krumbein, W.C., and J.W. Tukey. 1956. Multivariate anlayses of mineralogic, lithologic and chemical composition of rock bodies. J. Sed. Petrol. $26: 322-337$. 
LILCo (Long Island Lighting Company). 1980. Preoperational aquatic ecology study Shoreham Nuclear Power Station, Unit 1, 1966-1979. Prepared by GEOMET for Long Island Lighting Company.

Marcy, B.C. 1976. Fishes of the lower Connecticut River and the effects of the Connecticut Yankee plant, in The Connecticut River Ecologica1 Study: The Impact of a Nuclear Power Plant, D. Merriman and L.M. Thorpe (ed.). Am. Fish. Soc. Monograph No. 1. 252 pp.

Mulkana, M.S. 1966. The growth and feeding of juvenile fishes in two Rhode Island estuaries. Gulf Res. Rept. 2:97-167.

NUSCo (Northeast Utilities Service Company). 1982. Annual report, 1981. Monitoring the marine environment of Long Island Sound at Millstone Nuclear Power Station, Waterford, Connecticut.

NUSCo. 1982. Millstone Nuclear Power Station, Unit 3, Interim Environmental Report, Operating License Stage. Prepared by Stone and Webster Engineering Co. for NUSCo.

011a, B.L., A.J. Bejda and A.D. Martin. 1975. Activity, movements and feeding behavior of the cunner, Tautogalabrus adspersus, and comparison of food habits with young Tautoga onitis, off Long Island, New York. Fish. Bu11. 73:895-900.

Pearcy, W., and W.W. Richards. 1962. Distribution and ecology of fishes of the Mystic River estuary, Connecticut. Ecology 43:248-259.

Poole, R.W. 1974. An introduction to quantitative ecology. McGraw-Hill, Inc., New York. 532 pp.

Richards, S.W., A. Perlmutter, and D.C. McAney. 1963. A taxonomic study of the genus Ammodytes from the East Coast of North America (Teleostii: Ammodytes). Copeia 1963(2:358-377).

Ricker, W.E. 1975. Computation and interpretation of biological statistics of fish populations. Bull. Fish. Res. Board Can. 191. $382 \mathrm{pp}$.

Saila, S.B., M. Wigbout, and R.J. Lermit. 1980. Comparison of some time series models for the analysis of fisheries data. J. Cons. int. Explor. Mer 39:44-52.

Shuster, C.N. 1959. A biological evaluation of the Delaware River estuary. Univ. De1. Mar. Lab., Inf. Ser. Publ. 3. 77 pp.

Smith, B. 1971. The fishes of four low-salinity tidal tributaries of the Delaware River estuary. M.S. Thesis. Cornell University. 304 pp.

Snedecor, G.W., and W.G. Cochran. 1967. Statistical methods, Sixth edition. Iowa State University Press. Ames, Iowa. 593 pp.

TASC (The Analytic Sciences Corporation). 1979. Optimization of Brayton Point environmental monitoring programs. Prepared for New England Power Service Company. 
Tagatz, M.E., and D.L. Dudley. 1961. Seasonal occurrence of marine fishes in four shore habitats near Beaufort, N.C., 1957-60. U.S. Fish. Wild1. Serv. Sp. Sci. Rept. Fish. 390. 19 pp.

Warfe1, H.E., and D. Merriman. 1944. Studies on the marine resources of southern New England. I. An analysis of the fish populations of the shore zone. Bul1. Bing. Oceanogr. Co11. 9:1-53.

Zar, J.H. 1974. Biostatistical anlaysis. Prentice-Hall, Inc., Fnglewood Cliffs, New Jersey. 620 pp. 


WINTER FLOUNDER:

A REVIEW AND EVALUATION 



\section{MILLSTONE NUCLEAR POWER STATION}

\section{Introduction}

The abundance of the winter flounder in the Greater Millstone Bight has been evident from the beginning of environmental studies here. It has dominated the trawl catch of demersal fishes and has been the most numerous fish impinged on the traveling screens of the cooling-water intakes. Its larvae have been very abundant in spring and large numbers have been entrained through the cooling-water system. Following an intensive survey, it was found to be the third-ranked sport fish in Connecticut (Sampson 1981). It has also been a significantly important commercial species, with annual landings of 489 to 769 thousand pounds from 1977 through 1981 (Connecticut Dept. of Environmental Protection, unpublished data).

Unlike most marine fishes, the winter flounder is a product of local spawning with geographically isolated stocks associated with individual estuaries (Lobel1 1939; Perlmutter 1947; Saila 1961). Therefore, impacts of Millstone power plant operations, particularly entrainment of larvae through the cooling-water system, are of greater concern for the winter flounder than for other local fishes which are comprised of stocks with much greater geographical range and population size or have life histories making them less susceptible to impact.

This evaluation has focused on much of the research conducted on the winter flounder at the Northeast Utilities Environmental Laboratory, either concerned with that species alone or as part of larger monitoring programs. The data and analyses were examined to see if they were providing proper information necessary for the assessment of plant 
impact. The evaluation is broken up into sections which more or less cover major sampling programs. Particular emphasis has been placed on examining the population survey and life history studies as these programs had not been extensively evaluated, yet comprised a large portion of the time spent by the Fish Ecology Section. Where pertinent, general or specific recommendations or suggestions are made which are hoped will improve techniques, efficiency, precision, or accuracy in sampling or analyses.

\section{WINTER FLOUNDER POPULATION ESTIMATES}

\section{Summary of surveys}

Intensive work on the winter flounder began at Millstone in 1973 (Table 1). A brief summary of the annual population survey as well as a critical evaluation of some of the data obtained follows; details and methods of each year's studies can be found in the appropriate Annual Report. In some instances reanalysis of previous data both in past years and during this evaluation led to various corrections of the data base. Consequently various estimates or results found herein may not match those found in previous Annual Reports. Any newly revised figures should be used in all future reports.

Studies during the first two years were less intensive than those from 1975 to the present. In 1973, about 2,000 winter flounder larger than $25 \mathrm{~cm}$ were tagged with Floy anchor tags. Approximately 1,000 of these were released in the Niantic River during February and March and 1,000 in the Millstone area outside the River from April through June. In 1974, tagging was mostly limited to the Niantic River during February through April (about 2,300 winter flounder larger than $20 \mathrm{~cm}$ ); 300 were marked elsewhere, mostly Jordan Cove. Although recaptures of these fish 


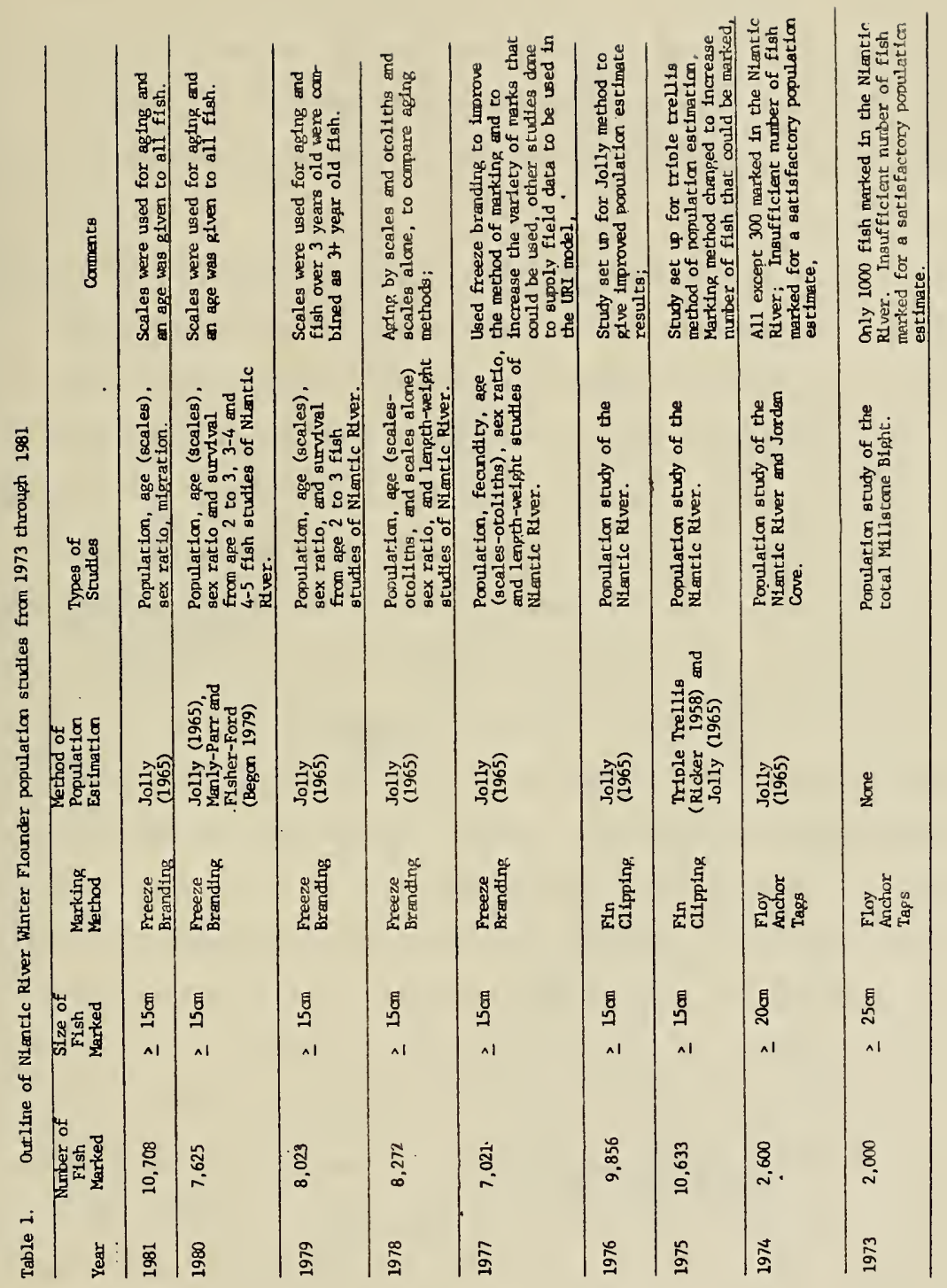


were few and sporadic ( $3 \%$ of the total tagged), the data were used to calculate population estimates using the Jolly (1965) method for open populations. However, results were judged meaningless because of the large negative estimates of recruitment, survival estimates much greater than 1, and large calculated standard errors (NUSCo 1975). For these reasons the 1973 and 1974 estimates have not been considered usuable for impact analysis.

In 1975, a more intensive sampling program was designed and undertaken to estimate the number of winter flounder found in the Niantic River during the spawning and immediate post-spawning seasons (NUSCo 1976). In general, samples for population estimates from 1975 to the present were taken over a 5 to 9 week period in late winter through early spring. Most sampling was conducted from two or three research vessels each using a 9.1-m otter traw1 on Monday and Tuesday of every week. Most tows were taken at the station or stations with greatest catch-per-uniteffort (CPUE) of that week. Most tows were approximately $5 \mathrm{~min}$ in duration, although some were as long as 30 min. Tow duration varied according to size of trawlable ground, expected catch, and amount of eelgrass and algae which clogged the nets.

The design of the 1975 study was based on the requirements for the triple-trellis method of population estimation (Ricker 1958). Eight stations throughout the Niantic River were sampled by trawl to capture winter flounder for tagging (Fig. 1). Fin clipping was used to mark individuals and 10,633 were marked during a 7-week period beginning on March 31. All fish larger then 150 mo were marked, a practice which has continued to the present. Three population estimates were calculated, one based on the triple-trellis techrique and two using the Jolly technique. 


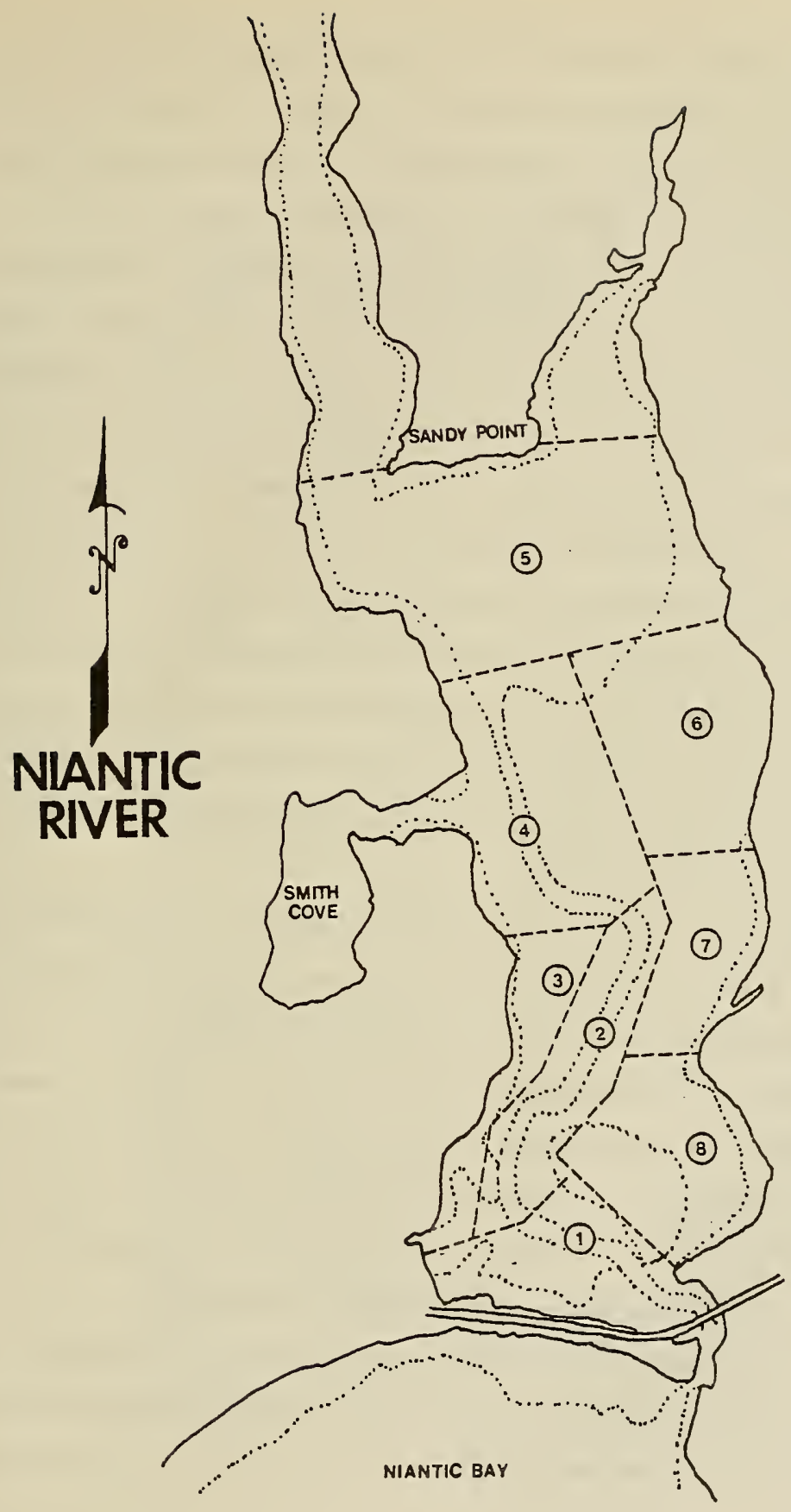

Figure 1. Location of Nlantic River winter flounder sampling stations. 
The triple-trellis technique does not require identification of fish recaptured more than once whereas the Jolly does so a model was devised which simulated multiple recaptures and Jolly estimates were calculated both with and without correction for multiple recaptures. The total population for the 5-week sampling period was obtained by adding the calculated number of recruits per week to the initial estimate. Weeks with survival probability (Jolly's phi) greater than 1 were assumed to have large recruitment so that the number joining was adjusted upward by the proportion above 1. Negative recruitment numbers were treated as zeroes. The population estimates (to nearest 1,000) for 1975 ranged from 147,000 as determined by the triple-trellis technique to $160,000 \pm$ 39,000 (2 standard errors) for the Jolly technique with correction for multiple recaptures to $168,000 \pm 37,000$ for the Jolly technique without the correction. The corrected Jolly estimate (Table 2) was used in subsequent reports as the best estimate for the 1975 Niantic River population of winter flounder.

In 1976, the winter flounder population survey was designed for use with the Jolly method (NUSCo 1977). Fish were still marked by fin clipping but recaptures were also tagged with a spaghetti tag to eliminate the problem of not recognizing multiple recaptures. Sampling began during the first week of March and continued through the last week of April and approximately 1,000 winter flounder were marked per week. A total of 9,856 winter flounder were marked and 699 were recaptured. The total population was calculated as $83,000 \pm 13,000$ (Table 3 ).

The population survey in 1977 took place during the weeks of March 7 through May 9. Fréeze branding replaced fin clipping as the method of marking and both week and station codes were branded on individual fish 


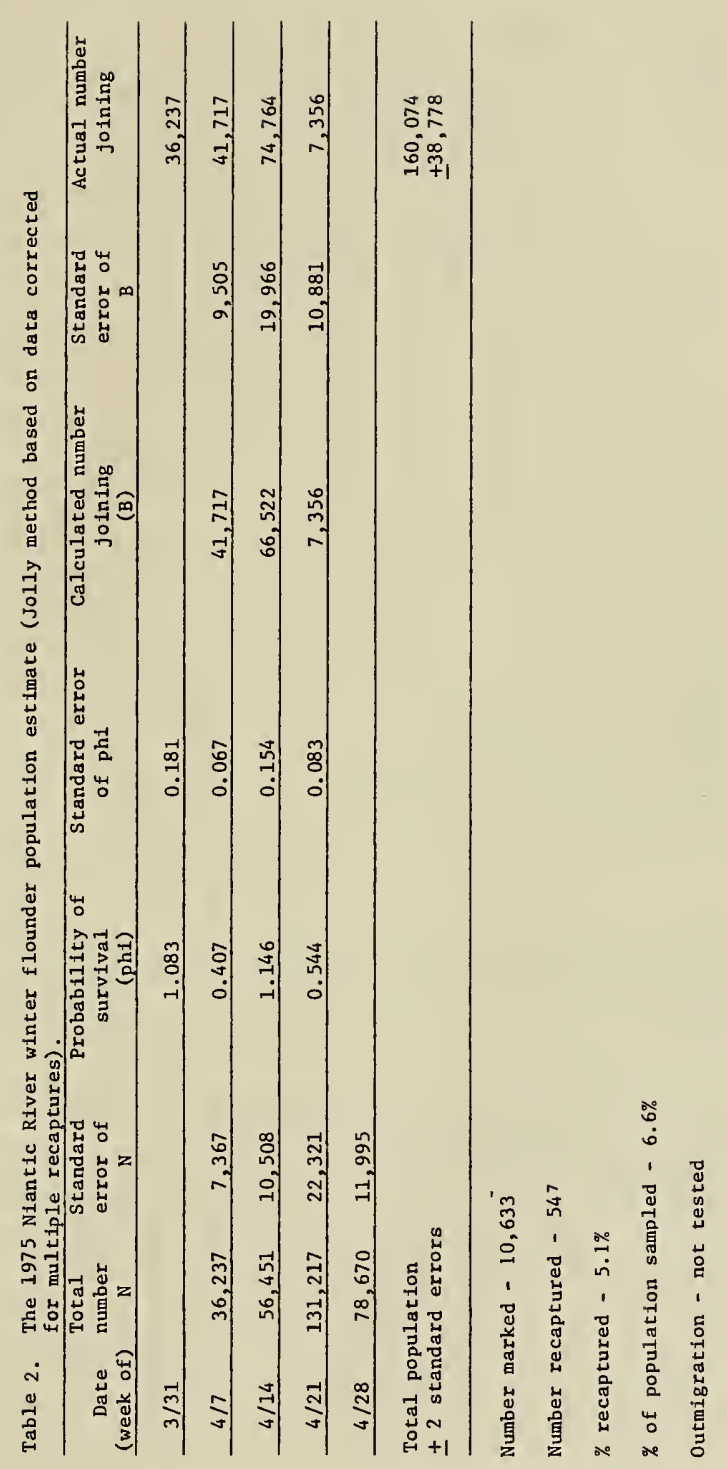




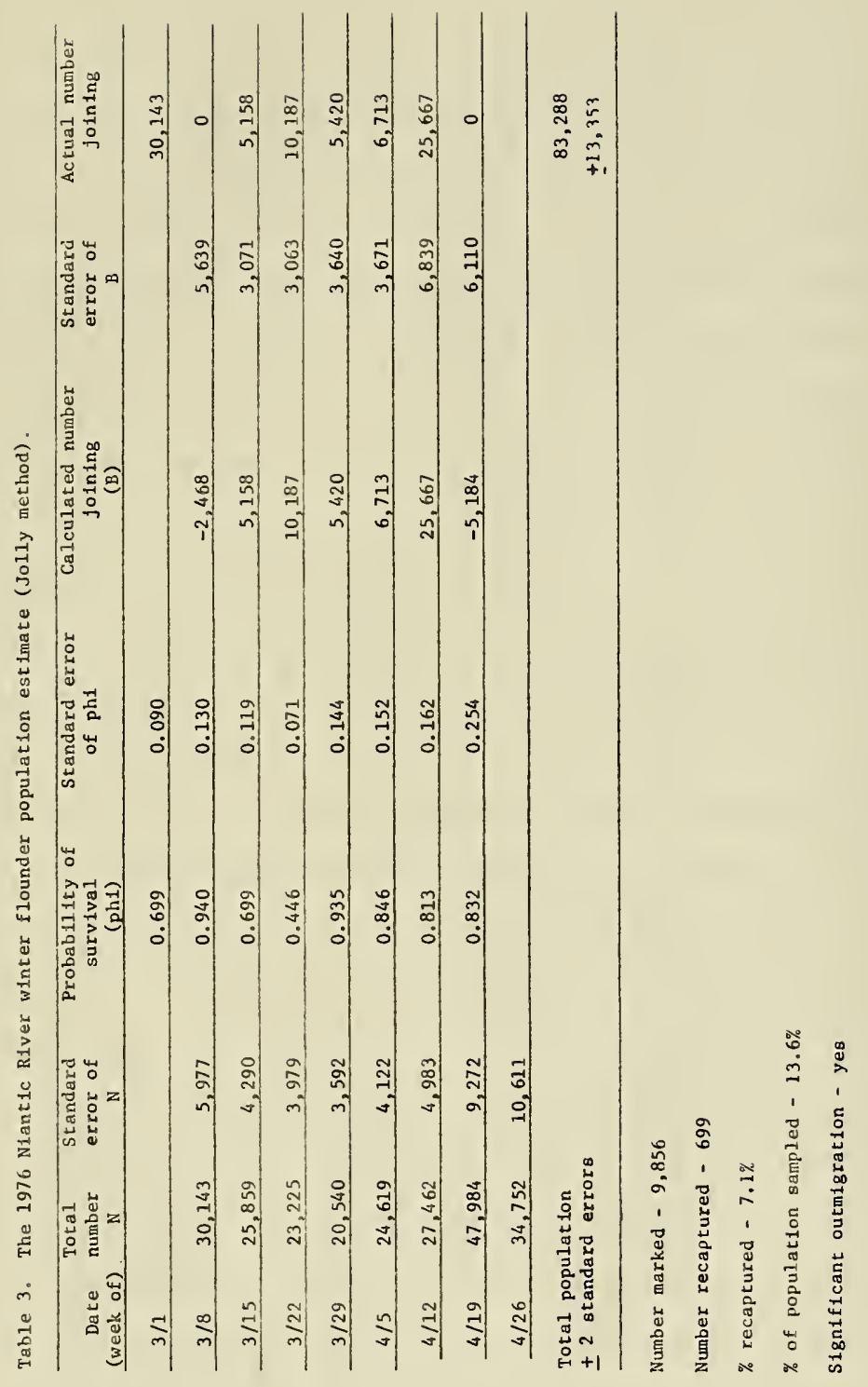


(NUSCo 1978). A total of 7,021 winter flounder were branded in 1977 with 624 recaptured. The total population was estimated to be $52,000 \pm$ 38, 000 (Table 4).

Similar methods were used in 1978 and 1979 with the survey taking place from early March to mid-May (NUSCo 1979, 1980). Some 8,272 were marked in 1978 and 8,023 in 1979; recaptures totaled 729 and 491, respectively. The population was estimated at 52,000 $\pm 17,000$ in 1978 and $54,000 \pm 21,000$ in 1979 (Tables 5, 6).

In 1980 , fish were marked with a brand marking the week but not the station (NUSCo 1981a). Some restrictions were placed on sampling and no tows were taken at stations 4,7 , and 8 . Sampling took place from the week of March 17 through May 6; 7,625 were branded and 963 recaptured. A population estimate of $33,000 \pm 14,000$ was calculated (Table 7).

The same restrictlons regarding sampling stations as in 1980 were also imposed in 1981 (NUSCo 1982). The survey was conducted from the week of March 2 through May 2. A total of 10,708 winter flounder were marked (934 recaptured) and the population was estimated as $92,000 \pm$ 23,000 (Table 8).

Although fish as small as $6.5 \mathrm{~cm}$ were branded beginning in 1981, the population estimates of winter flounder smaller than $15 \mathrm{~cm}$ have been calculated for each survey year based on the following proportion:

$\frac{\text { population of } \mathrm{fish}<15 \mathrm{~cm} \text { (unknown) }}{\text { total survey catch of } \mathrm{fish}<15 \mathrm{~cm}}=\frac{\text { Jolly estimate of } \mathrm{fish}}{\text { total survey catch of } \mathrm{fish} \geq 15 \mathrm{~cm}}$ Addition of the estimates of small and large fish gave a total population for the Niantic River (Table 9). 


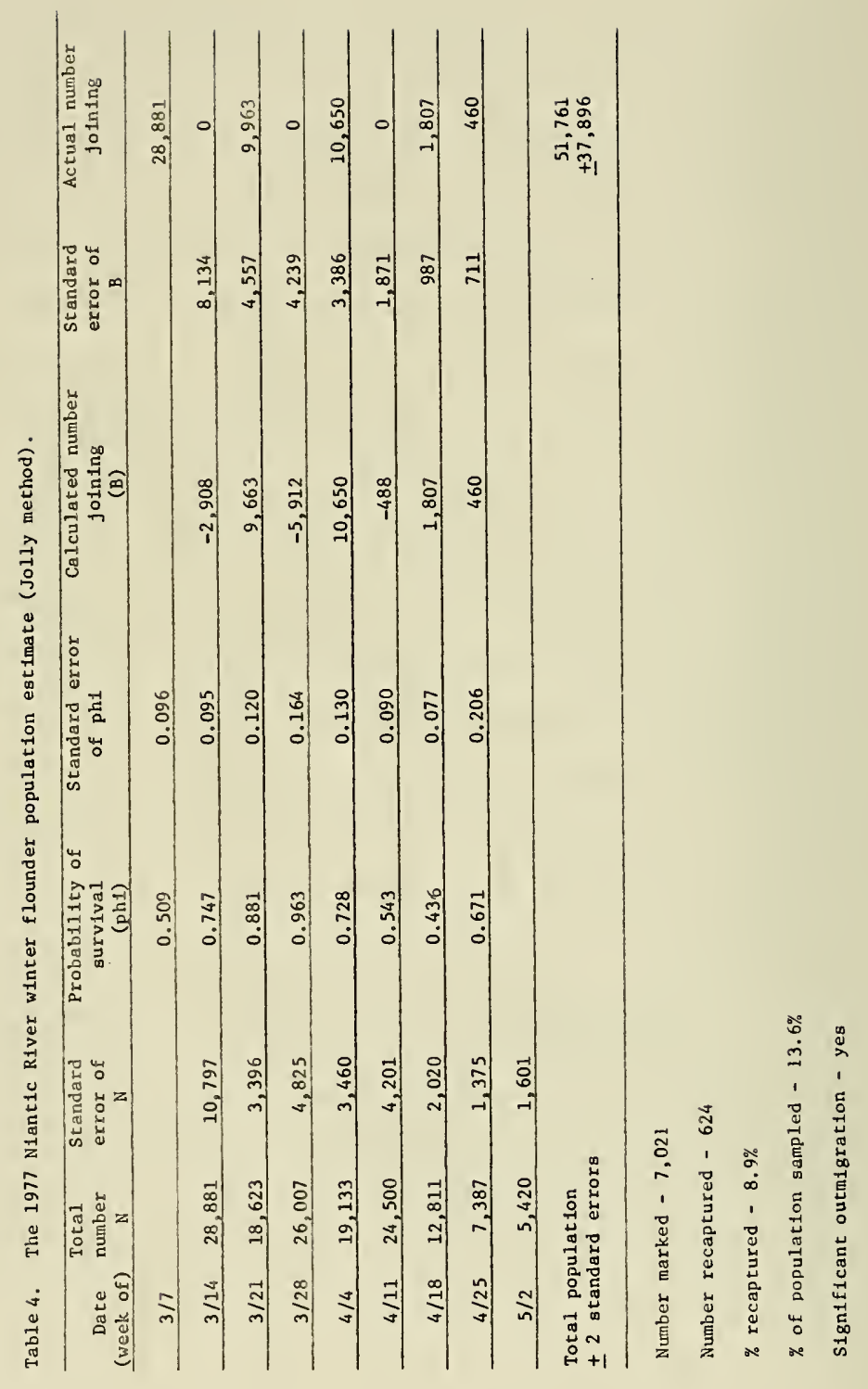




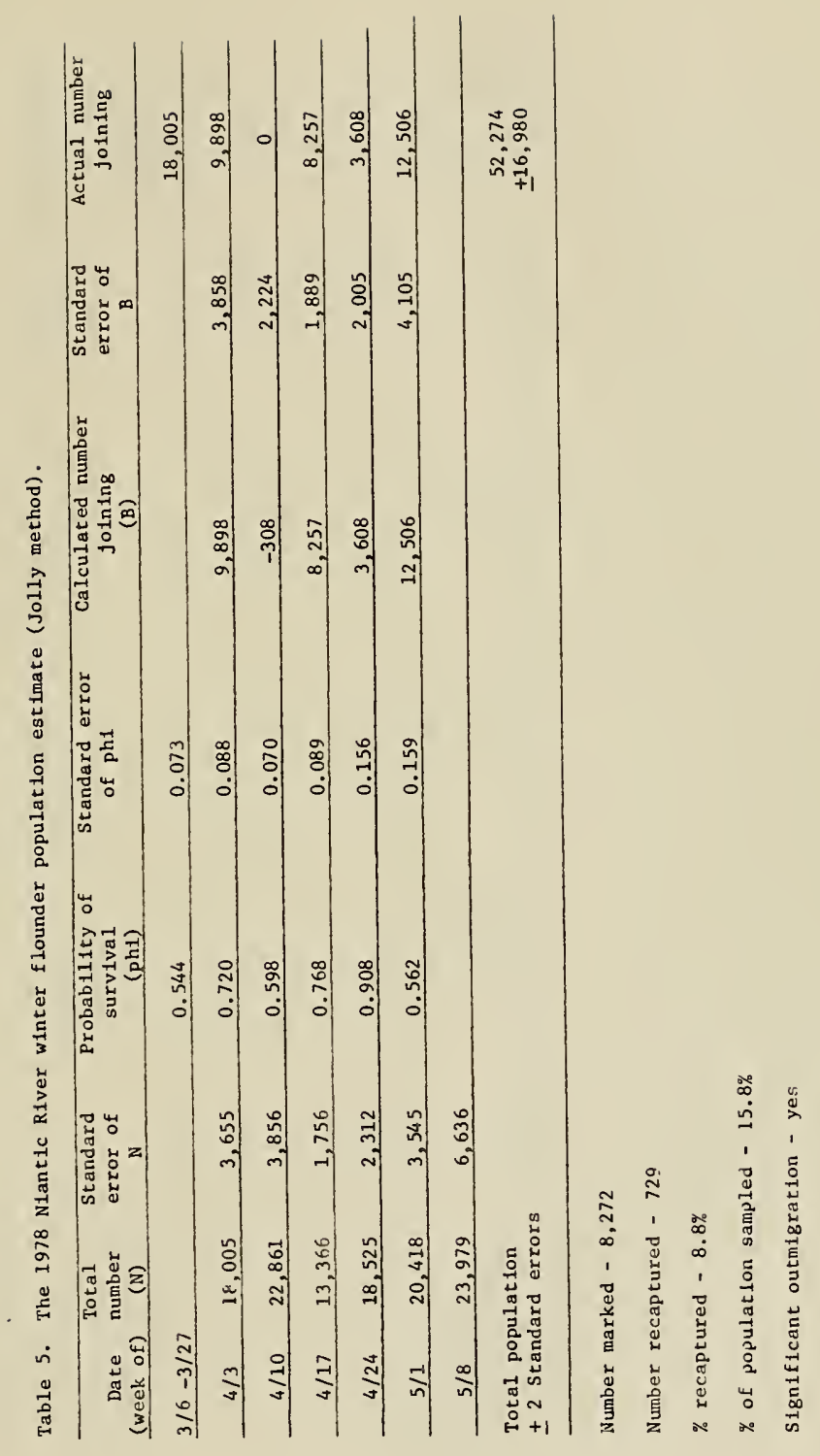




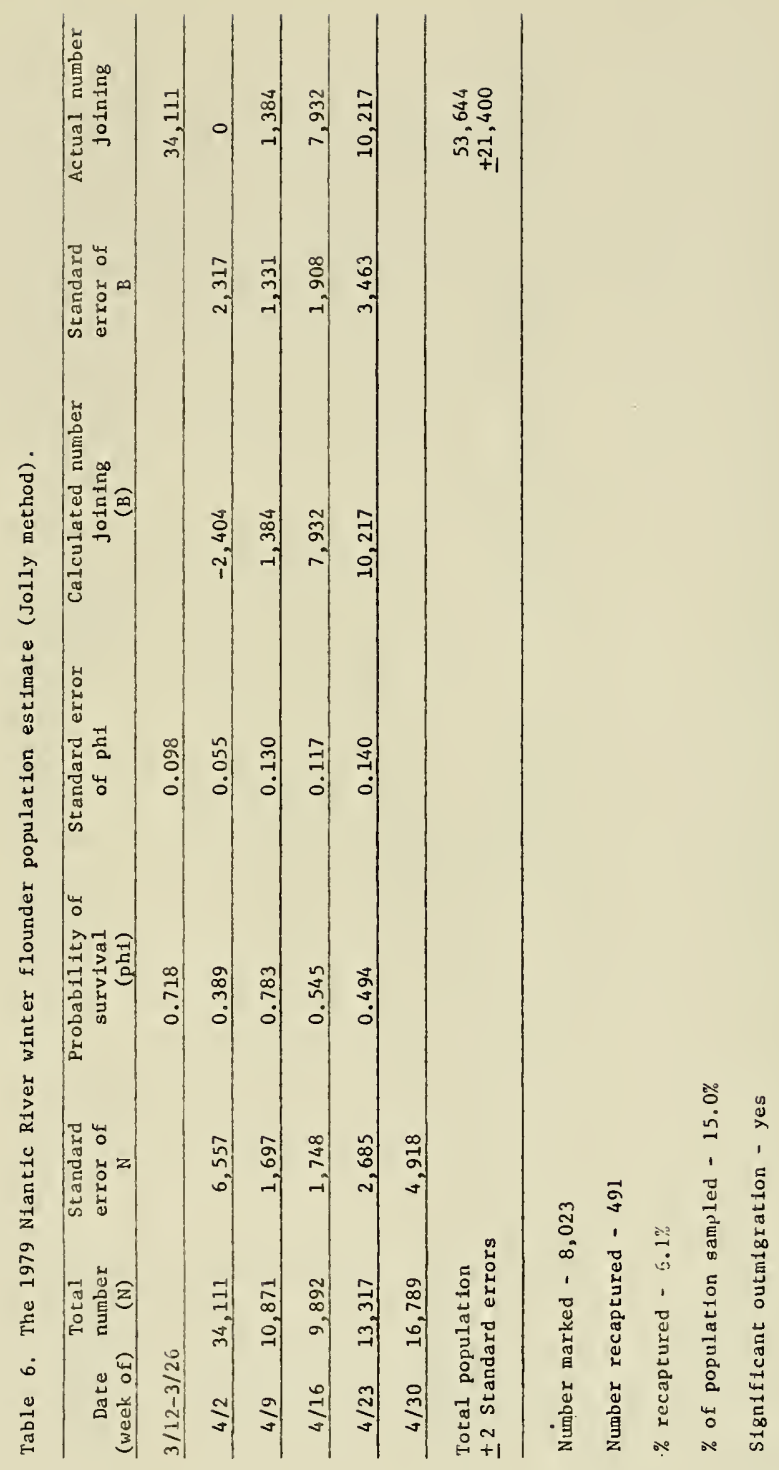




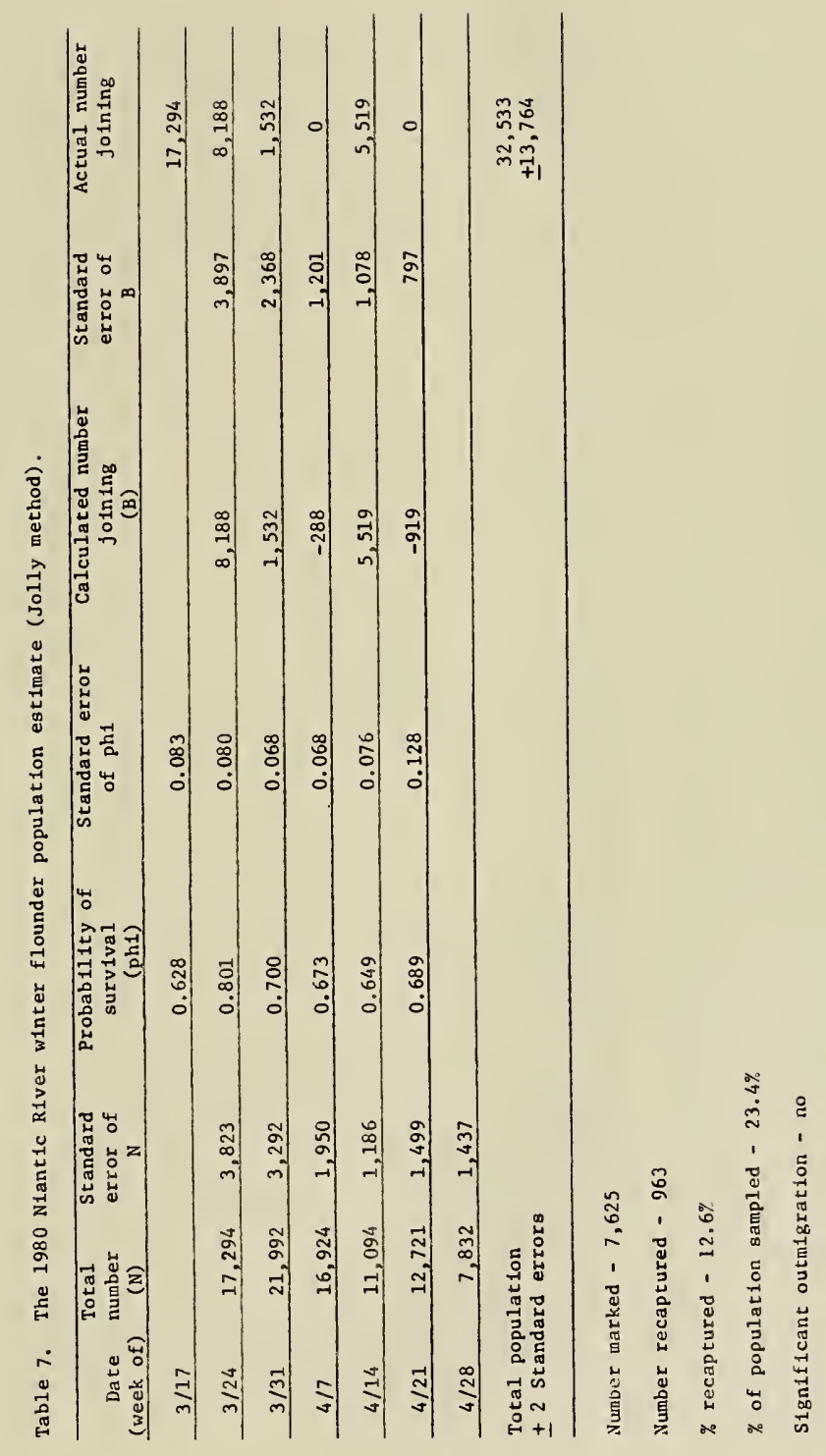




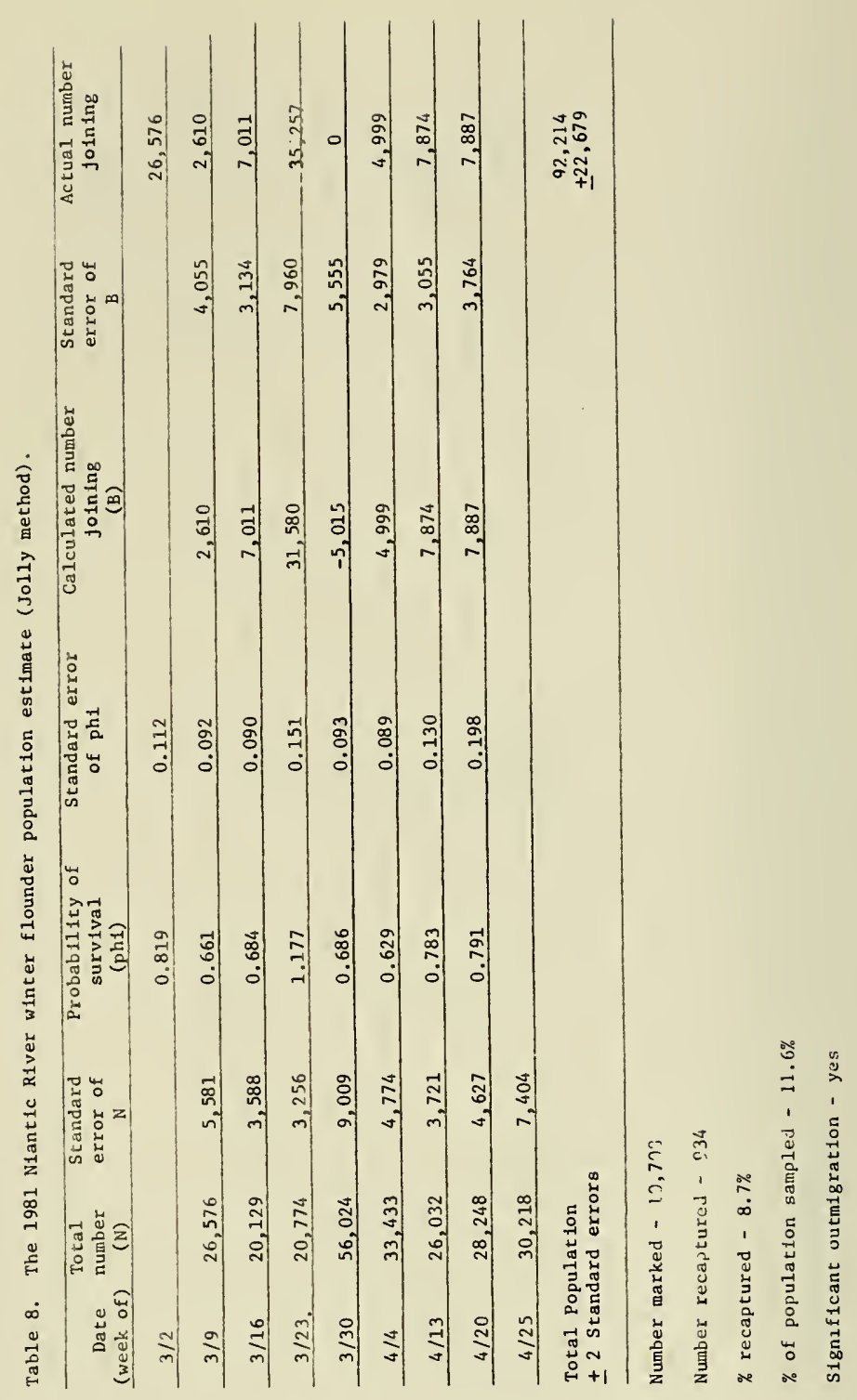




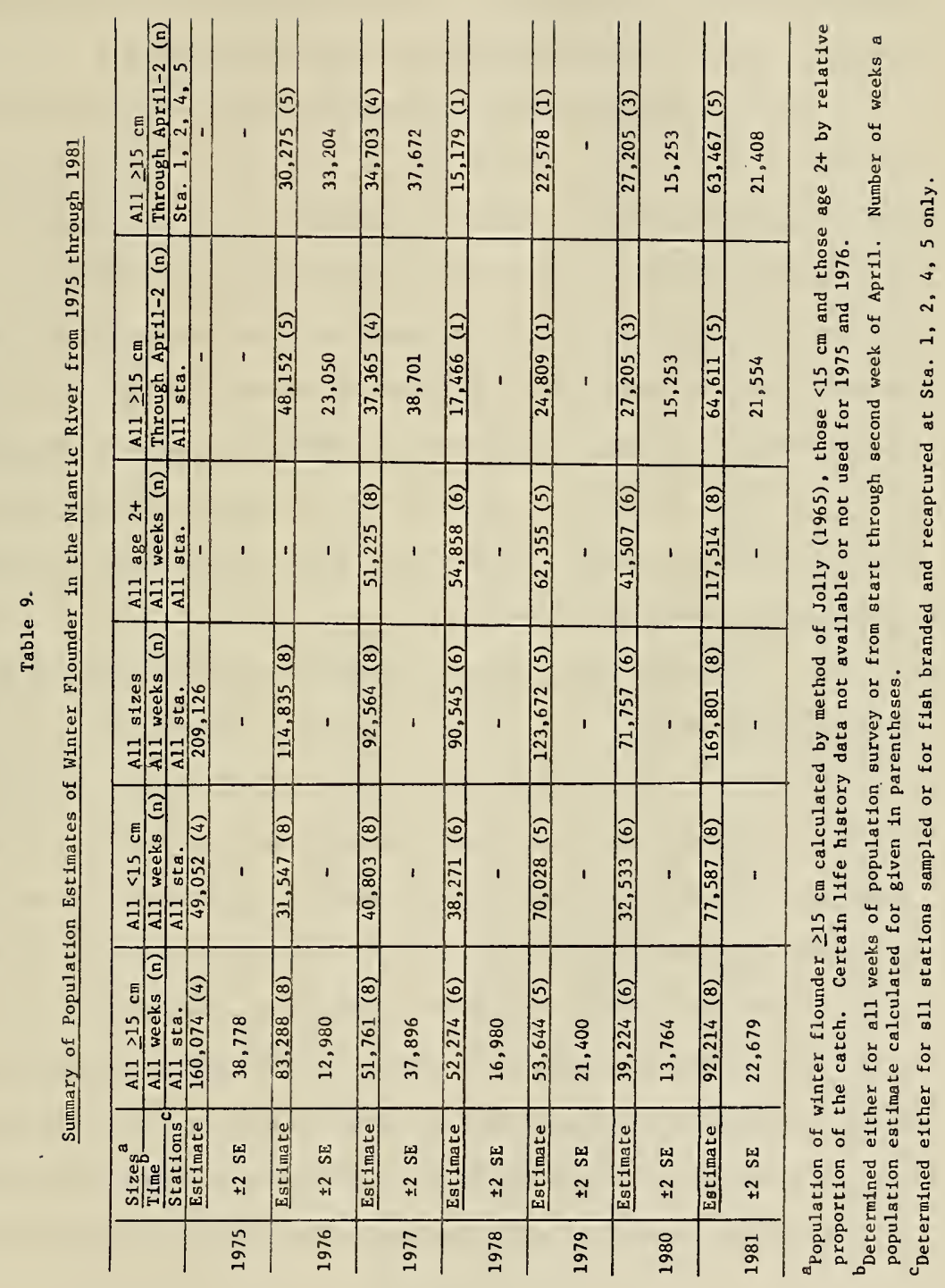


By use of life history information taken incidental to the population surveys, the total population of winter flounder age 2 and older was calculated (Table 9). These estimates were slightly larger than those for winter flounder greater than $15 \mathrm{~cm}$ because, except for 1977, a small percentage of 2 year olds was smaller than $15 \mathrm{~cm}$.

Finally, estimates from the beginning of each annual survey through the second week in April were calculated (Table 9). This period is considered the spawning period and estimates may be used with other life history information to calculate the number of spawning females and their total fecundity. This data may be used in various impact assessment analyses. Since restrictions on stations sampled have been made in recent years, estimates were also made using data from only stations I, 2, 4, and 5 for comparative purposes. Due to annual changes in effort, however, the contribution from stations 4 and 5 to these totals varied considerably from year to year.

Evaluation of the Jolly method of population estimation Assumptions of method

One of the major undertakings of this evaluation was to examine whether the surveys met the assumptions of the Jolly method and that the field data obtained and derived estimates are realistic. There is no doubt that the stochastic method of Jolly (1965) is an extremely powerful general formulation most appropriate for open populations (Begon 1979). It is the only technique which used all the information provided by the capture-recapture experiment and is also the most efficient estimate as long as failures do not occur in the basic assumptions (Cormack 1968). Although it may sometimes seriously overestimate the survival rate 
(Bishop and Sheppard 1973), it nevertheless remains the most useful method of population estimation (Southwood 1978).

Use of the Jolly method requires that certain assumptions be made. A summary of these is provided by Begon (1979) and below each is Iisted followed by a brief evaluation regarding the adequacy of the Niantic River winter flounder population surveys in meeting them.

\section{Assumption 1}

1. Marks are easily recognized, are not 1ost, and do not cause mortalites. The methods of fin clipping (1975, 1976) and freeze branding (1977 to present) were chosen to increase the reliability and ease in marking winter flounder. Adult $f$ ish marked by both means have been held in the laboratory in several experiments and little mortality has been observed from handling or marking.

In 1981, fish as small as $6.5 \mathrm{~cm}$ were branded. If successfully marked, the Jolly technique could be extended to estimate a large proportion of the 1 year old winter flounder as well as the older fish. Unfortunately, experiments to estimate branding mortality were not successful due to holding problems. Personal observations indicated that branding and handling mortality of small (less than $10 \mathrm{~cm}$ ) winter flounder may have been considerable at times. The proportion of winter flounder smaller than $15 \mathrm{~cm}$ recaptured in 1981 (4.4\%) was significantly less (test of equality of percentages, Sokal and Rohlf 1969) than that for winter flounder larger than $15 \mathrm{~cm}(8.7 \%)$, indicating either differential marking mortality or susceptibility to recapture or both. Therefore the method of population estimation of small fish by the proportional catch method is probably preferable than using a mark-recapture technique since the number of recaptures becomes less important. 
2. Being caught, handled, and marked one or more times has no effect on an individual's subsequent chance of recapture and marked $\mathrm{fish}$ mix completely with the unmarked population.

Samples for marking and recaptures were taken over a 2-day period a week apart curing each survey. Recaptures of fish marked within the sampling week were ignored for estimation purposes. It has been reasonably assumed that the week period between marking and recapture has allowed the marked fish to randomly mix within the population. In addition, all fish were released within their area of capture.

The number of specimens recaptured one or more times was examined to see if any individuals may have been capture-prone and thus biased the Jolly estimates. Similar proportions of capture frequencies were noted for each year with most $(88.2-94.8 \%)$ individuals recaptured only once and very few ( $0.7 \%$ overal1) recaptured more than twice (Table 10 ). Therefore it is unlikely that the population estimates were biased by variable catchability or the existance of particularly capture-prone individuals. Assumption 3

3. A marked fish has an equal chance of being caught as an unmarked fish. All emigration from the study area is permanent and therefore indistinguishable from death in the model.

This assumption was previously examined in detail in NUSCo (1980). The phenomenon of non-permanent or temporary outmigration can lead to overestimation of population and probability of survival using the Jolly technique as the fish that temporarily leave the study area are not subject to the same probabilities of survival and capture as those 


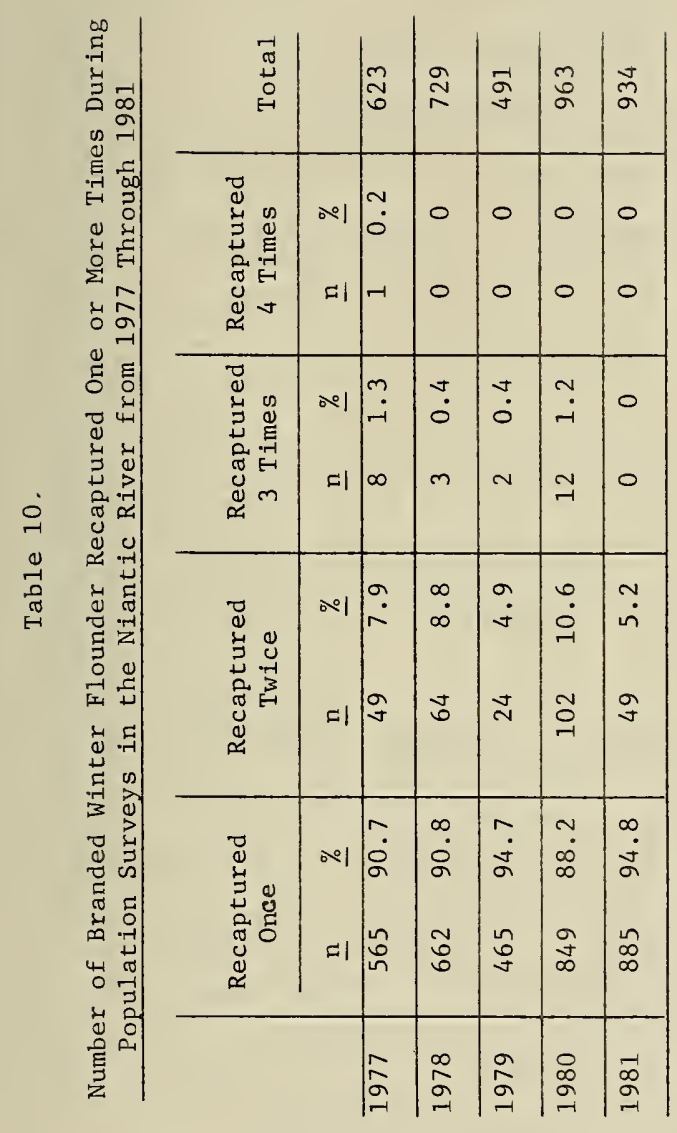


remaining during the sampling. The chi-square test developed to test

this assumption indicated that significant temporary outmigration occurred in all years except 1980. The analysis showed that temporary outmigration occurred only during the first 6 weeks of the population survey, was generally a 2-week phenomenon, and that stabilization of the population occurred about mid-April. This unfortunately indicates that the population of winter flounder during the spawning season, which is of greatest concern, may be subject to sampling error of unknown magnitude. It was suggested in NUSCo (1980) that modifications to the estimation procedures which would account for nonpermanent emigration be applied to improve the estimates of the population size. This recommendation remains relevant and should be investigated in further detail. Assumption 4

4. All individuals, whether marked or not, have inherently the same chance of being caught without regard for age, sex, or condition. All individuals from different classes within the population are sampled in the proportion in which they occur.

Begon (1979) stated that the analysis of a heterogeneous population will produce results applicable to neither the different individuals or classes nor to the population as a whole. He suggested that this assumption can be bypassed whenever possible by dealing separately with each sex or age class. Worobec (1981) noted this heterogenity in a similar population study of winter flounder using the Jolly technique in Rhode Island. She noted differential movements of males and females which confounded her population estimates and suggested that each sex should have been analyzed separately. 
It is likely that this assumption has also been violated during the Niantic River surveys. Since a highly mobile population seems to be present during the spawning season, differential movement of ripe and spent fish may occur to some extent. In addition, the movements of sexually immature fish probably differ as they have no inherent reason to enter the River spawning grounds from offshore wintering areas unless they move in response to preferential water temperature or food availability. The proportion of females, males, and those of unknown sex at time of branding and at time of recapture (Table 11) was examined by the G-test of independence (Sokal and Rohlf 1969). In all cases (year and segment within a year), a significant difference was indicated between the proportion of each sex category branded and recaptured. The relative proportion of unknown fish always increased in recaptures and that of males and females decreased from time of tagging. This change in proportions indicated a probable violation of the assumption and a source of error in population estimation. Several possible hypotheses exist to explain this finding. One is that differential movement occurred among the mostly sexually mature males and females and the sexually immature fish not sexed, as was suspected by Worobec (1981). Secondly, the susceptibility of capture may differ for the larger, sexed fish and the smaller, unsexed fish. Unfortunately, since relatively few fish recaptured were measured this could not be ascertained. Thirdly, the differences in proportions may have resulted from the method in which the winter flounder were sexed. Males have ctenii on the scales of the ventral caudal peduncle whereas the scales of females are smooth (Smigielski 1975). A much easier way of sexing, of course, is if the individual is ripe and extrudes readily identifiable eggs or sperm. A relatively 


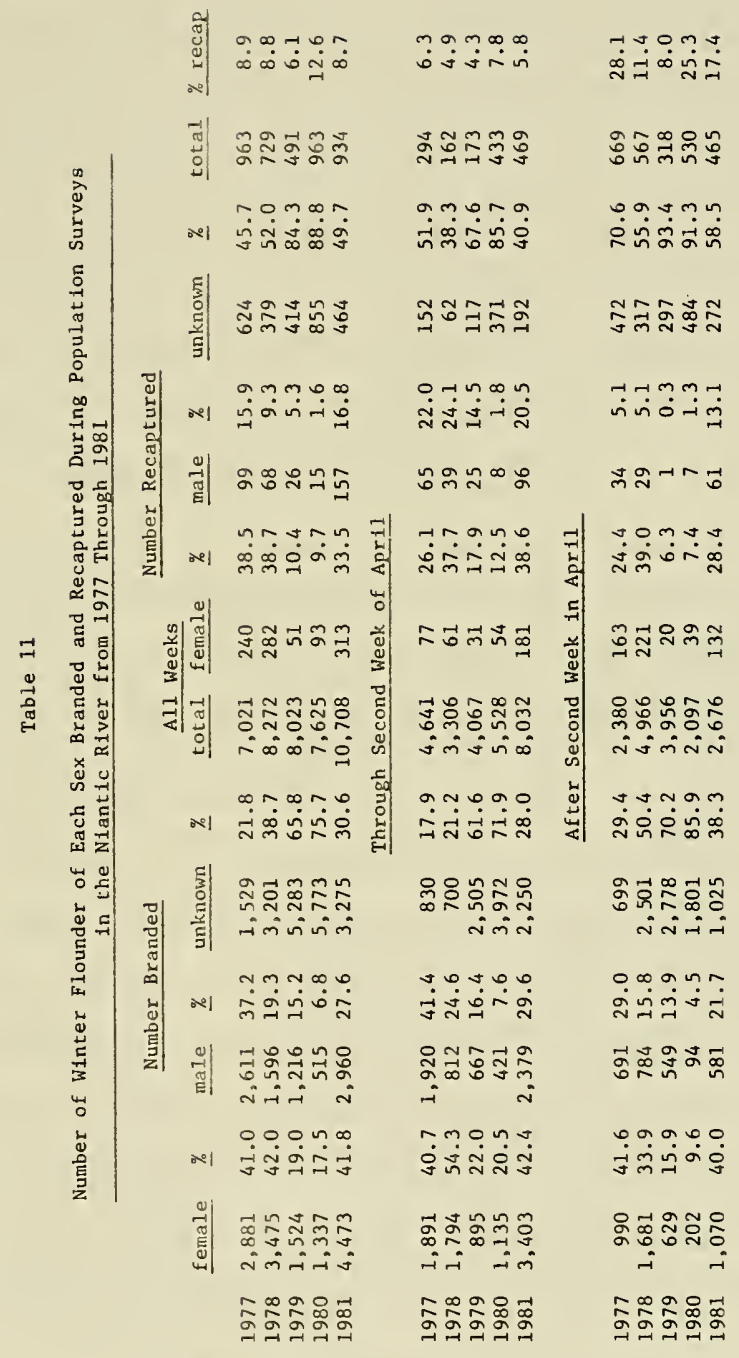


large percentage of small males (including many smaller than $15 \mathrm{~cm}$ ) were ripe during the spawning season and thus were easily sexed. But when spent, these fish may have been sexed as unknown because their scales were so small and weakly ctenoid that they couldn't be felt. This could have accounted, in part, for the large increase of recaptured unknowns and decline in the number of males.

\section{Other assumptions or restrictions}

6. Estimates are reliable only when $9 \%$ or more of the population is sampled (Bishop and Sheppard 1973; Southwood 1978).

7. For accurate results the coefficient of variation (SE of $N / N$ ) should be less than 5\% (Roff 1973).

8. Probability of survival (phi) greater than 1.00 indicates a major error (Southwood 1978).

Except for $1975(6.6 \%), 11.6$ to $23.4 \%$ of each year's estimated population was sampled (Tables 2-8). The coefficients of variation, however, ranged from $8.0 \%$ in 1976 to $36.6 \%$ in 1977 . Roff (1973), however, did note that the $5 \%$ level of precision was almost never obtained in tagging studies, so this restriction is probably of little concern.

Begon (1979) pointed out that estimates of survival probability (phi) of greater than 1 as well as the calculation of negative numbers joining ( $B$, usually referred to as births in most Jolly models) were biologically impossible values. He stated that since phi and $B$ are estimates, they are subject to error and that imperfect data produces impossible estimates. He recommended that the best estimate of any phi greater than 1 would be 1.00 and that for negative $B$ would be 0 . Negative gains should not be interpreted as losses and vice versa. 
The ten calculated negative values of B determined in Niantic River winter flounder Jolly estimates were treated as 0 values, but three estimates of phi greater than 1 were used to adjust the weekly Peterson estimate upwards to account for a supposed large increase in recruitment. This has resulted in a larger population estimate because of the upward adjustment. Following Begon (1979), the correct methodology should not be to adjust $B$ upwards. The estimates for 1975 and 1981 should be corrected downwards 15,551 and 4,677, giving revised population estimates of $144,523(-9.7 \%)$ and $88,547(-4.0 \%)$, respectfully.

\section{Sampling methodology}

As previously noted, restrictions in towing imposed by the East Lyme - Waterford Shellfish Commission have changed the areas sampled within the Niantic River from 1975 to the present. In addition, effort among various stations also changed from year to year based on the availability of winter flounder and amount of macroalgae and detritus present which affected trawl efficiency. It is possible that some of these changes may have affected the year to year comparability of the population estimates. In 1975 and 1976, 70 to $77 \%$ of the trawl hauls were made in the lower to mid-River at stations 1 and 2 in the channel and at 6 and 7 along the eastern shore, although most other areas were sampled as well (Fig. 1; Table 12). In 1977, 1978, and 1980, 85\% of the tows were made at stations 1 and 2 with relatively few elsewhere. Most tows were also made at these stations in 1979 (69\%) but additional effort was also made in other locations that year. In 1981, effort was divided nearly evenly between these lower channel stations and station 5 in the upper River. 


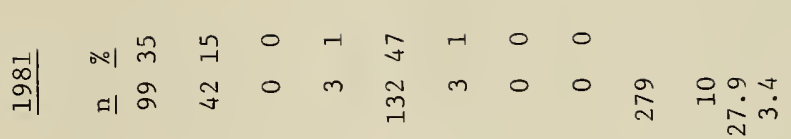

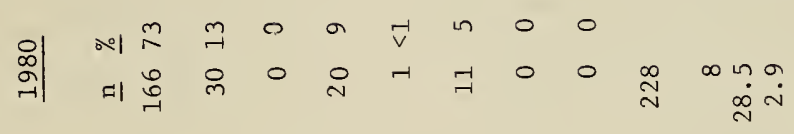

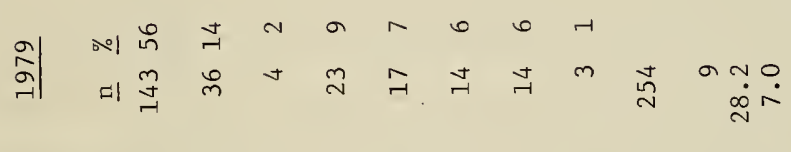

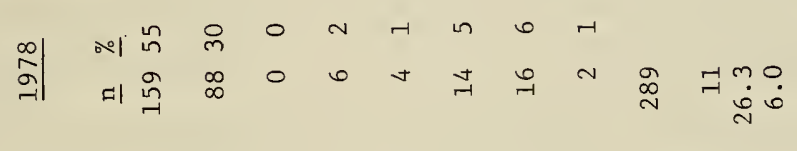

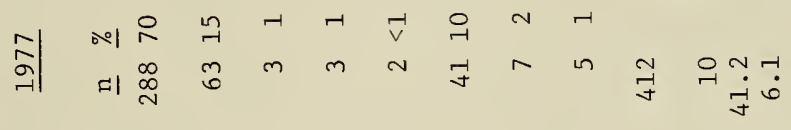

$$
\begin{aligned}
& \text { 空 } \\
& \text { In } \\
& \text { บ } \\
& \text { 年 }
\end{aligned}
$$

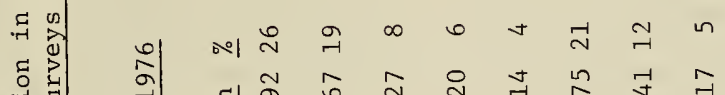

$$
\begin{aligned}
& \text { 혼 }
\end{aligned}
$$

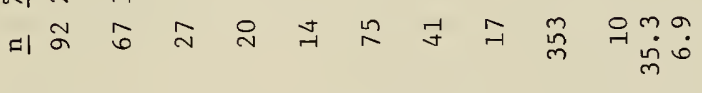

$$
\begin{aligned}
& \text { in } \\
& \text { (1) } \\
& \text { क. } \\
& \text { की }
\end{aligned}
$$

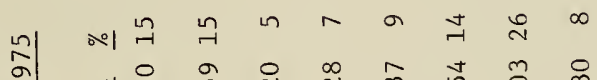

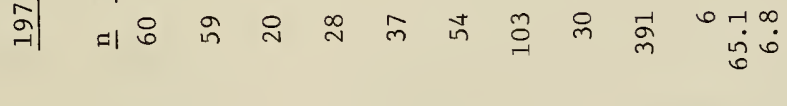

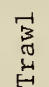

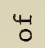

$$
\begin{aligned}
& \text { 热 } \\
& \text { 部 } \\
& \text { An, n. } \\
& \begin{array}{c}
x \\
0 \\
11 \\
3
\end{array}
\end{aligned}
$$

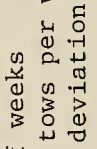

$$
\begin{aligned}
& \text { 넝ㅁㄷㄴ } \\
& 4 \text { 号 } \\
& \text { 㟧 } \\
& \text { 艾芒芯 }
\end{aligned}
$$


The number recaptured at a station was even more weighted towards station 1 with annual recapture percentages of 82.3 to $95.1 \%$ from 1977 through 1980; in 1981 the percentage dropped to $57.1 \%$ as $33.2 \%$ of the recaptures were made at station 5 (Table 13). This is not totally unsurprising as many winter flounder tagged at other stations may have been recaptured when leaving the River at station 1 which is near the mouth. This was examined in greater detail as winter flounder were oranded with a station code as well as a week code from 1977 through 1979 and interstation movements could be discerned (Table 14). Most recaptured fish branded at station 1 were also retaken there. Recaptures of fish branded at station 2 were taken mostly elsewhere, with many found at station 1. Although recaptures of fish branded at other stations were sparse, a relatively high percentage was made within each station; most recaptures off station were at stations 1 and 2 . Again, this is not unexpected given the relative effort expended at those two stations. Another comment on methodology concerns the $15-\mathrm{cm}$ size separation of winter flounder branded and the estimation of fish smaller than 15 $\mathrm{cm}$. The 15-cm size limit was somewhat arbitrary when originally chosen, but has proven adequate in separating 1 year olds and older fish. Some 2 year olds were smaller than $15 \mathrm{~cm}$, but aging of specimens from 10 to $15 \mathrm{~cm}$ allowed for an estimate of this relatively small number. As explained previously, a proportional method was used to estimate winter flounder smaller than $15 \mathrm{~cm}$. However, the actual number of small winter flounder produced from the Niantic River will probably never be adequately determined. One reason, also previously mentioned, was the suspected considerable mortality from branding of small winter flounder which would preclude a mark-recapture methodology using the present techniques. 


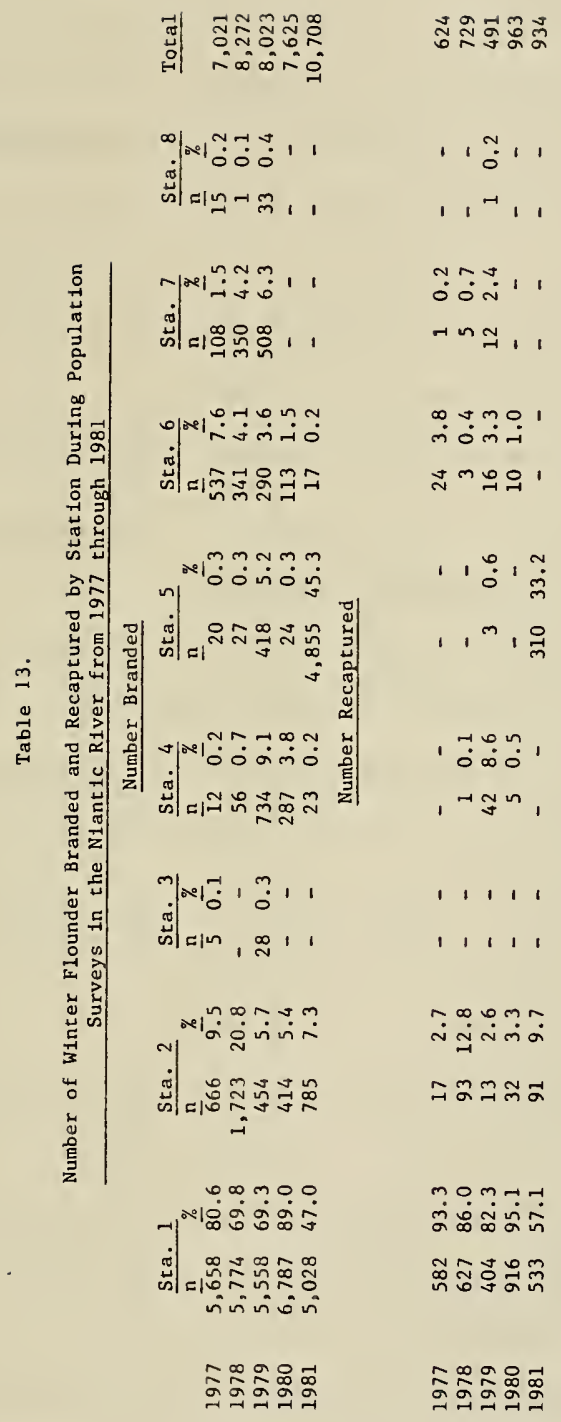




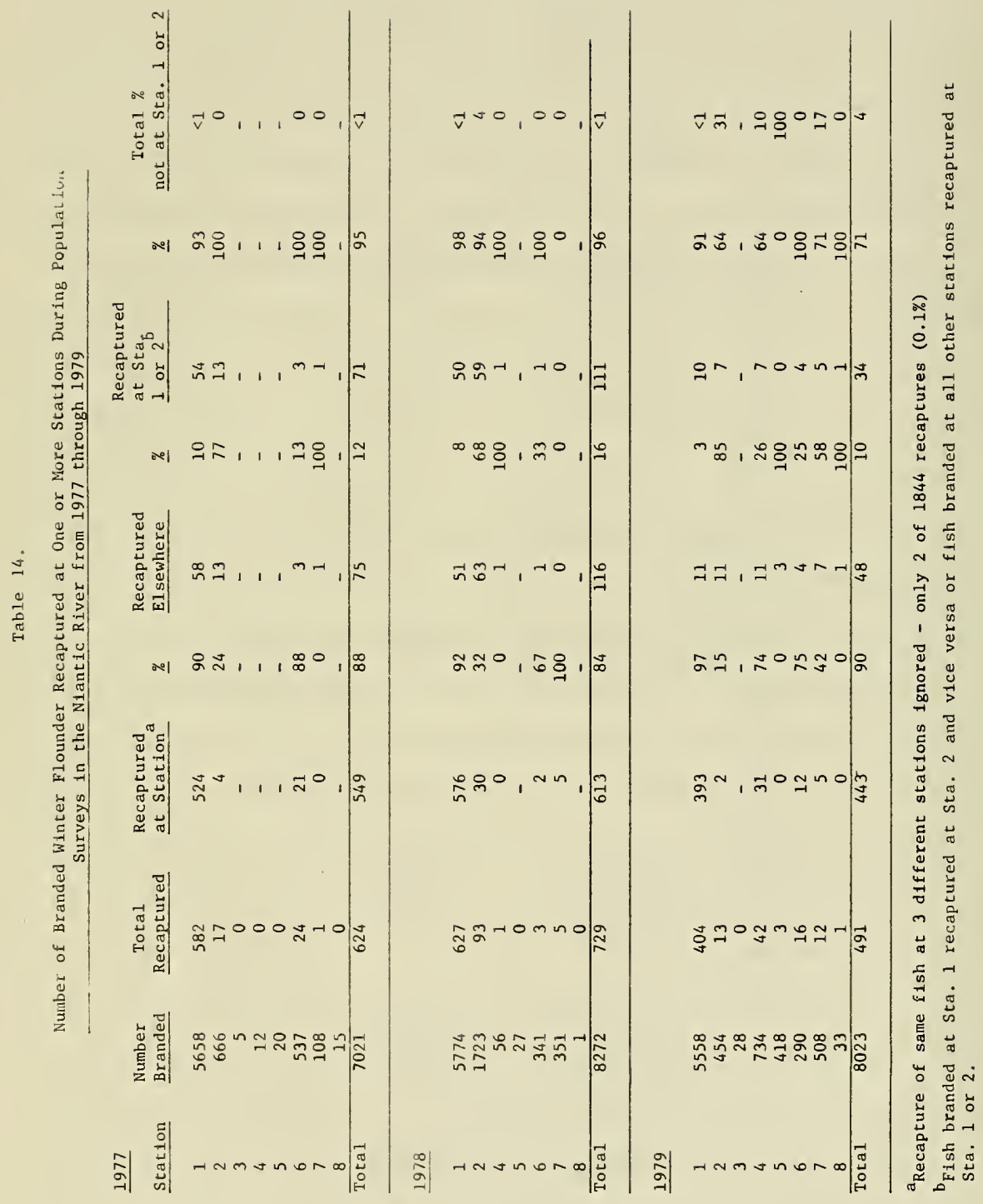


Perhaps more inportant has been the relative distribution of the smaller fish. Length frequency distributions of winter flounder taken in the trawl monitoring program indicated that age 1 and 2 winter fiounder were common at stations outside the Niantic River throughout the period of the population surveys. Because of their occurrence outside the River the true abundance of age 1 and possibly a segment of age 2 winter flounder may be impossible to determine using the present techniques of estimation.

Comments regarding the estimation of the number of spawning females will be made in another subsection of this report as that estimate perhaps depends more upon life history information gathered as it does upon the Jolly technique.

\section{Population estimates and CPUE}

A relationship seemingly exists between the annual population estimates and the grand mean catch-per-unit-effort (CPUE) of winter flounder from all tows made during the surveys (Fig. 2). Estimates of absolute population size may not be necessary for use in various impact analyses as long as relative annual changes in one or more indices of abundance are known. Use of a relative index would also eliminate any problems or uncertainties regarding the accuracy of the Jolly estimates. Therefore the relationship between the population estimates and the trawl CPUE were examined in further detail.

The original intent of the trawling was only to catch winter flounder for marking and for making recaptures. Consequently the tow times of the hauls weren't standardized by time or distance but ranged from 1 to $44.5 \mathrm{~min}$. The distance towed cannot be ascertained due to the uncertainty in the relation between distance and time because of variable boat 


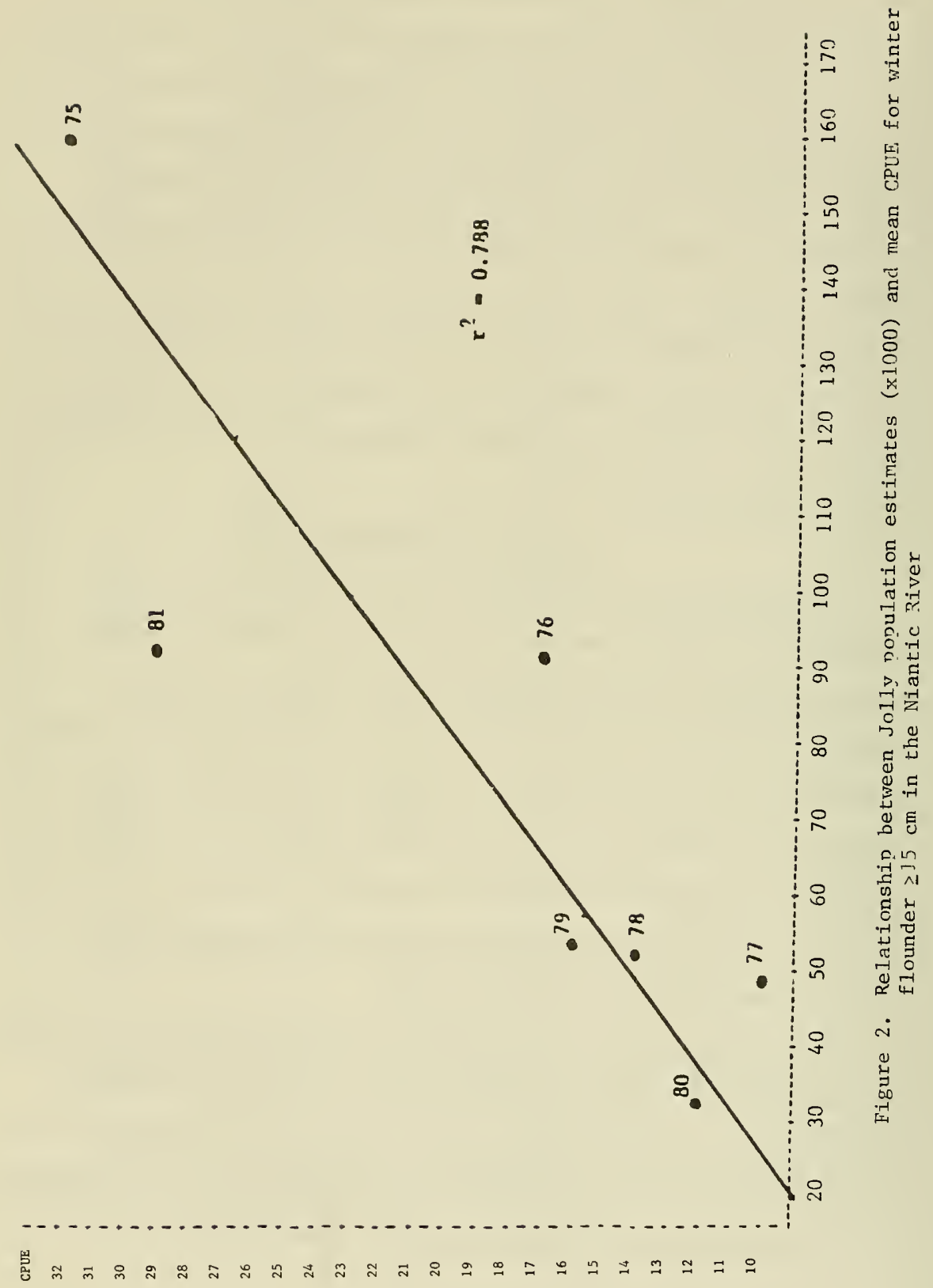


speed, tide, wind, and other factors. Annual means in tow time ranged from $8.0 \mathrm{~min}$ in 1975 to $17.5 \mathrm{~min}$ in 1980 (Table 15). Mean duration varied among stations with tows at the channel stations ( 1 and 2 ) longer than those at other areas. For simplicity each tow was standardized to a 10-min duration for the calculation of CPUE without regard for the additional variability this might have introduced into the data.

Another source of variability examined which may have affected CPUE was the various research vessels used throughout the studies. Although the same model 9.1-m otter trawl was used for sampling from year to year, the type of boats used generally changed every 1 or 2 years. Each boat used may have caused the trawl to fish differently due to its size, rigging, and towing speed. Where sufficient data existed, the catch of the two or three vessels used were compared within a year at a particular station by one-way analysis of variance. No between-year or betweenstation comparisons were made since the variability contributed by years and stations was thought to be much greater than that for boat and because most boats were only used during 1 year. A total of 21 boatstation-year combinations were examined; 18 of these were not significant. In 1979, the vessel Sisu had significantly greater catches than the vessel Mya at stations 1 and 4. Although it was a much smaller boat it may have fished better than the larger Mya which couldn't maintain steady towing speeds ( $J$. Castleman, personal commication). In 1981, the vessel Northeast I had significantly greater catches at station 1 than Northeast II. Although otherwise identical, the trawl rigging for these two boats is different with the former more properly rigged for trawling. Even though some differences due to boat were indicated, the variation in CPUE as a function of vessel cannot be quanitified because little direct comparative data exists among all the boats used. 


\section{All stations}

\begin{tabular}{|c|c|c|c|c|c|}
\hline & $\underline{\mathrm{n}}$ & mean (min) & $\underline{\mathrm{S}}$ & $\mathrm{CV}$ & Range. \\
\hline 1975 & 407 & 8.0 & 5.2 & $65 \%$ & $1-35$ \\
\hline 1976 & 390 & 9.8 & 4.8 & $49 \%$ & $2-35$ \\
\hline 1977 & 412 & 11.9 & 4.6 & $39 \%$ & $3-35$ \\
\hline 1978 & 289 & 12.8 & 5.2 & $41 \%$ & $1-30$ \\
\hline 1979 & 265 & 12.5 & 5.8 & $46 \%$ & $3-28$ \\
\hline 1980 & 228 & 17.5 & 8.5 & $48 \%$ & $4-44$ \\
\hline 1981 & 286 & 12.8 & 4.3 & $34 \%$ & $1-30$ \\
\hline
\end{tabular}

1975

1976

1977

1978

1979

1980

1981

1975

1976

1977

1978

1979

1980

1981

1975

1976

1977

1978

1979

1980

1981

1975

1976

1977

1978

1979

1980

1981

1975

1976

1977

1978

1979

1980

1981

61
95
288
159
145
166
100

100

\section{Station 1}

11.8
12.9
12.8
12.8
14.7
19.6
15.5

5.7

6.1

4.8

4.1

4.3

8.2

4.2

$49 \%$

$47 \%$

$37 \%$

$32 \%$

$29 \%$

$42 \%$

$27 \%$

Station 2

14.4
12.4
11.4
15.9
16.8
15.2
14.3

$4-25$

5-35

3-35

10-25

$5-28$

$5-44.5$

10-27. 5

\section{Station 4}

5.4

5.6

5.0

6.7

8.3

7.4

9.3

Station 5

6.8

4.7

7.5

5.0

7.4

10.0

10.6

Station 6

5.8

9.0

8.8

5.1

4.9

10.4

8.3
6.8

3.5

2.9

$47 \%$

$28 \%$

$26 \%$

5.0

5.5

$31 \%$

$33 \%$

6.0

$40 \%$

4.9

$35 \%$
$2.0 \quad 36 \%$

$1.6 \quad 28 \%$

$00 \%$

$2.6 \quad 39 \%$

$4.1 \quad 50 \%$

$4.9 \quad 67 \%$

1.2

$12 \%$

$48 \%$

$19 \%$

0.9

0

2.7

2.7

$0 \%$

$36 \%$

$---$

$39 \%$

$27 \%$

$38 \%$

$20 \%$

$18 \%$

$\begin{array}{ll}2.4 & 23 \% \\ 2.9 & 35 \%\end{array}$

$\begin{array}{ll}2.4 & 23 \% \\ 2.9 & 35 \%\end{array}$
10-35

$5-20$

$5-20$

$5-30$

$8-27.5$

8. $5-38$

4-30

4-15

5-10

5

5-10

$5-18$

$5-24$

8-10

3-15

2-5

5-10

5

$5-12$

10

5-20

1. 5-15

$5-15$

3-15

3-8

3-7

4-13.5

5-10 
The mean weekly CPUE for all stations and for selected stations through the second week in April (spawning period) are given on Table 16. No other statistical analyses were made on this data but the potential exists for further comparisons. The apparent relationship between the magnitude of the mean and the standard deviation in most instances indicates that some type of transformation is desirable when working with this data.

The relationship between the mean weekly CPUE (Table 16) and the weekly population estimates calculated (Tables 2-9) was determined for al1 weeks from 1975 through 1981, all weeks from 1976 through 1981, and for the spawning season from 1976 through 1981 (Table 17, Figs. 3-5). The 1975 data were eliminated from the latter two analyses because of uncertainty in two of the weekly estimates and because the weekly estimates were for weeks after the spawning period. The CPUE-population relationships were not entirely adequate as $r^{2}$ for the regression using all years, 0.617, decreased to 0.425 without the 1975 data. A slightly better fit was generated for the data from just the spawning season (0.493). Much variability exists among the weekly Peterson estimates and the uncertainty in relationship between these estimates and the CPUE, which may also be subject to error because of its method of calculation, should be investigated in further detail.

\section{Conclusions and Recommendations}

Overall, the winter flounder population estimate program is ambitious in scope and has provided a long time-series of data necessary for impact analyses. It can be looked upon with pride by Northeast Utilities because of the willingness of the scientists involved to continually improve techniques necessary to improve the reliability, accuracy, and precision of the estimates. 


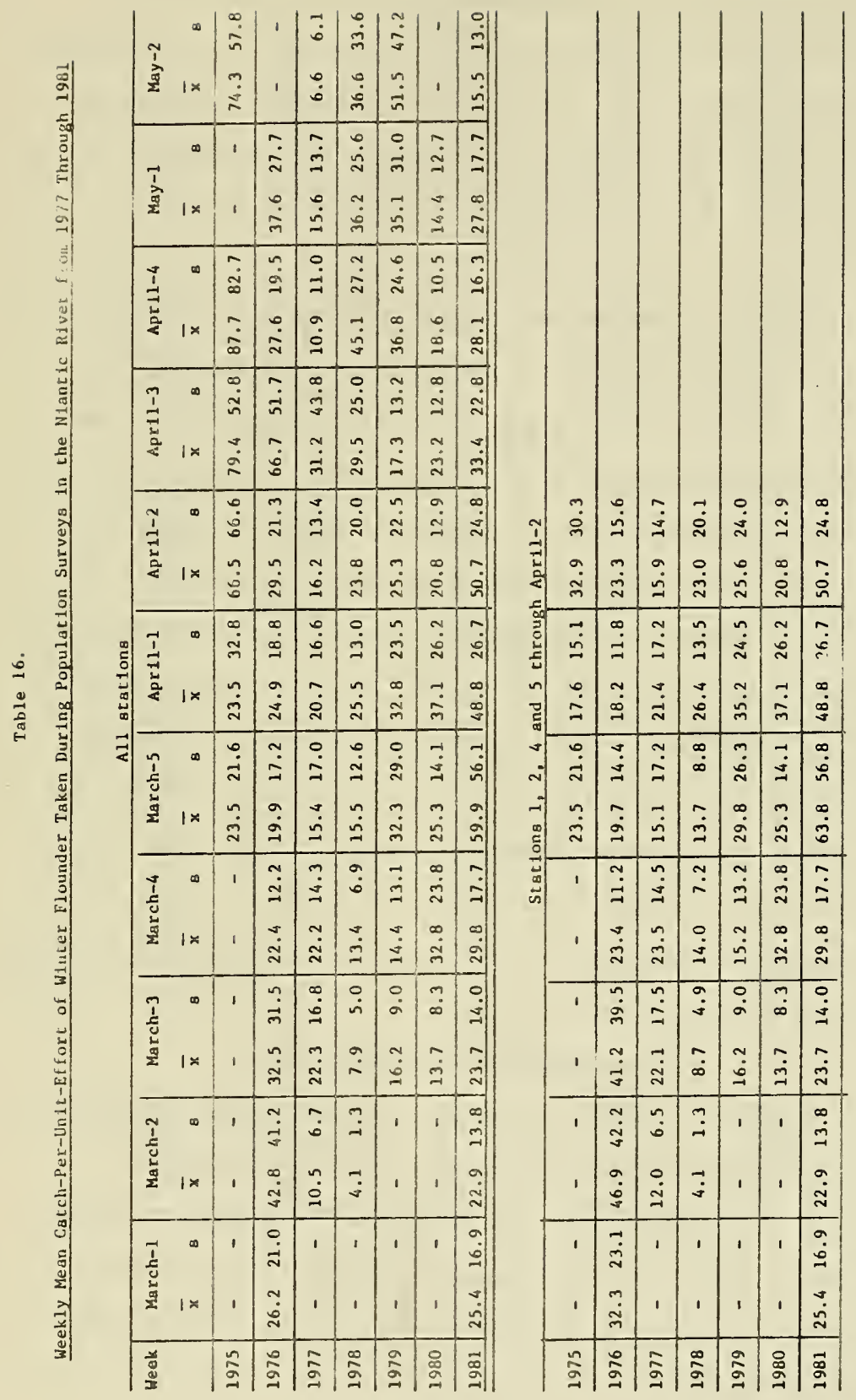


Table 17

Relationship Between Weekly Population Estimates and

Mean CPUE of Winter Flounder Taken During Population

Surveys in the Niantic River From 1975 Through 1981

\section{Period $^{\mathrm{a}}$}

A11 weeks/1975-81

A11 weeks/1976-81

Through Apri1-2/1976-81 19

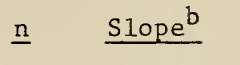

$46 \quad 6.17 \times 10^{-4}$

$427.86 \times 10^{-4}$

$10.41 \times 10^{-4}$
$\underline{S E^{C}}$

$0.744 \times 10^{-4}$

$1.446 \times 10^{-4}$

$2.562 \times 10^{-4}$
Intercept

16.406

12.692

9.099
$\underline{S E} \quad \underline{r^{2}} \quad$ C.V. $2.532 \quad 0.617 \quad 31.7 \%$

$3.538 \quad 0.425 \quad 30.9 \%$

$5.640 \quad 0.493 \quad 30.1 \%$

${ }^{a}$ Using data from all weeks of population surveys or through the second week of April (spawning period).

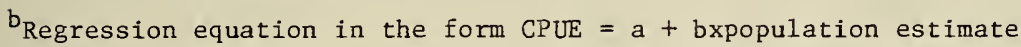

$\mathrm{c}_{\mathrm{S}}$ tandard error of estimate 


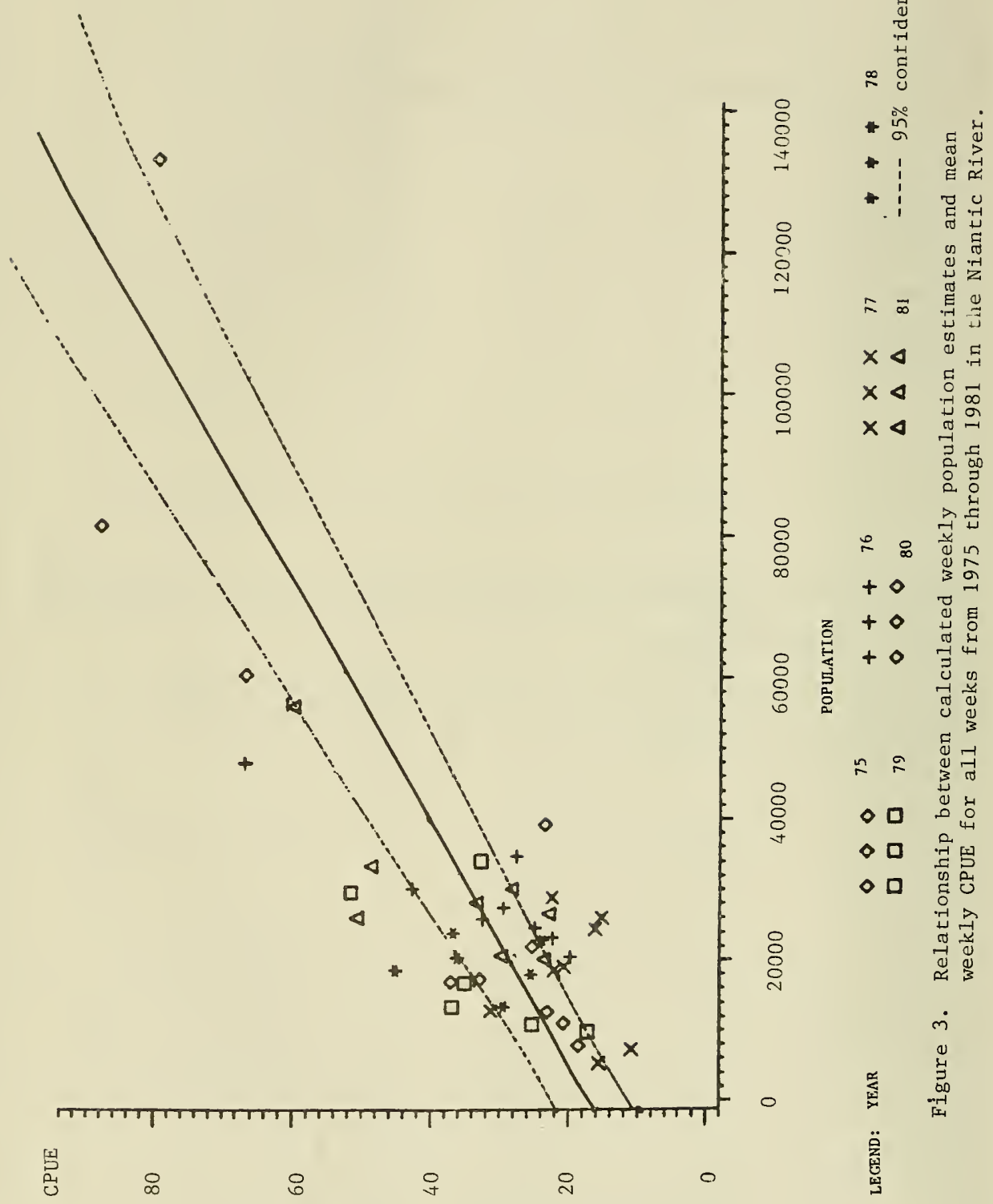




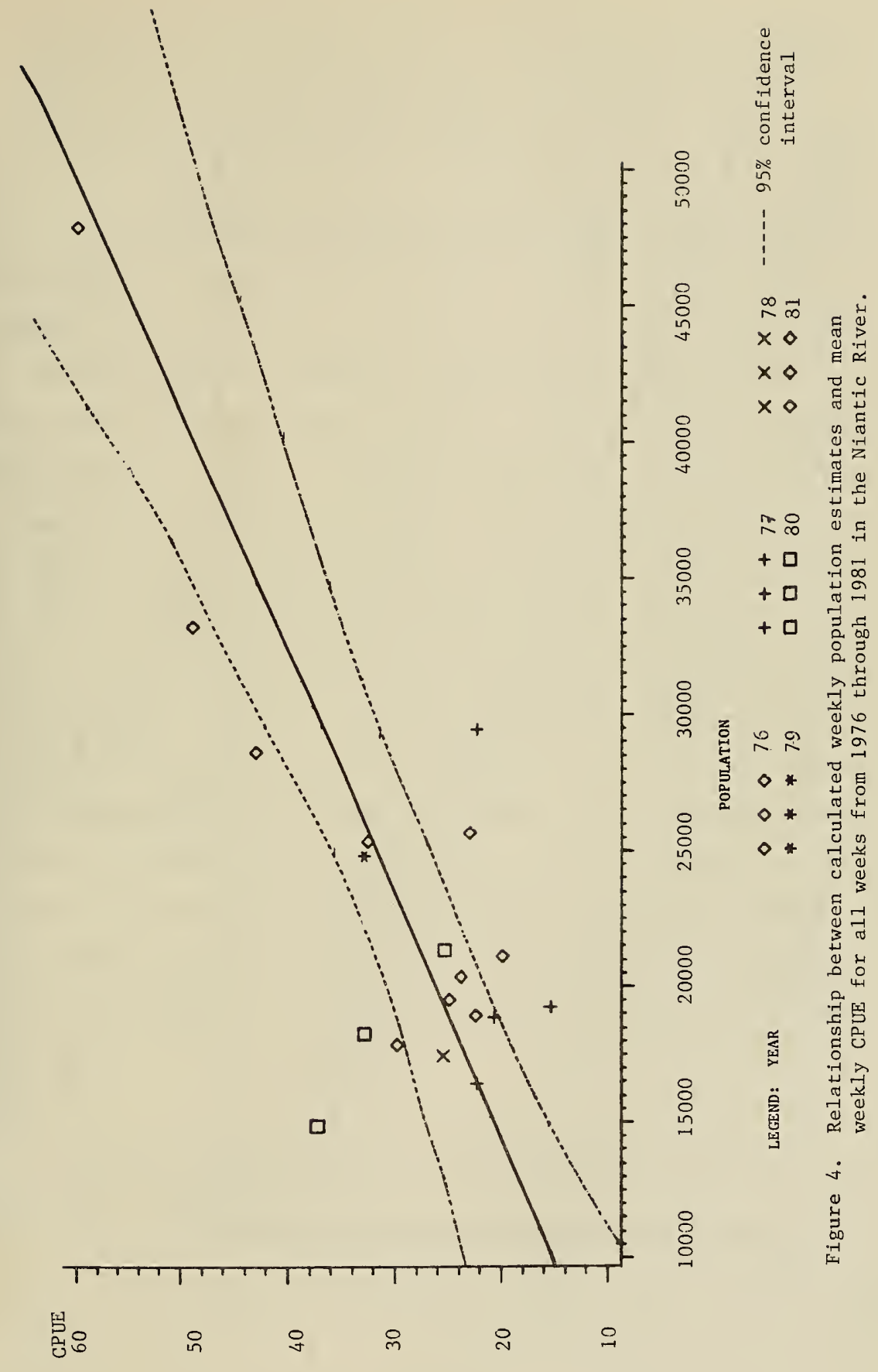




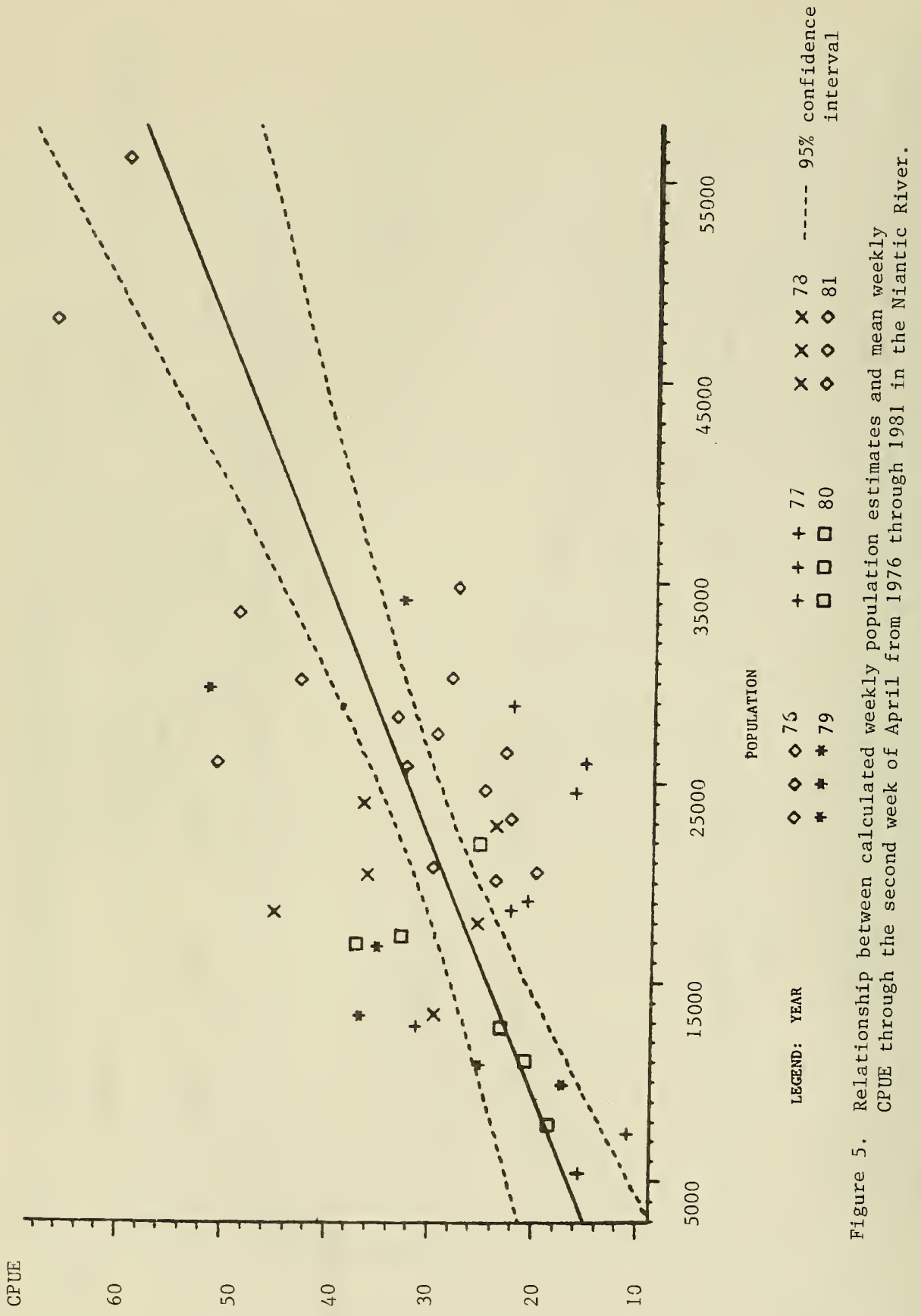


Some additional refinement of the the techniques has been suggested by this review as well as further analysis in some areas. A brief summary and discussion of each item follows.

$\underline{\text { Item }}$

1. The accuracy and usefulness of the 1975 population estimate is questioned.

Comment

The 1975 survey was originally designed for the triple-trellis technique, thus recaptures were never marked. The data had to be manipum lated based on a simulation of multiple recaptures to provide a Jolly estimate and the phenomenon of temporary outmigration could not be examined. The survey period was brief (only 4 weekly estimates made) and didn't commence until March 31, nearly the end of the spawning period. The calculated probability of survival (phi) was greatly above 1.00 during 2 of the 4 weeks, indicating a major error (Southwood 1978). For these reasons the 1975 estimate must be viewed with some suspicion and the numbers used with care in any analyses. This is not to say that the data are entirely without merit. There is no doubt that winter flounder were particularly abundant in 1975 as evidenced by the weekly CPUE, especially in late April and early May (Table 16). These figures and other life history information will continue to be useful in future analyses.

$\underline{\text { Item }}$

2. The accuracy and usefulness of the 1980 population estimate is questioned. 
Initial examination of the 1980 survey data seemingly indicates a highly precise estimate. For example, both the percentages of the estimated population sampled and that of recaptures made were 1.5 times greater than those of other surveys. The estimates of phi were among the least variable and had the smallest standard errors of all surveys. It was the only year in which no significant outmigration was indicated. The trawl effort expended (number of tows per week) varied least among the surveys. However, elsewhere in the 1980 data are indications that the population measured may not have been entirely the one for which the survey was intended. Over $75 \%$ of the winter flounder branded were classified as fish of unknown sex, far more than any other survey except 1979 (65\%). This indicated that mostly smaller (and non-spawning ?) fish were taken as was also evidenced by the significantly smaller mean lengths of age 3 and older winter flounder determined in comparison with other years. Additionally, the numbers estimated within age classes for the 1980 population did not correspond with the estimated numbers of those a year younger in 1979 or a year older in 1981 (see Table 24). Two reasons probably accounted for the above findings. The first is that the 1980 survey started in mid-March, the latest since 1975, and therefore may have missed many spawning adults. Secondly, only one haul was made at Station 5, which in 1981 and 1982 (personal observation) contained the majority of the spawning adults. Thus the 1980 estimate may have missed the majority of the adult winter flounder present in the Niantic River that year. However precise the estimate seems, Cormack (1968) notes that there is a serious error in being too precise and quotes Paulik as saying "an approximately right answer is always preferred to a highly precise but wrong answer". 
3. Examination of the data indicates violation of several assumptions including temporary outmigration and perhaps equal catchability of marked fish by sex or size.

Comment

Similar findings were made by Worobec (1981) in a study patterned after the Niantic River surveys. Some violation of assumptions invariably occur in capture-recapture studies with differing effects on precision and reliability of the estimates, depending upon the intent of the investigation (Begon 1979). The effect of assumption violations here are not yet known. It is recommended that the data be re-examined to minimize these errors and to obtain more accurate if not precise estimates for use in impact analysis. Pollock (1981, 1982) recommended the POPAN2 computer program package (Arnason and Baniuk 1978) for very powerful and flexible analyses of studies using the Jolly method. It has strong data manipulation capabilities such as the ability to stratify by age or sex. It can carry out various tests of $\mathrm{fit}$ to models and assess the influence of assumption failure on estimates. Recent steps have been taken to obtain this program and implement it on the data processing system. This program should greatly increase the reliability of the population estimate program data.

Other recommendations to assess the assumptions of the Jolly method include measuring all $\mathrm{f}$ ish branded and recaptured. Although this would increase the labor involved in the field, it would result in much more information available for data analysis including the ability to stratify by age (through an age-length key) and would allow the examination for size selectivity in recaptures. Data collected among many categories 
can always be reduced by combination; the converse is not always true.

A final recommendation would be to double brand a certain number of fish in a designed experiment. This would allow the detection of the proportion of brand "loss" or misidentification in the field.

\section{$\underline{\text { Item }}$}

4. Iegin the population estimate surveys as early as possible to more accurately determine the adult spawning population. Cease field work by mid-April after which many adults have left the River and the population is predominantly small fish.

\section{Comment}

Adult winter flounder are probably in the Niantic River and in spawning condition well before the population surveys commence. Movements following spawning may be complex and the influx of adults into the river which have spawned elsewhere may occur to an unknown degree. The usefulness of the population survey data mostly lies in its applicability in various models assessing plant impact. Furthermore the data used are mostly adult population parameters such as age structure, fecundity, mortality, and so forth. Therefore prolonging the sampling period to encompass a period when the majority of the population is smaller, mostly immature fish may not be warranted. In addition, the continuous distribution of age 1 and perhaps age 2 fish both inside and outside the Niantic River makes the estimation of their numbers impossible and no justification can be made to use survey data to measure their numbers.

\section{$\underline{\text { It em }}$}

5. Further investigate the relationship between the population estimates and CPUE. 
Comment

Some models which can be used for impact analysis only require that the relative number of winter flounder (total, within various age groups, etc.) be known from year to year, not the absolute number. This would eliminate the necessity of making a population estimate and instead an index of relative annual abundance such as CPUE, which is more easily obtained, could be taken. However, the long time serles of winter flounder population data needs to be analyzed in further detail to see if a good measure of CPUE can be obtained without sacrificing the accuracy and precision known about each estimate. Preliminary analysis has shown that a satisfactory relationship has yet to be found between the population estimates and CPUE as much variability exists within and between years. The data may not be entirely satisfactory for this purpose as unlike the trawl monitoring program, the sampling for winter flounder from 1975 through 1981 was not designed to measure CPUE. It is recommended that further work be undertaken to develop a satisfactory index of yearly relative abundance from the winter flounder population survey data.

\section{JUVENILE AND ADULT LIFE HISTORY OF THE WINTER FLOUNDER}

\section{Summary of methods}

Beginning in 1975,100 to 200 winter flounder were measured each week of the population survey. Although all fish from a particular tow were measured to avoid selection bias, the tows themselves were not randomly selected. Tows from various stations in the River were chosen for measurement to obtain a complete representative sample. In 1976 , the sex of each fish captured was determined insofar as possible by external examination using the method of Smigielski (1975) and a portion 
of the weekly catch of individuals larger than $150 \mathrm{~mm}$ was examined to determine the state of gonad development. From 1977 to the present all fish larger than $150 \mathrm{~mm}$ were sexed. The subjective reproductive categories of gonad development included near-ripe, ripe, and spent; fish considered to be in a non-reproductive condition were simply classified as male, ferale, or sex unknown. The percentage of females categorized as reprocuctive from the beginning of the population survey until the second week of April was used with population estimate data to calculate the total number of spawning females. This number when used with the length distribution of spawning females and the length-fecundity relationship gave the total fecundity for a particular year. Originally the number of spawning females was calculated as:

(\% females) x (\% age 3 and older) x (estimated population). In 1980, this formula was changed and the number of female spawners in each year was calculated as:

(\% length frequency length group) $x$ (\% female) $x$

(\% reproductive) $\times$ (estimated population).

This gave the percentage of spawning females within a length group. The sum of the number of females for all length groups gave the total number of spawning females.

Both otoliths and scales were removed from winter flounder for aging during 1977 and 1978. In 1979 and thereafter only scales were used since good agreement was made using both parts and scale removal was non-destructive. Fifty to $100 \mathrm{fish}$ were selected for aging per week; al1 fish larger then $100 \mathrm{~mm}$ from one or more tows were selected. If the fish for aging came from just one station during a week, another station was chosen for the sample the following week. Measurements of 
fish chosen for aging also became part of the measured winter flounder data base. Each winter flounder was aged by at least two individuals and if agreement could not be reached, an age was not assigned to that fish.

Two independent estimates of winter flounder fecundity were made in 1977, one using 52 specimens from the Niantic River and one using 48 specimens from the entire Millstone area. An log length-log fecundity relationship was calculated for each study using a simple regression.

Similar to that above, two independent length-weight relationships were determined, using data collected in 1977 and 1978. A log lengthlog weight relationship using a simple regression was calculated for 695 winter flounder taken in impingement samples during 1977. The data for winter flounder taken in the Niantic River during 1977 and 1978 was not log transformed and separate curvilinear relationships were determined during each year for ages 1 and 2, and for all older fish.

Beginning in 1979 , estimates of annual survival were calculated by comparing the estimated number of winter flounder of a specific yearclass found in the Niantic River during one spring with the number estimated for the following year.

In 1980, a disc tagging program was initiated which has continued to the present. The methods were described in NUSCo (1982). In 1980 and 1981, 2,154 mostly adult winter flounder were tagged and released primarily in the Niantic River and Bay with fewer at the other remaining trawl monitoring program stations. During 1982, an additional 1,481 were tagged, including 835 in the Niantic River during March and April. The remainder were tagged from April through July at all trawl monitoring program stations, including the River. No tagging was done in late July 
and August 1982 because the warm air and water temperatures were too stressful for tagging winter flounder.

\section{Evaluation of life history information}

Sex, reproductive condition, and spawning population

The sex ratio of winter flounder taken during the population surveys was weighted in favor of females, ranging from 1.14 females per male in 1977 to 2.59 in 1980 (Table 18). Sex ratios during the spawning season were similar to the overall ratios. The sex ratio did not remain constant but changed from year to year. For unknown reasons the ratio increased by approximately one female per male in even-numbered years. Since all fish were sexed externally, the process may have been subject to individual bias and error.

The proportion of females classified as reproductive during the spawning season ranged from 52 to $73 \%$ on a yearly basis (Table 19). Within group percentages ranged from $100 \%$ for the relatively scarce females of the large size classes down to $23 \%$ in the 22 to $26-\mathrm{cm}$ size group where females initially became mature. These proportions were used to calculate the total number of spawning females. The average size of maturity for female winter flounder is probably around $25 \mathrm{~cm}$ (Perlmutter 1947; Kennedy and Steele 1971). Therefore, except for the smallest size group, most, if not all larger females were mature and probably spawned in the River even though some were subjectively classified as non-reproductive. This has had the effect of lowering the annual estimates of spawning females and total fecundity. The original method of estimation had the opposite effect and overestimated spawning females. In this calculation the percentage of all females age 3 and older were 


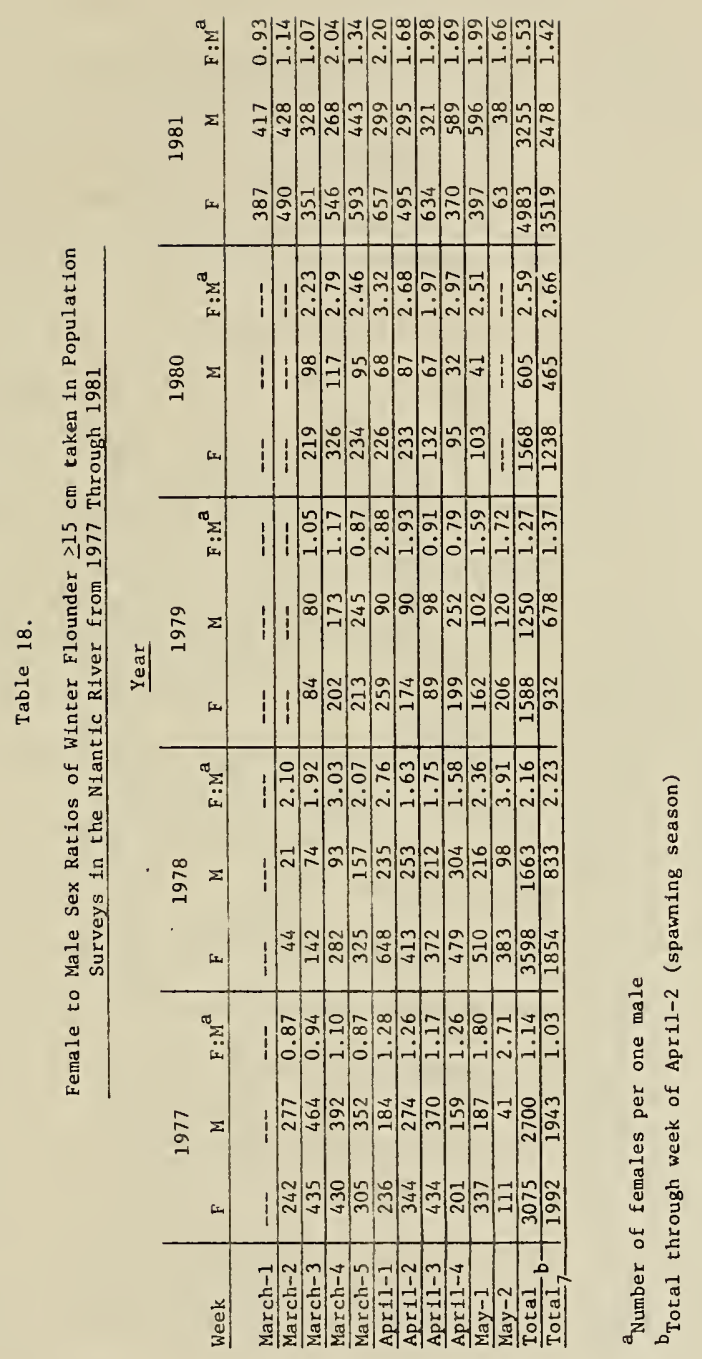




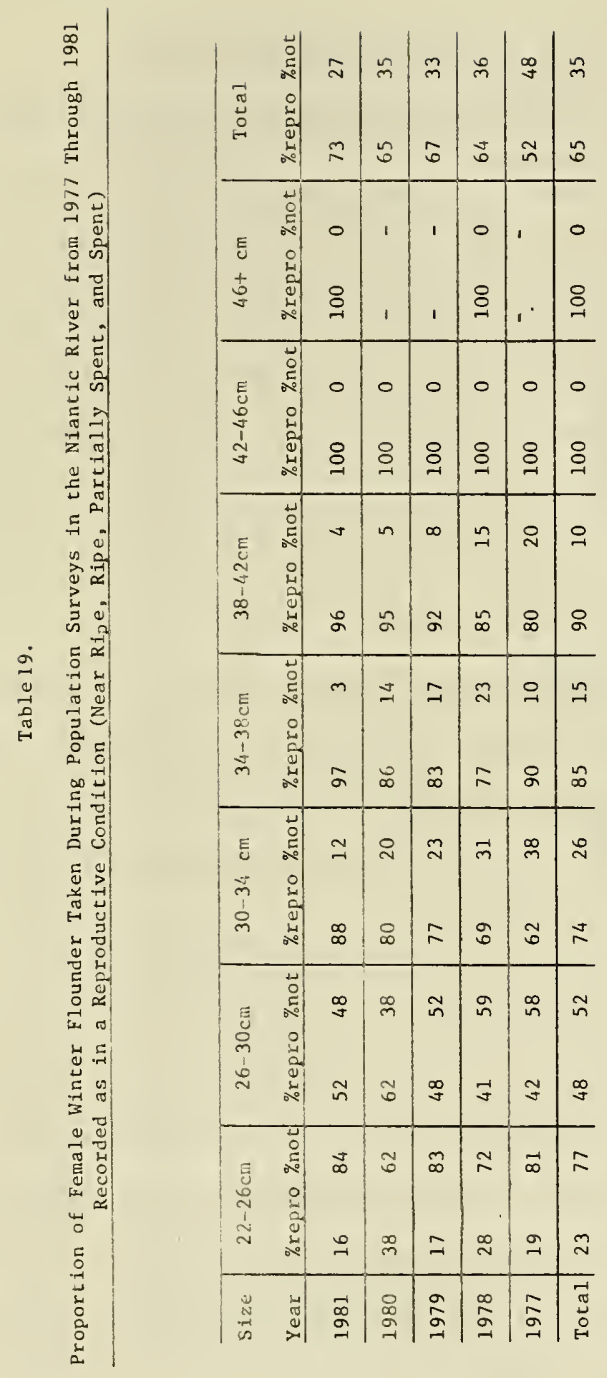


assumed to be reproductive whereas many of the three year old females were immature. If the size of maturity of the Niantic River female winter flounder is known, then all females above this size estimated to have been in the Niantic River should also have been assumed to spawn there. Although some females taken near the end of the spawning season may have spawned elsewhere and then entered the River, it is just as likely that some early spawners were not taken in the population surveys.

\section{Age and length samples}

Except for 1977 ( $9.3 \%$ ), the number of winter flounder aged was 23.9 to $30.1 \%$ of those measured (Table 20 ). Considerable effort has been expended since 1977 in processing the age samples in the laboratory and the number aged annually ranged from 228 in 1977 to 1,287 in 1981 . The number of winter flounder aged within a length group was generally proportional to that measured; two examples are shown in Figures 6 and 7. This is not surprising considering how both samples were chosen. In many cases far more fish of certain sizes or ages were aged then necessary to determine the age composition of the population. A more appropriate method for selecting specimens for aging is a stratified subsampling method (Ketchen 1950; Ricker 1975). In this method, which is most reliable when a large representative length sample is available, fish are selected for aging up to a uniformly fixed number. Depending upon the abundance of $\mathrm{f}$ ish in a length group, this could be a small fraction of smaller-sized fish or most of the older, scarce specimens. From the percentage of each age in the aging sample, an age composition for each length group of the length sample is determined, and by summation across ages, an estimate of the age composition of the population. The number 


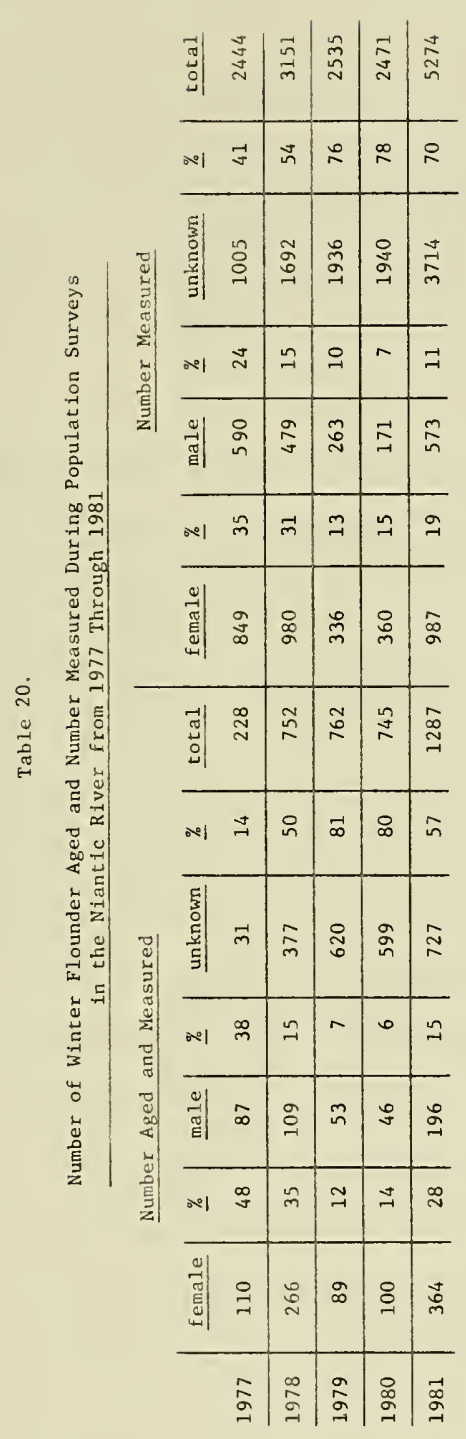




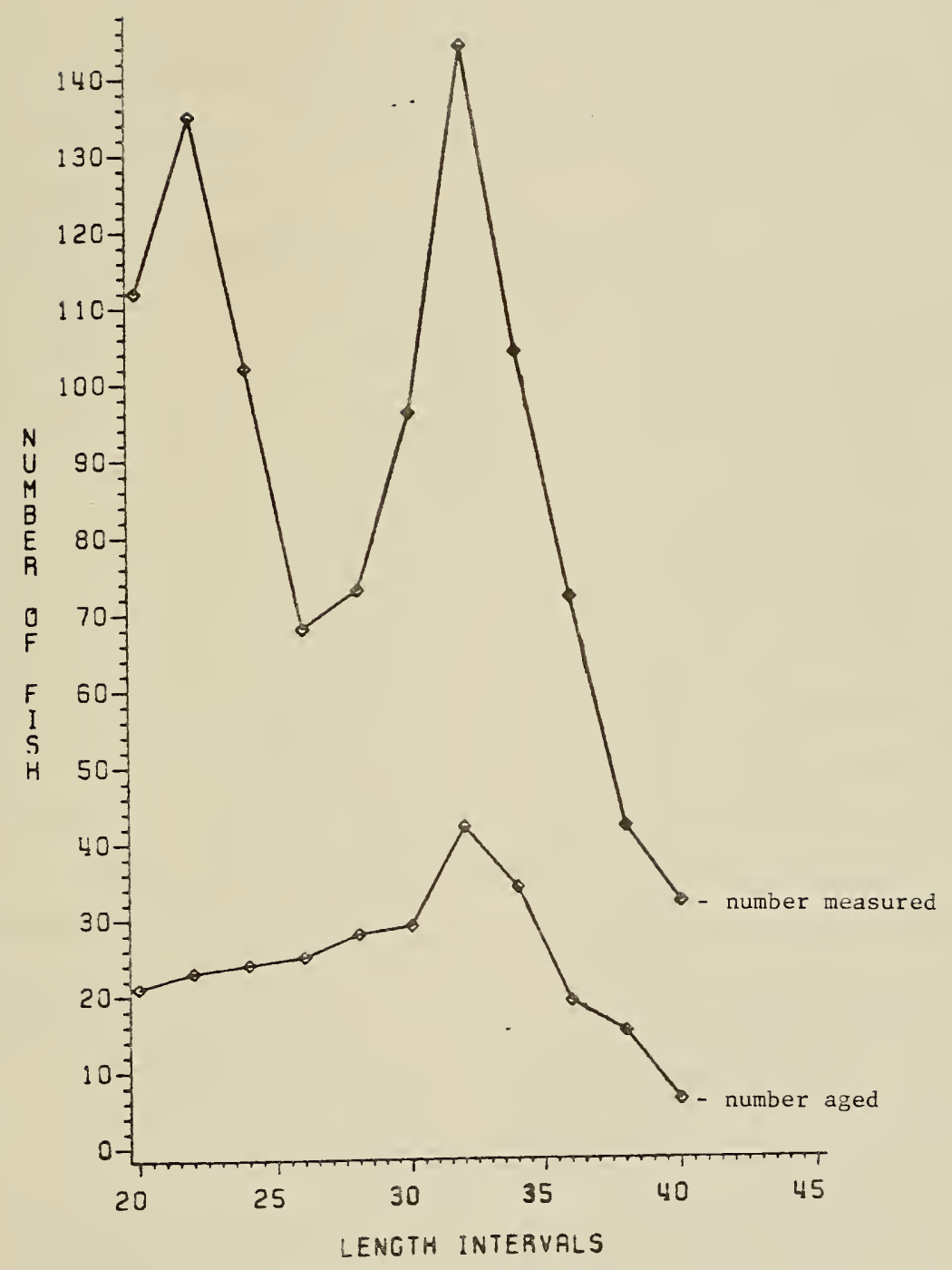

Figure 6. Number of female winter flounder measured and number aged from the 1978 winter flounder population survey in the Niantic River. 


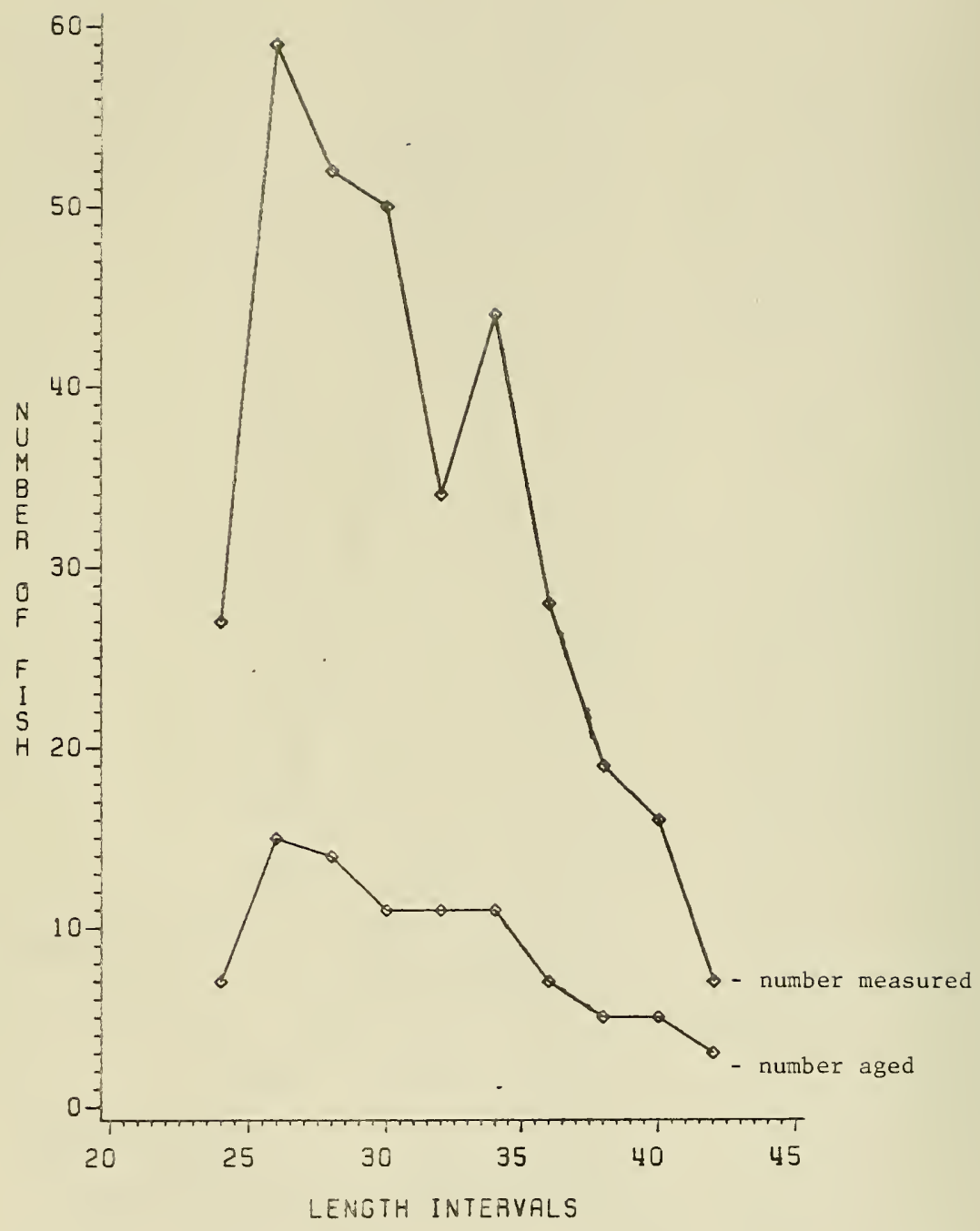

Figure 7. Number of female winter flounder measured and number aged from the 1979 winter flounder population survey in the Niantic River. 
of fish selected for aging within each length group should be dependent upon the time and man-power allocated for aging in the laboratory. This procedure would eliminate unnecessary labor and the possible selection. of a non-random sample by bias. The selection of a larger number of fish in older age classes would also increase the accuracy of the age composition sample. Increasing the number of winter flounder measured during the population surveys would also increase the precision of the calculated age structure.

Length - weight and Length - fecundity relationships

Length-weight and length-fecundity relationships were reported in NUSCo (1977). Both relationships were calculated independently by NUSCo and Battelle personnel; the former used specimens from throughout the Millstone area and the latter used specimens taken in the Niantic River. As these relationships were curvilinear, a $\log _{10}$ transformation was used in all cases except for the original 1977 Niantic River length-weight relationship in which three separate arithmetic regressions were determined for three age classes $(1,2$, and $3+)$. Differences among the calculated relationships were probably due to bias in sample selection and handing of specimens, differences in equipment or techniques used, and so forth. These differences may be iriportan in terms of estimation as Ricker (1975) noted that a small change in the exponent can mean a fairly large difference in computed weight or fecundity. Since the length-fecundity relationships computed for the two studies were not significantly different, the data bases were combined in hopes of improving the fit and lowering standard errors. When data were examined, it was found that the regressions calculated in 1977 could not be exactly reproduced. In most cases additional specimens were found in the data base and since it was impossible 
to determine what criteria were used to select specimens in 1977 , the relationships were recalculated separately before combination. Ricker (1975) noted that a functional geometric mean regression was more appropriate for these types of relationships than an ordinary predictive regression which has been used to date. Therefore a geometric mean cegrussion was also calculated for the combined length-weight and length-fecundity data. A comparison was then made among all the calculated regressions by using three different lengths with each regression and noting the percent difference between the 1977 relationships used most frequently in previous reports and the others. The 1981 winter flounder population survey data were also used with three length-fecundity regressions to examine the percent difference in total and mean fecundity produced with each.

Small (3\%) differences were found between the length-weight relationship calculated for Millstone winter flounder between 1977 and 1982 (Table 21 ). Larger $(-20-0 \%$ ) differences were found between the weights calculated from the arithmetic relationships for the Niantic River fish in 1977 and those from the 1982 logarithmic relationship. The combined Milstone and Niantic River data produced no 'change in $r^{2}$ and coefficients of variation. Little differences were also found among the ordinary regressions and the geometric mean regression. Largest differences between the 1977 Millstone relationship used most frequently and the others occurred at the smallest $(10 \mathrm{~cm})$ and largest $(40 \mathrm{~cm})$ sizes examined. The combined data base using a geometric mean regression is probably the most correct one to use and produces a $11 \%$ increase in weight at $10 \mathrm{~cm}$ and a $7 \%$ decrease at $40 \mathrm{~cm}$ in comparison to the 1977 Millstone standard: 


$$
\begin{aligned}
& \text { 矛 1 }
\end{aligned}
$$

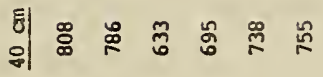

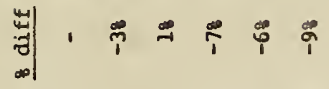

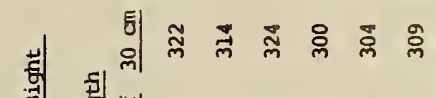

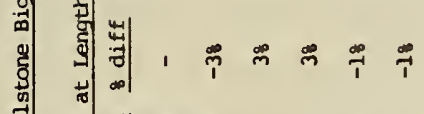

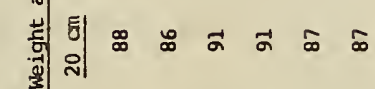

$$
\begin{aligned}
& \text { 需| } \\
& \text { 의 } \circ \text { ด ๓ } \cong \text { 웅 }
\end{aligned}
$$

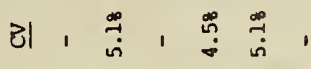

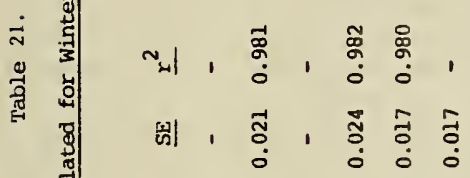

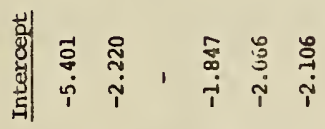

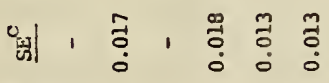

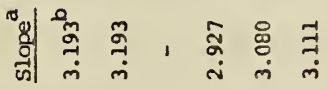

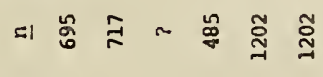

$$
\begin{aligned}
& \text { 苞| }
\end{aligned}
$$

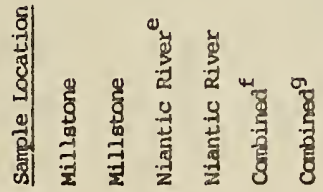

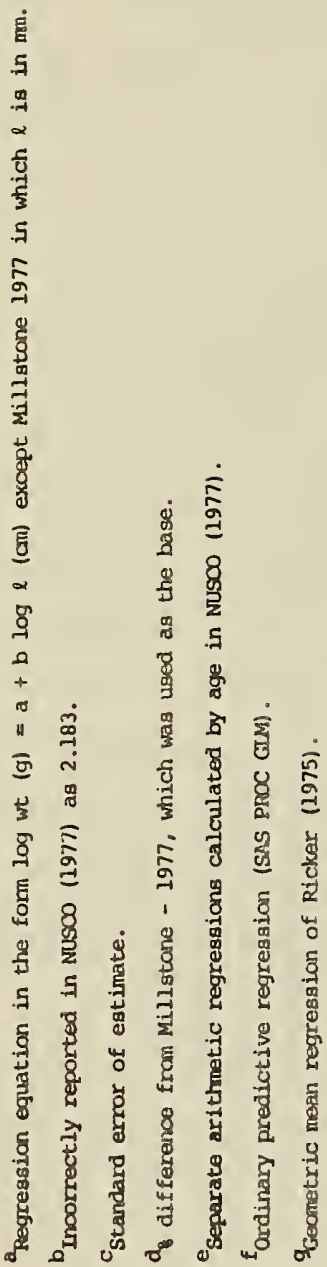


A similar approach was used in examining the length-fecundity relationships. The 1977 Niantic River equation has been used with length frequency data and population estimates to calculate annual total egg production in the Niantic River. The 1982 recalculated estimate differed only slightly for 25 and $30 \mathrm{~cm}$ fish (2-3\%) but was $10 \%$ higher for a $40 \mathrm{~cm}$ specimen (Table 22). The Millstone regression equations produced estimates $8-12 \%$ lower (1977) and 14-19\% higher (1982) than the 1977 Niantic River base. The addition of 16 specimens to the Millstone data base in 1982 caused increases of 24 to $35 \%$ in predicted fecundities for fish of the same length from that predicted in 1977. This is somewhat troublesome and illustrates how much variability can be produced in such studies. The combined Millstone and Niantic River data only improved the $\mathrm{r}^{2}$ slightly although the standard errors were reduced considerably. The simple regression determined with combined data had calculated fecundity estimates from 7 to $14 \%$ greater than the base. The geometric mean regression using the combined data produced lower estimates for a $25 \mathrm{~cm}$ fish (-9\%), little change for a $30 \mathrm{~cm}$ fish (1\%), and a large increase for a $40 \mathrm{~cm}$ winter flounder (17\%).

A comparison was made among the 1977 Niantic River, the 1982 combined, and the 1982 geometric mean regressions using the 1981 winter flounder population survey data to calculate total and mean fecundity (Table 23). The 1982 combined and the 1982 geometric mean regression produced total and mean fecundities that were 12 and $8 \%$, respectively, greater than the 1977 standard.

Finally, Tyler and Dunn (1976) reported that the winter flounder seemed to have a reproductive strategy that allowed it to sacrifice egg production to maintain body weight when food was scarce. Thus some 


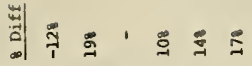

$$
\begin{aligned}
& \text { हो }
\end{aligned}
$$

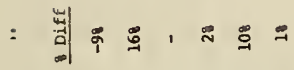

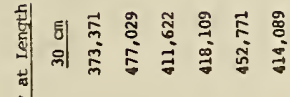

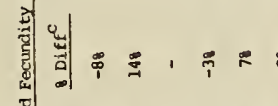

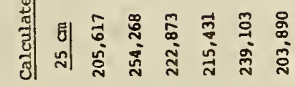

$$
\begin{aligned}
& \text { औ। }
\end{aligned}
$$

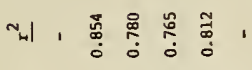

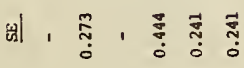

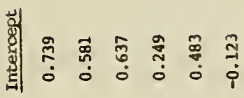

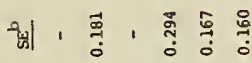

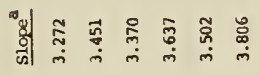

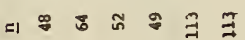

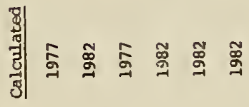

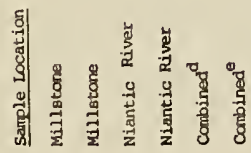

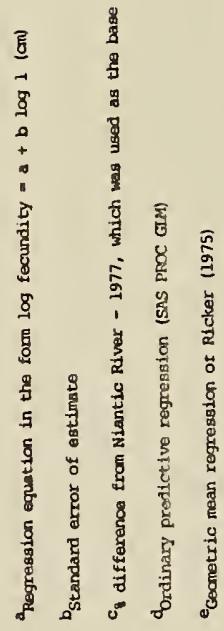




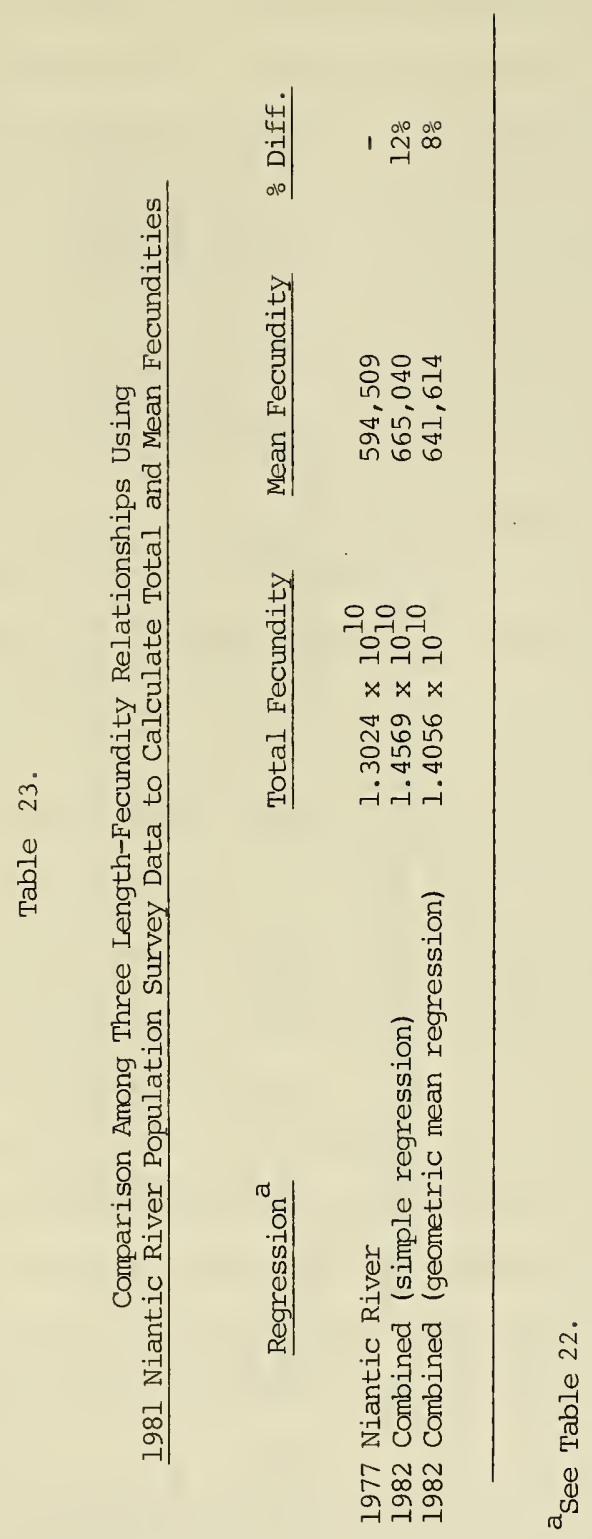


differences may occur from year to year depending upon prevailing conditions and a regression calculated in one year may or may not hold for other years. However, this cannot be ascertained for winter flounder spawning in the Niantic River without additional estimates of fecundity.

\section{Mortality and survival estimates}

Survival and its complement, total mortality, of the winter flounder has been calculated by dividing the estimated number of a specific year class in one year by the estimated number in the previous year. The mean of several of these calculations was reported as 0.3844 (NUSCo 1981a). This method, updated and shown on the upper portion of Table 24, is called cohort-specific by Ricker (1975). He noted that most methods of calculating mortality rely heavily on the existence of equilibrium conditions and are overly sensitive to fluctuations in year class strength. The cohort-specific method is independent of equilibrium conditions, whereas the time-specific techniques (comparison of the numbers present in successive age groups within a year) assumes equilibrium conditions. Examination of the Niantic River showed that in many cases no or unrealistic survival estimates were calculated by the cohortspecific simple ratio method because a larger number of winter flounder of a specific age were estimated in one year than was found in the previous year. These errors were probably caused by inaccurate population estimates, errors in aging, and bias in the selection of the aging samples. This particular method of calculation itself is also subject to bias and according to Gulland (1969) and Ricker (1975), the most proper way to determine survival (S) using this procedure is to calculate the instantaneous mortality coefficient, $Z$, which is equivalent to - In 


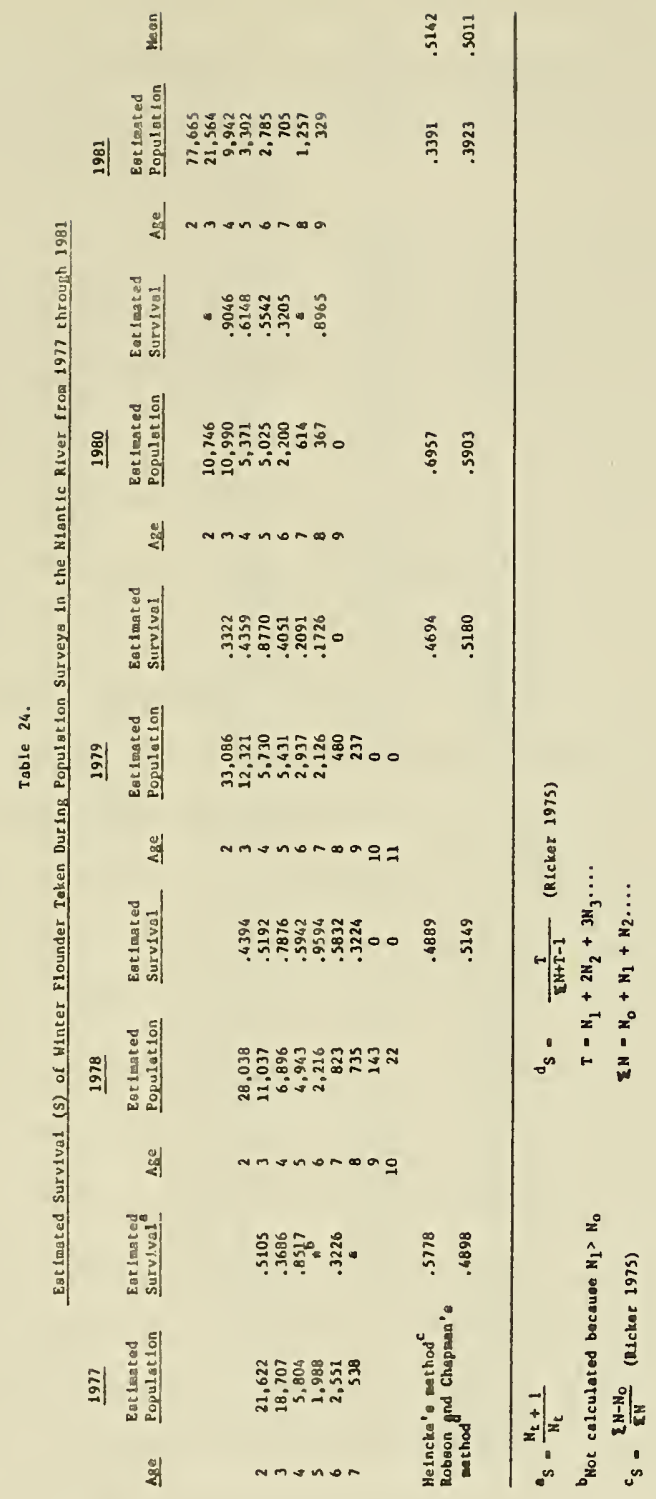


S. The best overall estimate of survival is then found by converting the simple mean of the individual estimates of $\mathrm{Z}$ back to $\mathrm{S}$. The mean survival of Niantic River winter flounder using this technique was 0.4823 (Table 25). However, the differences among the individual estimates again indicates systematic differences in mortality which may have been due to sampling errors or by age-specific differences in mortality.

Several methods of calculating time-specific mortality were investigated. These included the methods of Heincke, and Robson and Chapman (Ricker 1975) which gave survival estimates of 0.5142 and 0.5011 , respectively (Table 24). A plot of log frequency against age (catch curve method) gave an estimate of 0.4982 (Table 26). These different methods gave relatively similar estimates of survival which were considerably higher than that reported previously by use of the simple age ratio method.

\section{$\underline{\text { Disc tagging }}$}

To date 518 recaptures of disc-tagged winter flounder have been made (14.3\% of the number tagged). Many of these fish were recaptured during the winter flounder surveys and the traw 1 monitoring program and subsequently were released a second time. Most of the returns from the public were divided about equally between the sport and commercial fisheries. Returns from 1980 and 1981 tagged fish indicated that adults were generally found during summer in Niantic Bay and at locations a few miles to the east in New London County waters; some individuals moved further east along the coast of Rhode Island and Massachusetts. Very few tagged winter flounder moved westerly within Long Island Sound and very few have been impinged at Millstone. Analysis of returns in 1982 and subsequent years should reveal whether tagged winter flounder return 


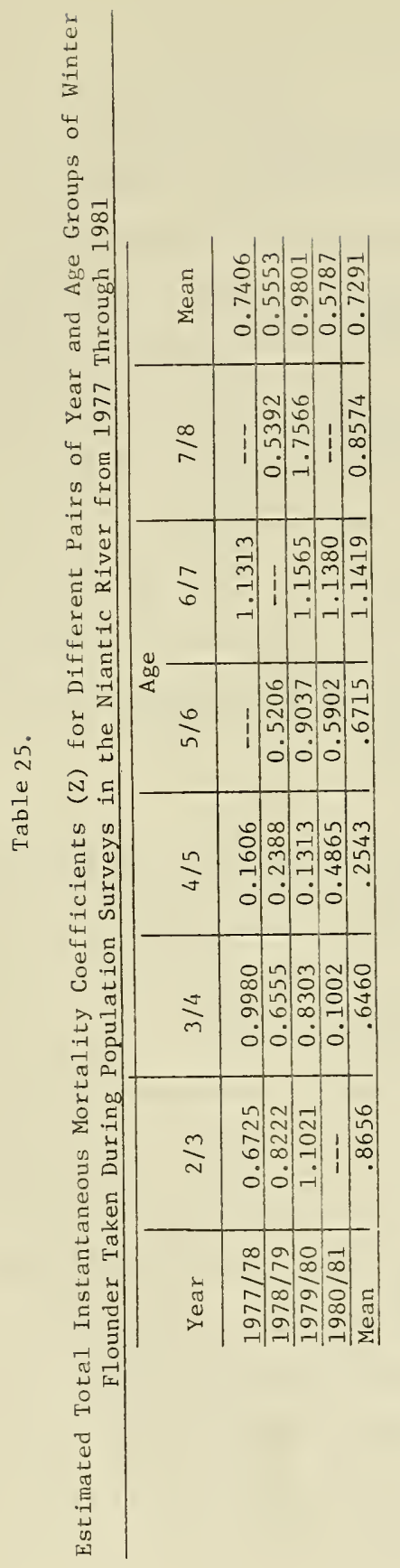

列

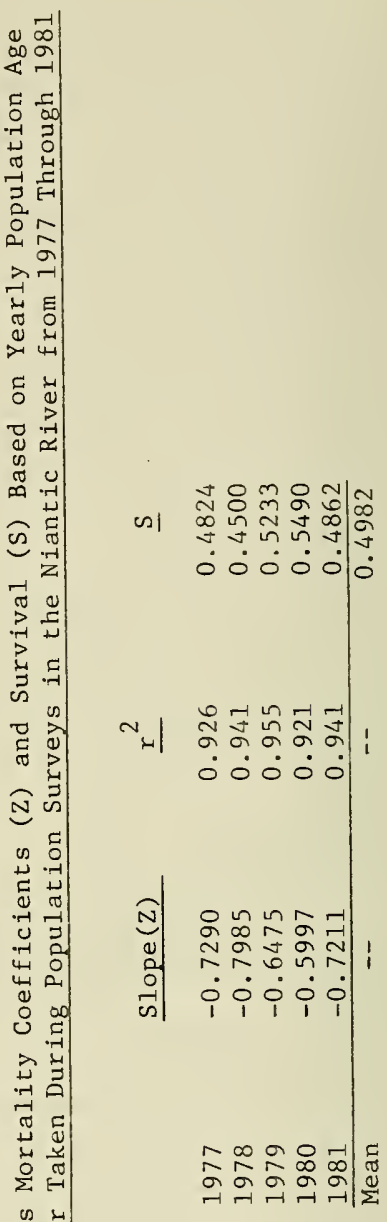


to the Niantic River and vicinity for spawning or whether a portion enters other estuaries for spawning. Tagging at the trawl monitoring program stations completed during the spring and early summer of 1982 and planned for the fall and winter of 1982-83 should help identify the source and movements of winter flounder at the trawl monitoring stations, particularly the offshore ones where preliminary data indicated that many winter flounder are transients and not from the Niantic River stock. In addition, the returns from the sport and commericial fisheries should allow the calculation of fishing mortality. This estimate may be used to partition the total mortality estimate previously mentioned into components of fishing and natural mortality. These estimates are necessary for many models used to assess power plant impact.

\section{Conclusions and Recommendations}

1. The life history information such as age structure, fecundity, and mortality gathered as part of the winter flounder population estimate program and during special studies have been invaluable in the assessment of Millstone power plant impact. The original deterministic model assessing impact data mostly used data reported in the scientific literature from studies of other winter flounder stocks. As data were gathered and refined at Millstone, the parameters estimated replaced those which were less suitable. The program for the future should focus on those parameters considered most critical for use in various models used to assess impact. Increased emphasis should be placed on improving techniques and efficiency in obtaining data. 
2. The sexing and classification of reproductive code of winter flounder should be accomplished by the most experienced personnel as much as possible. More definite criteria should be used to distinguish between females classified as "spent" (a reproductive code) and "female" (nonreproductive).

- The size at which $50 \%$ of all females are mature should be calculated by examining a selected sample of females in the critical size range. All females above this length found within the Niantic River during the spawning season should be considered mature for the purposes of estimating egg production.

4. All fish branded and recaptured should be measured. Although this procedure will increase the time needed in the field, the data gained may be invaluable not only for determining age structure but in the analysis of capture-recapture data for the Jolly model. This addition in labor may be offset by a corresponding reduction in the time spent handling and branding juveniles less than $15 \mathrm{~cm}$. As previously mentioned, there is serious doubt whether the present techniques can be used to estimate their numbers. Therefore little effort should be expended in dealing with them in the population surveys other than obtaining an accurate count of their numbers.

5. The sample chosen for aging should not consist of all fish captured in a tow but should be a stratified subsample of fish defined before the survey commences as a certain number within a length group of a particular sex. The total labor allowed for aging fish can be fixed in advance and 
the number of samples then allocated on that basis. The accuracy of the aging sample should increase as a proportionally larger sample would be taken from less abundant older age groups and fewer from the more abundant and easily aged younger groups.

6. The geometric mean regressions of length-weight and lengthfecundity should be used with the largest combined data bases for each as the best estimates available to date. Depending upon its usefulness in models for impact analysis, consideration should be given for the recalculation of the fecundity estimate to verify previous findings and to determine if annual changes occur in fecundity.

7. Methods of calculating total mortality and survival should continue to be evaluated. Methods used in this review indicated higher survival than previously reported. Although subject to some error because of fluctuating year-class strength, the cohort-specific methods may be more appropriate here because of errors in estimating population by age, which is necessary for time-specific methods of calculation.

8. The disc tagging program should be continued at least through 1982 to ascertain the movements and contributions of various stocks to the abundance of winter flounder in the Millstone Bight. The tagging data can also be used to calculate fishing mortality. The need for continued tagging can be evaluated following the spring 1983 spawning season. 
Summary of offshore and entrainment sampling programs for winter flounder larvae

The winter flounder has been a significant component of the ichthyoplankton at Millstone since studies began in 1973. A detailed review of the ichthyoplankton sampling program, including entrainment and offshore sampling, may be found elsewhere in this report. Only those studies which have been undertaken in whole or in part to provide additional information on the winter flounder are discussed below. Detailed presentations of data and analyses for any particular year may be found in the appropriate Annual Report.

The extensive ichthyoplankton monitoring program begun in 1973 had as one of its objectives the field verification of a winter flounder larval dispersal model (Sissenwine et al. 1973) including estimating concentrations at the model boundaries and within the model grid. Ten stations (numbers 1-10, Fig. 8) were sampled with a 60-cm bongo sampler (0.333- and 0.505-mm mesh) beginning in May 1973. A variety of tow types (oblique, surface, and bottom) were made both day and night, with day oblique tows predominating. Because of the May startup, few samples contained winter flounder larvae.

Entrainment studies establishing the seasonality, density, and mortality of entrained larval winter flounder and other species were intensified in March 1973. Weekly samples in triplicate were taken during both day and night at three different depths at the Intake, and at the Discharge, and at the Quarry Cut. The same sampling regime was followed through June 1975. 


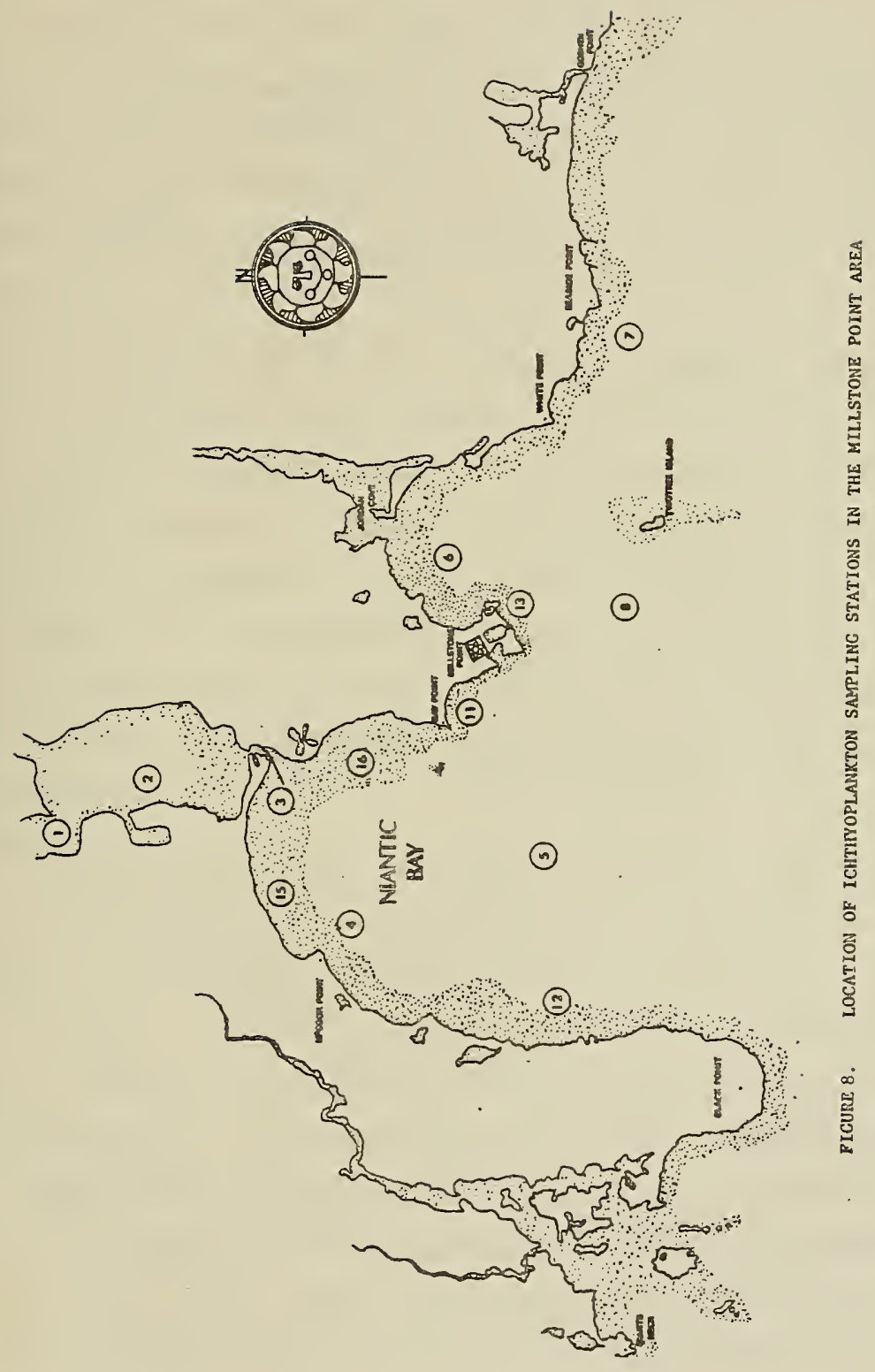

(9)

(9)

( 
In 1974, Stations 11 through 13 (Fig. 8) were added to more precisely determine the distribution of winter flounder larvae leaving the Nlantic River and to more closely associate offshore ichthyoplankton sampling with entrainment studies. Winter flounder larvae were collected during a minimum of 8 weeks at station 1 in the Niantic River to 20 weeks at 3tation 7 near White Point. They were more abundant in bottom samples diring both day and night and showed some differences in density by station.

Stations 14 through 16 were added in 1975 to provide additional information about winter flounder larvae in inshore Niantic Bay and at the boundaries of Millstone Bight. Samples were collected by various tow types both day and night at all 16 stations. Larvae were taken for a minimum of 10 weeks at station 1 to 21 weeks at station 3 off the mouth of the Niantic River. Higher concentrations of winter flounder larvae were found in the River and other inshore areas until mid-April, after which they were distributed widely throughout the Bight (NUSCo 1976).

During 1975, analysis of the exisiting offshore winter flounder data by the University of Rhode Island suggested that the objective of field verification of the winter flounder larval dispersal model was not possible from the sampling program (Vaughan et a1. 1976). This was mainly the result of large variability in the data due to inherent plankton patchiness, long time periods between samples, and short-term tidal variability. This resulted in a reduction of offshore sampling effort in 1976 to biweekly or monthly samples at six stations (2, 5, 6, 8, 11, and 14). The sampling objective for winter flounder larvae became one of general monitoring to make year-to-year comparisons and to 
relate larval densities to adult population sizes and estimated egg production. The $0.505-\mathrm{mm}$ mesh sample was not processed after 1975 and night samples weren't taken again until 1980.

Winter flounder larvae were first collected in February 1975, indicating spawning as early as mid-January (NUSCo 1977). Highest densities were found at station 2 in the Niantic River and 6 in Jordan Cove during March and April with progressiveley less at more offshore stations. Although numbers of larvae declines through late spring, some yolk-sac larvae were still collected as late as June at offshore station 14. Catch curves similar to those of Pearcy (1962) were prepared for each station in an attempt to localize areas of spawning or larval retention. Densities of winter flounder larvae were plotted against length at each station. The Niantic River and probably Jordan Cove were thought to be spawning areas in 1976.

Various analyses of the 1973 through 1975 entrainment data led to major changes in the entrainment sampling program (see Plankton Program Evaluation). A 3-day and night, 3-replicate sampling scheme (18 samples per week) was established at the Discharge station in July 1975. The first winter flounder larval period under this sampling schedule was in 1976 and this program has remained in effect to date.

Analysis of entrainment data showed the maximum density of winter flounder larvae occurred at the plant from mid to late April, several weeks after that in the Niantic River (NUSCo 1977). Larvae were most abundant at night, especially specimens $5.5 \mathrm{~mm}$ or larger during late spring. Densities were also greatest during maximum tidal currents, either ebb or flood. These findings suggested some changes in vertical distribution of larvae by time and by tide. The entrainment catch curve 
of larval winter flounder showed considerably reduced densities of larvae 3 to $6 \mathrm{~mm}$ in length and indicated that the plant was some distance from local spawning areas.

The offshore monitoring program in 1977 was similar to 1976. Length measurements suggested that gradual tidal advection of larvae from the Niantic River towards offshore stations occurred from March through June. Catch curves showed that the densities of small larvae at Niantic River station 2 were not much greater in comparison to the offshore stations. The monthly sampling frequencies were thought to be inadequate to measure actual variations in abundance. Further analysis of the entrainment data in 1977 showed that winter flounder larvae were again more abundant at night but no differences were found among ebb and flood tide and the two slack tidal periods.

In 1978, day oblique tows were taken monthly (January through March) or biweekly (April through August) at six stations (2, 5, 6, 8, 11, and 14). Day surface and bottom tows augmented the collections on one of the biweekly sampling dates per month from April through August. Tidal differences in density were found to mostly affect smaller larvae earlier in the season rather than older, more mobile larvae. Night samples at the discharge continued to have the greatest densities, especially of larvae over $6 \mathrm{~mm}$. The lack of night samples at the offshore stations limited the analyses and comparisons made between the offshore and entrainment programs.

An evaluation of the offshore plankton program was made in 1978. The effects of day or night sampling, net mesh size, tow type, station location, and number of samples taken per season were evaluated separately. To correct the imbalance in sample number between the offshore and 
entrainment programs and to increase the detectability in density differences, a new offshore program was designed. Station 5 (mid-Niantic Bay) was to be sampled with replicate day and night oblique tows using $0.333-$ mm mesh nets weekly from April through August and biweekly from September through March. Station 5 was determined to be the most representative offshore station in comparison to the discharge. In addition, weekly oblique tows were made during the day at Niantic River station 2 from March through May to cover the winter flounder larval season. Other offshore stations were deleted after 1978 since the number of samples and data were generally insufficient for analyses.

During 1979, more winter flounder larvae were again found at the discharge than at station 5. An examination of the length frequency distributions of larvae showed an increase of larvae larger than $6 \mathrm{~mm}$ at the discharge at night. It was concluded that these larger larvae had been undersampled by the short tow time in the bottom strata of the sawtooth oblique tows made heretofore. Beginning in 1980, the offshore plankton tows were made using a stepwise oblique towpath with equal duration across surface, mid, and bottom stata to better estimate abundance throughout the water column.

Analyses were conducted to see if the additional sampling at station 5 increased the power to detect differences in density between there and the discharge. The probability of detecting an annual mean density

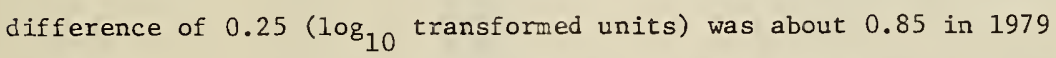
(NUSCo 1980). The probability of detecting a 0.15 difference in mean annual abundance $\left(\log _{10}\right.$ transformed) among years at the discharge was 0.61 . Thus the previous changes in sampling schemes had increased 
the power to detect differences in densities of the winter flounder.

Length frequency comparisons between the discharge and station 5 were again made in 1980 . The data further suggested real differences in behavior of winter flounder larvae between day and night resulting in changes in vertical distribution of large larvae (NUSCo 1981a). To improve the number of samples and comparibility between stations 2 and 5, sampling effort at the former was increased to four day and night weekly samples from March through early June. Improved estimates of density and catch curves at station 2 resulted.

Catch curves were used to provide information on larval mortality, which is discussed in more detail below. The data from 1974 and 1975 from station 1 produced reasonable catch curves, and monitoring was resumed there in 1981 and 1982; effort was divided equally between stations 1 and 2. One replicate bongo tow was made during the day and one at night from March through May and sampling at stations 5 and the discharge remained as before. The densities of larvae found in 1981 suggested that an early spawn in the Niantic River influenced the density of larvae offshore (NUSCo 1982). The unexpected high densities of 6 to 8-mm larvae found at Station 5 and the discharge each year (Figs. 9, 10) may have been the result of a second source of larger larvae or from a later, more rapidly growing cohort from the Niantic River which superimposed their densities over the intital River cohort. A second source of larvae was believed to be a more likely explanation for the relative increase of large larvae noted during several years. 

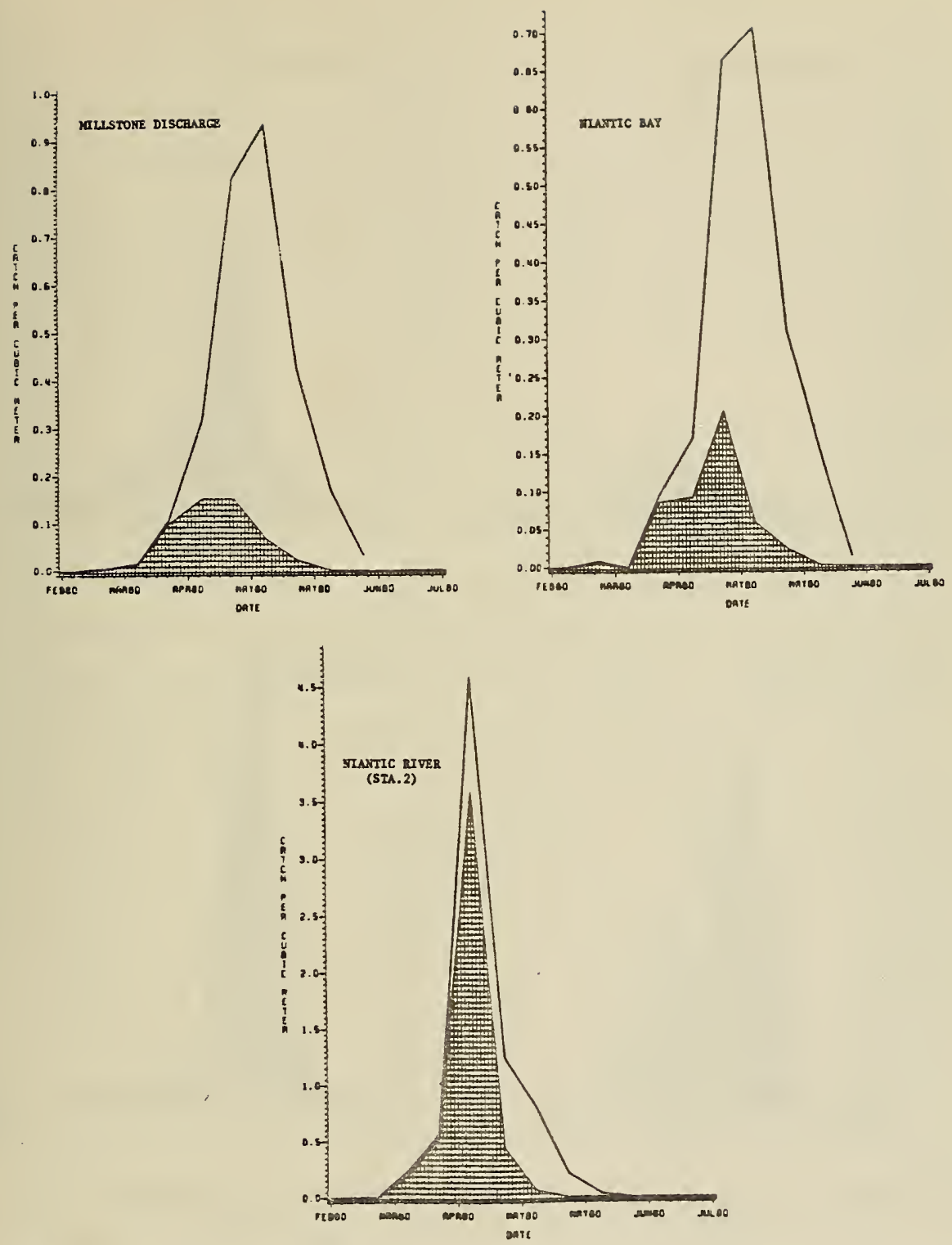

Figure 9. Winter flounder larval CPUE (catch per $\mathrm{M}^{3}$ ) by station for larvae of al1 sizes and larvae $\leq 3.5 \mathrm{~mm}$ (shaded area) during 1980 . 

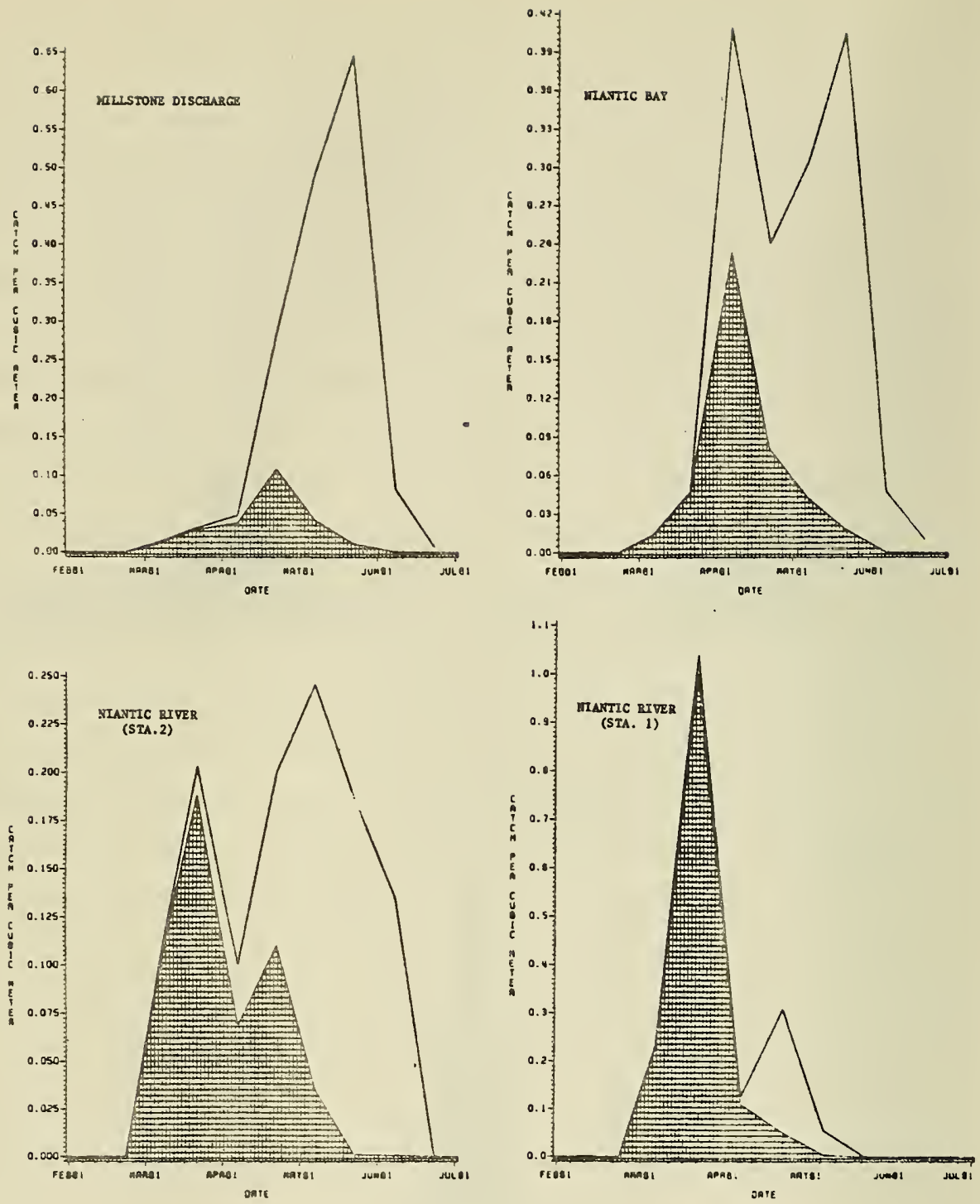

Figure 10. Winter flounder larval CPUE (catch per $\mathrm{M}^{3}$ ) by station for larvae of all sizes and larvae $\leq 3.5 \mathrm{~mm}$ (shaded area) during 1981. 
It became evident that survival coefficients for larvae would be necessary in impact assessment modelling to determine if winter flounder larval production in the Niantic River was sufficient to sustain the local population in light of entrainment losses at Millstone. Catch curves were produced for stations and years where data were sufficient. These station-year pairs included the discharge from 1975 - 1981, station 5 in 1975 and from 1979 - 1981, station 2 in 1975 and 1978 - 1981, and station 1 in 1974,1975 , and 1981.

Exponential regressions of the density by $0.5-\mathrm{mm}$ length increments were used to determine length-specific apparent mortality coefficients (Table 27). The discharge and station 5 did not have adequate lengthdensity distributions for the calculation of mortality because of the reduced number of smaller larvae in comparison with large larvae. The catch curves produced were flattened or showed an increase in density of larger larvae rather than the expected decrease from mortality.

Only stations 1 and 2 had length-density distributions over the full 2 to 9-mm larval size range necessary to calculate mortality using this approach. However, the number of samples taken and the sampling frequencies and methodologies used in the Niantic River varied greatly (Table 28). Until 1980, the need for increased sampling in the Niantic River was not apparent, thus limiting the utility of the data obtained previously. Little useful data were available from Station 2 in 1974 , 1976 and 1977 as the catch curves from those years were also flattened. Regressions were calculated for 1978 and 1979, but the small sample size made the results somewhat tentative. 
Table 27

Number of Samples, Mean Density ${ }^{a}$ (with SE and CV), and Length Specific Instantaneous Mortality Coefficient (2) for Winter Flounder Larvae Taken at Varfous Stations from 1974 Through 1981

\begin{tabular}{|c|c|c|c|c|c|c|c|}
\hline Year & Station & $\begin{array}{c}\text { Number of } \\
\text { Samples }\end{array}$ & $\begin{array}{l}\text { In Mean } \\
\text { Density. }\end{array}$ & $\begin{array}{c}\text { St andard } \\
\text { Error }\end{array}$ & $\begin{array}{r}\text { Coefficient } \\
\text { of Variation } \\
\end{array}$ & $\begin{array}{c}\text { Slope } \\
\text { (2) }\end{array}$ & $\begin{array}{c}r^{2} \text { for } \\
\text { Regression }\end{array}$ \\
\hline $\begin{array}{l}1974 \\
1975 \\
1981\end{array}$ & $\begin{array}{l}1 \\
1 \\
1\end{array}$ & $\begin{array}{l}21 \\
18 \\
46\end{array}$ & $\begin{array}{l}-2.242 \\
-2.182 \\
-1.656\end{array}$ & $\begin{array}{l}0.272 \\
0.204 \\
0.228\end{array}$ & $\begin{array}{l}56 \% \\
40 \% \\
93 \%\end{array}$ & $\begin{array}{l}-0.282 \\
-0.219 \\
-0.353\end{array}$ & $\begin{array}{l}0.328 \\
0.510 \\
0.877\end{array}$ \\
\hline $\begin{array}{l}1975 \\
1978 \\
1979 \\
1980 \\
1981\end{array}$ & $\begin{array}{l}2 \\
2 \\
2 \\
2 \\
2\end{array}$ & $\begin{array}{r}27 \\
8 \\
5 \\
75 \\
58\end{array}$ & $\begin{array}{l}-1.501 \\
-1.818 \\
-1.023 \\
-0.987 \\
-2.109\end{array}$ & $\begin{array}{l}0.201 \\
0.502 \\
0.915 \\
0.181 \\
0.136\end{array}$ & $\begin{array}{r}70 \% \\
78 \% \\
200 \% \\
159 \% \\
49 \%\end{array}$ & $\begin{array}{c}-0.162 \\
-0.235 \\
-0.288 \\
-0.357 \\
\end{array}$ & $\begin{array}{c}0.524 \\
0.510 \\
0.761 \\
0.875 \\
\ldots\end{array}$ \\
\hline $\begin{array}{l}1975 \\
1979 \\
1980 \\
1981\end{array}$ & $\begin{array}{l}5 \\
5 \\
5 \\
5\end{array}$ & $\begin{array}{l}48 \\
78 \\
76 \\
60\end{array}$ & $\begin{array}{l}-2.238 \\
-2.384 \\
-1.364 \\
-1.465\end{array}$ & $\begin{array}{l}0.103 \\
0.144 \\
0.146 \\
0.117\end{array}$ & $\begin{array}{l}54 \% \\
53 \% \\
94 \% \\
62 \%\end{array}$ & $\begin{array}{l}\star \\
\star \\
\star \\
\star\end{array}$ & - \\
\hline $\begin{array}{l}1975 \\
1976 \\
1977 \\
1978 \\
1979 \\
1980 \\
1981\end{array}$ & $\begin{array}{l}D^{C} \\
D \\
D \\
D \\
D \\
D \\
D\end{array}$ & $\begin{array}{r}64 \\
160 \\
178 \\
174 \\
161 \\
178 \\
123\end{array}$ & $\begin{array}{l}-1.963 \\
-1.359 \\
-2.049 \\
-1.844 \\
-1.720 \\
-0.978 \\
-1.420\end{array}$ & $\begin{array}{l}0.146 \\
0.096 \\
0.103 \\
0.096 \\
0.089 \\
0.078 \\
0.118\end{array}$ & $\begin{array}{r}60 \% \\
89 \% \\
67 \% \\
69 \% \\
66 \% \\
107 \% \\
93 \%\end{array}$ & $\begin{array}{l}* \\
* \\
\star \\
\star \\
* \\
\star \\
\text { * }\end{array}$ & $\begin{array}{l}\text { - } \\
\text { - } \\
\text { - } \\
\text { - }\end{array}$ \\
\hline
\end{tabular}

A Number of samples include just those containing a cumulative total of $90 \%$ of all larvae.

${ }^{b}$ None determined

${ }^{c}$ Discharge 


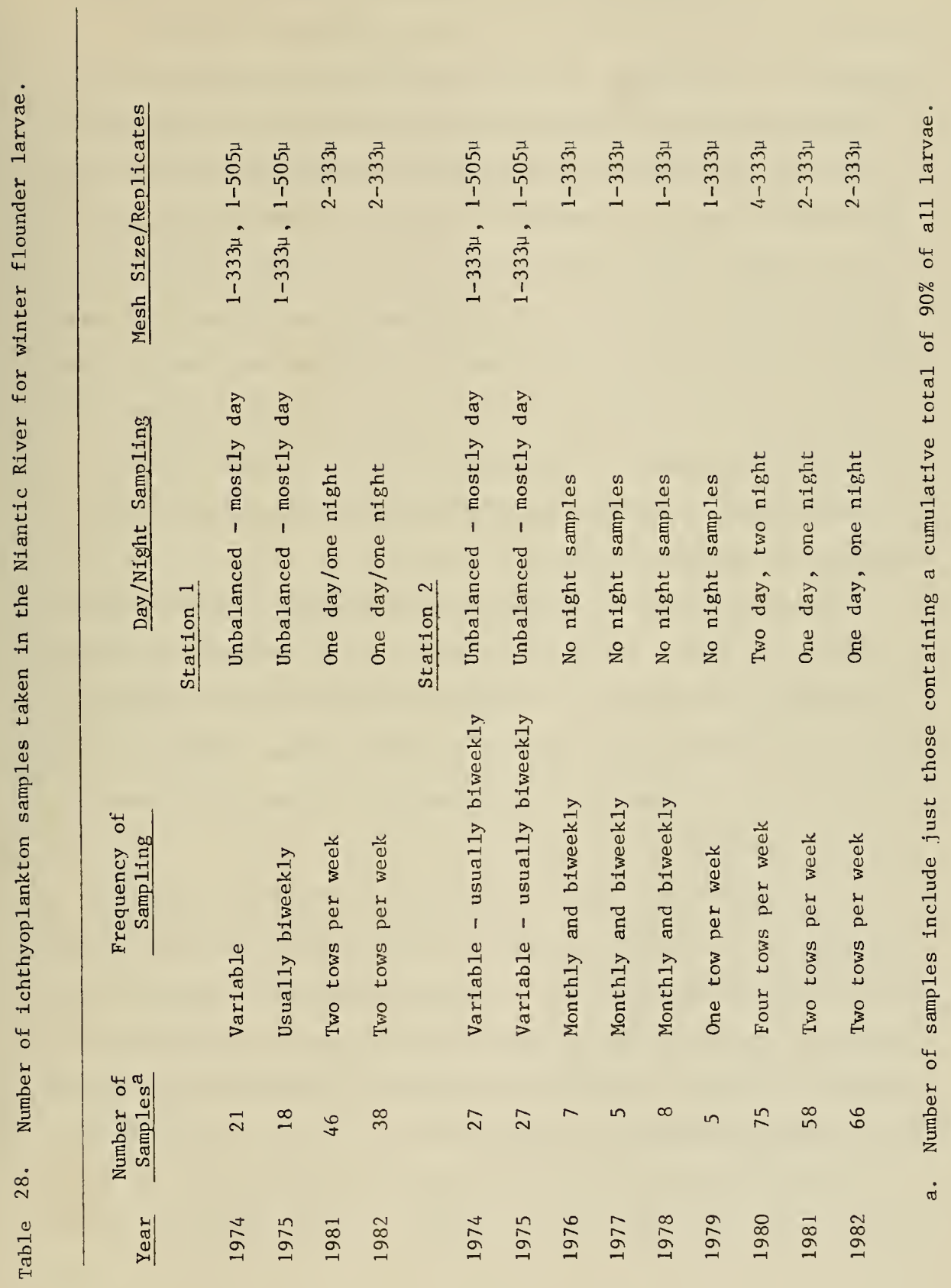


The increased sampling effort at station 2, prompted by the need for additional winter flounder larval data, produced a significant regression in 1980 (Table 27). The 1980 samples were analyzed further by partitioning them into balanced day and night data sets. Separate regressions were calculated and the two apparent mortality coefficients were compared. The day coefficient (0.404) was significantly larger then the one for night (0.337) probably because of under-sampling of larger larvae during the day. The day exponents for 1979 and 1980 were similar, however. Even more troublesome was the fact that no significant regression could be calculated from 1981 data for station 2 because of a flattened catch curve. This occurred despite the relatively large sampling effort. The 1982 data, with even more samples, was not yet available for analysis at the time of this report.

Because the number of samples, sampling frequency, and tow type all appeared to influence the catch curves, the effects of day or night and mesh size were investigated. Adjustment factors for each 1.0 -m length interval were determined and applied to station 2 data. Even with correction for undersampling of large larvae, no appreciable changes in mortality coefficients were found.

The distribution of winter flounder larvae at station 1 produced good catch curves and apparent mortality coefficients were generated for 1974, 1975, and 1981 (Table 27). The large densities of small yolk-sac larvae at station 1 indicated that this was an area of prime spawning, retention, or both. Preliminary results from 1982 indicated that larvae were again very abundant at station 1 . 
1. Knowledge of the larval stage of the winter flounder is of paramount importance because mortality is greatest then, it is most likely the stage at which any compensatory mortality occurs, and it is when the impact of the Millstone power station is greatest. Consequently much effort should be directed towards understanding larval dynamics and how they affect subsequent year class strength. The key to understanding local winter flounder larval production remains the Niantic River spawning area.

One of the strengths of the Millstone ichthyoplankton program has been the continual evaluation of the sampling programs which led to revisions when deemed necessary. Unfortunately, the changes have resulted in little continuity in the offshore sampling program from year to year, therby decreasing the comparability of the data. Although sampling occurred in the Niantic River as early as 1974, the number of samples taken were less than adequate until 1980 at station 2 and 1981 at station 1. This occurred mostly because the sampling in previous years wasn' $t$ specifically designed to provide the information now needed.

Inadequate sampling design for the most part can be seen in the failure to estimate larval mortality because of flattened catch curves in the River. The fact that significant differences can be found between day and night at the same station because of the differential catch of large larvae is indicative of this. The problem of advection of larvae also requires a carefully conceived design if it is to be measured. Based on the recommendation from the June 1982 Millstone Ecological Advisory Committee Meeting, a workshop will be scheduled for Fall 1982 
to bring together various expert scientists with the Northeast Utilities Environmental Laboratory staff. One of the results of this meeting should be a comprehensive study plan and sampling design to properly measure larval growth, movements, mortality, and abundance in the Niantic River. These parameters are vital for modelling efforts to estimate power plant impact.

2. The entrainment program has provided good estimates of the loss of winter flounder larvae at the plant. Changes in sampling have resulted in increased precision and the program has remained stable since 1975. One factor not adequately addressed has been survival of larvae through the cooling-water system and passage through the quarry. Presently, a conservative $100 \%$ mortality of larvae is assumed for entrainment, although experimental evidence suggested that larvae larger than $5 \mathrm{~mm}$ showed little mortality when exposed to temperature increases of $13^{\circ} \mathrm{C}$ (NUSCo 1975). If impact assessment indicates potentially high risk to the winter flounder population because of entrainment losses, then a program designed to measure entrainment survival should be considered as a way to lessen the estimate of projected impact.

3. There are some indications in the data from the discharge and at station 5 as well as from the earlier, more extensive offshore work that some fraction of the winter flounder larvae entrained may be from areas other than the Niantic River. Disregarding other sources of larvae would again make estimates of entrainment loss conservative when assessing only the Niantic River stock. This is another topic that should be discussed at the Fal1 1982 workshop. The complex movements of both 
larvae and water masses within Long Island Sound would require an extremely careful study design in order to resolve this question. This problem may only be important if the estimated potential impact of Millstone on the Niantic River stock is unacceptably high.

\section{TRAWL MONITORING PROGRAM}

The winter flounder was the most abundant fish taken by the trawl monitoring program from 1973 through $1981(64,513 ; 42.4 \%$ of total). A complete evaluation of the trawl monitoring program may be found elsewhere in this report and a portion of it is repeated here in regards to the winter flounder.

Among the objectives of the trawl monitoring program was the ability to distinguish naturally occurring changes from those resulting from power plant impacts. The winter flounder trawl data from October 1977 through September 1981 were analyzed. During this period tows of $0.69 \mathrm{~km}$ in length were made at each station regardless of the time it took; previous to this period tows of 15 min in duration were made at each station regardless of the distance towed. The catch frequency data from this period fit a negative binomial distribution and was appropriately transformed by $\ln ($ catch $+k / 2)$ where $k$ ( 0.83 for the winter flounder) was the coefficient of contagion calculated by the maximum likelihood method of Bliss and Fisher (1953). The pooled variance of the negative binomial data was used to determine the sample size required to detect specified differences in the means at various levels of alpha and beta using the formula of Snedecor and Cochran (1967). For log transformed data this difference becomes the ratio of the geometric means ( $R$ ). The percent difference in means detectable then is $(R-1) \times 100 \%$. Since the winter flounder is found throughout the study area all year, it may be 
potentially taken in a total of 468 samples (3 replicate tows $x 6$ stations x 26 sampling dates). This total may be compared to the aforementioned calculated sample sizes to give the percent change in means the present trawling program would be able to detect. For an alpha of 0.05 and a beta of 0.80 , the present sampling program can detect a difference of $15 \%$ in the log transformed means of traw1 catches (Table 29 ). Mean trawl catch of winter flounder from October 1977 through September 1981 was 21.03 (arithmetic) and 2.41 ( $1 \mathrm{n}$ catch $+\mathrm{k} / 2$ transformed). The latter mean when transformed back to a linear scale is 10.71 . This is the geometric mean and represents the central tendency of the winter flounder trawl catch. Thus the present sampling program can detect at least a change of \pm 1.60 from this mean. The $15 \%$ level of detection can be considered excellent in this type of monitoring program and represents one technique available to measure potential impact of Millstone Power Station operations.

In previous Annual Reports the winter flounder trawl data has appeared in both the Winter Flounder and Fish Ecology sections. Examination of the analyses used showed that the methodology of calculating catch per unit effort (CPUE) differed between these two sections as we11 as with that used in the trawl monitoring program evaluation trawl herein. CPUE as used in the winter flounder section was calculated as follows:

$$
\frac{\text { Catch per each replicate }}{\text { time of tow }} 15 \mathrm{~min}
$$

which gave the CPUE for a standardized $15 \mathrm{~min}$ tow. The mean catch per station would be the mean of the three replicates for that date. For analysis in the Fish Ecology section the CPUE was determined as: 


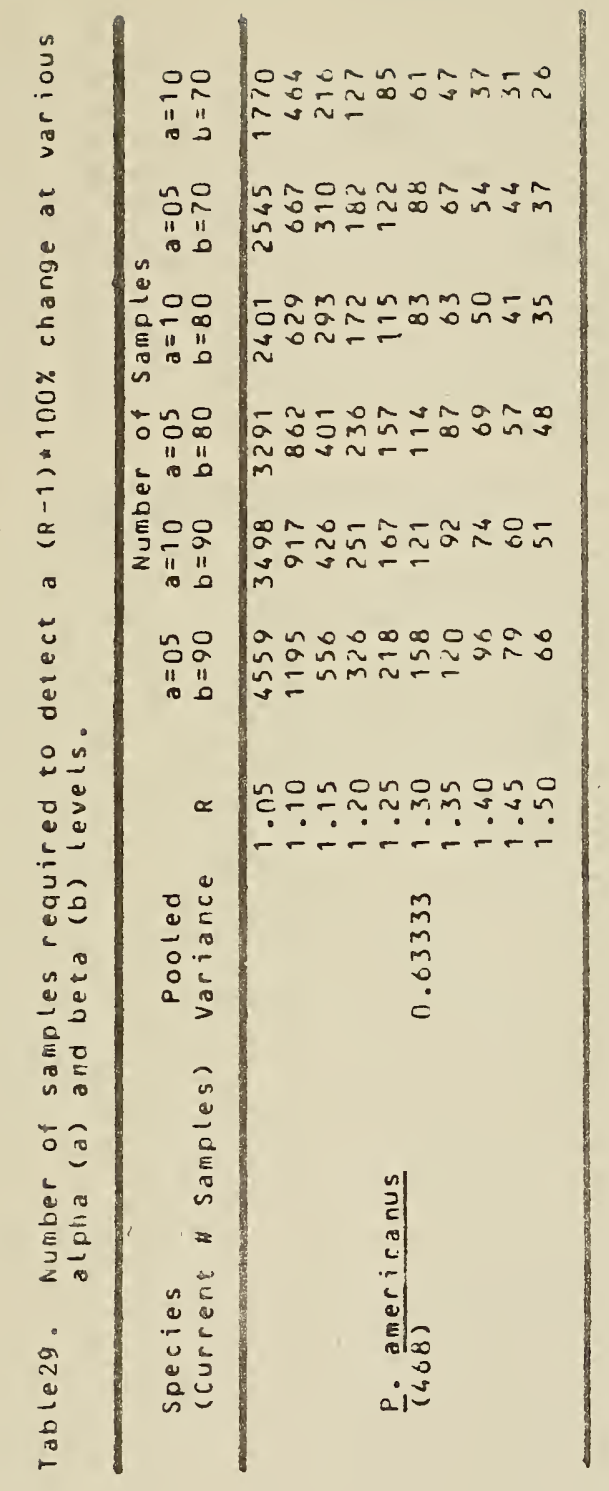


all catches at a particular station or stations $\times 15 \mathrm{~min}$

total time for the above tows

As previously mentioned, the CPUE used for the trawl evaluation was

simply the unadjusted catch (in terms of tow time) from the standardized 0.69-km tow. The two methods of adjusting the catch on a time basis add an unknown amount of varlability to the data as well as being internally inconsistent within the Annual Reports. For a benthic fish such as the winter flounder it is most reasonable to assume that the catch would depend mostly on the bottom ground covered by a trawl tow. Since trawling a standardized distance between two fixed points allows the ground covered by the trawl to remain the same for all tows (assuming all other factors affecting efficiency remain the same which is not entirely accurate), then the manipulation by time is nefther necessary nor justified. Factors such as tide, wind, and amount of debris in the net account for most of the variability in tow time at a station. Thus the trawl data which can be used with most confidence in any analysis is that from October 1977 -through the present without correction for time.

Finally, a second inconsistency was noted between the analyses used in the Winter Flounder section and the Fish Ecology section. The former had In $(C P U E+1)$ transformed data used with a parametric ANOVA to examine for differences among stations and time periods. The latter stated that in $($ CPUE +1$)$ values were known to be non-normally distributed and used a Kruskal-Wallis non-parametric ANOVA for similar examinations (NUSCo 1982). However, a previous evaluation (Millstone Ecological Advisory Committe Meeting Minutes, Nov. 29-30, 1979) noted that the winter flounder trawl data from 1973 through 1978 did approximate a normal distribution when in transformed and could be used with parametric 
ANOVA. The parametric ANOVA are robust tests which aren't affected by slight departures in normality and are much more powerful than nonparametric tests (Sokal and Rohlf 1969; Green 1979). The differences between these two analytical approaches should be examined further and conflicting viewpoints should be reconciled with one approach recommended. This suggested evaluation should also take into account a third viewpoint expressed in NUSCo (1982), namely that these data are autocorreleted and that a time-series analysis is the most appropriate technique of all.

\section{IMPINGEMENT MONITORING PROGRAM}

An analysis of the impingement program from its inception in 1971 through the present has been recently prepared and has details regarding changes in sampling methodology and frequency and data collection (see Impingement Program Evaluation). The winter flounder was one of the most abundant fishes impinged at Millstone with an estimated total of 71,653 from 1972 through 1981 at Units 1 and 2. It was particularly abundant in 1979 with 24,076 (33.6\% of the total) taken. Estimates from 1977 through 1981 ranged from 6,181 to 9,631. Most were taken during the winter when they were particularly abundant in local waters.

Since 1977, three samples per week have been taken to estimate the impingement of species collected at Millstone. Since the current program was designed to determine the number of organisms of all species impinged at Millstone, sampling effort was equally distributed throughout the year. If, however, one or more species are deemed more important than others because of abundance or value to a fishery, then it would be possible to redistribute sampling effort to the match the changing temporal abundance and variability of these species. Abundance and 
variability in impingement catch of most species changes considerably because of plant operations, local changes in number and distribution, and varying susceptibility to impingment due to changes in behavior or response to physical environmental factors such as water temperature and wind. Sampling effort should therefore change in proportion to the variability in catch in order to obtain more precise impingement estimates. The methodology of El-Shamy (1979) was applied to determine the precision of the winter flounder impingement estimates for the current sampling program and that for an optimum allocation of the same effort to reduce sampling variability within months. In addition, the precision was determined for various reductions in sampling effort.

The data for winter flounder impingement at Millstone Units 1 and 2 from 1978 through 1981 were used to examine the variability of the catch. The annual mean number of winter flounder per impingement collection during 1977-81 was 31.2 (Table 30). Largest and most variable impingement catches occurred in January (72.4) and February (122.5) and smallest and least variable from July through November (3.3-6.8). The precision for the current program with uniform sampling effort ( 3 samples per week, 156 per year) and with a standard error of 7.8 is $50 \%$ (Table 31 ). For optimum allocation, samples were redistributed among months with more samples in months with greater variability in catch in order to reduce the associated standard errors (Table 32 ). The first redistribution of effort was made without restriction to the number of samples per month, thus February was allocated 80 samples. The excess sampling days were then redistributed among the other months. The precision improved from 50 to $10 \%$ (standard error of 1.6 for the same mean of 31.2) when the same number of samples as currently collected was allocated 
Table 30. Monthly impingement catch of winter flounder at Millstone Units 1 and 2 from January 1978 through December 1981.

\begin{tabular}{|c|c|c|c|c|}
\hline Month & $\begin{array}{l}\text { Number of } \\
\text { Samples }\end{array}$ & Mean Catch & Standard deviation & Variance \\
\hline January & 55 & 72.4 & 151.6 & 22,993 \\
\hline February & 51 & 122.5 & 454.5 & 206,592 \\
\hline March & 54 & 53.4 & 71.8 & 5,151 \\
\hline April & 54 & 41.6 & 53.1 & 2,824 \\
\hline May & 56 & 17.4 & 17.9 & 320 \\
\hline June & 53 & 15.8 & 16.7 & 279 \\
\hline July & 55 & 6.8 & 7.7 & 59 \\
\hline August & 55 & 5.2 & 6.7 & 45 \\
\hline September & 54 & 4.1 & 11.4 & 129 \\
\hline October & 55 & 3.3 & 3.2 & 10 \\
\hline November & 53 & 5.7 & 7.6 & 58 \\
\hline December & 53 & 31.4 & 42.1 & 1,771 \\
\hline Total & 648 & 31.2 & & \\
\hline
\end{tabular}


Table 31.

Annual Mean Catch ( \pm 2 Standard Errors) of Winter Flounder and Estimated Precision Associated with the Current Sampling Program and for Various Reductions in Effort Through Optimm Allocation of Samples

\begin{tabular}{|c|c|c|c|c|c|}
\hline Program & $\begin{array}{c}\text { Sample } \\
\text { Reduction } \\
\end{array}$ & $\begin{array}{l}\text { No. of } \\
\text { Samples }\end{array}$ & $\begin{array}{l}\text { Mean Annual } \\
\text { Catch } \\
\end{array}$ & \pm 2 S.E. & Precision \\
\hline Cur ${ }_{-}$nt & $0 \%$ & 156 & 31.2 & 15.6 & $50 \%$ \\
\hline $\begin{array}{l}\text { Optimum } \\
\text { Allocation }\end{array}$ & $0 \%$ & 156 & 31.2 & 3.2 & $10 \%$ \\
\hline$"$ & $12 \%$ & 137 & 31.2 & 5.8 & $19 \%$ \\
\hline$"$ & $20 \%$ & 125 & 31.2 & 8.0 & $26 \%$ \\
\hline$"$ & $31 \%$ & 108 & 31.2 & 10.2 & $33 \%$ \\
\hline$"$ & $38 \%$ & 96 & 31.2 & 12.4 & $40 \%$ \\
\hline$"$ & $49 \%$ & 79 & 31.2 & 15.0 & $48 \%$ \\
\hline
\end{tabular}

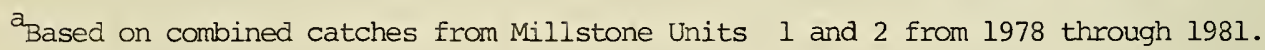

b 2 standard errors/mean. 


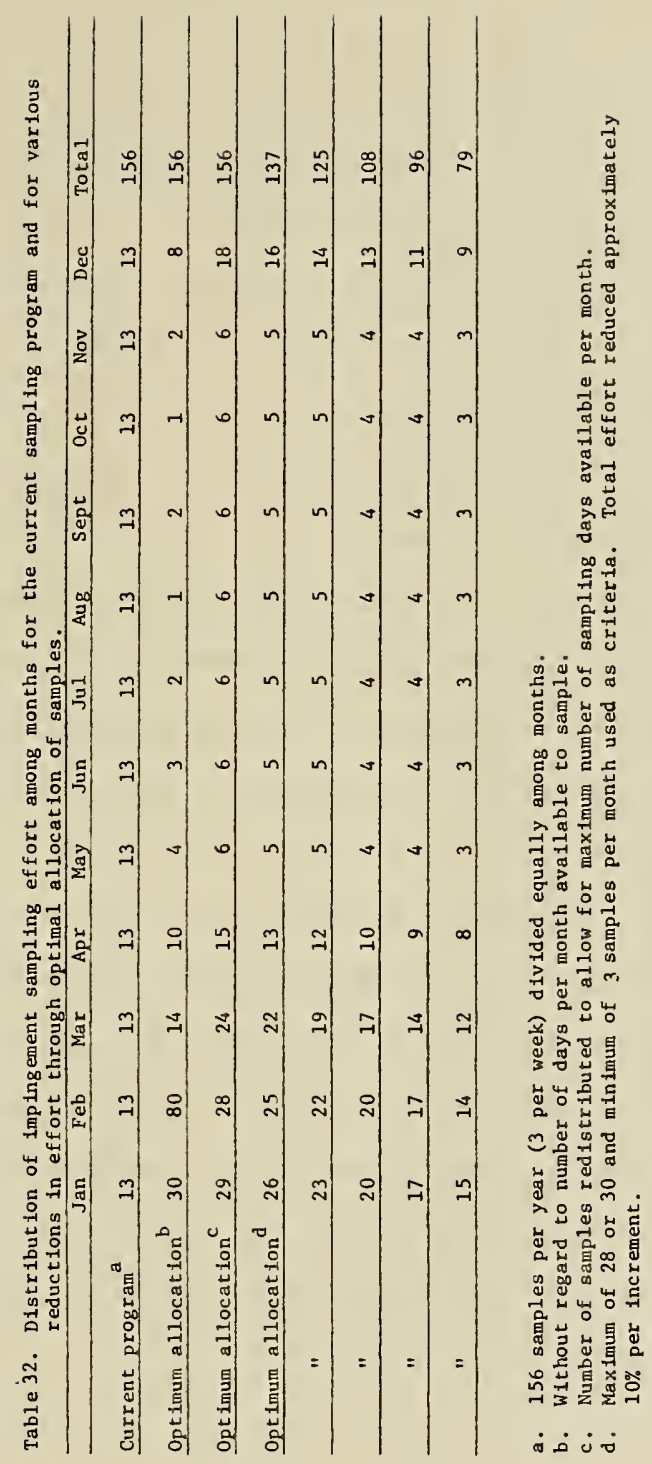


among months in proportion to variability. The number of samples was then reduced in approximate increments of $10 \%$ with the restriction that at least 3 samples per month should be taken. By redistribution of sampling effort through optimal allocation, the present impingement sampling effort for winter flounder could be reduced by almost half to achieve the same precision in the estimate.

It should be noted that the above analysis concerned only the winter flounder and ignored other potentially important species which may be more abundant during other months of the year. The same optimal allocation of sampling effort analysis appeared in the Impingement Program Evaluation using the data for nine selected abundant fishes and macroinvertebrates. A similar conclusion was reached in that most sampling should be scheduled for January and February. The largest difference between the analysis for the nine species and the one for winter flounder was the latter assigned more samples to March and fewer in December than the former.

Future installation of fish return sluiceways at Units 1 and 3 should significantly reduce impingement mortalities as winter flounder generally have good survival following impingement and sluiceway passage (Table 33 ). Successful installation should greatly reduce the effects of plant operations on juveniles and adults. After construction, followup studies will be undertaken to measure the effectiveness of the sluiceway return systems in reducing mortalities and preventing recirculation of fish back to the screens. 
Table 33. Summary of winter flounder impingement and sluiceway survival studies.

\begin{tabular}{|c|c|c|c|}
\hline Station & Reference & Survival & Remarks \\
\hline \multicolumn{4}{|c|}{ Impingement (immediate and delayed survival) } \\
\hline Millstone & NUSCo (1981 b) & $>88 \%$ & $\begin{array}{l}\text { December - eariy April only; } \\
\text { continuous, } 2-, 4-, 8-h \text { screen- } \\
\text { wash intervals }\end{array}$ \\
\hline Oyster Creek & Miller (1978) & $>78 \%$ & $\begin{array}{l}\text { Data from } 2 \text { years of extensive } \\
\text { sampling; mostly continuous and } \\
2-\mathrm{h} \text { screenwash intervals }\end{array}$ \\
\hline Mystic & SWEC (1978) & $44-85 \%$ & $\begin{array}{l}\text { December-May only; continuous, } \\
2-, 4-, 8-\mathrm{h} \text { screenwash intervals }\end{array}$ \\
\hline Maine Yankee & SWEC (unpublished) & $96 \%$ & Special $24-\mathrm{h}$ sample $(1 / 30-2 / 1)$ \\
\hline \multicolumn{4}{|c|}{ Sluiceway (immediate and delayed surviva1) } \\
\hline Pilgrim & (MRI 1982) & $100 \%$ & $\begin{array}{l}\text { Total of } 70 \text { specimens used in } \\
4 \text { trials }\end{array}$ \\
\hline
\end{tabular}




\section{IMPACI ASSESSMENT FOR WINTER FLOUNDER}

The primary means of assessing impact of the Millstone Nuclear Power Station on the winter flounder to date has been a deterministic model developed by the University of Rhode Island. It assesses the effects of entrainment as impingement losses are of lesser potential importance, particularly after installation of sluiceways. This model has been evaluated as an acceptible but conservative method of estimating impact (Gore et al. 1977; Thomas et al. 1978). It has been used as recently as this year in the Final Environmental Report for Millstone Unit 3, which is currently undergoing revision before submission to the U.S. Nuclear Regulatory Agency.

The model is described and critiqued in detail by Saila (1976). Portions of this work have also been published (Hess et al. 1975). The model assumed that the Niantic River was the source of all larvae entrained at Millstone and estimates of their annual losses were projected over the life of the plant. The primary reason for much of the research conducted on winter flounder at Millstone was to provide data needed for the model and to verify aspects of it.

Recent advances in impact modelling have made this model less acceptible for impact assessment. A deterministic model gives results applicable only for those particular sets of data or values input. Today more advanced stochastic models have been derived to estimate impact which take into account the random and natural variability of elements of the population and are much more realistic than deterministic models. For these reasons a stochastic matxix model developed by the University of Rhode Island for impact assessment was accepted during the 1982 Millstone Ecological Advisory Committee meeting as the basis for 
future evaluations. The model will be brought inhouse for use by Northeast Utilities.

The future research at Millstone specifically on the winter flounder should be directed by the requirements of the stochastic matrix model. A model of this sort is the best means to integrate and reduce the large amount of data available on the winter flounder to predict changes as a consequence of longterm plant operations. The projections may be coupled with a risk assessment analysis to determine the acceptibility of any estimated losses or reduction in local stock size. 

Arnason, A.N., and L. Baniuk. 1978. POPAN-2. A data maintenance and analysis system for recapture data. Charles Babbage Research Centre, St. Pierre, Manitoba. 269 pp.

Begon, M. 1979. Investigating animal abundance: capture-recapture for biologists. University Park Press, Baltimore. 97 pp.

Bishop, J.A., and P.M. Sheppard. 1973. An evaluation of two capture-recapture models using the technique of computer simulation. Pages 235-252 in M.S. Bartlett and R.W. Hiorns, eds. The mathermatical theory of the dynamics of biological populations. Academic Press, London. (Not seen, cited by Worobec 1981).

Bliss, C.I., and R.A. Fisher. 1953. Fitting the negative binomial distribution to biological data. Biometrics 9:176-196.

Cormack, R.M. 1968. The statistics of capture-recapture methods. Oceanogr. Mar. Biol. Ann. Rev. 6:455-506.

E1-Shamy, F.M. 1979. Impingement sampling frequency. A multiple population approach. Envir. Sci. Tech. 13(3):315-320.

Gore, K.L., J.M. Thomas, L.D. Kannberg, and D.G. Watson. 1977. Evaluation of Millstone Nuclear Power Plant environmental impact prediction based on monitoring programs. BNWL-2152, NRC-1. Battelle-Pacific Northwest Laboratory, Richland, Wash. 120 pp.

Green, R.H. 1979. Sampling design and statistical methods for environmental biologists. John Wiley and Sons, New York. 257 pp.

Gullard, J.A. 1969. Manual of methods for fish stock assessment. Part 1. Fish population analysis. FAO Man. Fish. Sci. 4. 154 pp.

Hess, K.W., M.P. Sissenwine, and S.B. Saila. 1975. Simulating the impact of entrainment of winter flounder larvae. Pages 1-30 in S.B. Saila, ed. Fisheries and energy production: a symposium. D.C. Heath and Co., Lexington, Mass.

Jolly, G.M. 1965. Explicit estimates from capture-recapture data with death and immigration stochastic model. Biometrika 52:225-247.

Kennedy, J.S., and D.H. Steele. 1971. The winter flounder (Pseudopleuronectes americanus) in Long Pond, Conception Bay, Newfoundland. J. Fish. Res. Board Can. 28:1153-1165.

Ketchen, K.S. 1950. Stratified subsampling for determining age distributions. Trans. Amer. Fish. Soc. 79:205-212.

Lobell, M.J. 1939. A biological survey of the salt waters of Long Island, 1938. Report on certain fishes. Winter flounder (Pseudopleuronectes americanus) Suppl. 28 th Ann. Rep., N.Y. Cons. Dep., Pt. I:63-96. 
Miller, G.J. 1978. Impingement of fishes and macroinvertebrates on the traveling screens. Pages 16-51 in T.R. Tatham, D.J. Danila, D.L. Thomas, and Associates. Ecological studies for the Oyster Creek Generating Station. Progress report for the period September 1976 - August 1977. Vol. One. Fin- and shellfish.

Ichthyological Associates, Inc., Ithaca, N.Y.

MRI (Marine Research, Inc.) 1982. Assessment of finfish survival at the Pilgrim Nuclear Power Station screenwash sluiceway - 1981. In Marine ecology studies related to operation of Pilgrim Station. Semi-annual report no. 19. January 1981 - December 1981. Boston Edison Company. 19 pp.

NUSCo (Northeast Utilities Services Company). 1975. Summary report, ecological and hydrographic studies, May 1966 through December 1974, Millstone Nuclear Power Station.

- 1976. Annual report, 1975. Ecological and hydrographic studies, Millstone Nuclear Power Station, Waterford, Connecticut.

- 1977. Annual report, 1976. Ecological and hydrographic studies, Millstone Nuclear Power Station, Waterford, Connecticut.

- 1978. Annual report, 1977. Ecological and hydrographic studies, Millstone Nuclear Power Station, Waterford, Connecticut.

- 1979. Annual report, 1978. Ecological and hydrographic studies, Millstone Nuclear Power Station, Waterford, Connecticut.

- 1980. Annual report, 1979. Monitoring the marine environment of Long Island Sound at Millstone Nuclear Power Station, Waterford, Connecticut.

- 1981a. Annual report, 1980. Monitoring the marine environment of Long Island Sound at Millstone Nuclear Power Station, Waterford, Connecticut.

- 1981b. Feasibility of modifying the Millstone Units 1 and 2 cooling water intake screen wash system to improve the return of fish to Long Island Sound. $67 \mathrm{pp}$.

- 1982. Annual report, 1981. Monitoring the marine environment of Long Island Sound at Millstone Nuclear Power Station, Waterford, Connecticut.

Pearcy, W.G. 1962. Ecology of an estuarine population of winter flounder Pseudopleuronectes americanus (Walbaum). Bull. Bing. Oceanogr. Coll. $18: 1-78$.

Perlmutter, A.. 1947. The blackback flounder and its fishery in New England and New York. Bull. Bingham Oceanogr. Col1. 11:1-92.

Pollock, K.H. 1981. Capture-recapute models: a review of current methods, assumptions, and experimental design. Pages 426-435 in C.J. Ralph and J.M. Scott, eds. Studies in avian biology 6. Estimating the number of terrestrial birds.

- 1982. A review of open capture-recapture models for biologists in wildlife and fisheries. Presented at Northeastern Division of American Fisheries Society Meeting, Cherry Hill, N.J., April 13-15, 1982. 
Ricker, W.E. 1958. Handbook of computation for biological statistics of fish populations. Bull. Fish. Res. Board Can. 119:1-300.

- 1975. Computation and interpretation of biological statistics of fish populations. Bul1. Fish. Res. Board Canada. 191:1-382.

Roff, D.A. 1973. On the accuracy of some statistical tests used in the analysis of mark-recapture data. Oecologia (Ber1.) 12:15-34. (Not seen, cited by Worobec 1981).

Saila, S.B. 1961. A study of winter flounder moveents. Limnol. Oceanogr. 6:292-298

- 1976. Effects of power plant entrainment of winter flounder populations near Millstone Point, Connecticut. U.R.I.-NUSCo Rep. No. 5. 134 pp.

Sampson, R. 1981. Connecticut marine recreational fisheries survey 1979-1980. Connecticut Dept. of Environmental Protection. Mar. Fish. 49 pp.

Sissenwine, M.B., K.W. Hess, and S.B. Saila. 1973. A mathematical model for evaluating the effect of power plant entrainment of populations near Millstone Point, Connecticut. MES-NUSCo Rep. No. 1.77 pp.

Smigielski, A.S. 1975. Hormonal-induced ovulation of the winter flounder, Pseudopleuronectes americanus. Fish. Bull., U.S. 73:431-438.

Snedecor, G.W., and W.C. Cochran. 1967. Statistical methods. Iowa State University Press, Ames, Iowa. 593 pp.

Sokal, R.R., and F.J. Rohlf. 1969. Biometry: principles and practice of statistics in biological research. W.H. Freeman and Company, San Francisco. 775 pp.

Southwood, T.R.E. 1978. Ecological methods. Halstead Press, New York. 523 pp.

SWEC (Stone and Webster Engineering Corporation). 1978. Fish impingement monitoring Mystic Station - Unit No. 7. Boston Edison Company. 54 pp.

Thomas, J.M., J.A. Mahaffey, K.L. Gore, and D.G. Watson. 1978. Statistical methods used to assess biological impact at nuclear power plants. J. Envir. Man. 7:269-290.

Tyler, A.V., and R.S. Dunn. 1976. Ration, growth, and measures of somatic and organ condition in relation to meal frequency in winter flounder, Pseudopleuronectes americanus, with hypotheses regarding population homeostasis. J. Fish. Res. Board Can. 33:63-75.

Vaughan, D.S., N. Buske, and S.B. Saila. 1976. Evaluating the effect of power plant entrainment on populations near Millstone Point, Connecticut. URI-NUSCo Rep. No. 4. $80 \mathrm{pp}$.

Worobec, M.N. 1981. Movements and abundance of winter flounder (Pseudopleuronectes americanus) in a Southern New England salt pond. Submitted in partial fulfillment for Ph.D., University of Rhode Island. 35 pp. 



HEAVY METAL INVESTIGATIONS:

A REVIEW AND EVALUATION 

INTRODUCTION

Addition of heavy metal to the Long Island Sound waters is an unavoidable consequence of operating the Millstone Nuclear Power Station (MNPS). The plant's once-through circulating water system is composed in part of (70-30) copper-nickel condenser tubes, which deteriorate through time due to physical (erosion) and chemical (corrosion) processes. Such deterioration releases particulate and dissolved heavy metals into the seawater used for condenser cooling. Another source of metal input to seawater is the service water system.

Since 1971, Northeast Utilities Service Company (NUSCo) has supported a metals monitoring program designed to determine the contribution of MNPS to heavy metal concentrations in Long Island Sound, and any subsequent bioaccumulation of metals by suspension-feeding bivalves. The intent of the present report is to; 1) recapitulate heavy metals investigations at MNPS through December 1981,2 ) evaluate the quality of the information obtained and, 3) suggest improvements in experimental design and analytic technique. It is not the purpose of this report to speculate with regard to potential repercussions of MNPS metal input on Long Island Sound waters or biota.

\section{PRESENT PROGRAM}

Environmental Technical Specifications (Appendix I) presently require seawater and tissue sampling for metals five times during the year (February, May, July, September, December). Seawater samples are taken from Giants Neck, Unit 1 Intake, Effluent, and Twotree Island Channel and analyzed for concentrations of $\mathrm{Pb}, \mathrm{Fe}, \mathrm{Cr}, \mathrm{Zn}$, and $\mathrm{Cu}$. Oysters are sampled from holding trays located at the Quarry, Fox Island (north), and Giants Neck. Mussels 
are sampled from natural populations at Fox Island (north and south) and Giants Neck. Tissues of both shellfish species are analyzed for concentrations of $\mathrm{Fe}, \mathrm{Cr}, \mathrm{Zn}$, and $\mathrm{Cu}$.

In addition to the above required collections, the monitoring program has sampled oysters in holding trays at White Point and oysters growing naturally in the quarry.

\section{CHRONOLOGY}

Sampling for heavy metals began in September 1971 and results through 1974 are presented in NUSCo (1975). Results from 1972 through 1979 are presented in NUSCo (1980) and as Appendix II here. Summaries of results from 1980 and 1981 are found in NUSCo (1982) and as Appendix III here.

Before discussing these results, it will be useful first to review sampling methods and analytic techniques employed at various times throughout the metals monitoring program; these are summarized in Table 1. The only change in the program from 1971 through 1979 involved the frequency with which shellfish were sampled. Originally, mussels and oysters were collected in May and December, but starting in May 1973, they were sampled on the same schedule as seawater. In 1980, changes were made in sampling procedure and analytic protocol. A smaller volume of seawater was collected, a different filter was used to partition soluble and insoluble metal fractions, and $\mathrm{pH}$ adjustment was lower. Fewer individuals of shellfish were collected and mussels were no longer taken from White Point. (This site is consistently and incorrectly referred to as Bay Point in tables, but not in text, of metals reports from 1971-1979). Shellfish were depurated for 1-3 days, a procedure not known to be practiced previously and first frozen, then shucked. In 1981, procedures were revised slightly to improve upon the previous year's accuracy 


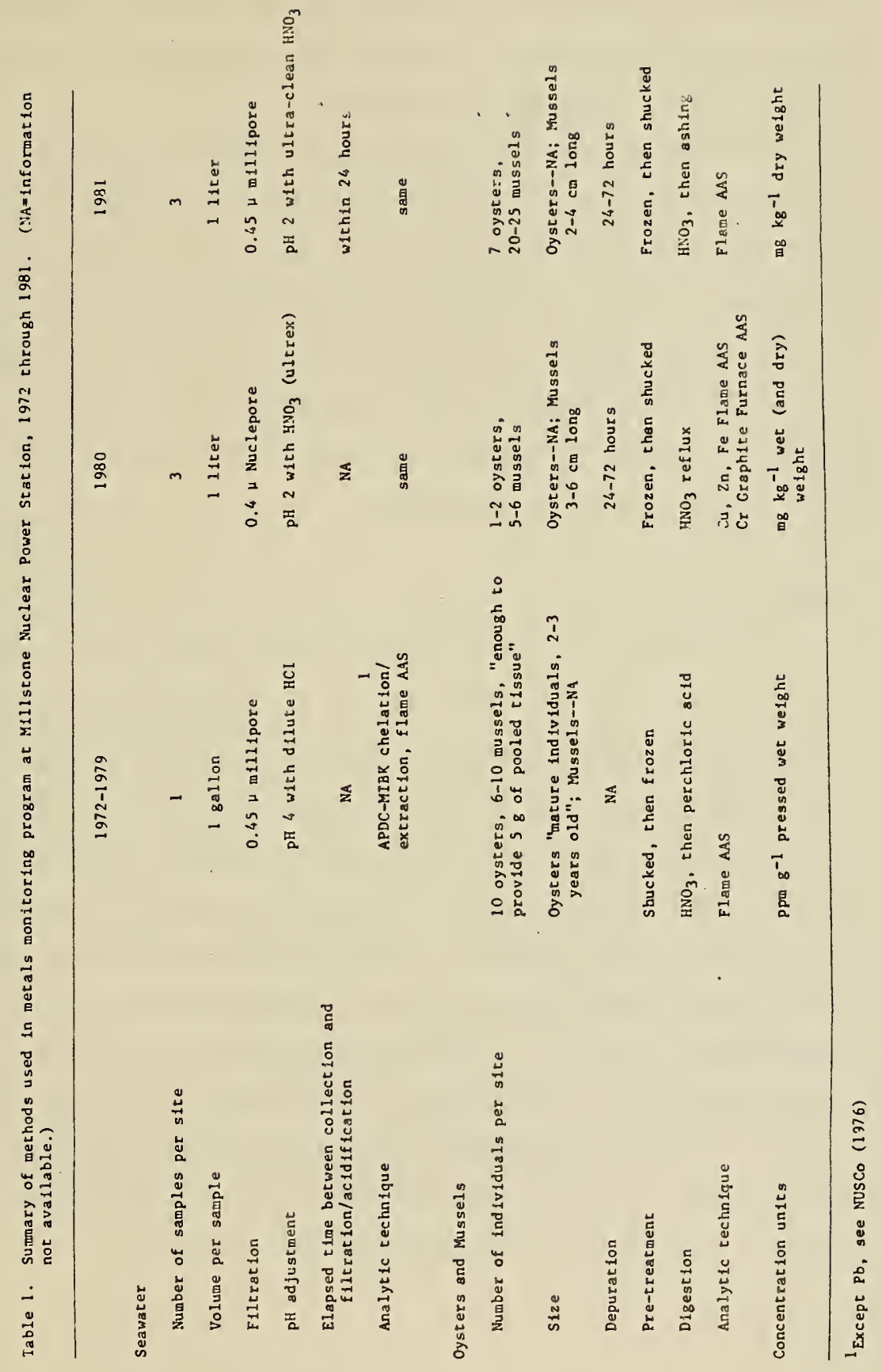


and precision. Changes made in 1980 and 1981 resulted from an increased appreciation of using "clean" technique to avoid contamination of samples during collection, processing, and analysis.

The viewpoint that "clean" technique is necessary for accurate determination of metal concentrations, especially in seawater, is quite correct and cannot be overemphasized (e.g., Moody and Lindstrom, 1977; Brulane et a1., 1979). For example, the relationship between technique and results is strikingly evident in the values for soluble $\mathrm{Cu}$ in Giants Neck seawater (Table 2). Although there is no reason to assume that metal concentrations should change with time, mean values in 1980 and 1981 were five to eight times less than in 1972 .

\section{SUMMARY OF RESULTS}

In the decade of seawater sampling at MNPS and nearby areas, the outstanding result is the overall decrease in reported concentrations of $\mathrm{Cu}, \mathrm{Fe}$, and $\mathrm{Zn}$. This trend, however, reflects increasing analytic sophistication and not actual decreases in concentration (see above). It is revealing that values continued to decrease subsequent to the start of Unit 2 operation in 1975. Therefore, only values determined from 1979 onward provide reliable estimates. (There are obvious exceptions; for example, Zn concentrations in 1981 were extraordinarily high and indicate contamination). There were no apparent long-term changes in $\mathrm{Cr}$ and $\mathrm{Pb}$ in seawater from 1971-1981, simply because these metals have been at or below detection 1imits. (N.B. Analyses of $\mathrm{Pb}$ are particularly prone to contamination and without extra-scrupulous technique, concentrations are likely to be overestimated (Patterson and Settle, 1979)). 
A clear result of the shellfish portion of the program is that exposure to the plant's discharge waters results in non-toxic bioaccumulation of $\mathrm{Cu}$, and probably other metals, by oysters living naturally in the quarry and those held there in cages. There appear to have been no elevated metal concentrations in oysters nor mussels located in other areas. However, any detailed comparisons between years is essentially meaningless because of changes in methodology through the course of the program. These alterations include the number of individuals analyzed, the sequence of freezing and thawing, depuration, and the reported unit of concentration, i.e., per unit dry or wet weight. In addition, contamination by shucking equipment was demonstrated to have occurred for analyses prior to 1979 (NUSCo, 1981). Within year comparisons should be more valid, but are complicated by seasonally-induced gonadotrophic cycles in the shellfish.

\section{SPECIAL INVESTIGATIONS}

Waslenchuck (1980, 1981) investigated the concentration and fate of $\mathrm{Cu}, \mathrm{Ni}$, and $\mathrm{Zn}$ in MNPS discharge waters. He found that soluble forms of al1 three metals and particulate phases of $\mathrm{Cu}$ and $\mathrm{Zn}$ increased in concentration following the passage of ambient Long Island Sound water through the plant. These increases were approximately $I_{\mu g} / I$ and $0.5 \mu g / I$ for dissolved and particulate fractions, respectively, and persisted about as long as the temperature anomaly of the discharge waters. Soluble $\mathrm{Cu}$ and $\mathrm{Zn}$ behaved non-conservatively and were found in excess in the discharge, apparently due to rapid dissolution of unstable metal-rich particulates. 


\section{RECOMMENDATIONS}

The program has improved through the years in the accuracy of its determinations. At present, values are reasonably close to those generated by state-of-the-art researchers (viz. Waslenchuk, 1980, 1981). Therefore, it is very important to deviate as little as possible from present sampling and analytic methodology so that future comparison, i.e., those which determine possible effects of Unit 3, may be made with a reasonable degree of certainty.

Statistical analyses of MNPS metals data are conspicuously rare and when performed, have been incompletely reported. Future reports should include appropriate statistics (e.g., ANOVA) and also provide raw data to allow statistical analysis by other scientists.

More information concerning the kinetics of metals in discharge waters is desirable. In his proposal to monitor metals in 1982 (Appendix IV.), Dr. D.G. Waslenchuk stated his intentions of amplifying his earlier research (Waslenchuk, 1980, 1981). He has shown, for example, that immediate filtration and acidification of seawater samples is necessary to properly estimate the respective contributions of soluble and particulate fractions to total metal content. 
Bruland, K.W., R.P. Franks, G.A. Knaur, and J.H. Martin. 1979. Sampling and analytical methods for the determination of copper, cadmium, zinc, and nickel at the nanogram per liter level in seawater. Anal. Chim. Acta 105: 233-245.

Moody, J.R., and R.M. Lindstrom. 1977. Selection and cleaning of plastic containers for storage of trace element samples. Anal. Chem. 49: $2264-2267$.

NUSCo (Northeast Utilities Service Company). 1975. Summary report, ecological and hydrographic studies. May 1966 through December 1974, Millstone Nuclear Power Station.

- 1976. Annual report. 1975. Ecological and hydrographic studies, Millstone Nuclear Power Station, Waterford, Connecticut.

- 1980. Annual report, 1979. Monitoring the marine environment of Long Island Sound at Millstone Nuclear Power Station, Waterford, Connecticut.

- 1981. Annual report, 1980. Monitoring the marine environment of Long Island Sound at Millstone Nuclear Power Station. Waterford, Connecticut.

- 1982. Annual report, 1981. Monitoring the marine environment of Long Island Sound at Millstone Nuclear Power Station, Waterford, Connecticut.

Patterson, C., and D. Settle. 1976. The reduction by orders of magnitude errors in lead analyses of biological materials and natural waters by evaluating and controlling the extent and sources of industrial lead contamination introduced during sample collecting and analysis. pp. 321-351 in Lafleur, P. (ed.), Accuracy in trace analysis, Proceedings of the 7 th materials research symposium, NBS Special Publication 422.

Waslenchuck, D.G. 1980. The concentration reactivity, and fate of copper, nickel, and zinc in a coastal power station cooling-water plume. Final report to Northeast Utilities Service Company, January 27, 1980.

- 1981. The concentration, reactivity, and fate of copper, nickel, and zinc associated with a cooling-water plume in estuarine waters. II. The particulate phases. Final report to Northeast Utilities Service Company, December 2, 1981. 



BIOFOULING AT MILLSTONE NUCLEAR POWER STATION:

A REVIEW AND EVALUATION 
Biofouling has been long recognized as a potential cause of inefficiency and eventual failure of cooling water systems. For ocean sited thermal power plants, the major types of fouling are: 1) slime formation in the condenser tubes, reducing heat transfer efficiency and enhancing corrosion, and 2) macroinvertebrate growth (particularly mussels) throughout the cooling water system, causing reduced water flow, blockage, erosion, and subsequent leakage.

Prior to construction of Millstone Unit I, biofouling was anticipated to be a problem, and provisions were made for anti-fouling procedures. Intake structures were designed to minimize regions of stagnant water, and protective coatings were applied where necessary. Equipment was installed to inject chlorine into the intake bays, intermittently for most of the year, and continuously during the presumed mussel spawning season (when ambient water temperatures ranged between 45 and $55^{\circ} \mathrm{F}$ ). Condenser cross-connect valves were also installed, to allow thermal back-flushing of condenser tubes and circulating water pump bays. Similar systems were incorporated in the design for Unit II.

The chlorination program for Unit I was initiated in August of 1970, and the diffuser system was redesigned in Spring of 1976. For Unit II, chlorination began in November of 1974 , and the diffusers modified in Summer of 1978. At both Units, the modifications were designed to allow more even diffusion of chlorine along the walls and floors of the intake bays. Unit I chlorinates circulating and service water systems simultaneously, at a rate of $2,500 \mathrm{lbs} /$ day; Unit II has separate systems for circulating and service water, injecting at a rate of $1,600 \mathrm{lbs} /$ day into the former, and $200 \mathrm{lbs} /$ day into the latter. The duration and cycle frequency vary betweeen Units. Since no significant 
correlation can be drawn between free available chlorine concentration at the discharge weir and total residual levels at the quarry cut (Chlorine Transport Study in 1977 Annual Environmental Operating Report) the dosages are somewhat empirically based on experience. However, values for chlorination time and total residual chlorine concentration at the discharge have remained well below limits established by the Environmental Technical Specifications and the NPDES Permit (TRC $<0.1 \mathrm{mg} / 1$; see, for example, the ETS requirement section of the 1981 Annual Report). Prior to 1978 , station procedures called for monthly thermal back-flushes of the circulating water systems of both Units, each pump bay to receive $110^{\circ} \mathrm{F}$ water for up to 1 hour. The service water systems cannot be therma1ly back-flushed.

Conclusion based on early chlorination experience emphasized the need for optimizing chlorination regimes, within permit limitations, as well as the ineffectiveness of chlorine alone for controlling mussel growth. In January of 1977 , a Biofouling Study was proposed, and a Seawater Systems Reliability Task Force was organized in August of 1978, primarily to deal with the problem of Unit I condenser tube leakage. A meeting on 8 September 1978 to discuss mussel fouling (Appendix I) presented an historical background, as well as an outline of the objectives and results of the EPB Biofouling Study to that point. Recommendations presented at the meeting included proposals to conduct laboratory experiments to determine optimum heat and chlorine treatments for mussel control, as well as operational procedures to test various chlorine dosages and thermal back-flush schedules.

Numerous inspection dives were conducted within the intake screenhouses. The inspections were initially made by contract divers, but 
since 1979, have been managed almost exclusively by EPB biologists.

Results from the dives are used to determine the need for thermal backflushes or manual cleaning of trashracks and intake structures; dives after these procedures assessed their effectiveness. We also look for evidence of mechanical failure, e.g., metal fatigue, blockage of chlorine diffusers, inadequate cathodic protection. Additionally, we have established in situ experiments to study mussel fouling.

Laboratory experiments were also designed to determine mussel growth rates, settlement patterns, and response to various time/temperature/ chlorine treatments. Much of the information from these studies and from the inspection dives was incorporated into the Millstone Station response to the NRC I \& E Bulletin No. 81-03 (Appendix II). One conclusion drawn from the studies was that the thermal back-flushes were effective in controlling mussel growth in the circulating water intake bays, with or without intermittent chlorination. Further, growth studies determined that the frequency of thermal back-flushes (mussel cooks) could be reduced from monthly to six times per year, spaced as far apart as 12 weeks in winter and 6 weeks apart in summer, and that the duration of the cooks could be reduced to 20 minutes. Unit I implemented the new schedule in 1981 with savings in excess of $\$ 100,000$ and no loss of mussel control effectiveness; based on recent cost differences between nuclear and fossil generation, annual savings for Unit II on a 6 vs. 12 cook/yr schedule are estimated to be approximately $\$ 130,000$. John Becker informs us that Unit II adopted the new schedule in 1982. Another result of recent studies is a corroboration of earlier ones, that intermittent chlorination, at least with the dosage and frequency used presently, is not effective in controlling mussel growth 
in the service water systens. In a letter from $W$. Romberg to R. Herbert, dated 4 December 1981, Wayne wrote, "Disassembly of the service water strainer on November 27, 1981 again revealed that the MP-1 chlorination system does not adequately protect the service water system from mussel growth". Ray Palmieri informed us that between August 1980 and October 1981, various heat exchangers in the Unit I service water system were opened 74 times to remove mussels and debris. In an attempt to reduce fouling and improve seawater system reliability, Unit II is presently continuously chlorinating their service water. Holmes (1970; The effects of chlorination on mussels. CERL $R D / L / R$ 1672) reported that marine fouling could be prevented with continuous chlorination at $0.5 \mathrm{mg} / 1$, and Marine Research, Inc., in a 1980 report to the Electric Power Research Institute (EPRI EA-1588; Selected alternatives to conventional chlorination), found that continuous low-level chlorination $(0.1 \mathrm{mg} / 1)$ prevented the attachment of mussels.

Accordingly, we have made a series of recommendations to Plant operations. One involves continuous chlorination of the service water system of both Units I and II. This procedure would require modification of existing Tech. Specs., which restrict simultaneous continuous chlorination. The change request has been submitted to NRC, but will probably not be acted upon if responsibility for non-radiological environmental monitoring is transferred to the state DEP.

Pending the outcome of the NRC hearing, some recommendations maximize biofouling control within present permit limitations, e.g., by partitioning the chlorine to increase the concentration in the service water system (which cannot be thermally back-flushed). Unit I in particular could increase dosage time considerably, and still maintain an 'intermittent' schedule. 
Regardless of the schedules followed, both Units are requested to work in close association with Environmental Lab biologists, and to keep us appraised of conditions that affect antifouling procedures, e.g. mechanical or logistic problems that reduce efficiency of chlorination or mussel cooks. By adhering to recommended schedules for chlorination and mussel cooks, biofouling and concomitant efficiency loss should be reduced to a minimum. It is expected that future biofouling related activities at the laboratory will include continued inspection dives in the intake structures, and cooperation with Stone \& Webster Engineering Corporation and EPRI in their attempt to test antifouling coatings at Millstone.

5 


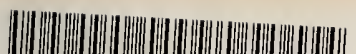 39153019582507}


